\title{
Coleoptera Microptera
}

BRU NSVICENSIA

$$
N \in \mathbb{N} \text { N } \mathrm{N}
$$

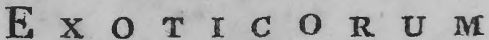

RUOTQUOT EXSTANT IN COLLECTIONIBUS

ENTOMOLOGORTM BRUNSVICENSIUM

INGENERAFAMILIASEISTECIES

$$
\text { DISTRIBUIT }
$$

DR. J. L. C. GRAVNIHORST Socihtatis Physicae Gozttitgexsig Sobuls.

HRUNSUGAE,

ATUDCAROLUM REIGHARD MDCECIT. 


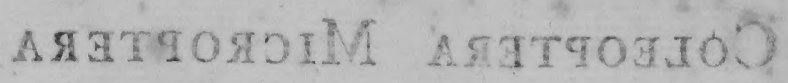

M I 1 औ

$$
\text { wok } 5 \approx x
$$

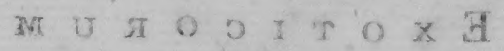

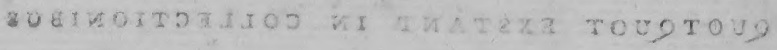

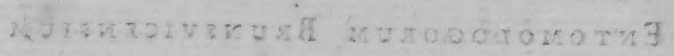

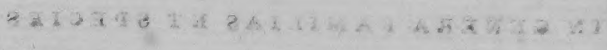

T)

T.

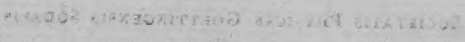

g. Youryacherey t? + $18.2102 \geq 4312$

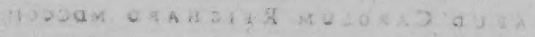
3181 


\section{I R O}

\section{ILLUSTRI ATQUE DOCTISSIMO}

\section{Joh. Christ. Lud. Heli W i g,}

DOCTORI PhilogophiaE, PUERORUM NOBILIUM IN ALLA BRUNSVIo CENSI PRAEFECTO, MATHEMATICAE ET HistoRIAE NATURA-

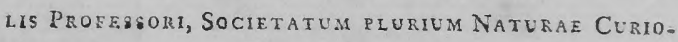
SORUM SOCIO,

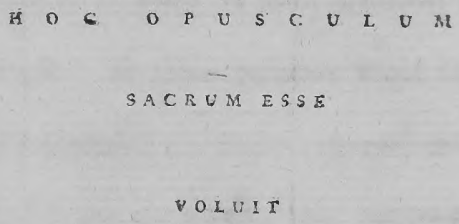

A. $C$ T $T$ R. 


\section{$09+3$}

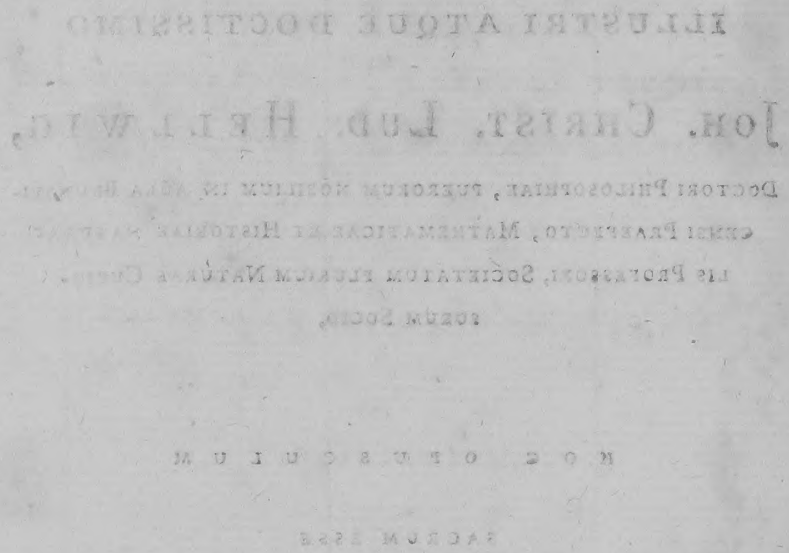

T1: $10 \%$

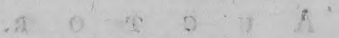


Tu, vir venerande, fuisti, qui primus me cognitione rerum naturalium imbuisti, et mihi ordinem atque finem earum probasti. Te duce conabar sequi viam, quam mihi ostenderas, et anicitia atque benevolentia tua proadminiculis erant mili, viam semel ingresso. Perpen. debain, quam amplus sit campus, qui ante octlos extendebatur, et quanta atque qualia necessaria es. sent, quo turo in eo progrederer; praeceptis attamen ducis peritissini fretus, audebam ulterius procedere, et meas quoque vires quantulascumque in ejus culturam impendete. 
Hoc opúsculo tibi, vir venerande, tentaminis primi mei rationem reddo. Utinam two atque reliqui publici entomologici applausu dignum sit.

$$
\begin{gathered}
\text { Seripsi } \\
\text { Brunsuigae, }
\end{gathered}
$$

mense martio MDCCCIr.

socoition on ans antit

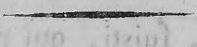

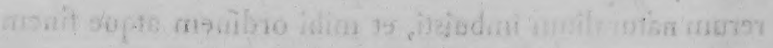

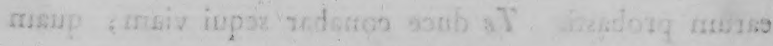

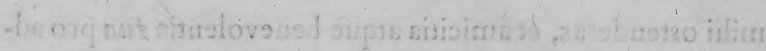

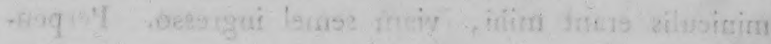




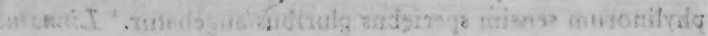

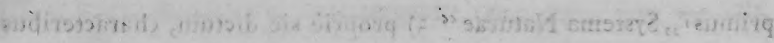

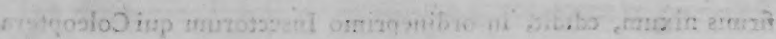

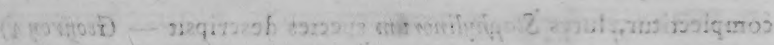

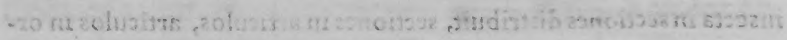

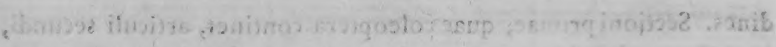

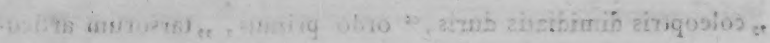

$$
\text { Prolegonena. }
$$

\section{S. I.}

\section{Historia culturae Coleopterorum} Micropterorum.

Coleoptra Microptera illa appella insecta, quibus sunt ", coleop. , tra dimidiata, et tarsi quinquearticulati; "“ characteribus enin his duobus a reliquis coleopteris facillime distinguuntur.

De his insectis in historiae naturalis cultorum vetustissimorum scriptis nihil certi invenimus, et eis ommino ignota fuisse videntur, Qui auten initio seculi decimi septimi vixerunt, primo quorumdan horun colcopterorum mentionem feccrunt Aldrovandus sub genere Forbicina tam Forficulas quan Staphyluros complexus est 1). - Mhenfetus insccta, ab Aldrovando "Forbicinae, appellata, separavit, et quardan Forficulas çuacda:n St aphysinos denominavit 2). - Dehine genus Sta-

I) Ulysses Aldrnyandi, Medici Benoniensis, de Animalibn linstctis libri VII, Bononiae I 602 (et alias alibi editi).

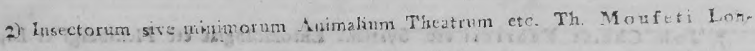
dinatis opera ete. perfectain ete. Landini I6.3.1. 
phylinorum sensim specietus pluribus angebatur. Linnaeus, qui primus ,Systema Natírae “i 3 ) proprie sic dictum, characteribus firmis nixum, edidit, iı ordineprimo Insectorum qui Coleoptera complectitur,plures Staphylinoruin species descripsit - Geoffroy 4) iusecta in sectiones distribuit, sectiones in articulos, articulos in ordines. Sectioni primae, quae coleoptera continet, articuli secundi, "coleoptris dimidiatis duris, "ordo primus, "tarsorum articulis quinque, "solum genus Staphylinorum continet, jam speciebus multis insigne. - Schaeffer 5) e Coleopteris, elytris dimidiatis, quae Culcoptera Microptera appellat, classen secundam insectorum constituit, cujus ordo primus Coleoptera Microptera, ",tarsis omnibus quinquearticulatis," solos scilicet Staphylinos Linnaeanos, comprehendit. - De Geer Coleoptera in classe insectorum octava congregavit. Sectio prima hujus classis couplectitur Coleoptera tarsis omnibus quinquearticulatis 6), inter quae etian Staphylinos Limnaeanos. - Fubricius hoc genus, hactenus indivisum, in tria genera dissolvit, Staphyli norum nempe, Oxypororum et Paederorum, et Coleoptera, ordinem insectorum primum, Eleutherata appellavit 7). - Multitudine autem specierum, et habitu earum vario, apparebat, haec

3) Carnli Linnaei Systema Nuturae etc. Lugduni Bataror. 1735 (et alias ajibi tedtum).

4) Histoire abrégée des Insectes par M. Genffroy. Tom. I. et II à Paris 1764 .

5) Jac. Christ. Schaeffer Elenenta Entomologica etc. Ratishonae I766.

6) Memoires pour servir a l'histoire des Insectes par Charles De Geer etc. rem. I - VII a Stockholm 1752 - I778.

7) Joli. Christ. Fabricii etc. Systema Entomologiat etc. Fiensburgi et Lipsise 1775 
genera in pluria naturalia adhuc disiungi posse. Hellueigitu, in Rossii Fauma Etruriae 8), quan. edidit (gen. 87), jam monuit, ,Ista tria genera Fabricii “ (Staphylinus, Oxyporus et Paederus) "non sufficere" et "Oxyporos rufum et maxillosum genus pe"culiare constituere" (geu. 88). - Olivier 9) genera quidem Fa. briciana retinuit, Staphylinos autem, secundum capitis magni: tudinem, in duas familias divisit, et Oxyporos plurimos Fabricii, illos scilicet, qui characteribus distinctivis, a Fabricio ipso huic generi propositis, haud respondefent, ad Staphylinos retulit. - Latreille, conservatis generibus tribus, quartum addidit, e Staph. biguttato, clavicorni et affinibus constitutum, quod Stenus nominavit 10). Coleoptera sunt cjus classis prima insectorum. - Cuvier 11), exemplo antecessorum, insecta in classes, sectiones \&c. distribuit. Classis quarta Coleoptera comprehendit; ordo $\mathbf{N}$ huius classis, "Coleoptera coleoptris dimidiatis, "6 quae sunt Staphylini Liunacani, Hoc genus in quatuor subdi. visit familias, scilicet a. Staphylinos, b. Pacderos, c. Oxyporos, d. Stenos.

Linnaeus, Geoffrey, Sihaeffer, horumqque virorum coëtanci, genus Staphylinorum characteribus multo melioribus et distinctioribus constituerant, quain multi eorum successorum. Ratione enim habita colcoptrorum dimidiatorum, antennarum, tarso-

8) Fauma Etrusca, sistens insecta, quae etc. collegit Petrus Rossius etc. iterum edita a Dr. J. C. L. Hellwig etc. T. I. Helmstadii I795.

9) Entomologie etc. par M. Olivier, Tom. I - III à Paris I 795.

10) Précis des Cbaractéres génériques des Insectes par le citoyen $\mathbf{L}$ atreille $\mathbf{d}$ Brive, an V de la R. $(1796)$.

II) Tableau elómentaire de l'histoire naturelle des aximzur par G. Cuvier, Paris, an VI (IFY7). 
rum \&tc, characteribusque ab his desumtis, genus Staphylino. rum optine a cogeneribus discreverant. Habitu autem externo duce, species huius generis commode in plura genera dispesci poterant, - Fabricius Staphylinos in tria gcnera sejungcbat, characteribus gencricis a solis instrumentis cibariis desumtis, infeliciter auten in singulis spccicbus haud examinatis et collatis, Inter charactcres Staphylinorum sunt "palpi quatuor filiformes;"6 quaero autem, num Staph. biguftata, atricabillo, fuscipedi, canaliculato, sanguineo, florali, poiceo ưtc. palpi sint filiformes? Oxyporos a cogeneribus distinguit, "paipis quatuor ingequalibus; an„ticis filiformibus, posticis securiformibus; "character, duabus tantum viginti trium specicrum bujus generis proprius; palpis enim Oxypori veri (e. g. O. rufus, maxillosus), Oxyp. iumulctus, subterronerus, rufipes cum affinibus, et Oxyp cellaris, analis. chrysonelinus \&c. longe diversi sunt. Idem valet in tertium ge; nus, nce Pdederis ripario, elongato, orbinlato \&r, palpi sunt iidcm. - Olivier et $P$ aykull 12) genus quidem $Q$ xypororun characteribus emendavcrunt, onmia scilicct coleoptera, in Systemate Fabricii, sub hoc genere complexa, Oxyporis mfo, maxilloso et similibus cxceptis, in genus Staphylinorum redigentes. Stahpylinis auten et Paederis partm operae dederunt, nisi quod illos, secundum capitis magnitudinem, cum thorace comparatam, in duas fanilias diviserint, quae tamen, magnitudine capitis huius generis insectormu adco variabili, parım prosunt.

Hac omnia me impellebant ad examen horum generum et specicrum accuratius instituendum, cui copia haud parva specie-

52) Vongraphia Staphylinotum Speciac a Gustaso de Pay kn ll. Ups.tize

1.89) 8 .

Gustati de Paskull Paunz Suecica Tom. III. Lepsalise 1 goo. 
eum, pro parte omnino adhuc novarum, quas undique collegetam, occassiobnem exoptatissimam ofièrebat. Constitutio generum, quae hoc opuscuio tractabo, fructus huits exaninis crat. Iricitatus a Prof. Hellwig, comiter mihi concedente usun collectionis divitis, speciebüis pluribus novis et specierum janjani notarum unana copia;' conspicuae, consilium cappiebam publice proferendi quae observaveran. Interea Prof. Knoch jan ảlrçitd temporis in examen horum coleoptcrorum intpenderat et plura nova geviera condiderat, scilicet e Staph. bigutteto, claviconit \&. genus Eyryops (Stenus Latreille); e Staph. fissipete, cdrinticulato, piceo, impresso (Oliv.) sulcato (Oliv.) \&c. genus Aleochara; e Staph. rivulari (Payk.), obscuro (Payk.), brumeo (Payk.) \&c. gents Anthophagus; ex Oxyporis Fabricianis, praeter, Oryp. ru/um, quaxilloszm et affines, genus Taihyporus. Cụm autem Pr. Knoch nondun in animo haberet, quae observaverat janı promulgare, haec mecum benevolenter communicabat. Nomina gencrum novorum Prof. Knoch retinui, et e collectione ejus divite inseçtorum, plures hactenus ignoțas speçies descripsi. Multa sunt, quae viris doctissimis, Professoribus Helluig et Knoch debeo, et illis auxiliantibus effectum est, si hoc scriptum ad aliquan perfectionem pervenerit. - Hic autem adnotare me oportet, Monographiam Coleopterorum Micropterorum Brunsvicensium jam maximam parten prelum reliquisse, cun consilium caperen, exotica quoque describendi, quotquot corum collectiones Comitis de Hofmamsegg, Professoris Hellwig, et Prafessoris Knoch continerent. Unde evenit, ut quibusdam generibus et speciebus vernaculis character unus vel alter desit, quo a generibus atque specicbus exoticis aflnibus differunt. E. g. characteribus genericis Anthophagi addendus est ,Thorax corda. "fus, "6 cutu "Antennis filiformibus, thorace postice truncato ce 
haud a Pinophilo, genere exotico, distingui possit. Diagnosi St. olentis , niger, opacus, " addendum est, antennis extrorsum tenuioribus", quibus a St. tomentoso, ex America septentrionali, differt. Lathrobium depressum e Lusitania familiam constituit peculiarem huius generis, habitu eniun de reliquis Lathrobiis omnino decedit; unde sequitur, descriptionem quoque generalem, Lathrobiis praenissam, ad hanc speciem non referri posse. - Praterea Coleopteris Micropteris exoticis quaedam indigena inserta sunt, quae in horum Monographia desunt, cum serius innotuerint.

\section{S. 2 .}

De characteribus generum, nec non de diagnosibus et descriptionibus

$$
\text { specierum. }
$$

Coleopterorum Micropterorum genera, quae condidi, adhibitis characteribus eorum essentialibus atque distinctivis, in ta. bellam sequentem redegi:

\section{Coleoptera}

coleoptris dimidiatis, tarsis quinquearticulatis.

\section{Coleoptera Microptera.}

I. Palpis anterioribus triarticulatis.

A. Antenuarum articulo ultimo ovato.

I. Articulo ultimo palporum posteriorum acuminato. Paederus.

2. Articulo ultimo palporum posteriorum ovato. - Stenus.

B. Antennarum articulo ultimo ylindrico. - Callinerus. 
II. Palpis anterioribus quadriarticulatis.
A. Articulis ultimis palporum inaequalibus, - Oxyporus.
B. Articulis ultimis palporum aequalibus.

1. Articulis ultimis palporum ovatis.

a. Thorace postice rotundato. - Staplyylinus.

b. Thorace postice truncato.

«. Antennis extrorsum crassioribus.

aa. Thorace marginato. - Onalium.

bb. Thorace immarginato. - Tachinus.

R. Antennis filiformibus.

aa. Thorace cordato. - Anthophagus.

bb. Thorace quadrato. - Pinophilhis.

2. Articulis ultimis palporum sccuriformibus. - Astrapaews.

3. Articulis ultimis palporum gracilibus subuliforuibus.

a. Thorace elougato. - Iathrobium.

b: Thorace brevi.

«. Tibiis laevibus. - Aleochara.

ß. Tibiis spinosis.

aa. Thorace laevi. - Tachyporus.

bb: Thorace foyeolato. - Oxytelus.

Pluria horum generurn rursus in familias dilabuntur, quas singulis generibus' anteponasn.

- E tabella praecedente quisque videbit, me, in constitutione generum, sysfertia artificiale secutum esse, et characteres genericós a quibusdam solummodo partibus desumsisse. - Systema mituríle, habitu toto insectorum fundatum, in praxi forsan op. timumı foret, in theorià autem difficile, cum sane lingua quaevis nimis inops sit, quan quod, brevibus verbis, habitunn itlum totum et modificationes ejus circumscribere possit, ct in fine, pro descriptione habitus, whil aliud quam descriptionem lon- 
gam partium omnium singularium, i. e. systema artificiale, das ret. Habituș autem me duxit in ista genera, quae postea chasacteribus, ut crecio, certis atque firmis, condidi; systema eriim artificiale eo melius esse, puto, rquo propius accedit ad, systema naturale. Colcoptera Microptera omnia, quotquoteorum possidebam, secundum habitum totum, in plures cohortes seu genera segregabam, hoc, facto disquirebam partes quarum forma singularis huic vel illi generi propria erat, et ubi character unus nondum sufficiebats partium plurim simul rationem habebam. Hoc modo cuique generi characterem, vel characteres quosdam erucban, qui conjoucting genera a coggneribųs distinguebant.

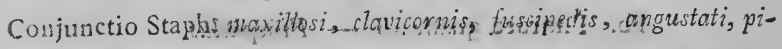

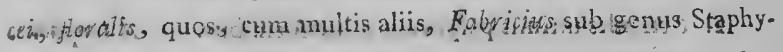
linowu complexus crat porro, conjunctio oxyp rufi et rufipe-

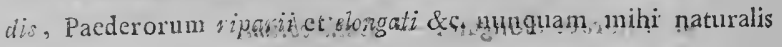
esse videbatur. Fxamine instituto, mihi facile persuadeban, singulum eorum, rum afinibus, peculiare genus, characteribus frmis et constantibus distinctum, condere posse: Simul auter experientia me doçebat, quăn sit difficile, systema naturale cum systemate artificiali absolute sonjungere. or Quaedam insectorum buc pertinentim, habitu to to simillime forma palporum plane invicem decedebant et cum aliis gencrideus, ovalde dissimilibus; conningenda fuissent; si chatheteres generun a palpis solis de-

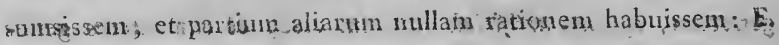

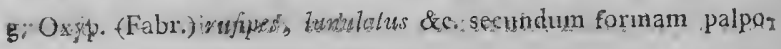

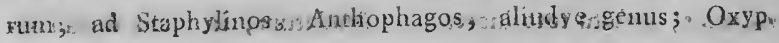

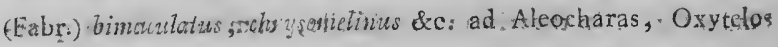
aliudve genus, relegaxidebuissent. Quia veru, Oxypori allegaprabr.; secundum principia systemat is mer, nec, formae dis vexpae palporum cansa, šb eode genere, manere poterant 
quanivis, habitu naturali, affines, (e. g. Tochini corticini-varien tates pallidae, nice non Tachimus suluralis et Tahypcri breviores fam: secundac), nec cum ullo alio genere, ob habitum nimis singularem,", conjungi poterant, in duo genera peculiaria diremti' surt, cum, characteribus conistantibus; de aliis etiam parti. bus corporis destimtis, a congeneristis - distingui possint. Oxy: poros ergo 'tunilatum, rufipedem, chrysonivelinutu et affines.(Fabr.) ấb reliquiis, "et veris, Oxyporis Fabricianis ef cogeneribus dis-

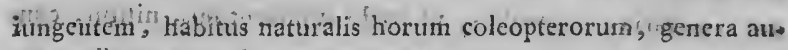
tem Tachýpororunf et Tachinorum constituentem, me principia systénátis artificialis duxerunt, hoc casu systemati naturali coritraria. Ista prisicipia postulabant etiam, ut Staphylinim $\mathrm{Ul}$ mi (Rossi), habitu Staphylinis familiäe tertiae (imprimis Staph

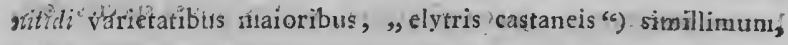
a cacteris removerein; rec hoin pàederum flavipedeps (Knoch), habitu' Lathrobiis (familiae Prederorum Knochr) shinitern, Ia La throbiis" et Paedcris; Callicèrun autcm ab Aleocharis, quibus habitu affinis est.

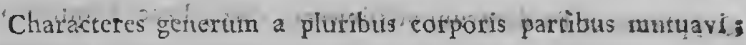
hatid crim fidebant; cur me oporttisset scmper unam eandernquite partem respicére, nec chatacteres distinctivos de cilla : vell de

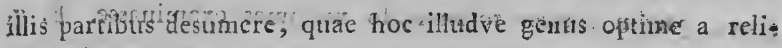

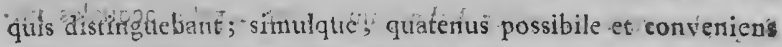

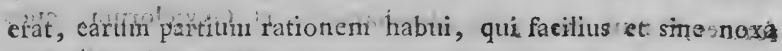
insecul dxaninari et observari potcràtet.- Hảud abrego, cha racteres, "quơs instrumenta cibaria praebent, forsan optimes fore, cuni forma corum, adeo milfifaria, 'semper attamen distrinstà et in generibüis constants esše videatur. Utinam, examen has rum partiun exiguarim, adeo operosim et a pluribus partibus unstituesiduth, seiniper sine pioxt insecti institui posset, neque 
saepius, iusectis minimis, plane impossibile esset. Э. C. Fabricius ipse, pater systematis entomologici, cuius characteres de instrumentis cibariis solis desuniti sunt, ora maiorum solummodo spécierum generum ab ipso conditorum examinavit, et de his paucis speciebus, quae saepius pars vix quinquagesima totius generis sunt, huius characteres desumsit, et reliquas cospecies, secundum habitum totum vel habitationem et modum vitae conmunes, illis coordinavit. Haec mea sententia, ninime vaga eut temeraria, ratıonibus, ut credo sufficientibus, nititur, cum longum per tempus examini sharacterum, ab oris partibus desumtorum, operam deşerim, haud attamen neglectis speciebus minoribus. Imprimis, autem veritas illius, quod jan dixi, mihi patebat, cuim, inductus certitudine, magnam inter multitudinem horum insectorum, quae collegeram, multas novas species fore, paucis in operibus autorum descriptis, consilium caperem, tenera Coleopterorum Micropterorum examinandi. Examine instituto, observationes meas ratione oris partium cum characteribus conferebam, quos Fabricius generibus tribus Staphylinorum, Oxyporum et Paederorum attribuerat; ccre, haec disquisitio et hacc collatio certiorem me faciebant, patrem ipsum systematis, cuiius fundamenta instrumenta cibaria erant, partim multa omisisse, partim..species solummodo maximas examinasse. E. g. Staphylinorum character Fabricianus sunt "palpi aequales filiformes;" num.vero: palpi Aleochararum et Oxytelorum, quos Fabricius generi Staphylinorum inscruit, filiformes? nullo mo: do, sed a palpis Staphylinorum, cuius generis species mininae. vix minores sunt quam species maiores Aleochararum et Oxytelorum, longe diversi. Porro: Oxyporis, secundum Fabricizm, "s palpi posteriores clavati “ sunt; eis autem Tachinos et Tachy. voros immiscuit, quorum insectorum maximum haud minimum 
Oxyporum, longitudine, acquat, et quorum palpi posteriores, utique a palpis posterioribus Oxypororum diversi, filiformes suut. Ut brevis sim: Nihil facilitis erat, quam, ipsa methodo Fabriciana, e tribus allegatis generibus duplo plura producere, adco instrumenta cibaria eorum diversa erant. Cum vero, charactcribits genericis, nollem solis partibus oris itti, ob causas supra partim iam expositas; characteres de illis tantum oris partibus desumsi, quae facile, in situ earum naturali et quieto, exaninari poterant: Palpi fere semper prominent, et cum praeterea, tam numero quam forma articulorum; praecipue ultimi, satis invicem differant, nuliarum aliarum oris partinm, quan palporum, characteribus generim distinctivis, rationem habui, quamquam non omittan, descriptionibus necessaria de instrumentis cibariis, quatenus ea examinare potui, inserere 1).

I) Examen partium oris in genere haud res facillima est, uti jam aliis locis ostendi. Palpi quidem facilius observari possunt, quam ulla alia oris pars, cum satis promikeant, examen autem eorum nihilominus diligentiam et attentum oesIum poscit. Fabricus vel in numeto spso yalporum intexâm erravis: Cychris, in Entomologia Systematica, quatuor tantumaodo palpos tribuit, cum attamen sex palpis distinctis fnstructi sint, quad atiam in recentissimo opere (Joh. Christ. Fabricii etc. Systema Eleutheratorum etc. 'Tomus 1 Kiliae I8OI) eorrexit. Characteribus classis Ulonatorum addidit „os palpis quatuor;" Forflulae a uricularize autem palpi sunt sex zeque distiucti, ac Cicindelis, Cas vahis etc. e classe Eleuthetatormm. Hi erroses certo inde orti sunt, quod palpus interint (set palpus anterior Fabr.) indinduo, quod examinabatur, arcie dorso maxillae adjaceres, et primo untuitu, pro ipso dnivo maxillae habetetur. Propria experientia mb docuit, kunc situm nimis facile decıpere posse. Forsan autem Fabricixs Forficulam a uriculariam nequidem examinavit, et a reliquis Ulonatorum generibus, omnino, quotquot illorum exammavi, palpio modo quatuer instructis, characteres huius classis matzavit. - Contra, aliquid gro salpo interierc haberi potest 2 quos nihil aliud est, quars processus maxil. 
Cun segregarem et describerem species generis alicuitis; omnia in co posita esse credebasu, quid sit essentiale quid fortwitum. Illud sunt characteres constantes, hoc autem inconstans est, nec in characteribus distinctivis speciei vel generis respicitur, sed tantummodo in subspecierum vel varietatum descriptione. Quid sit cssentiale, quid fortuitum, experientia, collatio et analogia docent. Proportio, forma, sculptura, color partium, quibus. dam speciebus essentiales esse possunt, quibusdam fortuiti. Quod attinet ad proportionen, sunt genera, quorum speciebus, caput, sine exceptione, thorace minus est (e. g. Tachinis); e contrario, cuorumdam generum speciebus, capur thorace vel minus vel maius, vel cjus magnitudine est (e. G. Staphylinis); immo sunt species, quarum individua, proportione capitis ad thoraccm, adco differunt, ut caput quibusdam thorace maius, quibusdam thorace minus, quibusdam thoracis magnitudine sit (e. g. Oxyporis et pluribus Staphylinorum atque Oxytelorum speciebus) 2). Proportio capitis ad thoracem illis ergo essentialis, his autem fortuita est. Longitudo etiam relativa antennarum variat in individuis quarumdam specierum (e. g. Staph. nitidi, Aleoch. Boleti) 3). - Forme partium jam minus variabilis est; sunt attamen species, quibus e. g. thorax vel transversus est vel orbiculatus (e. g. Aleoch. Bolfti), vel cornutus vel incrmis (e. g. Oxyt. tricorni); caput vel cornutum vel inerme (e. g. Oxytel. tricorni, cornuto). - Sculptura, in ge.

12e. Chrysomelae saltem et Galerucae, quas examinaxi, numquam palpoł sex habebant, sed proecssus maxillae exterior pulpo similis exat. - Confer quae ik* fra de hoc processu maxillas monebo (S. 6. not. 2).

2) Confer S. 4 .

3) Confer 5. 5. nos. 2. 
nere, cbaracteres praebet bonos, imprimis si partes sulcatae sunt. Puncta, numero, ordine et crassitie vel subtilitate, saepius variant; observationes attnmen et collationes repetitae probaveruut, numerum atque ordinem punctorum in seriebus tho. racis Staphylinorum familiae tertiae, specicbus perpaucis exceptis, constantissimos esse. - Color etiam nultis speciebus variabilis est (e. g. Staph. nitido, alternanti, Aleoch. Boleti, naną, Tachino melanocephalo \&c.). - Magnitudo antem variabilissima, et ne duobus quidem ejuedem speciei individuis eadem esse solet. Rarissime attamen individua reperiuntur duplo maiora minimo einsdem speciei (c. g. St. nitido, Al. Boleti, Tachino melanecephalo).

In diognosi speciei character sive characteres dantur, quibus ab omnibus cospeciebus, absolute, i. e. sine collatione cum aliis, se distinguit. - Quales sunt ergo characteres, quos diagnosis postulat? Tales, qui omnibus speciei individuis communes sunt, nec conjunctim (si nempe pluribus opus sit) ulli cospeciei tribui possunt. Nemo negabit, characteres optimos illos fore, qui, secundun analogiam, essentiales, i. e. talibus partibus et proprie. tatibus nixi sunt, quae quidern in speciebus, nec vero in individuis ejusdem speciei, variant, et quam distinctissime verbis exprimi posstint, respectu scilicet numeri, loci, situs, directiosis \&c. (e. g. Oxyt. caelatus, , thorace longitudinaliter quadri"foveolato, foveis duabus mediis arcuatis. " Nulli cospeciei Oxyt. caelati thorax est, „foveis quatuor longitudinalibus, inegdiis arcuatis," sed omnibus reliquis Oxytelis hae foveae, numero vel directione, differunt). Felices, si diagnoses omnes aeque distinctas dare possemus! sed, ehen, hoc nobis in pausissimis tantummodo concessum est. Plerumque necessitas exigebat ut colorem et formam partium consulerem, colorem, cuius mi- 
sturas adeo multiplices, forman, cuius speciessensim sensimque variantes, distincte et paucis verbis exprimere, nulla certe totius mundi lingua satis locuples erit. Sed, his omissis; wihi adhue gratularer, si diagnosi semper characteres eruere potiissem, qui omnibis speciei individuis communes fuissent, sinulquite speciem $\mathrm{ab}$ omnibus cospeciebus sufficienter distinxissent; hic autem haeret aqua, et quibusdam vel hoc mihi impossibile erat, atque nihil alìł reliquinn; quam àd descriptiones sequentes longiores et varietatés delegare 4 ), (e. g. Al. Boltti; quarum specimina nonsolum colore, sed proportione etiain et forma quarumdam partium, v: c. thoracis et antenmarim, variant):

Quia hactenus de modo, species describendi et diagnosin coricipiendi actum est; mihi etian liceat lectoribus regulas proponere, quas; receptu specierlm vel varietatum; secistus sum: Insectum; quod de omnibus reliquis, charactere èsseittiali; decedebat, haitd haesitabam, pro specie ab illis diversa habere. Character unicus adventitius, vel par talium characterini speriminis singuli nondum sufficiebant ad condendani tiovam spe-

4) Haud superflum existimo, hic adnotare, diagnoses specierum electos tantummodo characterum, quos erui, continere: Cuique, qui irstctum in hac monographia investigare studet, hand verba diagnosis sufficiant, si quod inve;igavit inverisse credat, sed insectuin cum descriptione sequente fusiore comparatldum et, ratione habitus, staturae; pastinm formae etc. cum quoxis alio insecto, ad quod delegatum erit, conferendum est; contingere enim potest; et verisimile saepius continget, ut insecto caeteris paribus, character adhuc essentialis inhae+ reat, cuius nec in diagnosi, nec in deseriptione mentio facts est, quod autem sufficiet, insectum pro specie, in hanc monographiam haud recepta, habere. Dıxi, me credere, hoc saepius contingere posse; generibus enim coleopterorum micropterorum hactenus tam parum cultis, et speciebus novis aden multis in solo ducatu Brunsvicensi repertis, persuadeo mihi, in aliis etiam terris mulkas novas, nondum in systẹma receptas species latere. 
ciem, imprimis, si variabilitas harum characterum in genere haud rara erat: Differentianı solam coloris unius partis, nultoque minus differentian solam magnitudinis, vel habitationem, unius individui, haud respiciebam. Characteres distinctivi, in genere quidem adventitiii, pluribus autem omnibusve speciminibus constantes, exisțimabam sufficientes ad noyam specicm eondendam. Nemini auten, ut credo, iniustus vel temerarius esse videbor, duo vel plura individua, characteribus, plerumque essentialibus, differentia, sub unam specien redigens, si, serie speciminum intermediorum, quibus hi characteres progressive variabant, invicem, aliud in alţerum, transibant.

Scripta cuctorum, quae saepius, veṛbị abbreviatis, allegavi, suit, ordine alphabetico, sequentia ;

$$
\text { 1. De Geer Ment. }
$$

Mernoires pour kervif à l'histoire des Insectes, par M. le Baron Charles Do Geer. Tome IV. ${ }_{7774}$ à Stockholm. 4. (Premicr Memoire: Des Staphylins.)

\section{2, Creutzer. Ent. Vers.}

Christian Creutzer Entomologische Versuche. Wien 1799. 8. (Stcopliylinus pag. 128.)

\section{Fabr. Ent. Syst.}

Foh. Christ. Fabricii d $c$, Entomologia Systenatica emendata et aucta \&c. Tom. I. Pars. II, Hafniae 1792. \&. (Staphylimus p. 519. Oxiporus p. 531 . Paelisus p. 5.36.)

$$
\text { 4. Fabr, Ent. Syst. Supt. }
$$

Joh. Christ. Fabricii \&c. Supplementum Entomoicgiae Syste. maticae. Hafniae 1798. 8. (Staphylimus p. 180. Oxyporiss p. 181.)

$$
\text { 5. Fabr. Mesut. }
$$

9oh. Clarist. Fabricii \&c. Mantissa Insectorum \&c. Tom. I 
Hafniae 1787. 8. (Eleuterata, gen. 87. Staphylinus, gen, 88. Oxyporus, gen. 89. Paederus,)

6. Fabr. Spec. Ins.

बुoh. Christ. Fabricii \&c. Species Insectorum \&c. Ton. I. Hamburgi et Kilonii 178r. 8. (Staphylinus p. 334. Oxyporns p. 338. Pacderus p. 339.)

7. Fabr. Syst. Ent,

尹oh, Christ. Fabricii \&c. Systema Entomologiae \&c. Flensburgi et Lipsiae 1775. 8. (Staphylints p. 264. Oxyporus p. 267. Pacderus p. 268.)

8. Fabr. Fn. Groent.

Otho Fabricius Fauna Groenlandica \&e, Hafniae et Lipsiae 1780 .

9. Fourir. Ent. Par.

Entomologia Parisiensis, sive Catalogus Insectorum quae in Agro Parisiensi \&ce. \&c. edente A. F. Fuurcroy \&c, Pars prima. Parisiis I785. 8. min. (Staphytinus n.)

10. Fuessin. Helv.

Fon. Casp. Fuesslin Verzeichniss der ihm bekannten Schweitzerischen Insekten, Zirich und Winterthur 1775, 4, maj. (Staphylimus.)
II. Geoffr. Hist.

Histuire abrégée des Insectes par M. Geoffroy. Tome I. à Paris 1764 . 4. (Staphylinus p. 359.)

12. Götze Beitr.

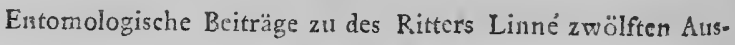
gabe des Natursystems von Goh. Aug. Ephraim Gölze. Erster Theil, Leipzig 1777. 8. (Stophylinus p. 730.) 
13. Linn. Fir. Slite.

Caroli Limasi \&c. Fauna Suecica \&c. Stockholmiae 176 r. \&. (Staphylinus p. 230.)

$$
\text { 14. Müll. Zool. Dan. Pr. }
$$

D. Fr. MIüller zoologiae Danicae Prodromus \&c. Havnias 1776.8.

15. Olivitr Ent.

Entomologie ou Histoire natuelle des Insectes \& Olivier. Coleoptéres. Tome III. à Paris 1795. 4. maj. (Staptülinus gen. 42. Oxuporus ger. 43. Pathmes gen. 44.)

$$
\text { 16. Payti. Fn. Suri. }
$$

Gustavi Paukull Fauna Suecica. Tomus III. Upsaliae i8on. 8. (Staphiglinus p. 368. Oxyporits p. 425. Paederus p. 42\%. Stemus p. 433.)

$$
\text { 17. Pxin. Men, Cer. Ap. }
$$

Monographia Caraborum Sueciae a Gustavo de Paykall. Upsaliae 1790. 8. - Appendix Staphylinorum p. 134.

$$
\text { 18. Pculs. Mion. St. }
$$

Monographia Staphylinorum Sueciae a Gustaio de Paykull. Upsaliae ${ }^{\prime 2789 . ~} 8$.

$$
\text { 19. Punzer Fir. Gernos, }
$$

Faune Insectorum Germaniae Inicia, - Deutschlands Insecten, herausgegeben von Dr.G.WF.F.Penary, I $-\delta+\mathrm{Hef}$, Nürnberg 1796 - 1801. 8. min. (Staphylinus, Oxapcyus, Puederus.)

$$
\text { 20. Pontopp. Daxn. }
$$

Eriih Pontoppilans kurzgefasste Nachrichten, die Naturhistorie in D:nnemark betrefiend. Aus dem Dätischen ibersetzt. Kopenhagen und Hawburg 1765. fol. min. (p. 21r.) 
2I. Rossi Fn. Etr:

Fauna Etrusca, sistens Insecta, quae in provinciis Florentina et Pisana praesertim collegit Petrus Rossius \&c. iterum edita a Dr. ‡. C. L. Hellwig, \&c. Tomus I. Helmstadii 1795. 8. (Stcphylivus, gen. 8\%. Oxyporus, gen, 88. Paederus, gen. 89.)

$$
\text { 22. Schailer Act. Hall, }
$$

Abhandlụngen dẹ Hallisçhen națurforschenden Geselischaft. Erster Band, Dessalı und Leipzig 1783. 8. (p. 324.)

23. Schrank Austr.

Francisci de Paula Schrank Enumeratio, Insectorum Austriae indigenorum, Augusțae Vindel, 1781, 8. (Staphylinus p. 229.)

\section{Sihrank in Fuessl. $M$.}

Fuessly. Net1es Magazin \&c. B. II. Zürich 1785. 8. "p. $324-$ Schrank. Verzeichniss der Berchtesgadischen Insẹten p. 3 r3.

$$
\text { 25. Schrank Boica: }
$$

Fauna Boica, - Durchgedachte Geschichte der in Baiern einheimischen und zahmen Thiere von Franz vor Paula Schrank. Erster Band. Nurnberg 1798. 8. (Staphylinus, p. 639. Oxyposus, p. 65I. Paederus p. 65़1.)

$$
\text { 26. Scop. Carn. }
$$

Joh. Ant. Scopoli Entomologia Carniolica, Vindobonae 1763. 8. (Stcphy?mus p. 99 .

\section{S. 3 .}

De corpore atque habitu Coleopterorum Micropterorum.

Corpus insectorum, quae huc relata sunt, statura est inagis minusve procera; maxime Lathrobiis, Paederis, Aleocharae elongatulae et similibụs, Tachyporo dissimili, Staphylinis fami- 
liae ultimae; minus reliquis Staphylinis, Aleocharis, Oxyporis, Callicero, Stenis et Tachinis familiae secundae. Corpus breve latiusculun Tachinis est familiae primae, Tachyporis familiae secundae, Omaliis, Oxyrelis et Anthophagis. Forma etiam propria partium singularium, nec non coniunctio et proportio mutua carum habitum externum commutant. Corpus Tachimorum, Tachypororum et Aleochararum fanil. șcundae et tẹrtiae, plitrimis continnum est, incisuris vel partium latitudine inąequali haud interruptum, partibus scilicet invicem arcte coniunctis, bene iusertis atque accommodatis, quod iam in reliquis generibus rarius obvenit. Paederis praeserțim et Stenis, capitibus magnis, thorace latioribus, orbiculatis. thorace rotundato, eoleoptris angusticre, et nexu soluto harum partium, habitus est singuilaris, de habitu cogenerum longe decedens. Capitis, thoraçis, coleoptrorum et abdominis latitudo ubique aequalis, Staphylinis faniliac ultinae et Lathrobiis, corpus autem latiusculum planinsculnm Oxytelis et Omaliis, propria sunt. Thorax et coleoptra 'Tachypororum et plurimorum e familia prima Tachinorum (e. g. Tachyp. humeralis, marginelli) coniunctin unum fornicem exlihent continumm, - De generum et specierum proprietatibus et differentiis reliquis locis aptis exponetur. Quod autem omnibus Coleopteris Micropteris commune est, atque eis habitum externum dat peculiarem, et unde nomen eorum ortum est, coleoptra sunt dimidiata, de quibus infra.

Corpus, vel ubique, vel quibusdam solummodo pattibis, vestitum solet esse pilis, vel confertis vel rarissinis, vel brevibus vel longis, vel lanuginosis vel setosis, " vel mollibus vel rigidis \&c. - Corpus ọuorundam Staphylinorim lana densa vestị 
tum est (e. g. St. hirti). Multis coleoptra vilis brevibus rigidis, vel erectis vel depressis, obsita sunt (e. g. St. plurimis familiae tertiac, v. c. St. splendenti, acneo), saepius sericantibus (e. g. St. micanti, sericeo). Pili, pari modo sericantes, saepius autent adeo subtiles, ut nitore tantumnodo sericante fugaci se prodant, sunt etian interdum in abdomine, rarissime in capite atque thorace (e. g. St. micantis et albipedis). Insuper, quaedam huiusgeneris coleoptera, partubus vel locis singulis, pilis coloratis tenuibus ornata sunt (e. g. St. erythropterus, castenopterus, pubescens). Vestimenta autem haec pilosa vel lanuginosa, causis varii generis, aetate, frictione \&c. magis minusve deteri possunt; et haud raro individua specierum alias pilosarum vel lanuginosarum, nuda occurțunt. Pili attamen breves rigidi, quibus colcoptra Staphylinorum plurium, margine inferiore, fimbriata esse solent, huic detrinento minus obnoxii sunt. - In genere Aleochararums yarietas pilorum haud aeque magna est. Plurimis, sicut etian Callivero, ad margines tantum segmentorum pili sunt rigidi et rari. Quaedam, abdomine, rarius superficie tota corporis, pilis brevissimis tenuissimis sericantibus, non nisi oculo bane armato conspicuis, vestitạe suḷt. Al. lamıginoṣa lanugine tenui tecta est, oculo autem nudo vix conspicua. - Lathrobio atque Pacderi abdomen habent pilis rarioribus singulis rigidis tectura; rcliquae corporis partes omnino fere depiles sunt, Paederis attamen riptsio atque littorali exceptis, ubique pilis ummerosis rigidis singulis vestitis. - Taihyporis et Tachinis caput thorax et colcoptra plane sunt depilia; abdomen vero ubioue, praecipue tamen ad margines segmentorum, setis valde longis, rigidis, numerosis, singulis, obsitum. - Onaliis, Anthophegis, Oxytelis, Oxppovis ect Stenis corpus est prorsum depile. 
\$. 4 .

\section{De capite.}

De partibus singulis horum insectorum ea modo narrabo, quae ad haec sola genera spectant; quae enirs omnibus insectis, vcl ommibus coleoptcris, communia sunt, jam satis cognita pono i).

Gapita id communc habent, ut supra plus minusve convexa, infra autem semper plana sint, quod vel de iis insectis valet, quibus caput planc globosum esse videtur (e. g. Aleocharis plurimis familiae primae). - Fema capitum multiplex est, Basi plçrumque sunt obtusa, angulis rotundatis; rotundata illis tantum, quorum thorax apice itidem est rotundatus; his capuk et thorax solutius coniuncti sunt (e.g. Al. minoribus faniliae primae, Paedero orbiculato \&c.) Capita porro sunt vel longitudine latitudińis, vel latitudine longiora (oblonga), vel longitudine latiora (trans. versa); haec praecipue St. maxilloso et speciminibus quibusdam St. aenei, nec non Oxytelis piceo atque carinato, „capitibus maio„ribus ce cacteroquin autem rariora. Caput orbiculatum Tachinorum et Aleochararum transversum esse videtur, cum plerumque magnam partem sub thoracem retractun sit. Capite oblongo plures praeditae sunt species e familiis tertia et quarta Sta-

I) De partibuc coleoptrorum vide, inter alia multa: "Neue Beyträge zur Lnsec. "tenkunde von A. W. Knoch. Erster Theil. Leipzig I80I. B. Einlcitung "P. I9 et 59 . - Anatomen Staph, erythropteri, et deluneationam atque descriptionetn partiun ejus singularum vide is ,Deutschlakds Insectenfante etc. 2) fï: das Jahir I795 von Georg Wolfgang Franz Panzer, Nürnhexg 8 . min. (Maxillae autem (f. $\hat{3}^{*}$ et f. $4^{*}$ ) labiuzí (f. 13 ) et vitimus antennarum articulus prave delineati sunt). 
phylinorum, Lathrobia, Tachini lunulatus, melanoconhalus \&c. De hac forma capitis oblonga haec autem notanda sunt: Caput vel ovatun est, lateribus rotundatis, angulis basis obtusis (e. $g$. Staphylinis huc referendis familiae tertiae et Lathrobiis); vel basi latius, angulis obtusis, apicem versus sensim angustatum (e. g. Staphylinis huc referendis familiae quartae et Tachinis lunula. to, atrucapillo \&c.). Capitibus longitudine latitudinis latera vel sunt rotundata, quo forman induunt orbicularem (capita orbiculata) e. g. Staphylinis caeteris familiae tertiae, Aleocharis, Paederis \&c., vel recta, quo magis forman quadrati induunt (capita quadrata) e. g. Staphylinis plurimis familiae secundae et ultimis familiae quartac. - Notandum est, in quibusdam speciebus familiae tertiae Staphylinorum differentian capitis orbiculati et ovați haud sațis comstantem et definitam esse, ița, ut, in cha. racteribus harım specierum distinctivis, ratio eius haberi posset tanquam characteris essentialis. Habcant enim quaedam caput semper orbiculatum (ut St. splendens, aenerts \&c.) quaedam caput semper ovatum (ue St. politus, decorus \&c.), species attamen nonnullae sunt intermediae, quarum capita, speciminibus hị, eodem iure ad capita orbiculata referemus, quo, illis, ad çapita ovata referimus; haec observamus praecipue in St, nitido, variante, sanguinolento, - Capitis magnituslo cum thorace collata, de hac eıin șola agitur, valde diversa esț; Staphỵlinis primae se. çumdae et quartae familiae, Paederis, Oxytelis, Oxyporis et Stenis caput est circiter thoracis magnitudine; Staphylinis plurimis familiae tertiae, Aleocharis, Lathrobiis, Omaliis, Tachinis et Tachyporis thorace minus; minimum autem Aleocharis tertiae, Tachyporis secundae et Tachinis primae familiae. Cuae autem de magnitudine capitum protuli summatim tantummodo valent. Nulla forsan pars corporis horum insectorum, ratione magnitu- 
dinis cum aliis partibus collatae, adeo variabilis est quam caput. Plurimae specierum, de quibus modo dixi, caput eis esse magnitudine circiter thoracis, pervariabiles sunt, et inter copiam maiorem speciminim quaedam occurrunt capite paulo latiore, quaedam capitc paulo anguistiore quam thorax, quaedam capite thoracis magnitudine. Hanc varietatem praecipue tamen in Oxyporis et quibusdam Oxytelis (e. g. Oxyt. carinato, morsitante, caelato) observavi, ibi perinsignis est 2). Individuis, capitibus maioribus, instrimenta etiam cibaria inaiora et validiora erant quam reliquiis. - Eamderis variabilem capitis magritudinem in caeteris quoquie Micropterorum speciebus observavi, ipsis in illis, quac capitibus minimis prueditae sunt (e. g. in Tachinis); his autem ratius eam atteridinus, cum caput semper sub thoracem latum, convexum, capite multo maiorem retractum sit, et eum numquam, parte tertia magnitudinis, aequet. Quo maius autem caput est, eo magis prosilit, quia sub thorace minore

2) An haec varietas magnitudinio relatitae capitis in una eademque specie ad differentiam sexualem respiciat, non audoo diudicare. Idem atem incrementum sensim auctun, idemtque transitus progressivas $\$$ b extreno ad extremum, quos aliis etiam parsibus (e. g. sntenuis at tarsis, de quibus infra exponetur), longitudinem es crassitiem esrum comparans, vidi, me unn fugerunt. Poratuug ergo, hanc differevtiam partium crm differentiz sexuali in consensu esse, de magnitudiine earnm gradatim decrescente argumentari licebit, vim stirpen pro. creandi individuis quibusdam perfectiotem, quibusdam debiliorem esse. Non nisi bis pat hornm coleopteroram, et quidem Aleocharae Boleti, cuius individua, ratione antennaram et thoracis formae adeo variant, et Steni flavipedis, in copula cepi; ambobus autem mas femina, colore, partium forma, et magnitudine comparativa, plane congruebant. - Hae differentiae cum raequidem sufficiant ad discernendum marem a femina, uti e praecedentibus mihi persuasum habeo, mulıo ergo minus characteres praebent duarum vel glurilim spen sierng, speciminibus, uti imm dixi, aliud in alind transentatibus. 
non abscondi potest; et caput hoc prosiliens insecto dat habitum singularem, quo a cacteris, capite parvo retracto, omnino de. cedere videtur, et quidem eo magis, si caput basi, thorax apice, rokundati sunt atque collo tenuissimo tantum cohaerent (e. g. Paedero orbiculaio et plurimis Aleochararum ininorum familiae primae). Microptera, quibus caput est minutum, sub thorace absconditum, superne adspecta, capite onnino carere videntur; quod attamen de mortuis solummodo valet, viva enim et se moventia caput protendunt.

. Quod ad superficiem capitis, varietas rugarum, punctorum \&c. in his generibus magna est. Rarissime caput est prorsum laeve, nitidum ct glabrun (e. g. Tachinis familiae secundae et Tachyporis), in minimis enim Aleocharis ipsis familiae primae, et $\mathrm{Oxyporis,} \mathrm{aliquid,} \mathrm{rugis} \mathrm{vel} \mathrm{foveolis} \mathrm{simile,} \mathrm{inter} \mathrm{antennas}$ et interdum etiam pone oculos, deprehendinus, capite reliquo valde glabro et nitido. - Omnibits Staphylinis familiae tertiae et quartac et St. maxilloso, nee non Paed. ripario, littorali et bicolori, caput medio laevissimum, nitidissimum, lateribus autem, inprinis in angulis pone oculos, punctis pluribus vel paucioribus, crassioribus vel subtilioribus, inpressum est. Staphylinorum reliquorum et Lathrobiorum capita ubique punct is impressis obsita sunt, punctis autem multo crebrioribus, subtilioribus et confertioribus, quain in Staphylinorum faniliis tcrtia et quarta. Stenis caput est crassissime punctum; Aleocharis autcm familiarum secundae ad quintain, Tachinis familiaè primae, Paed. orbiculato ct angustato, omnitun certo subtilissime, ita ut puncta, ope tantum microscopii bene augentis, videri possint. - Rugas capitis in his insectis, quorum modo méntionem feci, haud facile deprehendimus, si vero adsunt, saltem perexiguae et plevumque inter antennas sitae sunt, Eo magis capita Oxytelorum, 
Omaliorum, Anthophagorum, rugis sulcata sunt, quarum tres vel duac longitudinales distinctae inter anteunas sitae sunt. Oxytelis cormuto et tricorni id praeterea proprium est, ut caput quorumdam speciminum (verisimile maris) cornutum sit, cornubus scilicet duobus porrectis acutis inter antennas ante oculos positis; plurimis vero speciminibus (verisimile feminis) haec arma desunt 3).

Pars capitis anterior, qqitae, sutura transversali inter anternas, terminata esse solet, et clypeus nominatur, plurimis hue relatis insectis, brevis et lata est; longior vero ct angustior $\mathrm{Ta}$ chinis, ita ut caput, apicem versus, sensim angustetur; vel emarginata (e. g. Oxytelis et Oxyporis), vel, idque plurimum, integra.

Oculi, ad latera capitis siti, in variis generibus et speciebus varii etiam sunt; raro exacte orbiculati, plerumque forma irregulari vel magis minusve ovata; Staphylinis plurimis planiusculi parvi immersi (exceptis Staphyl. tristi, boope, attenuato, quorum oculi magni planiusculi sunt) imprimis familiae quartae, porro Lathrobiis, Oxytelis, nonnullis Aleocharis (e. g. Al. rufficorni, Iucidae, canaliculatae, cimnanonzeae, depressae \&c.), Tachinis familiac secundae, Tachyporis. Oculi Paederorum illis Staphylinorum sinillini sunt, nisi quod paulo magis prosiliant. Oxyporis oculi sunt parvi prosilientes; minus prosilientes Callicero; magni, planiusculi Tachinis familiae primae, nonnullis Aleocharis (e. g. Al. fuscipedi, acutae \& .) Staphylinis tristi, attenusto et boopi; modici, semiglobosi, Anthophagis et Omaliis; Stenis an tem maximi et valde prosilientes.

3) De consenu capitis th thotacis, ratione irregularitaruan y. S. 8, 110 \%. 1. 


\section{S. 5 .}

\section{De antennis.}

Aute oculos antennase positae sunt, membra, in variis generibus et speciebus haud minus; et forsan magis; varia et variabilia, quam aliae corporis partes. Constant ex undecim articulis et $b u l b o$, seu basi vel radice totius antennae, qui; instar articuli exigui atque globosi (et strictissime nihil aliud etian est, quam articulus primtis antennae duodecimarticulatae) maximam partem in capite est absconditus, ita ut vix in speciebus maximis, multo ergo minus in minoribus vel ninimis, videri possit. - Avticulus primus plerumque longissimus est; vix vel paulo tantum articulo ultino longior Paederis, Oxytelis , Aleocharis, Tachinis, Tachyporis; Anthophagis et Omaliis; longus ct validus Staphylinis familiae quartae; Lathrobio fracticorni longissimus, longitudine scilicet tertiae partis totius antennae; Callicero autem brevissinus; longitudine tertiac partis articuli ultimi. Quam bre vis autem sit vel quam longus, forma attamen semper magis minusve elongata (longitudine latitudinem superante), clavata, subinciurva est, quae, articulo lonigiori, procerior, articulo breviori, minus procera esse solet. Semper etiam frrmior est articulo secundo, inprimis Oxytelis; crassior autenı, ullo reliquoriun articulorun, illis, quibus antennse filiformes sunt (e. g. Anthophagis) vel extrorsum paulo tantum crassiores (e. g. Tachinis, Tachyporis, quibusdam Staphylinis \&c.) vel extrorsum tenuiores (e. g. Staph. olenti, morioni \&c.); illis autem speciebus, quarun antennae, medio vel extrorsum, multo sunt crassiores, quidam articulorum mediortm primum latitudine onmino praestant (e. g. Oxyporis, Oxytelis, nonnullis Aleocharis atque Staphylinis , praecipue Staph. maxilloso). - Articulus secundus plo- 
rumque tertio brevior est, raro autem, is unico scilicet solummodo genere Stenorum, haee differentia magna est, et in Lathrobiis, Anthophagis, Tachinis et Callicero vix locum habet; inmo quiburdan articulus hie secmudus tertio longior et crassior esse videtur, (e. g. Al. impressae, sulcatae, gagati, Staph. elongalo, ochraceo, Oxyselo tricorni \&cc.). Articuli secundus et tertius clavati sunt, saepius autem perbreves (e. g. Callicero) et intterchim fere globosi (e. g. Oxyporis).

Respectu formue, antennae sunt vel ubique eiusdem crassitiei (filiformes) vel extrorsum crassiores aut graciliores. Hace differentia dependet a forma articutorum nediortum, porumque mutua proportione: Cum autem articuli latiores vel transversi nagis minusve compressi sint, ideoque, certo situ, multo angustiores appareant, idem etiam de antemis, quae ex articulis latis compositae sunt, valet, et eaedem antennae, hoc situ multo crassiores, illo autem multo graciliores esse videntur. Articuli medii, seu articuli inter tertium et ultimun siti, vel sunt camnanulati, vel pateraeformes. Anbubus illud est commune, ut apice truncati, basin versus angustati, et basi ipsa rotundati sunt; diferunt autem eo, ut campanulati latitudine longitudinem haud praestent, pateraeformes autem longitudine sint latiores. Singulti articuli medio apicis articuli praecedentis infixi sunt, basi in stylum brevem terminata, qui vero adeo exiguus est, ut vix cerni possit, praecipue articulis latis anteniarum valde brevium et crassarum. Antennis filiformibus articuli medii nunquam pateraeformes sunt, sed campanulati, et vel invicem aequales (e. g. Staph. simili, aeneocephato, splendenti \&c. Lathrobiis) vel longitudine decrescentes (e. g. Anthophragis et quibusdam Tachinis atque Tachyporis). Antennis, apicen versus gracilioribus, articuli medii itidera sunt campanulati, nunçuam pateraeformes, 
et sensim longitudine et latitudine decrescunt (e. g. St. olenti, cyaneo, morioni). Antennis autem extrorsum crassioribus distingucudum est, an sensim crescant, vel apice tantum crassiores, medio autem filiformes, sint: Hoc in Stenorum genere vidimus, quibus articuli antennarum primus et secundus clavati sunt, ter tius pergracilis et perlongus, reliqui, inter tertium et sextum, graciles, longitudine vero decrescentes, septrmus et octavus la. tiores atque campanulati, nonus et decimus campanulati, prae. cedentibus multo latiores, ultimus orbiculatus, latitudiue praecedentis. Antennac apicem versus sensim crassiores frequentissimae suut; graduum autenl, quibus haec crassities vel crescit vel decrescit, tottdem fere sunt, quot existunt species insecto. rum huc spectantium. In genere obtnet haec regula: „Articuli "medii sensim latitudine crescunt, ita ut quartus et quintus, in"terdum etian sextus, campanulati, saepe subglobosi, " (Aleoch. nanae fere pateraeformes) „, sequentes autem semper pateraefor„nes sint, et quid(m nonus latior, quam ullus reliquorum." Ab hac regula exceptae sunt antennae Calliceri, quarum articulus decimus cylindrico-campanulatus est, et triplo longır ullo reliquorum articulorum mediorun pateraeformium, qui, longitudine, acquales sunt. Quo breviores et latiores antennae sunt, co latiores et paterae similiores articulos etian silagulos esse oportet, (confer antennas St. maxillosi, Oxypororum, Aleach. nanse, lucidae, fuscipedis, fumatae \&c.) Interdum antenuarum pars media basi perparum crescit, apicem versus autem multo citius (c. g. Oxytelis, quorum articuli antennarum quartus ad septimum campanulati, octavus autem nonus et decimus pateraeformes sunt). Caetcrum mihi liceat adıotare, haec, quae de articulis mediis dixi, generalissima tantumnodo esse, si enim in unsquaque levi varietate commorari vellew, mox in nimiam 
verbositatem inciderem, praesertiun his partibus antenmarum, forma adeo variantibus et incoustantibus, ut saepius unius eiusdemque speciei individuis quibusdam campanulatae, quibusdam auten pateraeformes sint (e. g. Staph, nitidi, Al. Boleti \& c.). $^{2}$

Forma, in variis generibus st speciebus multiplici quidern, constantiore auteu, ideoque muioris momenti est articulus ultimus, seu indecimus. Fraecipue in genere Calliceri insignis est, cylindricus nempe et praelongus; longitudine sriplo superat articulum primun, longiorem aitamen ullo reliquorum, penultimo excepto, et paulo adhuc crassior est. In reliquis autem generibus hic articulus nunquam longissimus simulque validissimus est. Quod ad collationem eivs cum articulo primo, vide quae Initio huius $\oint$ dixi; si auten circiter articuli primi longitudine est, crassitie etiam ei non cedit. Latior articulo medio latissimo fere nunquan est et solo Paedero angutato articulos medios singulos hoc respectu superat; alias, antennis vel extrorsum crassioribus, ad sumnum latitudine articuli penultimi est. Forma cius plcrumque ovata est, apice acuto, interdum formae globosae propior, apice acuto (e. g. Oxytelıs, Stenis); vel brevis, subcanpanulata, apice oblique seu parabolice truncato, quae solis Staphylinis familiarum trium primarum propria est. Staphylinis attamen qubusdam e familia tertia, illis praecipue, qui, ratione formae thoracis, jam reliquis e familia quarta affi. nes sunt, hace articuli ultini antennarum forma magis minusve submutatur, et in subovatam, apice vel rotundato - obtuso vel subacuto transit. Cavendum autem est, ne error obveniat: $C_{u m}$ enim hic axticulus, si latior est, "apicem versus compressus sit, Eorma ejus, a variis partibus visa, varia esiam est, a duabus scilicet brevis, apice obliçue truncato, a duabus autem ovata, 
apice actuto; ego semper latitudinem maximam respexi. Id, quod monendum erat, quo errores et contradictiones evitarentur.

Longitrdio antennarum, cum aliis cos poris partibus collata, non solum in specicbus, sed in ipsis specici unius eiusdemque speciminibus, aeque variabilis et multiplex est, ac earum crassities 1), quod praesertim in Alcochara Boleti et Staph. nitido, observavi,

I) Quibusdam Coleopterorum Macropteromm speciebus longitudinem et crassitiem antemnarum suaiorom vel ninorem charecteren distinctivum sexus cistere fertut (e. g. Ceram ycibus) et qubusdan veritas huius opinionis experientia quotidia-

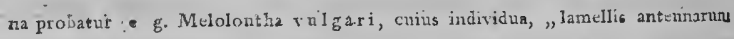
"maioribus," quod omes scinus, mares, "lamellis antelnarum minoribus," feminae sunt). Dubito, an idenx de illis Coleopterorum Micropterorum specie. bus statuendna sit; quarum individua anteunis longioribus tenuioribusque es bxerioribus crassioribusequ variant. De antennis Aluoch. Boleti et Staph, nitidi, q̧uorum magnan speciniuim copiam legi, dfrrmaxe saltem possum, tas semsim, tam longitudine quam crasstie, decrescire, sexno exgo diffetentian haud distinctam et, exta longitudine vel crassitue, definitam exhibcre, quod eo maiore fiducia asstrete audeo, cum ipse pay Altock. Boleti, copula iuncturi, pre: Hendexin, qno anven nullam, ne miniman quidem, differentiam externam inter merem et feminam observo - Hac occasione aliam adluc notan addere ruibi liceat: Quihusdan Coløopterorum Macropterorum speciebus latitudinem tarso. rum anticorum masorem vel minorem differentiae sexuali respondere ferunt. Sunt etian species Coleopterorum Micropterorum, nominatim Staphylinorm familiae tertiae, quarum inditudua tarsis anticis dilatatis et gracilibus variant. Omuino non crédo, hanc diferentian ad differentian sexus respicere vide §. IO. not. 2); nullo modo autem antennarum longitudo et crassitudo, uma cum tarsorum anticorum, latitudine vel gracilitate, ad differentiam sexualem respiciunt, cum inter antenuas et tarsos, ilo respectu, plane nullns consensul sit, et proportio eorun mutua mullis firmis et certis regulis respondeat: E. $\mathrm{g}$. Staph. nitidi individua occurtunt $\mathrm{reI}$, ,antennis brevibus crassis, tarsis anticis

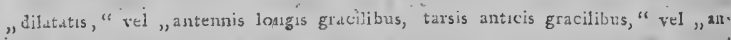
"temis longis gracilibus, tarsis breribus latis, " $\in \mathbb{l}$ "2utemis brevibue crassis, "tarsis anticis gracilibus longis." 
quorum copiam magnam legi, ita ut generalia huius proportionis hic uon dare possim, specialia autem generum atque specierum descriptionibus iunxero.

S. 6 .

\section{De partibus oris.}

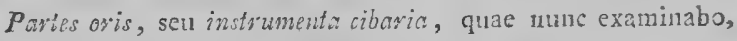
atcentione et duligentia maxima digna sunt, cum partim, ratione oeconomiae insectorun, tanti sist momenti, partim autem, ob multiplicen simulque constanten formam ct proportionem, apta sint ad characteres genericos praebenłos. Hae partes sunt: Labrun, mandibulae, maxillae cum palpis anterioribus, labiun cum palpis posterioribus, et mentum.

Labrun 1) longitudine est latius; Tachinis attem angustius, quan reliquis generibus; Pacdero orbinlate, caeteris paribus, uaius, margine antico integro, guo capitis pars antersot dilatatur et producitur. Reliquis horum insectorum generibus labrum, quantum mihi obsurvare licuit, nargine antico magis minusve emarginatum, seu incisum, et interdum in duos lobos (clypeus, verrucis binis setosis, Panzer) Sissim est, quod in: Staph. olente, polito, Lathrobio brunnipede ct Oxyporis, satis distincte aninadverti. Margine setis crebrioribus, haud vero confertis, cilaatum est.

Mankibuice apice incurvae et acutac sunt; dorso lacres, integrae, nuabe, arcuatae, interdun planiusculie ita ut nurgincs

I) Yate oris pars, quam YlIiger primus labrum nominat, a fonkms anctoribus labium superius appeliatrir, atque earem est, guam Panker fig. IX, tis. XII Itbelli entomologici, supre iam aliegats) onb ronise "Ciypeus, 3, verruci, binis setosis" exhbuit. 
duo distincti dorsum et latera mandibulae definiant. - Margo interior mandioulae duplex et acutus est; intervallum, inter hunc marginem duplicem, alveatum est et eo latius vel angustius, quo latior vel angustior mandibula tota est. Oxytelis piceo, carinato triorni unus horum marginum interiorum adeo retrocedit, ut dens introrsum versus huius margınis a dorso oriri videatur. Quorumdam horum coleopterorum mandibulae, nargine inte. riore, dentibus armatae sunt, quorumdan autcm inermes, et hae, sine exceptione, breves, latae, apicen versus sensim angustiores (e. g. Tachini rufipedis, Aleoch. fuscipedis, canoticulatae, Tachyp. analis). Mandibulae dentatae plerumque graciliores sunt; in genere Stenorum gracillimae et falcatae, apice profunde incisac, vel, si mavis, dente longo acuto subcurvato, apici propiore, armatae; paulo latiores St. olentis, politi, maxillosi, erythropteri, nec non Paed. litturelis et riparii, medio marginis interioris dente porrecto subobtusiusculo armatae; Oxypororum et Lathrobii elongati, dentibur duobus; Paed. orbiculati, dentibus tribus vel qquatuor. Mandibulae Oxytel, picei, carinat ct tricornis, forma, illis Aleochararum, Tachinorum \&cc. similes, apice colem modo incisae sunt, quo in Stenormm genere; Calliceri exsertae, paulo angustiores quan Aleocharis, nargine autem interiore denticulatae, Stuph. stercoravii breves, crassae, latae, marginis interni usedio dentibus validis brevibus armatae. Mandibulae auten ambae nunquan invicem omnino aequales et similes sunt: Irregulariţares et fleziones carum ita sitae sunt, ut alterae alteris respondeant, i. c. ut, coniunctis et complicatis mandibulis, tuberculi, seu dentes, seu convexitates unius, in foveolas, scu incigiones, scu concavitates alterius inserantur, \&c. quo haccinstrumenta aptiora redduntur ad rapinam et cibum tenendum et comminuendum. Inde dentium numerus et situs 
varii quarumdam specierum, (Paed, crbiulati mandibula altera quadridentata est, altera tridentata; Staph. steriorarii ahtera tridentata, altera bidentata) et quidem ita, ut mandibula sinistra, capite scilicct superne viso, dentibus semper pluribus instructa sit, quam dextra.

Wiraxillae constant c basi et duobus processibus. - Illa est farma irregulari, angulata, subquadrata, radice latior, dificicilis descriptu. - Prccessus interior, qui ad latus internum basis oritur, altus autem illa ascendit, compressus est, medio latissinus ven. tricosus, apicem ct basin versus angustatus; dorso, scu margine extero, quibasi adjacet, recto, laevi, nudo; mirgine interno medio ventricoso, apicem versus ciliis brevibus pectinato, interdum etiam basin versus çiliis fimbriato (e. g. St. polito, Pacdero orbiculato). - Processus exferior insidet in apice truncato basis; forma est clavata, plerumque subincurva, interdum ensiformi (e. g. Lathrob. elongato); apice setis densis seu ciliis incumbentibus vestitus; coloratu et crassitie substantiae membranaccae variis in areas tres divisus, quarum inedia reliquis obscurior esse solet 2).

2) Quibusdam horum coleopterormm hic processus, longitudine et atearum colorato, palpum triarticulatum mentitur (e, g. Staph. olenti, erythroptero, Iuathrob. elongato etc. multis), et facile pro palpo vero haberi potest. Examine autem diligentiore, et comparatione inter palpos et frocessus maxillde plurium insectorum, institutis, haud difficile dignoscencum to oculis aeque ac verbis distinguendum exit, quid sit palpus rerus, quid processns maviliae: Palpus, artaculs pluribus comeis, vi motus proprii instructis, eonepositus, maxillae ita insertus est, ut, maxilla ipsa quiescente, quoquoverstis et relociter se moxere possit; articulus eius ultimus 1uumquam pils vistitus, sed iz=vissimus est; interdum articulus primus, et pletumgne asticulorum medorum to primi apices setis quibusdam, havd vero confertis, vestiti sunt. Processus $\in x \pm e-$ sior maxillae membramaceus est, numquam articulatus, nec ita maxilat inset- 
Palpi anteriores singuli apici basis maxillarum, inmediate an. te processum exteriorem, inscrti sunt, et proveniunt e tuberculo exiguo, haud confundendo cum articulo palporum primo brevi. Raro triarticulati sunt (Stenis nempe, Paederis et Callicero); ple. rumque quadriarticulati, - Avticulus primus, brevis, clavatus, numquam parte quarta artíuli secundi longior est. Articulus secundus clavatus, tertio numquam brevior plerumque auten paula longior est (e. g. Oxyporis, Staph. olenti, maxilloso, polito, ster. corario, Oxytelo piceo, Tachino rufipedi). Articulus tertius etian clavatus est et, si ipse ultimus est (e. g. Callicero, Paederis, Stenis), aut si articulus quartus pertenus est, (e. g. Alcocharis, Lathrobiis, Oxytclis) praevaidus. - Articulus quartus forma est inuliplici: 1) Vel nihilo vel paulo tantum angustior penultimo, ovatus, ct quadem apicc vel obtusus (Staph. faniliae primae et Staph. majoribus famliae secundac) vel acutus (Staph. reliquis, Oxyporis, Tachinis, Omaliis, Pınophilo): 2) penultimo latior, ecuriformis (Astrapaeo): 3) brevis, tenuis, multo gracilior penultimo, subuliformis (omnibus reliquis Coleoptero. rum Micropterorum generbus.

Palpi posteriores triarticulati, dorso seu superficici externae labii inserti sunt, et proveniunt e tuberculo, quod, radice prolongata, articulo propria simile, motus autem spontanei haud potens est. Articulus primus minor est, et forma brevi clavata; secundus clavatus, plerumque reliquis longior, quod auten in Staph, polito, erythroptero, ster-

sertus, ut per se moveri posset, et si interdum motus spontanei compos esse ycetur, had motus effectus suinstantiae ejns flexibilis est, quae pressioni cedit. Maxullae, palpis dunbus retris instractze, sunt Carabis, Dyticis, Cicindelis, Cy" chris, Furfiedae áuricnlistae etc. - Plura, huc pertinentia vide \$. 2 . not. I. 
crario, Stenis, Tachino rufipede, Altoch. canaliculata, Oxytelis piceo, carma et tricorni, Latrob. elongato nullus est momenti, qubus articuli primus et secundus ferce eiusden longrtudnis sunt; articulus ultinnus vel de articulo ultimo palporum anterio. rum, forma, decedit (e. g. Oxyporis, Paederis, Stenis et Callicero), vel ei aequalis est (in reliquis generibus) 3 ).

Mentum comeum plurimis generibus Jongitudine latius est, et quiden apice, cui labium insidet, latissimum, truncatum, integrum, gulam versus angustatum; Oxyporis autem et Stenus latitudine longius et rhomboidale. - Alia guaedam de mento vide in nota 4).

3) Palpi anteriotes semper sub capite magis minuste prominent, ipsis etian mixillis, rupbus inserts sunt, absconditis. Palpl postexinges, multo quidem anterioribus bicriores sunt; porrectis autem, articulus saltern vilimus commode et sine noxa insccti oloservan et exuminari potest. Cum autem forma

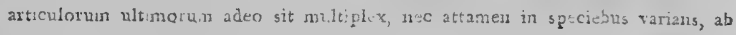
ea prateipue claracteres Eenericos desunsi, - Palpi filıformes sunt ubique eizusden crass.tici, articul s primis clavatib, ultumo orato; secursdacei, urticulis primis clavitis, ulimo triangulan at seturiformi, pratecdesisbus latiore; acuminat $i$, articula bltimo suiulforni, multo breviore te teuuiore quan punultimus.

4) Cum loo loco quaelan de differentia labii et menti addere mihi propoitux sit, mox possum quin indicem, me, in denominutione oris partium, Don. 111 igger secltum esse, qui illas in prafatione ad, Elumerationem Co.

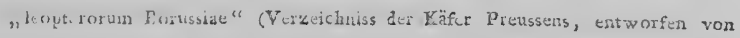
Jol. Gottl. Kugelanu, arisgearbeitut vern Joh, Karl Wilbeln 111 gex

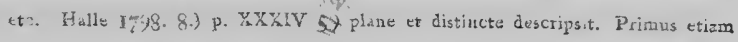
labium te $m \in n t u m$ distukxts, et d funitiontem harun partum raulto faciliorem recididit. - Fabricius, in scriftis prinis Eutomologicis, sub labio inferiore mentum sinul et labium comprehiendit, hocatutem pro processu interno linguaforni illius habuit, quod putet e verbi, cius propriis, „Labia horizonntalia, os superne inferneque tegentia; ulimo interòm elongato in linguae 
Labium, superficiei internae et apici menti adnatum, multo autem altius ascendit quam illud; membranaceum est, lateribus autem et sub palpis substantia multo crassiore. Non vero audeo, de forma eius aliquid certi dicere velle, quia iure dubito, labia, insectorum, quae examinavi, integra fuisse, cum saepius apice, - parte eorum longe tenuissima, adeo irregulacia seu lacerata vel

"Iacinias interiores" (Viàe I. C. Fabricii Systena Entomologiae - in Prolegomenis. - I. C. Fabricii Entonologia Syste!natica. Tom, $I$ in pratatione, p. V). Mentum ergo et labium sub uniwersali nomine „labii in") furioris" comprehendens, cum labii apicis mentionem factet, tum de apice menti, labio scilicc proprie sic dicto deficiente, vil oculis cius Jatente, Inçuebatur, quod plase apparct e comparatione operis eius recentissimi (I. C. FaExicii Syctema Eleutberatorum. Tom. I. Kiliat ISOI. 8.) cun operibus praecedentibus. In illo enim partes easdem stiunxit, quas Ifliger iam ante sum, sub nominibus $m \in n \varepsilon i$ et $1 d$ bii distinkerat, illud autem labium, hoc ligula appellavit; et saepius legimus , ligula trufida, Iigula bufiła, ligula inteis gra" ubi in scriptis prioribus einsdem auctoris de "labio trifido, labio bifidn „labio integro" Iocutum estr; sáepius autem "labium exnarginatum, ligula nulla, "labium cylindricum, labium integrum " eto. ubi, quoqut in Entomologia sj* stematica, "Jabium emarginaton, labiun cylindricum, Jabium integrum" legimus. "Penicilli duo" Lucani, qai sunt "ligula bifida penicilletal" Lucani (in Syst. Eleutherat.) Jalium sunt. - Differentiam inter labium el mentun Dom. Sturm figuris diligentissinge sculptis quatuor tabularum, quas libello entomologico (Verzeichuibs meiner Insectenbammling ttc. ven Jacob Sturm. Erstes Heft, Nürnberg I $\$ \infty 0$. 8.) adivulust, perelaxe proposuit. Insecta, et instrumenta eorum cibaria, tuhilis illis exhibita, ab insectis, quae hic tractan. tur, Jonge quidem discrepant; sed collatione partinm multa iam clarona redduntur. Maximis praterea Sraphy-linis, colore nigro seu obscurn, nihil facilius Ast, quam mentum et Iabiam discernere, cum nonsolum substantia, illins schisct cornea, hrius membranacea, scd ipso colore, menti zigro, Jabi flavo, differänt. Confer quae Prof. Knaoll, in opere supra iam allegato, (Neue Bey̆träge zur Insectenkundc von A. W. Knoch. Erster Thesl. Leipzig I8Or - Einleitung) ds are disseruit. 


\section{Partes oris.}

corrugata apparerent, ut non credere possim, me illa sub forma corum propria et naturali vidisse. Attamen, ligulam enargi"natam cunı mucrone " (Fabr.) Oxypori, nee non , ligulan "cylindricam integran “ Paederi (Fabr.) vidi, haud vero, li"gulan trifidam " Staphylinorum (Fabr.) e quibus Staph. maxillo. sum, olenten, stercorarinn et politum examinavi, labium autem nunquain fissum conspexi. Ea labii pars, quae infra palpos posteriores sita est, Paed. ripario et on biculato, "Tachino rufipedi, Aleoch. fuscipedi et canaliculatae, Oxy telis carinato et tricorni, lon. gitudine latior, forma rectanguli, erat; Staph. polito, maxilloso, olenti, Lathrob. elongato, basi latissina, apicem versus sensim angustata; e contrario, apice latissina, basin verus sensim angustate, Stenis erat 5). - In superficie interna labii partes duas conspicimus, pectinilus siniles, quorum dentes perpendiculariter in superficie intema labii erecti sunt 6 ). Hi pectines, situ, formae labii respondentes, in Staph. maxilloso et Lathr. elongato, quoruin labia accuratius examinare pout, coniunctim figuram anguli acuti exhibent cuius apex gulan versus spectat. - Labum, cum palpis ct his pectinibus, a latere visum, exacte maxillan reprassentat, cum pectines, substantia et figura, onrino pro. cessui interno maxillac similes sint, et solo defectu processus exterioris ab illa differt 7 ).

5) In characterihus gencricis maquam libii rationern habui, praecipue eam ob cansam, quod de vera huins partis figura saepe nimis incertns essem, et quod ab illa la'ui parte, quate pone palpos ascenđit, parte adeo tenui, quat facillime whlnerari aut deformari possit, characterem genericum nollem desnmere.

6) Limula, laçinius linearibus intus dentatıs, Copris $\mathbf{F}_{2} \mathrm{br}$. - Confer tabulas in libello Eotomologico Sturmii, quen iam in mota b) huius $S$ allegavi.

7) Labium ergo, cum duobus palpis in superficie externa, et duobus pectinibus 


\section{S. 7 . \\ De Thorace.}

Thorax, circumdatus canaticula marginali, quac instar sulculi angusti, in speciebus minimis vix conspicui, totum thoracem ambit, maroine auten anteriore fere evanescit. - Infra hanc canalisulam thorax adhuc paululum continuatur, quae continuatio, ora lateralis a me appellata, acque ac thorax, canalicula marginali propria circumdata est, semper, aut m lacvissima nitidissima, licet thorax vel confertissime punctus sit (e. g. Staphylinis familiae secundae). Stenis solis haud minus confertin et crasse puncta est, quam reliquae thoracis partes. Plerumque orae laterales cum thorace proprio angulam exhibent acutum; acutissimum autem, oris nenpe lateralibus omino fere ad superficiom inferam thoracis refexis, in Tachyporis, Tachinis, Alcoch. fuscepede, ruficomi \&c, ut paucis dicam, in omnbus illis, quorum thorax latus valde convexus atque lateribus deftexus est. Inde Staphylinis, Aleocharis famliae primac \&c. hic anguItus minis est acutus; rectus, Oxyporis, Paederis, Lathrobiis; obtusissimus Stenis, quorum thorax nulla canalicula marginali circuudatur, sed lateribus linca solummodo subelevata obsoleta ab ora laterali separatur. Forma orae lateralis duplex est; ple-

in superficie interna, ommino eum maxilia duplici comparari potest, et, secundum analogiam, meliore forsan iube maxilla nominaretor, cum tam ratuo ne situs et motus ausscendertis tt descendentis, quan scrie duplici dentium superficiei internae, maxilize reliquorum animalium melius respondeat, quam ille partes oris colenpterorum, quae hactenus maxillae rominatae sunt. Cum autem permutationem firmm dennminationmm multae confosiones stqui possent, et certo sequerentur, nomitia usitata partinm oris servari, et nihil magis opto, quam qृuod çursçue ta servet. 
rumque scilicet linearis, apicen versus angustata; Lathrobiis vero, Oxyporis et Paederis triangularis, basi latissima.

Thorax proprius, seu pars thoracis stupera, semper matis minusve convexus est; disco enim deplanato, latera saltem declinata sunt (e.g. Aleoch. depressar et deplanotae); lateribus autem planiusculis, discus convexus est, (e. g. Onaliis, Aleocha: rae strumosce \&(c.). Thorax planissimus ililis generibus est, quae, habitu toto, valde plana sunt (e. g. Oxytelis, Onaliis); convexissumus Tachyporis et quibusdam Aleocharis (e. g. Al. fuscipedi, lanuginosae, bipunctatae, nitidae et affunbus). Latera thoracis nominantur vel declivia, vel deflexa, vel delinato quo magis vel minus, quo abruptius vel lenius descendunt. - Furma tho. racis, vel eius circuitus, in generibus variis varia etiam est: Orbiculätus thorax est quibusdaun Aleocharis familiae secundae; subquadratus, angulis obtusis, margine basis rotundato, Staphylinis familiae secundae; suborbiculatus, margine apicis truncato, Staphylinis familiae tertiae; subrectangulus, angulis obtusis, Staphylinis familiae quartae et Lathrobiis; longitudiue latior; seu transversus, Tachinis, Omaliis, et plurinis Tachyporis atque Oxytelis; fusifornis, vel subcylindricus medio paulo latior, Steuis plurimis; gicbosus, Aleocharis familiae primae et nonnullis Pacderis; cordalus, seu apice latior, basin versus angustatus, Anthophagis. Superflum autern foret, de maquaque differentia formae thoracis, quae in singulis speciebus magis minusve diversa est, hic ian loqui, cum infra, in descriptione specierum, omnia repeterentur, - De proportione thoracis ad capit supra (6. 4.) ian locutus sum.

Quod adhue menorandim est spectat ad irregulcritates thoracis. Thorax nempe: 1) totus est gluber, laevis, sine ulla ir. regularitate, 'Tachisis et 'Tachyporis; 2) punctis subtikssimis 
oculo non bene armato vix conspicuis, sparsus l) (e. g. Tachino mifipedi \&c. Aleoch. fuscipedi, lanuginosae \&c.) 3) punctis, nudo ciculo conspicnis, confertis, impressus (e. g. Staphylinis plurimis faniliae secundae, Lathrobiis, Oxytelo tricorni \&c.). His autem colcopteris linea est thoracis media longitudinalis, laevissima, nitida, interdum nudis oculis vix conspicua vel obsoleta, praecipue, si thorax confertissime atque subtilissime punctus est (e. g. quibusdam Staphylinis familiae secundae), interdum autem latissima, si thorax punctis q̨uidem multis, haud vero confertis, inpressus est (e. g. quibusdam Lathrobiis). Staphylinus olens, solus inter Staphylinos indigenos, hac linea longitudinali thoracis caret, et nunquam ne vestigum quidem exus vidi, quanquam thorax subtilissime et confertissime punctus est. 4) Staphylinis familiarum tertiae et quartae thorax est laevis nitidus, et plerumque seriebus punctorum longitudinalıbus impressus. Hąe series distmetae et, ipso punctorum numero, constantes esse solent, ita ut ab hoc characteren distinctivum specierum desu: mere ausus sim. - Series autem duae mediae, quas series dorsa. les appello, chacacteres optımos praebent, et punctorum, e quibus finguntur, in speciebus variis, sunt tria ad duodeviginti. Fere sine ulla exce, torre, juxta harum serierum singulaun altera est, itidem longttudinalis, plerumque autem magis minusve arcuata, arcus convexitate intus versa, punctis duobus ad octo constans; hae series'sunt llae, quas sevies laterales appello. Immediate ante canaliculan marginalem lateralcm, puncta sunk plerumq̨ue duo, raritus tria vel quatuor distincta, e qubus, utrc-

7) Forsan corpoira onuium coleopterorum puncts subtilissmis spatsa stut, quae zutem, is muinis, ope tuitum nicioscopii multo angentis atprebenci possunt. 
que thoracis latere, seriesmarginalis composita est. - Hae series thoracis ita dispositae sunt, ut, in regula, numerus punctorum seriei dorsalis maior sit nunero punctorum seriei lateralis, et hic maior numero punctorum seriei marginalis; exceptis attamen Staph. elongato et gldbro, quorum series dorsales et laterales, numero punctorum, aequales sunt. Series thoracum elongatorum Staphylinorum familiae quartae e punctis longe pluribus compo. sitae sunt, quam series thoracum orbiculatorum breviorum Staphylinorum familiae tertiae, ita, ut numerus minimus punctorum thoracis in familia guarta, maximus sit in familia tertia (nulla scilicet ratione habita Staphylinorum, quorum thorax haud puncto-striatus est). In familia quarta Staphylinis quibusdam (e. g. Staph. ochrareo, elongato) series lateralis, septen - vel octo-puncta, et series marginalis, tri-vel quadripuncta, apice ita incurvatae sunt, ut jungantur, et junctim figuram pedi epis. copalis exhibeant. - Quod de sericbus punctorum thoracis summatim dixi, de plurimis tantummodo, non de omnibus, Sta phylinis familiae quartae obtinet; nulia enim regula sine excep. tione: Sunt Staphylini nonnulli, quibus thorax punctis paucis sparsis impressus est (e. g. St. splendenti, laminato, fulninanti, alternanti); Staph. puncto thorax est lateribus nultupunctus, punctis haud in series dispositis, seriebus autem dorsalibus distinctis, octo-ad decempunctis; item Staph. ruffuenni thorax est multipunctus, punctis autem disparsis. - 5) Tanden thorax quibus. dain Micropteris sulcatus est vel foveclatus, idque diversimodo: Est vel laevis, dorso sulco uno longitudinali canaliculatus, (e. g. Oxytelo mositanti, Alencharis obscurae et sulcatap); vel laevis, basi quibusam foveolis longitudinalibus abbreviatis inpressus (e. g. Al. impressar, gergati); vel crasse punctus, sulcis et foveis longitudinalibus, longitudine thoracis, exaratus, (e, g. Oxyte- 
lis piceo, carinato \&c. Omaliis pluribus \&c.); Omalio vugoso autem sulculis abbreviatis rugosus; vel foveola parva orbiculata ante scutellum impressa (e. g. Aleocharis pluribus). - Alias im. pressiones thoracis, vel minus notatu dignas vel rariores, hic pratermitto, et in singulis speciebus adnotabo. Quaedam autem htr spectantra, imprimis ratione consensus inter caput et thora. cen, vide 0.8 .

\section{S. 8 .}

\section{De coleoptris et alis.}

Coleoptra, forina; minus sunt multifaria quam thorax. In situ naturali quieto vel sunt tronsversa (longitudi:se latiora), la. teribus parallelis (e. g. Staph. simili, Aleocharis familiae tertiae) vel rectongula (latitudine longiora) (e. g. Staph. famliae quartae, Paedero rivario, Lathrobiis, Omaliis, Anthophagis \&c.) vel quodrata (longitudine latitudivis) (e. g. Staphylinis plurinis, Aleocharis familiarum primae et secundae, Oxytelis). Pectoris sem. per sunt latitutine, quae autem, cum latitudine aliarum corporis partium collata, multiplex est: Coleoptra, thorace multo an. gustiona, his insectis nunquan inveniuntur; latiora autem sunt Paederis, Oxyporis, Stenis et praccipue plurimis Aleocharis fa. miliae primae: Respectu longitudinis relativae, coleoptra optime cum thorace comparari possunt: 'Longissina sunt Omaliis et Anthophagis, quorum coleoptra, longitudine et latitudine, thoracem saepius duplo superant; breviora quidem, thorace atta. nen longiora, Tachinis, Tachyporis, Oxyporis, Oxytelis, reliquis longitudine circter thoracis. Coleoptra, respectu longitudinis, cum abdonine conferre, eam ob causam non censeo, quod quaedan horum inscctorum, morte, abdomen sacpius 
contrahere soleant, ita ut multo abbrevietur, quo ergo proportio longitudinis harum partiun valde mutatur et variatur; Tachinis autem, Tashyporis, Onaliis familiae secundae et Anthophagis, abdomen raximam parten a coleoptris tegitur; Aleocharis vero, Staphylinis, Paederis \&c. minimam partem. Coleoptra plerumque sunt planiuscula, eoque magis, quo magis totum corpus deplanatum est (e. g. Oxytelis, Ornaliis), eoque minus, quo minus illud deplanatum est (e. g. Tachyporis et Tachinis). - Elytsa apice truncata sunt, plerumque oblique, ita, ut margo suturalis margine laterali brevior sit, angulis exterioribus apicis magis minusve rotundatis, praecipue Aleoch. fuscipedi, Staph. simiti, olenti \&c., omnibusque illis Micropteris, quorum coleopera perbrevia sunt, nee e. g. 'Tachypotis, Tachinis, minime autem Omalis, quorum elytra, e contrario, ita truncata sunt, ut margo suturalis margine laterali longior, immo, Omalio Ranunculi, praeterea productus seu appendiculatus sit. Colcoptra marginibus lateralibus deflexa sunt, angulo attanen haud acuto, sicut orae laterales thoracis, sed pars ista deflexa, nec mar,ine distincto acuto, seu linea clerata, uec canalicula marginali, separata, substantia, irregularitatibus vel lasvitatc, coleoptrorum superficiei aequalis est, nec in essentialibus ab ill diversa. - Hunerus, in angulo elytrorum basis exteriore, pars altior elytrorum esse $c t$, instar gibbuli, enincre solet; in generibus autem, quorum colcoptra convexa sunt, (e. g. Tachinis et Tachyporis) vix paululum prominet. - Reliquae coleontrorum irregularitates sunt vel puncta, vol cicaticulae, vel sulculi, vel lineae impressac. - Puncta, omnium frequentissimae, vel subtilissima stunt et confertissima (e. g. Staphylinis faniliae secundae, Aleocharis \&cc); vel crassiora et minus confetta (e. g. Stapinglinis phrimis faniliac tertiae, Lathrobiis, Paederis, Onyte- 
lis plurimis, et praecipue Stenis); vel in series disposita (e. g. Staph. impresso, elongato, ochraceo, Omal. rugoso, crenato, brunneo, striato) seriebus atuteu raro distinctis, cum puncta passim vel in lineas impressas subconfluant (e. g. Omaliis rugoso et crenato), vel dispergantur et vix vestigium serierum relinquant (e. g. Staph. ochraceo, Oraalio brunneo \&c.); vel in disco solo elytrorun dispersa, (e. g. Oxyporis) 1). - Cicatriculosa, seu punctis

x) Hoc loco non possum non mentionem fecere consensus intex caput thoracem et coleoptra, ratione punctorum rugarum vel aliarum irregularitatum superficiei eorum: Si una harim partium prorsum est laevis et glabra, duae etiam alterae lates et glabrae esse solent (e. g. Tachyporis, Tachinis familiae prinae tc.). Colenptris punctis, caput atian et thorax punctis impressi erunt, haud vero semper enden modo, sed, capite subtiliter ct confertim puncto, thorax etian et coleoptra subtiliter et confertim puncta sunt (e. g. Staphylinis familiae secundae, Alenchatis familiarum tertiae et secundae multis); capiti thoracigque, subtilissine et coufertissime punctis, Staphylinorum plurimornm familiae secundae, linea media est longitudinalis laevis nitida, Staph, oleute attamen excepto, qui hac linea caret, etsi caput et thorax eius pun ctulatissimi sunt; capite lateribus tantummodo puncto, thoracis etiam latera sola puncta sunt, punctis autem plerumque regulariter et in series positis, (e. g. Staphylinis familiarum iertiae et quartae), coleoptra vero ubique punctz sunt, punctis interdum in series subdispositis, (e. g. Staph, elongato, ochrav ceo.) Immo, puncta capitis, quantitate ef qualitate, punctis thoracis respon dent, ita, ut, illis subtilibus et frequentibus, vel crassioribus et crebrioribus, haec etiam subtilia et frequentia, rel crassiora et crebriora sint, et vice versa, (confer Staphylinorum et Lathrobiorum species). Stenis caput, thorax et con leoptra punctis confertis crassio obsita sunt. Capite rugis exarato, thorax etian rugosus esse solet (e. g. Oxytelis, Onaliis). Oxyteli tricornis caput et thorax, quibusdan speciminibus, armati, quibusdam, inermes sunt. - Quod autem hactenus de cousensu capitis thoracis et coleoptrorum dixi, summatim solummodo valet, tt "mulla xegula sine exceptione:" Inter omnia Coleoptera Microptra milum occurrit coleeptris cornutis, aliove modo armatis, quamquam quibusdam caput $v \in 1$ eaput et thorax axisati sunt (e. g. Oxytel. cornu- 
irregularibus, subconfiuentibus impressa, elytra sunt Oxytel. picei, carinati. - Sulculi nomnulli longitudinales, valde autem breves, basi coleoptrorum Aleoch. impressae et gagatis insculpai sunt. - Lineae longitudine totius elytri, in his generibus haud reperiuntur, lineis duabus coleoptrorum parallelis, juxta suturam sitis, exceptis, quae omnibus fere horum insectorum speciebus communes sunt; praeterea elytris Oxypororum, disco, lineae duae longitudinales, abbreviatae, subobliquae, impressae sunt; et vestigimu hartum linearun quibusdam etiam Tachinis familiae secundae superest, lineis nempe vel obsoletis et interruptis, vel in puncta tria remota dissolutis.

\section{De 2 lis.}

Sub coleoptris alac, situ naturali quiescente, artificiose complicatae, absconditae sunt, spatio perexiguo, cum, explicatae, multo longiores et latiores toto corpore sint. Membranula earum 13ulto crassior est quam membranula alarum Forficulac auriculariae, et modo multo simpliciore, costis paucis, explicantur et complicantur 2). Tres harum costarum oriuntur basi alae, ex

to et tricorni, Anthophago armigero). Porro, Oryporis et quibusdam Tachinis familiae secundae elytra sunt disco puncta ts striata, capite thoraceque laevissimis.

3) Nec miramor; nti in alis Forficulae a uricuiariae, multitudinem, tenuita. ten, ord:nem costarum et liganentortm, quae membranuam subtilissinam sustinent, nec effectum musculorum et nervorum invisibilium, qui, svechasismo artificiosissino, costas ullas, nedio geniculatas, regunt, expandunt, retrahumt, et ope earum, alam explicast, vel complicant et sub coleopira occultant. (Confur. Memoirts etc. par C. De Geer T. III. Mem. XII. p. 514. - Bon-

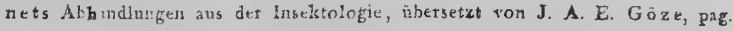


ca parte, quae cum trunco corporis cohaeret, apicem versus attenuantur, et fine omnino evanescunt. Prima, sicdicta marginulis, ipse margo superior alae est, et in apice alae desinit; valida est, medio lata plerumque colorata, apicem versus attenuata. Secunda, seu furcata, ortu siniplex, mox in duos ramos discedit, qui in margine inferiore alae, superior autem apici propior, inferior in medio marginis, desinunt. Tertia, quam breven apello, desinit eo, ubi margo basis alae et margo inferior alae coniunguntur, multo est brevior quam costae furcata et marginalis, et, cum margine basis alae, exiguam tantummodo partem membranulae includit. - Hae tres costac, quae e radice alarum oriuntur, distinctae sunt, et omnıbus Coleopteris Microp• teris conmunes esse videntur. Interdum autem ab illis, tanquam ramuli a trunco, quaedam costae breviores et graciliores proficiscuntur, numero et directione variis, quas autem hic praetereo, cum parvi momenti sint.

\section{\$. 9}

\section{De trunco corporis.}

Truncus corporis, i. e. corpus, capite thorace et caeteris mentbris privatum, constat pectore et abdomine.

Pectus, incisura laterali, ab abdomine separatum, supra tu* midiusculum est, post mortem insecti auten exsiccatum et col. lapsum, alis et coleoptris omnino tectum; infra pedibus poste. rioribus instructum (vide 6.10 ). - Medio partis anterioris superioris scutellum adnatum est, quod, situ partium naturali quieto

549). Haec omnia in 2 lis coleopteroium micropterornm desideramus (Confer.

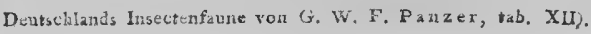


atque incolumi, inter angulos interiores elytrorum basis prodit. Staphylinis hoc scutellum elongatum est, basi latum, apicern versus sensim angustatum; Lathrobiis triangulare, exiguum; $\boldsymbol{P}$ aederis perexiguum, obtusum; Anthophagis et Stenis vix conspicuum; reliquis parvum triangularc.

Abdomen supra et infra convexum est, marginibus lateralibus clevatum, unde pars eius iuferior, Guae venter nominatur, semper convexior est, quam pars supcrior, seu dorsum abdoninis, eoque magis vel minus, quo angustius et crassius vel latius ct depressius totum corpus est. - Abdomen compositum est e septem aunulis corneis, qui segmenta, ultinus autem speciatim anus, nominantur, quorun quinque prima, longitudine, aequalia sunt, sextus autem reliquis longius esse solet. Hic segmentorum numerus constans est; abdomine autem, morte, contracto, haud raro accidit, quin unum alterumve corum, praecipue ultimorum, in segmentum praecedens retrahatur, quod Tachinis et Tachyporis saepius obvenit, atque numerus segmentorum minor esse videatur; cave, ne, hoc dcceptus, credas, abdomen e sex vel quinque segmentis compositum esse. Segmentum penultimums sive sextum reliquis segmentis longius esse solet, imprimis in genere Tachinorum, et partes (verisimile genitales) inciudit, quae, speciebus nonnullis, instar penicillorum et forcipularum, numero auteı non semper eodem, ventre, sub segmento ultimo, prominent (e. g. in specicbus quibusdam Staphylinorum, Lathrobiorum, Paedero ripario; distinctissime autem ct copiosius in Tachinis familiae primae). - Quod ad forman seguentorum, haec, dorso, omnibus Coleopteris Micropteris, eaden est, nisi quod latirudine interdum diversa sint: Staphylino palmulae abdomen apicen versus latitudine crescit, Tachinis Tachyporis et quibusdam Staphylinis familiae tertiae (v. c. Staph, attenuato) la- 
titudine decrescit; anus, vel segmentum ultimum, reliquis semper angustius est. Ventre segmentum penultimum, vel hoc et segnentum antepenultimum, interdum a reliquis differunt: Nonnullis Staphylinorum speciebus (e. g. Staph. maxilloso, olenti) seg. mentum penultimum, quibusdam individuis, nargine medio, arcu parvo sinuatum est, quibusdam autem integrum; nounullis Tachinorum speciebus, praecipue maioribus (e. g. T. rufipedi, humerali, subterraneo) segmentum penultimum, quibusdan individuis, margine sinuatum est, quibusdam integrum; nonnullis Staph. variantis et politi speciminibus segmentum penultimum margine medio incisum est seu fissum, aliis integrum; Staphylini laminati segmentum penultimum, infra, vel sub ano productum est, vel simplex et haud longius quan supra; Staph. splendenti vel segmentum penultimum, infra, margine medio, profunde fissum est, simulque antepenultimum arcu parvo sinuatum, vel utrumque integrum 1),

1) Cum autem individua specierum hio allegatarum, et certe multarum adhuo aliarum, caeteris paribris, forma sola huius segmenti differant, et baec differentia adeo frequons sit, eam non sufficienten esse putari, ad plures species condendas. Coniicio autem, hanc stgmenti penultımi duplicem formam in sexum auplacem specierum teforri posse, idque tanto neliore iure, cum observavarits, penicilla ista, quorum in $S$ mentionem feci, individuis, margine seg. menti penultumi infra sinuato, longiora esse quam reliquis. Hunc attamen consensum sexus et formae segmenti penultimi conincere tantum, nec affirmare, possum; nondum exim par indrviduorun ex qualibet allegatarum specierum in copula reperi, nec credo, hanc differentian individuorum in reliquis Micropte. rorum speciebus, pracker Staphylinos et Tachinos familiae primae, locum ha. bere; ego salnem eam haud ubiq̣ue vidi, quamquan, multis speciebus, copiam haud exiguam speciminum possideo, et par Aleoch. Boleti nec non Steni fla ripedis, copula iunctun, prehendi. 


\section{S. Io. \\ De pedibus.}

Pedes Coleopterorum Micropterorum, respectu numeri et situs artuum, omnibus generibus atque speciebus, nec non inter se, aequales sunt; respectu autem proportionis, semper pedes antici brevissimi et validissimi sunt, pedes postici longissimi atque gracillimi. Constant capite fonoorum, fentore cum troitantere, tibia et tarso, et proportioni pedum inter se proportio artuum respondet, qui, pedibus anticis, validiores et breviores, pedibus posticis, longiores et graciliores sunt, exceptis capitibus femorum, quae, pedibus anticis, validissina quidem, sinut vero longissima, pedibus autem posticis, brevissima esse solent. Hi pedis artus, omnes simul, ope capitis femoris, moventur, singuli autem, per se, motus etian peculiaris in artu praecedente, haud attamen omnibus directionibus, potentes sunt: Caput femoris (squamnla articuliformis Panzeri), quod, qquamquàm, motu pedum, magri momenti est, plurimi Entomologi nostri aevi practeriveruut, basis cst totius pedis; partim in acetabulo situm, i. e. in cavitate corporis, formac eius exacte respondente, et motum ei certum concedente; hic motus attamen non uisi prorsum atque retrorsum, neque lateratin, fieri potest. Femur in capite femoris lateratim movetur, et si insectum incedit vel currit, atque pedes prorsun et retrorsum movere cogitur, capita femoris antica omnino prorsum, posteriora autem omnino retrorsum flexa sunt, ita ut pedes, respectu quiden totius corporis, antrorsum et retrorsum, in capitibus femorum auten lateratin, moveantur. Basi femoris, introrsum, trocharter (inter $23-24$ et $28-29$ tab. XII libelli Eutomologici Panzeri situs), tanquam appendicula, iunctus est, qui autem motus spon- 
tanei haud potens esse videtur. Nescio, quod de eius fine et usu proferam. Eodem modo, quo femora in capitibus femorum, tibla in femoribus, et tarsi in tibiis moventur. - Omnes hi artus ita formati sunt ut, complicati, singuli singulis arcte se adplicent. Caput femoris, quousque ex acetabulo prominet, superficie superiore convexum est, superficie autem inferiore eo magis vel minus concavum, quo magis vel minus fenur, superficie superi.re, quae, replcando femoris, superficiei inferiori capitis femuris adplicatur, convexun est; margines femoris, iu.primss maıgo exterior, acuti sunt. Femur itidem, superficie inferiose, co magis vel mmus concavum est, quo magis vel minus supeficics superior tibiac, quae illi adplicatur, eonvexa esi i).

Copita femorum, situ longitudine et crassitie, varia sunt; basi semper latiora quam apice; plerumque, si longiora sunt, fortia et pyranidalia (e. g. pedibus anticis Staphylinorum). Proportio eorum ad fenora pedibus omnibus diversa esse solet: pari antico, capita fenorum plerumque longissina et validissima sunt; pari medio breviora et debiliora; pari postico brevissima, maxiuam parten in acetabulo abscondita, parte prominente subglobosa, apice subtuberculato. Differentia longitudinis inter capita femorum antica et media in Onaliis vix est conspicua; et Stenis omnia aeque sunt brevia. Capita femorum paris singuli approximata esse solent; Oxyporis attamen atque Aleocharis_capita fenrorum paris medii subremota sunt.

I) Quae hactenus de artubus pedum dixi sane etiam ad omnia reliqua coleoptera xeferri possunt, pedibus, generaliter et quoad articulationem artuum, prorsum invicem congruentibus. Variant auteso forma, nec non suswero atque proportione articulorum tarsorum. 
Femora, forma, multo minus variabilia sunt; caeteris paribus attamen Paederis et Stenis gracillima longissima, Lathrobiis brevissima validissina. Trochanter eo distinctior esse solet, quo gracilius femur ipsud est, (e. g. Paederis, Stenis, Aleocharis \&c.).

Tibice, longitudine, propemodum fenora aequant, basi subangustiores sunt quam apice, plerunque paululum incurvatae; Stenis solis rectas. Staphylinis, Tachyporis et Tachinis breves sunt atque validae, setis rigidiusculis, et inter setas spinis quibusdam longioribus, vestitae, imprimis attamen tibiae anticae. Oxytelis autem multo validiores, spinis veris armatae, et anticae practerca (quod, e coleopteronm micropterorm generibus, huic soli propriun est), apice, sinu obliquo marginis interioris, eoden modo ut Aphodiis, emarginatac sunt. Lathrobiis, Qmaliis et Paederis tibiae sunt graciliores atçue minus spinosae, ciliis rigidiusculis vestitae; quanvis inter Omalia quaedam occurrant tibiis validioribus et fere aeque spinosis ac tibiae Oxytelorum (e. g. Omal. rugosunn). Oxyporis et maioribus Aleocharis graciles sunt atque subciliatae; Stenis et minoribus Aleocharis gracillinae atque laevissimae. - Spinae et cilia, de quibus actun est, praecipue uarginibus acutis interioribus et exterioribus, validissimae auten et longissinae, sine exceptione, apici tibiarum insident. Ante omnes duae spinae, longitudine ct crassitie insigntes • margine interiore apicis, instar furculae bifurcae, prominent. Hoc par spinarum omibus Coleopterorum Micropterorum generibus, vel illis, quorum tibiae, marginibus lateralibus, laevissimae vel solummodo ciliis tenuibus vestitae sunt, commune, co autem longius est, quo plus tibiarum uargines laterales spinis vel ciliis instructi sunt; Stcnis autem minimum. Omnes hae spinae et cilia, sine exceptione, apicem pedis versus directae sunt, quo 
conitcio, eas, insecto incedenti vel currenti, pro adminiculis servire, quortm ope corpus promovetur.

Tarsi, omnibus huc relatis generibus, compositi sunt ex articulis quinque, quorum ultimus, seu unguis, forma clavata set pyriformi, apice ungula deplici armatus est, - De tarsis generaliter idem obtinet, quod iam de femoribus et tibiis dixi: Antici scilicet brevissimi, postici longissimi sunt, Tarsi autem antici vel perbreves sunt simulque valde dilatati, vel graciles et longi; illi Stzphyl, omnibus faniliarmu primae et secundae, plurimis Staph. megacephalis familiae tertiae, er quibusdam familiae quartac (e, g. Staph. fulgido, alternanti), porro Lathrobiis plurimis; graciles omnibus reliquis generibus et speciebus. Hic vero notandum est, tarsos anticos, quibisdam specicbus, medium tenere inter graciles et dilatatos; imıno, specierum quarumdam specimina, tarsis dilatatis, tarsis tenuibus et tarsis intermediis variare (e. g. Staph. mtidi) 2). - Articuli quatuor primi, infra, ungucun versus, subproducti et pilis brevibus tentibus densis, prorsum inclinatis, tecti sunt, et quidem eo crebrius, quo latior tarsus est; apice incisi esse videntur, ita ut incisura superne appareat, et articulus insequens e hac incisura provenirs videa.

a) Sunt, qui credunt, forman tarsornm anticorum in consensn esse cum differentia sexuali, illaque specierum itrdividua, quortur tarsi antici dulatati sunt, maxes, reliqua autem feminas esse; äicun mambus cum un finem tersos anticos Iatroites et valiliores esse, quo, оре еотum, feninis, copria, arctius inhaereant. His autem non adsenture possmn, cam tarsi antici, ommibus individuis Staphyluorum familiarum prinae et secmedae, quotquot eorum vil, dilatath, plurimis autem aeliquis generibus et speciebus graciles sint. Staph. nitidus unica est spccies, in qua tarsos anticos et dilatatos et graciles depreliendi, spe. eminibus attameis laud ceficientibus, quibus tarsi intermedii erant, i. e. qui, foilen iure, graciles rel latos nominari poterant, (confer S. S. nota I). 
tur; revera articuli apice truucati, spinis autem duabus porrectis validis armati sunt, quae speciem illius iucisurae simulant. Cun autem tarsi antici semper posterioribus breviores sint, articulos etiam corum breviores esse oportet. Illis, quorum tarsi antici perbreves et dilatati sunt, articuli etian sunt perbreves, transversi, lati, medii latissini; quorum tarsi antici autem graciles sunt, articulus primus elongatus, articuli medii breves et, ob spinas apicis, cordati sunt. Articuli singuli tarsorum posteriorum longiores sunt articulis singulis tarsorum antieorum: Tres medii plerunque breves, cordati; Oxyporis autem et Lathrobiis articuli, secundus oblongus, tertius et quartus breves, cordati; quibusdam omucs longi graciles (e. g. Тachinis familiae secundae et Tachyporis, quibus generaliter pedes valde graciles suut). Articulus primus, fere sine ulla exceptione, longissinus est; Oxyporis auten et Lathrobiis secundo haud longior, saepius brevior esse videtur 3). Omaliis et Oxytelis articuli quatuor primi perbreves sunt, ultinus autem longus validus, ungula etiam, caeteris paribus, validiore et longiore, quan in cogeneribus. Cacterum, unguis omnibus, forma, constans est, nee nisi ratione lougitudinis et crassitiei interdum, ut modo vidimus, differt.

3) Fabricius verisimile articulun secundum iongiorem, nna cum atticulo prime breviore, pro uno tantam atque primn habuit, te Paederis te Oxyporis tarsos quadriaticulates tribuit, qquo simul confumavit iả quod ian supra (S. 3.) dixi "Fabricium nempe maiores solummono species generum storum accuratius "examinayisse. " Inter tius enim Oxyporos et Pateros, maioribus solis (e g. Oxypotis rufo te maxilloso, Lathrobiis tongato bruinipedietc.) articulus primus brevis, articulus secundus ionglas ist. Reliquis autem Oxypoxis et Paederis Fabricianis (Tachinis, Tachyporis et Paederis veris) articuli quinque tarsorum distinctissimi sunt, et articulus primus sequentibus longior; inseota vero ipsa, in genere, jlis multo minora. 


\section{\$. II.}

\section{De habitatione et vitae genere horum} insectorum.

Vitae genus et habitatio Coleopterorum Micropterorum permultiplices sunt: Degunt partim in cadaveribus et fimo, partim in botetis vel agaricis et in aliis substautiis putrescentibus, partim in locis tenebrosis suffocatis, partim in floribus varii generis, ibique victum quacrunt. Haud vero quaeque species, et multo minus quodque genus, eadem semper habitatione eodemque victu utuntur. Staphylini reperiuntur in stercore, cadaveribus, agaricis vel boletis, et aliis substantiis vegetabilibus putrescentibus, in locis tenebrosis suffocatis \&ce; Lathrobia in suffocatis humidiusculis, ubi funus seuvegetabilia putrescunt; ibique Paederi; Alcocharae in fimo, cadaveribus, boletis et agari. cis, sub arborum cortice; Omalia et Anthophagi in foribus; Oxyteli non nisi in fimo, Táchypori plurimi in fimo, nec minus frequentes in floribus, muscis, quisquiliis, gramine, \&c.; Ta. chini familiae primae in fimo, familiae secundac in agaricis et boletis; Steni in locis humidis, arenosis, ad ripas, in lacunis exsiccatis \&c. - Sed de vitae ratione horum insectorum nimis mance disscruissem, si modo dıctis iam desinerem, cum in familiis et ipsis speciebus generum plutimorum hoc vel illud obveniat peculiare, saepe admodum singnlare et notatudignum; ita ut credam, me, non sine ullo pro scientia usu, lectoribus meas observationes communicaturum.

De orlu, vitae epochis variis, et copula horum insectorum illud tantum scinus, quod cum omnibus coleopteris commune habent: Femina, aliquot tempus post copulam, ovula deponit in locum, larvis futuris, quae ex illis provenient, commodum. Larvae proreptae si, folliculis phuries depositis, ad certam 
magnitudinem accreverunt, in pupam incompletam (nympham) mutantur, e qua tandem insectum perfectum provenit. De vitae ratione atque victu horum insectorum, in statu imperfecto, proprias observationes haud addere possum, nunquam enim mihi successit, larvas speciei cuiusdam maioris Staphylinorum (Staph. olentis? St. similis?) 1), quas nonrunquan in sylvis, locis tenebrosis suffocatis, sub truncis arborum caesarum, semper autem solitarias (ut insecta perfecta) reperi, nsque ad perfectionem zlere. Educatio atque nutritio harum larvarum, et observatio earum per omnes vitae epochas, res difficilis est, quod quisque mihi concedet, qui periculum fecit. Vitac rationem in insectis solis perfectis obscrvavi. Si de habitatione insectorum agitur, fortuita a vera bene distinguenda cst. Haec est ubi insectum

I) Saltem autem mihi liceat, descriptionem harum lartarun hic iungere : Corpus apterum, elongatum, longitudine 8-Io lin., mgrum, convexum, capite et duodscim segnentis, aequali latitudine, lateribus deflexis, constabat. Caput, cum autennis et instrumentis cibariis, capiti capitisque partibus insecti perfect simile, ninus attamen, erat; mandibulis filcatis, haud destatis. Segmentum prinum, subtransveram, a yice paulo angustius, segmenus sequentibus longius, capite larivs, infra pedibus anticis instrnctum, thoraci insecti perfecti respondebat. Sermenta secundum tf tertium, singula prino pauiulam breviora, sequentibus pauln longiora, jnfra pare pedum instructa, pectori insecti perfecti respendebant. Segmenta sequentia, longitudine et latitndine simifı, transversa, imbricata, lateribus deHexa, marginulo laterali subelevato, abdomen erant; ultimum autem, sub penultimum retractum, anun emittebat cyliadricum, longitudine segmenti, eo autem quadruplo angustiorem, et supra, spinis duabus, segmento longioribus, tripartısis, quoad formam cotnua cervisa sequantibus, armatum erat. Pedes erant quinquearticulati; articulo primo, capiti femornm respondente, buic etiam :imillimo; articulis sequentibus subcylincrucis, apice paulo crassiorabus, armatis infra spinulis; secundo reliquis vix breviore; sequentibus cirussitie decrescentibus; ultimo, apice, ungula duplici paululun curvata, armato. Cacterum pedes, ratione longitadinis proportionalis, pudibus ansecti perfecti respondebant. 
constantissime et copicsissime reperitur, et cum certitudine non indicari potest, nisi insectum aliqua copia, constanter, et temporibus diversis, loco quodam occurrat. Fieri enim potest, ut multitudo magna speciminum ciusdem speciei uno eodem q̨ue loco reperiatur, cum modo ibi provenerit, (experientia enim docet, multa insecta, statu imperfecto, longe secus vivere et locis habitare longe diversis, quam statu perfecto (e. g. Lucanus Cervus, Melolontha vulgaris atc), vel tutelanı contra frigora hyemis ouaesiverit (uti e. g. Omalium depressum, quod, autumno anni 1799 et vere anni 1800 , frequens domi ad fenestras cepi; vel Oxyteli piceus et carinalus, quorum copia haud exigua, vere, sub lapidibus, in quisquiliis, locis apricis, occurrit), paucis autem diebus praeterlapsis evanuerit, quia huius insecti habitatio propria longe alio loco est. Unde sequitur, multitudinem solam speciminum speciei, semel loco quodan repertam, nos, hoc respectu, nondum maxima certitudine ducere posse, potius habitationem constantem hic maioris momenti esse, quam illa. Qui individum unicun speciei alicuius loco reperit, ubi plurimae reliquarum cospecierum habitare solent, verisimile ibi re. perit, ubi proprie degit, et vice versa (e. g. Aleoch. longiconis specimen modo unicum possideo, idque in fino repertum; cum autem Alcochararum affinium longe maxima multitudo in fimo victitet, credo etiam, me illam loco proprio et naturali cepisse. E contrario, Aleochara opaca, quam semel tantum, et quidem in flore Echii vulgaris cepi, proprie, ut mihi persuasum est, alio loco degit, nullam enim huius familiae Aleocharan unquam in floribus reperi), - $\mathrm{Si}$ cuiusdan speciei multitudo speciminum magna est, et in diversis substantiis victitat, ita vero, ut longe plurima in una harun substantıarum degant, crẹdo, hanc victum eis proprium pracbere, his attamen distincionibus: Forsan co. 
pia insectorum quorumdan in hunc vel illum pastum incidit, cum nullum alium invenire potuerit, quem illi praeferat, de quo autem facile nos certiores facere possumus, si haec insecta per plurcs dies observanus, certe enin hatd diu permanebunt, sed mox alium locum quaerent; ope praeterca aualogiae, et collato vitae genere reliquarum cospecierum, facile intelligemus, an haec insecta loco proprio atque naturali prehenderimus, an non. Quamvis autem plurima locis certis libentitus habitent, et substantiis certis libentius victitent, quam aliis, sunt attanten quae substantiis, saepe valde diversis, par1 modo delectari vilentur, (e. g. Aleoch. fuscipes habitat aeque copiose in cadaveribus atque in fimo et bolctis putrescentibus, et in omnibus, uti videtur, sibi placet atque vita fruitur minime famelica sed iucundissima Omaliuu rivulare in fimo, in floribus, et in boletis degit. Stercus autem, carnis putrescens, boletus et flos res admodum diversae sunt.

In articulo praecedenti breviter momenta exposui, vel ad habitationen fortuitam vel ad habitationem propriam respicientia. Quae autem sunt causae, cur quaedam harnm specierum, etsi speciminibus divites sint, nunquam, quaedan attew, individuis haud ditiores, saepe, et interdun copia hatd exigua, locis, fortuitis reperiantur, licet nulla ratio andit, cur hic potits habitent (e. g. si victus earum maturalis et proprius haud procul est, et haec habitatio fortuita nec locus cst, ubi tutelam quaesiverint, nec locus, quo ovula deponant \&c.). Oxytelum depressum, cuius habitatio propria, sine dubio, in stercore est, aliquando copiose in floribus Echii vulgaris, et saepe in grasnine legi; Tachinum melanocephalum et Aleoch. nonam, species duas, indiviảuis adhue ditiores, quau Oxytel. depressus, semper in boletis vel agaricis, et numquau alıbi. An sensus, qui insecta, habitationes et vir 
ctum quaerentia, ducit, fortasse quibusdam hebetior, quibusdam acrior, causa huius differentiae sit?

Aliud autem, ut credo, notatu dignum, illud est peculiare et singulare in toto habitu talium generum familiarum et specierum, quae, vitae ratione singulari, a reliquis decedunt: Inter onnia Coleoptera Microptera Staph. maxillosus unicum est, quod in cadaveribus solummodo victitat; quantopere autem, antennis brevibus crassis, thorace, corporis signaturis, et, ut brevis sim, habitu toto, ab omnibus reliquis cospecicbus et Staphylinorun cogeneribus differt! Staphylini primi familiae secundae (e. g. Staph. olens, similis \&c.) locis habitant suffocatis tencbrosis, sub lapidibus vel arborum truncis, numquam in stercore; corpore autem opaco, obscuro, subtilissime puncto, thorace quadrato, antennis apicen ver us inagis minusve tenuioribus, ab omnibus relıquis Staphylinis decedunt. Staphylini ultimi huius familiae, qui in fino degunt, habitu sunt longe alio, et vel vestimento corporis magis minusve lanuginoso differunt (e. g. St. pubescent, nebulosus, murimus), vel colore elytrorum pallido (e. g. Staphyi. oythropterus, castcnopterus \&c.). In familia tertia Staphylini, qui, fere sine ulla exceptione, in fimo victitant, et nitore splendidiore, nec non forma atque punctura thoracis distincta sunt, singularitates quasdan observaluus: Staph. marginatum, thoracis margine favescente distinctum, cum ommibus cospeciebus huius familiae thorax unicolor sit, nullibi, quam in sylvis altioribus umbrosis, in fimo bovino, reperi, nunquam locis apricis, in campis vel pratis; species quasdan minores, elytris pilis grisescentibus brevibus tectis, capite thoraceque interdun subsericantibus (c. g. St. fulvipeden, miconten \&c.) saepius sub vegetabili. bus putrescentibus, in lacunis exsiccatis, quam in fino; species plurimas familiae quartae saepius sub arborum cortice et sub 
lapidibus, quam in fino. - Paederi viparizus et littoralis, colore rufo et habitu toto, a cospeciebus satis distincti, occurrunt in gramine, locis humidulis vel umbrosis, inter quisquilias, ad radices arborun; reliquos huius generis non nisi sub lapiaibus reperi. - Aleuchara prima familiae prinac, Aleoshore cannliculata, habitu toto nec non partibus quibusdam singulis, e. g. forma et fovea lata thoracis, de reliquis speciebus decedens, rictitat, nec șub arborum cortice, nec in fimo, nec in boletis vel agarieis, nec in cadaveribus, sed semper sub lapidibus, ubi nunquam alia quaevis Aleochara mihi occurrit; reliquae huius fumiliae Aicocharae, "capite thoraceque globosis, " in boletis et agaricis vel sub arborum cortice putrescente degunt; Aleocharae "sonctac, thorace lato, apicen versus angustiore gibbo„so," quae suat plurimae familiae tertiae, et quaedam familiae secundae, in fimo habitant; plurimae autem familiae secundae, et guaedam e familia tertia minus coactae et thorace minus gibboso, in boletis et agaricis, vel sub arborum cortice. - Oxyteli in fino tantummorio degunt. - Duo genera Colcopterorum Micropterorum, Omaliunt scilicet et Anthophagus, ab omnibus reliquis cogeneribus, "60„leoptris longis, et abdomine lato depresso, ano acuto" distincta, habitationem in floribus sibi sumserunt. - Species familiae secundae Tachyporormn, tam vitae genere, quan habitu externo toto, inter se differunt: Qunasdam, pallidas, nigro signatas, nitidissimas (e. g. Tuchyp. chrysomelinum, chalenn \&c.) in floribus, gramine \&c., et interdum in fimo siceiore, reperi; quasdam autem, subnitidas, subsericantes, obscuras (e. g. Tachyp. pu bescentem, cellaren \&c.) modo sub arborum cortice. - Fauniliae duae Tabhinorum, et vitae genere, et habitu toto, valde inter se differunt: Species familiae primce, quae in fino tantummodo 
habitant, latiores surt, minus nitidae, capite orbiculato, colore multo opaciore, quam species faniliae secundae, quae nunquan alibi quam in boletis vel agaricis inveniuntur. - Oxypori degunt cum fanilia secunda Tachinorum. - De Stenorum habitatione et vitae racione veris nondum aliquid certi comperi, cum species huitus generis, habitu toto, inter se admodum congruentes, a cogenerbus autem oninino diversae, locis diversissimis repererim, uti infra videbis; in genere autem terram humiliorem amare, et diem atque solis lucem minus fugere videntur, quam species relıquorum cogenerum.

E praecedentibus apparet, plurima horum insectorum vel in fino vel in agaricis et boletis degere. Eruere autem possumuse characteres universales, quibus illa ab his differunt. - Illa scilicet generaliter colore sunt opaciore, vel nitore caeciore; colore plerumque nigricante, interdum antenuis pedibus elytris pallidioribus, his nempe vel subsangumeis vel castaneis rel friscis, ( $e$. g. Staph. quibusdam familiae tertiae, Aleocharis familiae tertiac, Oxytelis, Tachinis faniliae primae), rarius ochraceo-vel rufovel testaceo-signatis, (e. g. Staph. evythroptero \&c. Oxytelo piceo, Tachino subterraneo). - Quae semper in boletis vel agaricis babitant, nitore sumt nitidissino; et colore pallido; plerunque rufa vel testacea, capite, angulis inferioribus coleoptrorum, anoque saepe nigris vel fuscis (e. g. Oxypori, Tachini familiac secundae, Aleochara naric). - Character practerea notatu dig. nus, et solis $\mathrm{Cxy}$ poris at⿱u日e Tachin is familiae secundae proprius, lineae stmt duae inpersae clytrorum suberenato - punctae, quae autem Tachinis inferdum interruprae sunt, et fere omnino cvanescunt. 


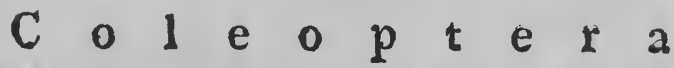

\section{Microptera.}

\author{
$\longrightarrow$ \\ Genus I. \\ $S$ t a p h y 1 i n $u$ \\ Palpi filiformes
}

Thor $3 \mathrm{x}$ basi rotundatus.

\section{Corpus elongatum.}

Caput, angulis obtusis; infra planum laeve; supra convexum - Antennis noniliformibus, undecitnarticulatís; articulis, primo longiore, secundo et tertio brevioribus, caeteris brevissimis.

Thorax, antice truncatus, postice rotuindatus; convexus Ora laterali infra refiexa.

Coleoptra angulata; angulis obtusis; thoracis circiter magnitudine; depressiitscula; lateribus defiexa.

Abdomen elongatum, marginatum a dorsô vehtreque con. vexum; latitudine coleoptrorum. 
Pedes-cursorii - Capitibus femorum approximatis; anticis femore multo crassioribus, vix longioribus; mediiis fe. more paulo brevioribus et crassioribus; posticis brevissimis, maximam partem in acetabulo absconditis - Tibios spinosis - Tarsis quinquearticulatis; articulo primo longiore.

Famitia I. Thorace lateribus basique rotundato; angulio anticis acutis.

Funitic II. Thorace subquadrato.

Familia III. Thorace süböbiculato.

Fanilia IV. Thorace elongato.

\section{Fa th. I.}

Corpus nitidum.

Caput subquadratun, angulis obtusis; nitidissimum, laeve; basi lateribusque punctum - Oculis parvis - Antennis capite paulo longioribus, extrorsum crassioribus; articulin, primo longo, clavato, crasso; secundo et tertio clavatis, brevioribus et tenuioribus; quarto et quinto subglobosis; sequentibus pateraeformibus, latitudine crescente; ultimo eblique truncato.

Thorax nitidissimus, laevis, lateribus punctus.

Coleoptra subquadrata, angulis obtusis; thorace longiora et paulo latiora; plana, pubescentia,

Ablomen pubescens.

Pedes, tarsis anticis dilatatis.

1. Sk. moxillosus, niger, nixidus; fascia coleoptrorum cinerea: ventrc candido. 


\section{Staphylinus. F.1.}

Rongitudo $5-8$ lin.

Variat fascia coleoptrorum continua vel medio interrupta; abdomınis dorso cinereo - maculato vel nigro; capite latiore vel angustiore quam thorax.

Habitat ubique in cadaveribus,

St. maxillosus Linn. Fn. Suec. 11. 841.

- Fabr. Ent. Syst. St. 11. 9.

- Payk. Mon. St. n. 2.

- Payk. Fn. Suec. St. n. 2.

- Sihrank Boic. n. 86t.

- Rossi Fn. Etr. n. 60\%.

- Olivier Ent. St. n. 2. pl. I. f. 5. घ.

- Panzer Fn. Germ. H. 27. t. 2.

- nebulosus Fourcr. Ent. Par. St. n. 5 .

- belteatus Fabr. Fn. Groenl, p. igia

- De Geer Mém. St. u. 4.

- fasciatus Fucsslin Helv, n. 410.

Geoffr. Hist: St, n. 5.

De confusione St. maxillosi et St. olentis cel. Hellnkig in „Fauna Etruriac Rossii “, quain edidit, uberius disseruit.

\section{Fam. It.}

Corpus confertim punctum.

Caput confertim punctum - Oculis parvis - Antennis arthculis, primo longiore clavato, secundo es tertio breviori . bus clavatis, sequentibus campanulatis, uisimo obliquıte truncato.

Thorax subquadratus, confertim punctus, lateributs antise subdefiexuis. 
Coleoptra quadrata, angulis obtusis.

$P$ edes tarsis anticis dilatatis.

3. St. olens, niger, opacus.

Longitudo 8 - 13 lin.

Corpus confertissime subtilissimeque punctum.

Caput quadratum, angulis obtusis, magnitudine thora* cis. Anternis capite paulo longioribus, extrorsum decrescen. tibus.

Coleoptra thorace vix longiora et latiora.

Habitat, vere, sub lapidibus ef arborum demortuarum truncis, in sylvis. .

St. olens Fabr. Ent. Syst. St. ni. 6 .

- Payk. Mon. St. n. 4.

- Payk. Fn, Suec. St. n. 5.

- Olivier Ent. St. n. 4. pl. I. fig. I.

- Panzer Fin. Germ. H. 27. t. t.

- májor niger De Geer Merm. St. n. 3 .

- maxisillosis Fourcr. Erit. Par. St. n. I.

- Schrohn Austr. n. 434.

- Fuesslin Helv. n: 409.

Greffr: Hist. St. n. I.

Cel. Geoffroy, loco allegato, citavit etiam Linnei St. maxillusuni (Linn. Fn. Suec. n. 603; et Act. Upsal. de anno 1736 p. 15 n. 23). Omnia atitem hace citata ad St. maxillosum et ejus varietatem totam nigran referenda sunt. Loco, e Gcoffroyi Hist. Ins. allegato, St. olentent describi, ex omnibus characteribus et e nuggnitudine apparet, cum St maxillosts, "lengituảine undecin linearum " nunquam occurrąt.

Cel. etiatñ Sichrank perperam St. maxillosunn Linnei citavit. 


\section{staphylinus. Ji.ll.}

Confer quae sel. Helloig in editione „Faunae Etruriae, "

n. 607 monuit,

3. St, sim il is, niger, subopacus; linea longitudinali media ca. . pitis thoracisque nitida,

$H r b i t u$ St. olentis; differt autem corpore minore et paulo nitidiore, çoleoptris thorace brevioribus, linea capitis thoracisque nitida.

\section{Longitudo $5 \frac{1}{2}-8$ lin.}

Habitat, haud raro, sub lapidibus, in humidis, monttosis,

St, similis Fabr. Ent. Syst. St. n. ?.

- Payik. Mon. St. n, 5 .

- Payk. Fn. Suec. St. n. 6 .

- Schrank Boic. n. 863.

- O!ivier Ent. St. 1. 12, pl. V. f. 42 ?

- niters Sihqank Austr. n. 436 .

Geoffr. Hist. St. n, 3 .

St. globulifer Fourcroy Ent. Gar. St. n. 3.

- minor niger De Gier Mem. St. n. 7 .

Staphylinum De Geeri, quem hic citavi, non ad St. por litum Linn. referri posse, e multis ejus characteribus me persuasum habeo.

Allegavi etian St. nitentem Sclor. , thorace punctis quin"que maioribus, infinitis minoribus; longitudine septem „lin. “ Quamquam enim puncta quinque majora theracis speciminibus mẹis desunt, caeteri tamen characteres plane conyen iust.

Nullo modo St. olens huc pertinet; et Dom. Sehrank (Boic. n. 863.) St. olentenn Payk, allegans, omnino errat. Di- 
eit enim ipse, thorax (St. similis) elytris longior est haec species a praecedente discernitur.

Descriptio Fabriciana huius insecti maxime cum meis speciminibus convenit, quia lineae elevatae capitis thorarisque, ab omnibus Entomologis ante Fabricium praetermissae, mentionem facit.

4 St. morio, niger, subnitidus; antennarum apice, palpis, tibiis, tarsisque fuscescentibus.

Habitu St. praccedentis; linea etiam capitis thoracisque. Differt autem ab illo, corpore paulo angustiore; coleoptris paulo longioribus; canite thoraceque nitıdioribus et minus confertim ac subtiliter punctis.

Longitudo $6 \frac{\mathrm{r}}{4}$ lin.

St. norio Mus, Prof. Knoch.

s St. cyan nus, ater, opacus; capite, thorace, elytrisque coeru. lescentibus.

Habitu St. praecedentium. Antennis autem extrorsum subcrassioribus; thorace paulo convexlore.

Longiludo $6-8$ lin.

Caput et thorax linea media longitudinali laevi.

Colcovtra thoracis magnitudine.

Variat thorace cyanescente vel nigricante.

Habitat in montusis, sub lapidibus, cum St. simili ot St. aeneosenalo; interdum etiam in fimo; primo vere.

St. cyaneus Fabr. Ent. Syst. St. $x$. it.

- Poryk. Mon. St. n. 7.

- Psyk. Fn. Suec. St. 11. 4 .

- Panzer Fn. Germ. 11. 27. t. 2. 


\section{Staphylinus, F.II.}

St. Olivier Ent. St. n. 13. pl. I. f. 4.

- ophthalmicus Scop. Carn. u. 300.

- coerulescens Fourcr. Ent. Par. St. n, ze

Geoffr. Hist. St. 11. 2 .

6 St.tricolor niger, opacus ; elyeris cyanescentibus;-pedibus, palpis, antennarumque basi rufo-testaceis.

Habitu quidem St. praecedentis; satis autem distinstus.

Longitudio $5_{2}^{\frac{T}{2}}$ lin.

Caput orbiculatum, thorace multo minus, confertim punctum ; punctis autem crassioribus quam in St. praecedentibus; linea media longitudinali obsoleta laevi; atroçoerulescens, nitidum. Antemis capite duplo longioribus, filiformibus, fuscis, basi rufis. Clypeo rufo. Labro fusco. Paipis gracilibus, tenuioribus quam in St. praecedente, rufis, apice fuscis.

Thorax quadratus, coleoptris vix angustior, subritidus, crassius punctus quam in St. praeccdeate, linea medıa longitudinali laevi.

Coleoptra quadrata.

Abdomen pilis brevissimis tenuissimis griseo-sericantibus tectum. Segmentis penultimo et antepenultimo, margire, pilis fulvo - sericantibus fimbriatis.

Pedes rufi; capitibus femorum nigris.

St. trivolor Mus. Prof. Knocite

7 St. crassicollis niger, opacus; tarsis fuscis; capite thoraceque nitidis.

Habitu St. sequentis. Differt autem statura latiore, capitis thoracisque punctis minus confertis, thorace convexiore \&c. 


\section{Longitudo $?$ lin.}

Thorax subquadratus; angulis anticis obtusioribus quam in St, sequente ; punctus, medio laçvissimus; latidudine co. leoptroruim.

Coleoptra quadrata, thorace paulo breviora:

$S t$, crassicollis - Mus. Prof, Knoch,

8 St, a eneocephalus, nitidus; capite thoraceque nigro - ae. neis, linea media longitudinali glabra; coleoptris fusco-vel rufo - grisescentibus,

Habitu St. Morionis $(\mathrm{n}, 4)$; capite autem orbiçulațo, paulo angustiore quam thorax,

Caput confertissime subtilissimeque puncțm; punctis quibusdam srasssiorịbus lațeralibus impressum; nițidum; lị. nea media longitudinali glaberrima,

Thorex confertissime subtilissimeque puncțus; punctia quibusdam maioribus, saepius obsoletis, quorum sex ve! decem in series dụas dorsales disposita sunt ; linca media lonv gitudinali glabra,

Magnituda et color pervariabiles sunt,

Var. I St. aeneo-nitidus; elygtris, antennarum basi, tarsisque, fuscis; abdominis dorso lineis quinque grịscis longițdinalibus; longitudine 6 linn.

$V a r .2$ St. aenęa-nịtidus ; elytrịs, antennis, pedibus: que fusçis: abdominis dorso linea longitudinali, segmentornumque marginibus, grisẹs ; longitudine 6 lin,

Var, 3 St, aeneo = nițidus; anțennarum basi, palpis, tarsisque rufis; colcoptris, lineisque quinque abdominis longrtudinalibus, griseo - seriçeis ; longitudine $4-5$ lin. 
Var. 4 St. var. 3 similis; linea autem abdouninis unjca tantum, marginibusque segmentorum griseis.

Var. 5. St. niger, capite aeneo; coleoptris, abdominisque dorsa, griseosericantibus; antennis tarsisque rufis: longitudune 6 lin.

$V$ ar. 6 St. niger; capite thoraceque aeneis; antennis tarsisque rufis; longitudine $7 \mathrm{lin}$.

Omnes hae varietates, habitu semper codem, altera in alteram sensim transcunt. Nitor serıceus elytrorum et linearum a plis griseis tenubus depressis proficiscitur; quibus derritio, elytra fusca seu rufa, abdomen autem nigrum nitidum apparent.

Habitat haud raro in montosịs apricis, sub lapidibus; praecipue tempore autumnali.

St. aeneocephalus Payk, Mon. St, n. 6.

- Payk. Fn. Suec, St. n. 10.

- supreus Olivier Ent. St. n. 16. pl. II. f. 16 ?

Nondum audeo dijudicare, an St. cupreus Oliv. et St. afnoocephalus Payk. ejusdeun sint speciei. Olivier nihil quidem de linea media thoracis dixit; caetera autem plane con. gruunts.

Dubito, an St. aeneocephatas De Geeri et Fabricii huc re: ferri possit, cum nihil neque de lineis abdominis, neque de punctis thoracis capitisque dicatur; et Fabricius St, aeneocephahum "a afinem St. erythroptero et forte meram ejus variec g, tatem "appellet, cum quo St, noọter nihil commune tabet.

Dom, Panzer sub nomine St, aeneccephali (Fn, Ger̦m, H. 27 t. 5.) longe aliain speciem quam Paykullianam ex. hibuit. 
QSt. fos or niger; capite thoraceque fuscis; coleoptris, tibiis, tarsisque rufis.

Habilu St. erythropteri. (n. II.) Colore autem, thoracisque linea media longitudinali elevata, differt.

Longitudo 5 - 6 lin.

Hibitat - Mus. Prof. Hellwig es Knoih.

St. fossor Fabr. Ent. Syst. St. \$2. 16.

- Ponzer Fn. Germ. H. 2 \%. t. 6.

so St. castonopterus niger; coleoptris, pedibus, antennis. que rufis.

Habitu St. sequenti simillimus, a quo tamen magnitudine, et thorace semper toto nigro differt.

Longitudo 5 lin.

Frons, cervix, scutelium, pectus, abdominisque dorsum saepius flavo-sericant.

Habitat haud raro in fino.

St. castanoptevus - Mus. Prof. Knoch.

- erythropterus Scop. Carn. n. 306 v. 2.

- Olivier Ent. St. 11. 10. pl. II. f. 14.

- Rossi Fn. Etr. n. 609 var.

Haec species, characteribus constantibus distincta, hu. cusque pro varietate minore $S t$, erythropteri habita e6t.

St. erythropterus niger; clytris, antennarum basi, pedibusque rufis; margine thoracis postico flavo.

Longitudo 6 - 10 lin.

Corpus subnitidum.

Caput orbiculatum, thorace latius, confertissime subtilissimeque punctum; antennis extrorsum paulocrassioribus. 
Thorax subqurdratus, paululun elongatus, confertissime subtilissimeque punctus; margine postico semper flavo.

Coleoptra quadrata, angulis obtusis, thorace latiora.

Habitat in fimo et, primo vere, in arena sub gramice spisso collis aprici prope Brunsuigans. .

St. crythropterus Linn. Fn. Suec. n. 842.

- Frzbr. Ent. Syst. St. n. 14.

- Pruk. Mon. St. si. 3.

- Payk. Fn. Suce. St. n. 3.

- Rosi Fn. Eti. 11. 609.

- Schrarz Boic, n. 85z.

- Schrank Austr. no 435.

- Scop. Carn. n. 306. var. I.

- Fourror. Ent. Par. St. n. 9.

- De Geer Mem. St. n. 6.

- Panzer Fn, Ferm. H. 27. t. 4.

Geoffr. Hist. St. 11, S.

12 St. stercorarius niger, opacus; antennaruin basî, elytris, pedibusque rufis.

Stet lura et partiun forma satis a St. praecedentediffert Proportione partium et forma St. olentis; antennis autem extrorsun crescentibus, punctis capitis thoracisque crassio. ribus.

Cxput magnum, quadratum, angulis obtusis; atrum, opacum. Clypeo testaceo. Labro, palpis, aniennisque fus. cis; his capite vix longioribus, extrorsum crassioribus, basi rufis.

Thorex ater, opacus; linea media longitudinali, laevits antice obsoleta, poctice laevissima nitidissima. 


\section{Scutellun nigrum opacum.}

Coleoptra quadrata, angulis obtusis, thoracis magnitudi. ne, aurantiaca, pilis rigidis depressis obsita.

Pectus nigrum, pilis flavo - sericantibus vestitum.

Abdomen, dorso, maculis duabus segmentorum singulo. rum flavicantexhs -sericeis; ventre, basi segmeutorum flavo-sericea,

\section{Longitudo $5 \frac{\mathrm{x}}{2}-6$ lin.}

Habitat in Stercore bovino, apud nos rarissime; semel tantumnodo captus prope Seesen, die 8 Junii anno 1800.

St. stercovarius Olivier Ent. St. 11, 18 pl. III. f. 23.]

Is St. pubesoens; nigra-fusco - flavoque sericeo - nebulosus; thorace angulis anticis obtusis,

Longitudo $4-6 \frac{\mathrm{x}}{2} \mathrm{lin}$,

Caput orbiculatum, thoracis magnitudine, opacum, metallicum, punctum; puncțis maioribus passim impressum; ląungine flavescente vestitum; linea media Inngitudinali, laevissima, nitida, medio in rhombum, plus minusve transyersum vel latum, laevem, nitidissimum, dilatata. Clypeo testaceo. Labro rufęscente. Antennis capite longioribus, 'extrorsum crassioribus; articulis, primo clavato longo, secundo et terțio brevioribus clavatis, quarto et quinto subglobosis, sexto ad deçimum campanulatis ; articulis quinque basis rufis, apice nigra; cacteris totis uigris. Palpis nigris. Mandibulis nigris, basi rufis,

Thorax quadratus, angulis obtusis; coleoptris angustior; subtilissime confertissimeque punctus; lanugine rara tectus; linea media longitudinali, antice subobsoleta, postice laevịssịną nitida. 


\section{Staphylinus. F. II.}

Seutellun triangulare, nigro - sammetinum, marginibus lineaque inedia longitudinalı nudis.

Coleoptra subquadrata, angulis obtusis; opaca, nigro. cinereoque nebulosa seu tessellata.

Abdomen dorso flavo - cinereo - nigro - fuscoque varium, punctis interdum majoribus nizro - sammetinis duobus segmenti singularis; ventre pectoreque villis densis argenteo. sericeis, punctis minutis nigris passim intermixtis, vestitis.

$P$ edes, femoribus nigris, nitidis, nudis, annulo rufo; tibiis tarsisque obscuris, pilis grirescentibus vestitis.

Variat capite patulo latiore vel paulo angustiore quam thorax.

Habitat in humidis arenosis, in fimo bovine.

St. pubescens Fabr, Ent. Syst. St. n. 5.

- Payk. Mon. St. ת. 9.

- Payk. Fn. Suec. St. n. it.

- De Geer Mem. St. n. 2.

- Olivier Ent. St, n. 15. pl. İt. f. 15.

- chrysocephalus Fourcr. Ent. Par. St. a. 8.

Geofjr. Hist. St. n. 8 .

14 St. nebulosus, obscuro-nebulosus; palpis, pedumque gew niculis tibiisque rufis, thorace angulis anticis acutis.

Longitudo $6-?$ lih.

Caput orbiculatum; thoracis magnitudine, subtilissime punctum, opacum, griseo-virescens, obscure-nebulosum; linea media longitudinali aeneo - nitida, laevi, obsoleca. Clypeo, labro, palpis, antennarumque basi rufis; apice antennarum fusca. Mandibulis nigris. 
Thorax quadratus, basin versus sensim engustatus; an. gulis anticis acutis; colore capitis; subtilissime punctus, opa... cus ; linea media longitudinali obsoleta, basi nitida.

Scutellum St. pubescestis; interdun autem, sammeto de. srito, laeve, opacum, nigerrinum punctum.

Coleoptra quadrata, angulis obtusis; thorace Iatiora; opaca, subtilissime puncta; colore thoracis.

Abdomen nigrum, dorso subgriseo - virescenti - nebulo. sum, osellis segmenti singularis duobus nigro - sammetinis, fulvoque sericeis, sacpius autem obsoletis; infra, segmen. torum basi, pectoreque argenteo + sexicantibus.

Pedes ruń; tibiis apice obscurioribus; frmoribus basi igris; femorum capitibus nigris, argenteo-subsericantibus.

Habitat in fimo.

St. nebulosus Faibr. Ent. Syst. St. n. 3.

- Payk. Fr. Suec. St. n. $\mathbf{~ t .}$

Geoffr. Hist. St. n. 6.

${ }_{5} \mathrm{St}$. murinus, abdomine palpisque nigris; capite; thorace, clytrisque subaeneo-nitidis, obscure-nebulosis."

Habiti St. pracedentis; statura autem minore, thorace basin versus vix ac ne vix quidem angustato, oculis multo majoribus, palpis nigris \&c.

Longitudio 4- 6 lin.

Caput quadratum, angulis obtusis, subtransversum, punctum, cupreo-vel olivaceo-subaeneum, obsolete nebulosum. Clypeo et labro concoloribusa Mandibulis palpis. que nigris. Antennis rufescentibus vel fuscescentibus, vel basi pallidioribus, caeterum anteunis St. praecedentis similibus. 
Thorax magnitudine circiter capitis; quadratus, angulis anticis acutis; capitis colore; punctus, opacur; linea unedia longitudinalı obsoleta, basi autem nitidissima laevissima.

Scutellum et coleoptra St. praesedentis.

Abdonen nigrum; segmento primo et secundo, dorso, fulvo-nigroque subsericantibus; infra, segmentorum basi, pectoreque subargenteo-sericantibus.

Pedfs plerumque nigri; interdum autem apice femorun, basique tibiarum rufis.

Variat capite paulo angustiore vel paulo latiore quan thorax; colore plus minusve nitido vel obscuro et opaco.

Habitat in fimo.

St. murime Fobr. Ent. Syst. St. n. 4.

- Ressi Fn. Etr. n. 608.

- Payk. Mon. St. n. 14.

- Payk. Fn. Suec. n. 1I.

- Olivier Ent. St. n. 14. pl. VI. f. 5 \%.

- Panzer Fn. Germ. H. 66. t. 16.

\section{F am. III.}

Corpus ritidum.

Copnt nitidun, lacve, lateribus basis punctum. Antennis extrorsum crassioribus; articulo primo longiore clavato, ultimo obtuso. Palpis, articulo ultimo acuto ovato.

Thorax suborbiculatus; antice truncatus, angustior, angun lis nempe deflexis; nitidus, laevis, punctis quibusdam impressus. Canalicula marginali crenulata.

Coleoptra subquadrata, angulis obtusis, thoracis magnitudi. ne vel paulo majora; nitida, confertim puncta. Abcionen nitidum. 
16 St. splendens niger, nitidus; elytris viridi saeneis; thora. ce punctis quibusdam singulis injpresso.

Longitudo $4 \frac{\mathrm{T}}{2}-6$ lin.

Caput orbiculatum, thoracis magnitudine, pone oculos punçum.' Antennis, articulis, primo longiorè clavato, se. sundo et tertio brevioribus clavatis, seq̣uentibus subcampa. nulatis, ulcimo oblique truncato.

Thorax glaber, punctis aliquot inajoribus in angulis anticis impressus.

Coleoptros thorace paulo longiora ct latiora, pilis brevibus vestita.

Abdontben infra, speciminibus quibusdam, segmento pes nuitimo profunde inciso, antepenultimo sinuato; quibus. dam autem segmentis omnibus simplicibus.

Pedes, tarsis anticis dilatatis.

Variat capite pautlo latiore vel paulo angutstiore quasi thorax.

Kiabitat ubique in fimo:

St. splendens Fabr. Ent. Syst. St. n. ig.

- Payk. Fn. Suec. St، n. 9.

s7 St. lam inatus niger; nitidus; capite thorace; elytrisque viridi-aeneis; thorace glaberrimo, impuncto.

Habitu omnino St, praecedentis. Statura autem capite: que minoribus; capite thoraceque nitidissimis; hoc glaber rimo laevissimo.

Longitudo $4-5$ lin.

Capiut thorace paulo angustius.

Abdomen, infra, segmento penultino quibusdain producto, quibusdam simplici. 


\section{Staphylinus. F. III.}

Variat thorace viridi - vel atroviridi - vel violaceo - aeneo.

Habitat in firno bovino, rarior.

St. laminatus Creutzer Vers. p. 128. 8. 3. \&. 3 .

- Panzer Fin. Germ. H. 67. t. 20.

- aeneus De Geer Mem. St. n. 9.

28 St: acneus niger, nitidus; elytris viridi - aeneis; thorace riebus dorsalıbus quadri - punctis; capıte orbiculato.

Habitu St. preecedenti similis; sexiebus autem punctorum distinctus.

Longitudo $3 \frac{T}{4}-4 \frac{\pi}{2}$ lin.

Caput orbiculatum, thoracis circiter magnitudine. Antennis, articulis sexto ad decimum transversis pateraeformi. bus.

Thorex laevis, punctis, marginali uno, lateralibus duo. bus, seriebus duabus dorsalibus quadripunctis.

Variat capite paulo angustiore vel paulo latiore quam thorax, orbiculato vel, rarius attamen, transverso.

Habitat in fimo.

St. aeneus Rossi Fn. Etr. n. 613.

19 St. politus niger, nitidus, elytris aeneis; thorace seriebus dorsalibus quadripunctis; capite ovato; alis fuscis.

Habitu St. praecedentis; statura autem graciliore; punctis subtilioribus; capite ovato; tarsis anticis simplicibus etc.

Caput ovatum, thorace plus minusve angustius.

Thorax punctis marginalibus duobus; seriebus lateralibus tripunctis, dorsalibus quadri-punctis.

Abdomen, infra, segmento penuitimo quỉbusdam inciso. quibusdam eimplici. 
Color et magnitudo variant.

$V$ ar. I St. capite, thorace, elytrisque viridi - acneis; longitudine $4-4 \frac{T}{2}$ lin.

Var. 2 St. niger; elytris nigro - aeneis; longitudine $4 \frac{T}{4}$ lin.

Var. 3 St. niger; elytris viridi-aeneis; longitudine ; Iin - Frequentissimus.

Habitat in boletis, in fimo, ubique, per totum amaus St. politus Fabr. Ent. Syst. St. n. 20.

- Rossi Fn. Etr. n. 606.

- Payk. Mon. St. n. 3 r.

- Payk. Fin。 Suec. Sto 11. 3i.

- Linn. Fn. Suec. n. 843?

- Olivier Ent. St. n. 31. pl. II. f. 10.

- aeneus Fourcr. Ent. Par. St, n. 1\%.

- Geofir. Hist. St. n. 17.

Entomologorum plurimi asserunt, numerum punctorum thoracis hujus speciei valde variabilem esse. Manifesto autem plures species (e. g. St. polituns, variantem, punctuns \&c.) confundunt, bene tamen distinctas. Mihi, inter mag. nam Staphylinorum copiam, nunquan St. politus , seriebus „dorsalibus thoracis quinque punctis, vel St. punctus "lateg, ribus thoracis parumpunctis " \&c. occurserunt.

Eaden constantia punctorum thoracis longe plurimis Staphylinis hujus familiae est; et minime ad sententiam Paykulli accedo, dicentis „Numerus punctorum excavato, rum thoracis (St. politi) variat, quod de specie praecederr"te (St. nitido) et sequente (St. marginato) etiam valet. "

Ratione etiam coloris ego nunquam talem inconstantiam observavi, qualem alii observasse contenàunt. St. politum 
elytris rufis seu pedibus pallescentibus nunquatn vidi; inde credo, St. politi Scopol i varietates „elytris rufis et pedibus „p pallidioribus" ad alias sp.cies, forsan ad St. nitidum vel ad St. corruscumn \&c. referendas esse.

Quisque jam conjicict, ex hac specierum diversarum confusione multa etiam falsa citata auctorum profecta esse. Es Ies ita se habet. St. aeneus De Geeri (Mem. St. n. ९.) quem Dom. Paukull et Ponzer allewaverunt, varietas est St. laminati (n. 17.) - St. sminorem nigtum De Gecri (Mein. St. n. 7.) a Dom. Fabricio citatum, ail St. Similem (is. 3.) retuii; item St. dirum \&c. Geoffreyi (Hist. St. n. 3.), quen Dom, Penzer sub St. polito (St. pumito) citavit - Hic autem Staphylinus, a Dom. Panzer (Fn. Germ. H. 27. t. 7.) sub nomine St. psliti exhibitus, simillinus est St. puncto, et liceat mihi, illum ad hunc referre. Taceo de illis auctoribus, qui quidem St. politum decripserunt, cum aliis antem similibus, conjunxe. runt; horum enin numerus maximus est.

20 St. deçorus niger, subnitidus; capite, thorace, elytrisque aeneis; capite ovato; thorace seriekus dorsalitus quadripunctis.

Frabitu praecedensi simillimus; capie aucem paulo ma. jore, plerumque viridi - aeneo; elytris depilibus; puartis subtilioribus; nitore caeciore.

Longitudo $4 \frac{\pi}{2}-5 \frac{\pi}{2}$ lin.

Variat capite thorace elysrisgue viridi - vel cupreo - vel nigro - aeneis.

Habitat passim in fimo, in quisquiliis, sub lapidibas.

St. decorsss - Mus. Prof. Kroch. 
2I St.varian's niger, nitidus; elytris aeneis; alis albis; capite ovato; thorace seriebus. dorsalibus quadripunctis.

Habitu St. politi (n. 19.); statura autem minore; nitore splendidiore; punctis crassioribus; alis albis, puncto marginali fusco; elytris depilibus:

Longitudo $3-3 \frac{\pi}{4}$ liu.

Variat elytris viridi-vel nigro aeneis; thorace seriebus dorsalibus quadripunctis, vel, rarissime tamen, quinque. punctis; tarsis anticis subdilatatis vel tenuibus.

Habitat in fimo, frequens.

St. varianis Fabr. Ent. Syst. St. n. 22.

- Payk. Mon. St. et Fn. Suec. St. n. 33.

- Olivier Ent. St. n. 35. pl. V. f. 46.

- politus Linn. Fn. Suec. St. n. 843?

- Sihrank Austr. n. 437.

Haec Staphylinorum species saepius cum aliis, praecipue cum St. polito (n. 19.) confusa esse videtur - St. politi Paykulli var. $\delta$, elytrorum macula sanguinea "s ad $S t$. bipustulatun (n. 54.) speciem satis distinctam, pértinet.

32 St. $p$ unctus nitidus, niger; thorace lateribus multi-puncto.

Habitu St. praecedentiun; satis autem distincta specier.

Longitudo $3 \frac{\pi}{3}-4 \frac{\pi}{3}$ lin.

Caput orbiculatum, thorace vix angustius, nigrum, nitidum, confertim punctum, medio laevissinum.

Thorax niger, nitidus; lateribus multi-punctus, punctis interdum in series tres subdispositis; seriebus dorsalibus con. stantibus, octo - ad duodecim - punctis.

Coleoptra nigro-vel subviridi-aenea, depilia. 


\section{Staphylinus. F. III:}

Habitat in paludosis, sub vegetabilibus putrescentibur, cum pluribus hujus generis.

St. politus Panzer Fn. Germ. H. 2\%. t. ?.

23 St. atvatus, niger, nitidissimus; elytris aeneis; capite orbiculato; thorace, seriebus dorsalibus quadripunctis. '

Habitu St, praecedenti sinillimus; punctura St. politi, punctis autem crassioribus; nitore splendidiore; elytris depilibus.

Variat elytris nigro - vel virescenti - aeneis.

Habitat cum St. praecedente, in paludosis.

24 St. Iucidus, niger, nitidus; elytris viridi-aeneis; pedibus fuscis; capite orbiculato; thorace seriebus dorsalibus quadri-vel quinque - punctis.

Habitu St. praecedentis; statura autem minore; elytris subpilosis; pedibus fusco - piceis.

Longitudo $2-2 \frac{\pi}{2}$ lin.

Habitat - Mus. Prof. Hellwig.

:jSt. conoinnus, niger, nitidus; elytris viridi-aeneis; pedi. bus fuscescentibus; capite suborbiculato; thorace seriebus dorsalibus quinquepunctis.

Habitu St. praecedenti simillimus; statura autem majore; thorace semper seriebus dorsalibus quinquepunctis; èlytris depilibus.

Longitudo $2 \frac{\mathrm{T}}{2}-3$ lin.

Habitat - Mus. Prof. Hellurig.

26 St. Boops, niger, nitidus; antennis pedibuisque testaceis; oculis magnis; thorace seriebus dorsalibus tripunctis. 
Statura, St. praecedentibus; minor et crassios.

Longitudo $1 \frac{3}{4}$ lin,

Caput orbiculatum, thoracis latitudine; oculis magnis, oblongis, sapitis fere longitudine; anternis capite paulo lon. gioribus.

Thorax puñetis serierum crassioribus,

Colcoptra subyiridi - aenea.

Habitat - Mus, Profo Hellzwig of at . . ........

(0 7 5t. cephalotes, niger, nitidus; elytris viridi - aeneis; ant - Itmn sedibusque fuscis; capte laticre quam thoras; hoc sersebus dorsalibus quadripunctis, ${ }_{-1}$ -

Habitu St. praecedentium; capite autem multo latiore. Long îudo $2 \frac{3}{4}$ lin.

Caput orbiculatum, thorace lativis; oculis parvis.

$\because \quad$ I Habitat- Mus. Prof, Hellweig.

flacrimens frow.

28 St. brevicornis, niger, nitidus; thozace seriebus dorsalibus quinque - puncts; capite orbiculato, antennis paulo breviore.

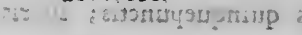

Stature, St. praecedentibus gracilior.

Longitudo $3 \frac{3}{3}$ lin.

Capat orbiculatum, thorace paulo angustius. Antennis it.- capitc vix brevioribus, rigidis, crassis; articulis sexto ad decinum transwersis. 
Abdomen gracile, elongatum; coleoptris plus triplo lont gius.

\section{Habitat - Mus. Prof, Hellwig.}

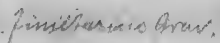

29 St. rigidicorsis, niger, nitidu6; eigtris aeneis; pedibus piceis; antennis brevibus; thorace seriebus dorsalibus quad̦̣i- punctis.

Habitu St. praecedentis; statura autem minore; capife majore; thorace paulo longiore \&c.

"Longitudo $2 \frac{3}{4}$ lin.

Caput suborbiculatum, tharacis magnitudine; antennis St. praeced.

Thorax suborbiculatus, latitudine paulo longior, coles operis angustior.

Coleoptra viridi - aenea.

Habitat - Mus. Prof. Hellwig.

3o St. parvicornis, niger, nitidus; elytris aeneis; capite ovato, antennis brevibus; thorace seriebus dorsalibus quadripunctis.

Habitu, praecedentibus multo gracilior, quo cum varie(atibus St. fulvipedis magis congruit,

Longitudo $=\frac{\pi}{2}$ lin.

Caput parvum, ovatum, thorace angustius; antennis St. brevicornis.

Thorax suborbiculatus, coleoptris angustior.

Habitat - Mus. Prof. Hellwig.

35 St. carbonarizis, niger, nitidus; antennis pedibusque fuscis; thorace punctis aliquot obsoletis impresso. 
Habitu St. brevicornis (n. 28.); capite autem minore, an. tennis longioribus, thoracis punctis obsoletis \&c., differt A varietatıbus quibusdam St. nitidi, capite minore, prac. cipue autem thoracis medio haud dilatato, distingui potest.

Longitudo $3 \frac{2}{3}$ lin.

Coput ovatum, thorace angustius; antennis capite duplo fere longioribus, articulis sexto ad decimum campanulatis, Habitat - Mus. Prof. Hellwig.

32 St. marginat us, niger, nitidus; thoracis margine laterali, pedibusque flavescentibus.

Habilu St. variantis (n, 21.).

Longitudo $3-4$ lin.

Caput suborbiculatum, thorace ininus; antennis capitis thoracisque longitudine.

Thorsx sericbus dorsalibus quadripunctis, colcoptris pall. lo minor.

Coleoptra thorace paulo longiora, nitida, nigra; pilis brevissinis, tenuibus, cinereis, decumbentibus, tecta.

Pedes, capitibus femorum anteriorum, femoribusø̨ue Aavis; tarsis, tibiis, geniculisque fuscis.

Habitat in Silvosis montosis, in fimo bovino.

St. marginatus Fabr. Ent. Syst. St. n. 30.

- Payk. Mon. St. et Fn. Surec. St. n. 32.

- Olivier Ent. St. n. 33. pI. III. f. 29.

33 St. fulvipes, ater, nitidus; clytris pedibusque rufo - testaceis; thorace seriebus dorsalibus sexpunctis.

Statura, St. praecedentibus gracilior.

Loneitudo $-2 \frac{1}{2}-4$ tin. 
Caput parvum, ovetum, thorace angustius, nitidissimun, ngrun; antennis capite thoraceque paulo longiori. bus, extrorsum subcrassioribus, hasi testaceis vel fuscis.

Thorax coleoptris paulo minor, niger, nitidus; seriebus marginalibus bi-, lateralibus tri-, dorsalibus sex-punctis.

Coleoptra thorace paulo longiora, subquadrata, nitida, confertissime subtilissimeque puncta, pilis brevibus tenuibus tecta, sufo - testacea.

Abdonsis nitidum, nigrun; ventre, pectoreque subflavo. sericantibus.

Habitat in paludosis, sub vegetabilibus putrescentibur, seuppose vernali.

St. fulvipes Fobr. Ent. Syst. St. n. 3r.

- cruezizus Oliv. Ent. St. n. 34. pl. V. E. 49.

Credo utique, me verum St. fulvipeden Fabr. cescripsis. se. Locus, quein in Fabr. Ent. Syst. obtinet, et comparà. tio ejus cum statura et magnitudine St. marginati boc con. firmant - Sunt, qui hume Staphylinum ad St. flavipeden Fabr. (Ent. Syst. St. 11. 39.) referunt, minus autem apte, uti snihi videtur, hujus enim in Systemate locus et descriptio dissuadent.

St. fulvipes Panzeri (Fu. Germ. H. 2\%. t. 9.) longe est diversa species, ad unum alterumve familiae quartae Staphy. linum, forsan ad St. ochraseum (n. 65.) referenda.

34 St. micans, niger, nitidus; griseo-sericans; pedibus testa. ceis; thorace seriebus dorsalibus sexpunctis.

Hatitu omnino St. praecedentis.

Longitudo $3-4$ lin.

Antrnae fuscae, basi pallidae. 
Caput et thorax nigri, nitidissimi, colore flavescente fu. gacissimo sericantes.

Coleovtra subquadrata, fuscescentia, pilis brevibus griseo-sericantibus vestita.

Abdonen subfusco - sericeum.

Habitat cum St. praecedente.

St. micans - Mur. Prof, Knoch.

Quanqquam autem hic Stophylinus et St. fulvipes ejusdem sunt staturae et puncturas, et quamquan socialiter vivunt, distnctue attament speçies esse videntur. Inter specimina plusa ntinquam St. fulvives, , capite thoraceque sericantibus, "clytrisve grisescentibus, " nee St. micans ,elytris rufis,

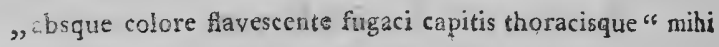
occurrerunt,

35 St. opacus niger, nitiáus; pedibus subfuscescentibus; elytris subgrisescentibus; thorace seriebus dorsalibus quinque. punctis,

Habitu St. praecedentium; słatura autern subcrassiore.

Longitudo $2-3 \frac{\pi}{2}$ lin.

Coleoptra, quibusdam speciminibus, pilis brovissinjs ad. pressis grise - fuscescentibus, tecta; quibusdam autem fere nuda fuscescentia - Cave, ne horum individua quaedans sum varietate secunda St. bipustulati (in. 54.), cui similia sunt, confundes.

Habitat cnm praecedentibus.

St. cpacus - Mus. Prof. Kizoch,

$\$$ St. niters, niger, nitidus; autennis pedibusq̨ue fuscis; ely. tris subgriseo - fuscescentibus; thorace seriebus dorsalibus quadripunctis. 
Habitu St. fulvipedis (n, 33.) 3 statura' autern paulo gracili. ore.

\section{Longitudo $2 \frac{\pi}{3}$ lin.}

Caput "subovatun, thorace angustius; antennis capitis thoracisque longitudine.

Thorax punctorum ordine St. politi (11. x9.).

Habitat, cum St. praccedentibus, in paludosis, sub ve. getabilibus putrescentibus.

37 St. nitidulus, nigricans, nitidissinus; anternis, palpis; pedibusque pallidis; thorace serisbir rorsalikus quacripunc* tis; capito suborbiculato.

IIabitu St. sylendiduli (n, 60) hujus autens fesilitas.

Longitudo $\mathrm{I}_{\frac{1}{2}}-2 \mathrm{lin}$.

Caput suborbiculaum, thorace minus, nitidissimum, laeve, purtetis perpatucis basi impressum. Anternis capite lonjioribus; artisulo ultimo subgloboso, suboblique - truncato.

Thorax suborbiculatus, 'latitudine 'vix paulo longior, co. leoptris paulo anjustior, nitidissimus, laevis, seriebus puns. torum St. politi (n. 19.); punctis autem feré obsoletis.

Pedes rufi, vel rifo-testacri.

St. nitidulus - Mus. Prof. Knoch.

38 St. attenuatus, niger, nitidus; pedibus, antennis, palpisque pallidis; oculis magnis; abdomine longo.

Statura, St. praecedentibus preserior.

Longitud $103 \frac{\text { II lin. }}{2}$.

Caput crbiculatun, thorace vix angustius, nitidissiv tnum. Oculis nagnis oblongis. Antennis capite thoraceque brevioribus, luteis, apice fusci $\beta_{4}$ 
Thorax coleoptrorum magnitudine, nitidissimus, laevis $\$$ punctis, marginali uno, lateralibus duobus, seriebus dorsalibus tripunctis, punctis autein obsoletis.

Coleoptra quadrata, subnuda, fuscescentia.

Abdonen gracile, apicem versus sensim attenuatum, co. leoptris quinquies longius, nigrum.

Pedes testacei, tibiis posticis fuscescentibus.

Habitat Brunsuigae. -

39 St. binotatus, niger; pedibus, elytrorum apice, segmentorunque marginibus rufescentibus.

H.bitu St. praecedentis; oculis antem parvis \&c.

Longitudo $=\frac{x}{2}$ lin.

Caput suborbiculatum, thorace angustius, nitidissimum, laeve, punctis putucis basi impressum, nigerrimum; antennis, capite thoraceque vix brevioribus, fusceseentibus; palpis rufescentibus; oculis parvis.

Thur ax coleoptris vix angustior, nitidissimus, glaber; punctis duobus dorsalibus, unoque marginali, distinctis, impressus; nigerrimus.

Coleoptra subquadrata, subtilissime puncta, nitidula, fuscescentia; marginibus lateralibus pallidioribus; apice, vel inacula elytri singuli apicis, testacea.

Abdomen elongatum, apicem versus sensim angustatum, nigricans, subgriseo-sericeum; segmentorum marginibus rufescentibus.

St. binotatus - Mus. Prof. Knoch.

$40 S t$. albipes niger, nitidus; antennis rufis; pedibus testaceis; capite subovato; thorace sericante, seriebus dorsalibus qua. dri-punctis. 
Stofura, St. micante (n. 34.) minor et latior, sui caetcrum affinis est.

\section{Longitudo $1_{\frac{3}{4}}^{3}$ lin.}

Caput subovatum, thorace angustius. Antenuis, capits plus duplo longioribus, palpisque fuscis.

Thorax niger, nitidus, colore fugacissimo griseo sericans, punctis St. variantis (n. 21.).

Coleoptra quadrata, thorace paulo longiora et latiora, nigra vel obscure - picea, pilis brevibus tenubbus tecta.

Abilonven nigrun vel obscure - piceun.

Habitat Brunsuigae.

4t $S t . f u s c u s$, nigro-fuscus, nitidus; thorace pallidiore, se. riebus dorsalibus obsolete quadripunctis; elytris pedibusque rufis; capite orbiculato.

Habitu St. sequentis; statura autem capiteque latioribus.

Longiterdo $2 \frac{\mathrm{x}}{2}$ lin.

Caput orbiculatum, thoracis latitudine; entennis capite longioribus.

Coleoptra depilia.

Habitat - Mus. Prof. Hellivig.

42 St. 6 zubliformis fuscus, nitidus; thorace, clytrio, pedibusqque pallidioribus; capite subovato.

Habitu varietatum minorum pallidiorum St. nitidi (n. 46.); corpore autem graciliore, thorace hatd dilatato.

Longitudo $2 \frac{2}{3}$ lin.

Caput subovatum, thorace paulo angustius, nitioissim ınum, nigrum. Antenuss capite longioribus.

Thorax laevis, impunstus, rufus. 
Coleoptra et pedes rufo-testacei.

St. subuliformis - Mus. Prof. Knoch.

43 St. iesuinnius, fuscus, nitidus; pedibus, clytris, thora. cisque margine postico, rufis; thorace seriebus dorsalibus quadripunctis.

Habitu St. praccedentis; statura auten paulo majore, antennarum articulo primo crassiore.

Longituslo 3 lin.

Coput orbiculatun, thotacis magnitudine, nitidissinum, nigro-fuscum; clypeo, palpis, antennisque pallidioribus; his capite paulo longioribus, arciculo primo paululum lon* giore et crassiore quam in cospeciebus hujus familiae.

Thorax colcoptris paulo angustior, sericbus dorsalibus quadripunctis, nitidissimus, obscuro-fuscus; margine bagis rufo.

Coleoptro nitida, rufo-fusca.

Abdonen fuscum; marginibus segmentorum pallidioribus: subgriseo - sericans.

St. terminatus - Mus. Prof. Knoch.

44 St. fragilis, fuscus, titidus; thorace rufo, seriebus dorsalibus quadripunctis; elytris pedibusque testaceis; capite orbiculato.

Hobitu onnino St. subutiformis (n. 42.); statura autem Eraciliare.

Longitudo $2 \frac{\pi}{3}$ lin.

Mabitat - Mus. Prof. Rallevig. 
is St. lepidus niger; antennis, pedibus, segmentorumque marginibus piceis; elytris rufescentibus; thorace seriebus dorsal tbus quadripunctis; capice ovato.

Habitu St. fulvipedis (n. 33.); capite autem latiore.

Iongitudo $2 \frac{\pi}{4}$ lin.

Caput thorace angustius; antenuis capite longioribus.

Habitat - Mus. Prof. Hellicig.

46 St. nitidus, nitidus; thorace medio latiore, angulis anticis declivis glabris; capite suborbiculato.

Caput suborbiculatum vel subovatum, plerunque thora* ce paulo angustius, interdum autem thoracis latitudine. An. tenris vel capite vix longioribus, crassis, articulis sexto ad Necimum pateraeformibus; vel capitis thoracisque longitldine, cxtrorsum vix crassioribus, articulis quarto ad d\&cimum campanulatis.

Thorax nedio latior charasterem sistit, quo hace species facile $a b$ omnibus praecedentibus distinguitur. Plerumque glaberrimus laevissimus est, puncto tantum uno alterove majore inpressis; rarius puncto, marginali uno, lateralibus duobus, et scriebus dorsalibus tripunctis; punctis interchum obsoletis vel confluentibus.

Coleoptra quadrata, thoracis latitudime, nitida, plerumque pilis brevibus tenuibus obsita, rasius nuda.

Pedes tarsis anticis, speciminibus quibusdam, dilatatis, quibusdam autem, gracilibus.

Inter omnes Staphylinorum species haec facile plurimum variat, tam colore et magnitudine corporis, quain partium quarundam ริorrua et proportions. 
$V$ ar. $t$ St. nigerrimus; antennarum apice fusca; $100 \%$ gitudine 5 lin.

$\operatorname{Var} .2 S t$. niger; antennaruln apice tarsisque fuscis; longitudine $3-5$ lin.

Var. 3 St. niger; antennis pedibusque fuscis; sutura rufa; longitudine $3 \frac{\pi}{2}$ lin.

Var. \& St. niger; antennis, segmentorumque marginibus, fuscis; pedibus testaceis; longitudine 3 lin.

$V a \% .5$ St. niger; thorace, pedibusque fuscis; sutura rufa; longitudine 3 lin.

$V a r .6$ St. niger; antennis segmentorumque marginibus fuscis; elytrorum marginibus, pedibusque rufis; longitudine 4 lin.

Var. 7 St. nigro-fuscus; capite, coleoptrisque obscus rioribus; longitudine $4 \frac{T}{2}$ lin.

$V$ ar. 8 St. fuscus; capite nigro; pedibus testaceis; longitudine 4 lin.

$V$ ar. o St. niger; antennis, segnentorum marginibus, suturaque fuscis; pedibus testaceis; longittdine 3 lin.

$V$ ar. so St. rufo - fuscus; capite, thoraceque nigrio; longitudine $2 \frac{3}{4}$ lin.

Var. "x St. niger; antennis, elytris pedibusque fuscis; longitudine $4-5$ lin.

$V$ ar. I2 St. nizer; anternis pedibusque fuscis; coleoptris castaneis; longitudine $5-6$ lin.

$V$ ar. 13 St. niger; abdomine pedibusque fuscescentibus; elytris testacris; longitudine $3 \mathrm{~lm}$.

Haec variztas speciminum, quam magna etiam in hac sgecie sit, attamen non sufficit ad plures novas species con- 
dendas. Varietates enim ounnes, una sensim in alteram, ita transeuns, ut nulla certis fi ribus gaudeat.

Habitatio horum Staphylinorum haud minus multiplex est; habitant enim sub cortice arborum putrescente, in boletis, in fimo, immo, quamvis rarius, in floribus.

St, ritidus Fabr, Ent. Syst. St. n, 24.

- Poyk. Mon. St, et Fn. Suec. St. n. 30.

- Schrank Boic. n, 864.

- saxatilis Rossi Fn. Etr, n. 6r5.

- Sihrank Austr, n. 442.

- fulvopterus Fourcr, Ent. Par, St. n. Ir.

Geoffr. Hist. St. n, II,

Staphylinus huic similis St, picipennis Payk. (Fn. Suec, n. 8.) esse videtur; an eadem species? Fabricii autem St. picipennis hue non est numerandus; auctor enim staturam ei omnino St. simitis tribuit.

St, nitidus, quem Dom. Panzer (Fn, Germ. H. 2\%. t. 8.) exhibuit, longe est diversa species, ad St. glabrumb (n. 67.) referenda.

O 47 , corruscus, niger, nitidus; elytris rufis; thorace seriebus dorsalibus quinque - punctis.

Habitu St. praccedentis; statura autem graciliore, capite minore, thorace medio angustiore.

Longitudo $3 \frac{x}{2}-4$ lin.

Caput subovatum, thorace angustius; antennis, capite duplo longioribus.

Coleoptra quadrata subdepilia.

Yabitat in fino, rarios. 
48 St. Iristis niger, nitidissimus; antennarum articulo primo, palpisque rufis; thorace seriebus dorsalibus tripunctis.

Habitu St. nitidi (11. 46.); corpore autem latiore, oculis magnis, thorace medio angustiore \&c.

Longitudo 5 lin.

Caput orbiculatum, thoracis latitudine. Octilis magnis oblongis. Antennis, capite paulo longioribus, fuscis, articulo primo rufo.

Thorax punctis, marginali uno, lateralibus duobus, seriebus dorsalibus tripunctis.

Coleoptra quadrata, thoracis latitudine, opaca, puncta; punetis subtilioribus quam in speciebus praecedentibus; pilis brevissimis, praecipue marginem lateralem versus, testa. Abdomen nigrum, subaeneum.

$\boldsymbol{P}$ edes nigri; tarsis fuscis, anticis dilatatis.

Habitat Brunsuigae, raro.

St. tristis Fabr. Ent. S) st. St. n. 2 r.

49 St. fuliginosus, uiger, nitidus; elytris opacis; antemnis tarsisque fuscis; thorace medio latiore, seriebus dorsalibus tripunctis.

Habitu, varietatibus majoribus nigris St. aitidi similis; corpore autem latiore, colcoptris opacis. A St. praecedente oculis parvis, et thorace lato differt.

Longitudo $4 \frac{T}{2}$ lin.

Coput orbiculatum, thorace vir angustius. Antenuiscapite paulo longioribus.

Pedes antici tarsis dilatatis.

Habitat - Mus. Prof. Hellwig. 
zo St. lateralis, niger, nitidus; coleoptrosum margine laterali rufo; antennis tarsisque fuscis.

Habitu St. nitidi (n. 46.).

Caput suborbiculatum. Antennis capite paulo longioribus.

Thorax seriebus dorsalibus obsolete quadripunctis; punctis conflicutibus.

Pedes antici taris dilatatis.

St. lateralis - Mus. Prof, Helluig.

C: $x$ Tanks

51 St. impressus niger, nitiłus; elytris rufo-marginatis, tripuncto - striatis.

Habitu St. nititi (n. 46.); thorace autem minus declivo. Longitudo 4 lin.

Elytera tripuncto - striata hane specien ab omnibus simio libus satis discernunt.

St. impressus Panz. Fn. Gertm. H. 36. t. 21.

- cinctus Pouk. Fn. Suec. St. 1. $3 \%$.

Habitat - Mus. Prof. Hellhwig.

$52 \mathrm{St}$ debilis, niger, nitidus; elytris piceo-testaceis; thorace sericbus dorsalibus quinque - putctis; capite suborbiculato.

Habitu, St. praecedentubus gracilior.

Longitudo 2 lin.

Caput suborbiculatum, thorace angtistus, nigrung; ar. tentis, capite longloribus, fuscis,

Thorax lateribus minus deflexis quam in cospeciebas hi: fus familiae; seriebus marginalibus bi-, loteralibus tri., dorsalibus quingue-punctie. 
Abdonven, apicem versus attenuatum, atrum; infra, seg. mentorum marginibus fuscis.

Pedes fusci.

Habitat - Mus. Prof. Hellwig.

53 St. sanguinolentus, niger, nitidus; elytris sanguineo-notatis; sutura sanguinea; thorace serıebus dorsalibus quinque punctis.

Habitu St, variantis (n. 2r.); capite auten orbiculato, sutura semper sanguinea, qua etiam optime a speciebus duo. bus sequentibus discernitur, quae nunquan sutura sanguinea occurrunt.

Longitudo $2 \frac{2}{3}-4$ lin.

Variat elytrorum signaturis :

$V a r$. I St. coleoptris pallido-sanguineis; margine-laterali et postico nigris; pedibus pallidioribus.

$V$ ar. \& $S t$. elytris nigris; marginibus sanguineis; pedibus pallidis.

I ar. 3 St. elytris nigris; striga humerali, suturaque sanguineis.

Var. 4 St. elytris nigris; puncto hunerali, suturaque dinidia, sanguineis.

$\operatorname{Var} .5 \mathrm{St}$. elytris nigris; sutura sanguinea.

Far. 6. St. coleoptris nigris; sutura sanguinea.

$V$ ar. 6 St. coleoptris nigris; vitta arruata sanguinea. -

Arcus incipit summo elytrorum humero, et medio sukurae sanguineae jungitur. Oritur, striga humerali elytrorum varictatis tertiae proiongata et sutura sanguinea conjunctis. 
Inter multa hujus speciei specimina individuum vidi unicum varietatis sextae, thorace seriebus dorsalibus sex - punctis.

Habitat frequens in fimo bovino et equino, cum St, sequentibus.

54 St. bipustulatus, niger, nitidus; elytris sanguineo - no. eatis; sutura nigra; thorace seriebus dorsalibus quinquepunctis.

Habitu St. praecedentis; capite autem angustiore, suborbiculato; sutura semper nigra. - A. St. sequente corpore minus glabro et nitido, colore elytrorum obscuriore, thorace sericbus dorsalibus quinque - punctis, facile distingui pürest.

Longitullo $2-3_{4}^{\mathrm{T}}$ lin.

Variat elytrorum signaturis.

Var. $x$ St. clytris, macula oblonga laterali sanguinea.

$V$ er. 2 St. clytris subrufo-nitentibus.

$V^{\prime} a r .3 \mathrm{St}$. elytris, macula apicis sanguinea.

$V$ ar. 4 St. elytris, striga humerali sanguinea.

$V$ ar. 5 St. elytris striga disci sanguinea.

$V u r .6$ St. elytris, puncto humerali sanquineo.

$V$ ar. 7 St. elytris, puncto humerali et striga discoida$\mathrm{li}$, sanguineis, confluentibus.

Habitat in fumo cum St. prace.

St. bipustulalus Panzzer Fir. Germ. H. 27. t. 10.

- varians Payk. Mon. St. el Fn. Suec. St. n. 33. F.

Haereo, an St. bipustulatum Fobr. (Ent. Syst. St. r. 3..) hur referam. 
St. bipusiulatus Rossii (Fri. Etr. n1. 602.) potius ad Alea. charam quamdam, statura et habitu Al. fuscipedis vel bipunctatar \&c, referendus est, quod desçriptio hujus insecti "thorax gibbus, clytra rotundata, "longitudo, latitudo et habitatio probant. Loco, e Rossii Fr. Etr. allegato, delenda ergo stint citata "Fabr. E. S. Staph. n. 34 " nec non "Panzeri Fn. Ins. G. H. 16. t. 21, "“ quae Oxyporum bipushTotum Fubr. exhibet, insecta plane diversa.

s5 St. binaculatus niger, nitidissinus, elytrorum macula magna rufo-testacca; thorace scriebus dorsalibus quadripunctis.

Habitu St. praecedentis; capite autem tisoraceque glabris ritidissimis; hoc, sericbus dorsalibus quadripunctis \&c.

Lonsitudo $3-3 \frac{3}{4}$ lin.

Thorax punctorum distributione St. politi (n. 10.).

Elytra vel testaceo-rufa, marginibus nigris; vel nigra, macula apicis magna rufo-testacea, semper pallidiore quam in St. praecedente.

Habitat cum St. praccedente; rarius autem occurrit.

55 St. discoideus, niger, nitidus; palpis, anternis, pedibus, elytrorum segmentorumque narginibus rufis; thorace seriebus dorsalibus quinque punctis.

Habitu St.. sanguinolenti (n, 53.); statura autem paulo crassiore; capite orbiculato, thoracis latitudine; antennis capitc paulo longioribus.

Zongitudo $2 \frac{1}{5}$ int.

Habitat - Mus. Pros. Hebwig. 
52 St. ofhropus, niger, hitidus; anteunis fuscis; pedibus palLidioribus; thorace sériebus cororsalibus quinque - punctis.

Habitu plurimorum hujus familiae Staphylinoriun; thorase autem paulo longiore.

Longitidio $2-2 \frac{\pi}{2} \operatorname{lill}$.

Caput suborbiculatum, thoracis magnitudines palpis an1tennisque fuscis; his articulo ultimo vix oblique trunsato, potius ovato obtuso.

Thorax sub-orbiculatus, antice vix angustior vel defiexus; latitudiue paulo longior; serisbus dorsalibus quinque. rarius sex - punctis.

Colecptre subquadrata, thoracis latitudine, viridi - vel nigro - aenea.

Habitat in montosis sylvosis, in stercore equino et bo. vino.

Ss St. tenuis, niger, nitidus; thorace, coleoptrorum dimidis parte posteriore, pedibusque rufo-testaceis.

Habitz casterartim hujus familiae specierum; thorace autem longiore; antennarum articulo ultimo haud obliquee truncato, sed obtuso ovato.

Longitudo 2 lin.

Caput ovatum, glaberrimum, laevissimum, thosace paulo angustius.

Thorax subovatus, antice vix angustatus vel defexus, nitidus, seriebus dorsalibus sex-punctis; punctura St, fulvipedis (n. 33.).

$P$ edes fusci, femoribus testaceis. 
Habitat sub lapidibus, in colle graminoso eprico, prope Brunsuigam, rarissimus; semel tantum captus, tenpore vernali.

St. tenuis Fabr. Ent. Syst. St. n. 43 .

Paederus dimidiatus Panzer Fn. Germ. H. 27. t. 24.

\section{F am. IV.}

Corpus lineare, nitidum.

Cayut angulatum, angulis obtusis, punctum, thoracis circiter magnitudine. Antennis, articulo prino magno cla. vato; sectindo et tertio brevioribus clavatis, ultimo ovato - acuto.

Thorex obiongus, angulis obtusis; punctus.

Coleoptra elongata, thoracis magnitudine.

59 St. rufipennis, niger, nitidus; antennis pedibusque fuscis; elytris rufis; capite thoraceque multipunctis.

Longitudo $4 \frac{2}{3}$ lin.

Caput orbiculato - angulatum, thorace paulo latius, mul. ripunctun. Mandibulis palpisque gracilibus longis. Antennis capite longioribus, articulis mediis campanulatis.

Thorax latitudine paulo' longior, basin versus subangustatus; angulis anticis deflexis; multupunctus, subpunctostriatus; medio nitidissimus, laevissimus.

Coleoptra latitudine paulo longiora, thoracis latitudine, nitida, puncta.

Pedes, tarsis tentuibus.

Habitat - Mus. Prof. Hellwig. 
бо St. sqlendidulus, nitidus, obscurus; antennis, elytrit, segmentorum marginibus, pedibusque pallidioribus; therace seriebus dorsalibus quinque - punctis.

\section{Longitudo $1 \frac{\pi}{2}-2$ lin.}

Caput oblongun, thoracis latitudine, laeve; punctis aliquot impressun; nigrum; palpis, antennisque rufis; his capite paulo longioribus, articulis sexto ad decimum paterae. formibus.

Thorax oblongus, basin versus subangustatus, coleop. tris paulo angustior; punctura St. opaci (n. 35\%)

Colecptra subrectangula, nitida, puncta, depilia.

Color hujus speciei variat:

Var. r St. niger; antenuis, elytris, segnentorumg̨ue marginibus fuscis; pedibus rufis Adultior.

$V a r .2$ St. fuscus; capite nigro; pedibus, segınento. runque marginibus testaceis - Junior.

St. splendidulus - Mus. Prof. Knoch.

6I St. nigritulas, nitidus, nigricans; antemuarun basi, pedibus, palpisque rufescentibus; thorace ovato, seriebrs dorsalibus quinque - punctis.

Habitu St, praecedentis; differt autem thorace subovato, nec basin versus angustato; antennis longioribus.

Longitudo $1 \frac{\mathrm{T}}{3}$ lin.

Hakitat Brunsuigae.

S2 St. cterrinnu, niger, nitidus; palpis, antennis, pedibus= que fuscis; thorace seriebus dorsalibus sexpunctis.

Habitu, St. splendidulo (n. 6o.) paulo gracilior; nitore mimus fulgido, antennis rigidioribus. 


\section{Zongitudo $1 \frac{x}{2}$ lin.}

Caput oblongum, angulis obtusis, basin versus paulo angustatum, nitidissimum, laeve, in angulis basis punctum; nigrun; artennis rigidis capite paulo longioribus, palpisque obscure fuscis.

Thorax rectangulus, angulis obtusis; punctura St. fulvipedis (11. 33.).

- Culeoptra subrectangula, thorace paulo longiora et latiora, confertim puncta, pilis brevibus tenuibus parcis vestita.

Pedes ruio-fusci.

Habitat sub vegetabilibus putrescentibus, tempore ver* nali, haud frequens.

yin tis. 60 .

Gs St. parvulus, niger, nitidus; pedibus, antennis, palpisque rufo-testaceis, thorace scriebus dorsalıbus quinque - punc: tis.

Hcbitu, St. praecedentibus gracilior; capite apicem ver* sus angustato; articulo primo antennarum crassissimo \&c.

Longitudo $\leq \frac{r}{2}$ lin.

Corpus filiforme, gracile, nitidum.

Caput oblongum; basi latum obtusum, apicem versus sensiun angustatum; punctum, medio nitidissimum laevissimu!n; nigrum, palpis antennisque rufis apice fuscis. Anternis capite paulo longioribus; articulis, primo longissimo erassissimo clavato, secundo et tertio brevibus, quarto ad decimum pateraeformibus, latitudiac crescente.

Thorex basin versus paululum angustatus; angulis anticis deflexis; nitidissimus, punstura St. opaci (13. 35.). 
Coleoptra rectanguln, thoracis magnitudine, nitida, confertim puncta, pilis brevibus tenuibus sparsin vestita, obscure picea.

Abdomer elongatum, apirem versus sensim attenuatum, nigrtn; marginibus segmentorum obscure rufis. ?

Habitat sub cortice arborum demortuarun, rarissimus. Semel etiam captus in flore Crataegi Oxyacanthae.

64 St. linearis, niger, nitidus; pedibus testaceis; thorace serebus dorsalibus multipunctis.

Habitu St. sequentis; statura autern multo minore, tho. racisque ptinctura difiert.

Longitudo $1 \frac{\pi}{3}$ lin.

Thorax seriebus snarginaiibus bi - , lateralibus tri •, dos. salibus sex - ad octo - punctis.

St. linearis - Mus. Prof. Knioch.

limeses.

6s St. ociraceus, nitidus; colore variabili; thorace seriebus dorsalibus et lateralihus multi - punctis.

Hajitu St. parvuli (3. 63.) thorace.autem longiore et basin versus angustiore, abdounine obtuso Gic.

Longituedo $2-3$ lin.

Caput nitidum, punctur; punctis subtilissirais, haud confertis; medio nitidissimum laevissimum.

- Thovar oblongus, basin versus sensim angustatus; serie. bus dorsalibus novem - ad sedecim - punctis, lateralibus sep. tem-vel octo-puncris, marginalibus tri-punctis; punctis subtilibus. - Series latcralis et marginalis apice ita inclina. tae sunt, wi, junctim, figuran pedi episcopalis exhibeant.

Coleoptva rectangula, puncta, vel subpuncto-striata, 
Color variabilis est:

Var. I St. niger; elytris obscure piceis; pedibur antennisque rufis.

$V a r .2$ St. niger; thorace, elytris, antennisque fus. eis; pedibus rufo-testaceis.

$V$ ar. 3 St. niger; antennis, elytris, pedibusque rufis.

$V$ ar. $4 S t$. fuscus; capite nigro; elytris piceis; pedibus anternisque rufis.

Habitat sub cortice arborum putrescentium, sub lapidi. bus in ulyginosis.

St. o.hraceus - Mus. Prof. Knoch.

- affinis Payk. Fn. Suec. St. n. I6?

- Linearis Olivier Ent. St. n. 21. pl. IV. f. 38?

- fulvipes Panzer Fn. G. H. 27. t. 9.

Paederus fulvipennis Panzer Fn. Ferm. H. 27. t. 23?

Pacderus testaiers Olivier Ent. Paed. n. 3. pl. J. f. 6? ?

Omnia hic citata insecta, habitu et magnitudine corpo. ris, partiumque forma ac proportione St. ochvaceo Knochii sinillina sunt, uti figurae et descriptiones eorum exhibitae probant. Plurima autem seriebus punctorum thoracis carent, et, nisi incuria delineatorum hae series omissae sint, quod jure suspicor, ad alias species removenda sunt. Qulan parum autem rationis hucusque sericrum punctorum thoracis habitum est, figurae nec un cescriptiones Staphylinorum, in Olivieri Entomologia exhibitae, Panzeri Fama InsectoYum Germaniae, et multa alia opera, in quibus Staphylini tractantur, probant, seriebus punctorum vel omnino omissis, vel horum numero neglecto. - His coactus, synonyma St. ochracei interrogative tantum allegavi, St. fulvipede Panzeri excepto, qui, seriebus thoracis in fizura exhibitis, 
omri jure huc referri potest, nec ad St. fulvipedem Fabr, quem Fabricius ipse, ratione staturae et magnitudinis, cum St. marginato, insecto satis distitucto, comparat. - Paede. run fulvipennem Panzeri potius ad hunc Knochii Staphyli. num, quam ad P. fulvipennem Fabr, referre volui, cum Fa. bricius ipse dixerit, hunc Paedero elongato paulo majorem et ei affinem esse, quod e figuris, in Panzeri Fauna delinea. tis, nemini sane apparebit.

66 St. elongatus, mitidus, thorace seriebus dorsalibus quinque - vel sex - punctis, lateralibus septera - vel octo - punctis.

Habitu omnino st. praecedentis; statura autem paulo majore; punctis capitis thotacisque crassioribus

Longitudo $2 \frac{T}{2}-{ }_{3} \frac{\pi}{2}$ lin.

Thorax, seriebus lateralibus et marginalibus eodem mo. do junctis ut in St. praecedente.

Color variat:

$V$ ar. $x$ St. fuscus; anternis, elytris, pedibusque rufescentibus. fuscis.

Var. 2 St. niger; antennis, elytris, ano, pedibusque

$\operatorname{Var} .3$ St. niger; antennis, ano, pedibusque fuscis.

$V$ ar. 4 St. niger; pedibus, segmentorumque marginibus rufescentibus.

$V$ ar. 3 St. nigerrimus; elytris semper puncto - stria-. tis. - Punctura crassissima, magnifudine maxima insignis.

Habitat haud raro in fimo equino et bovino, primo vere.

St. elongatus Fourcr. Ent, Par. St, n, 27. 
67 St. glabev niger, nitidus; antennis fuscis; elytris pedibus. que rufo-testaceis; thorace sericbus dorsalibus sex - ad no. vern - punctis.

Habitu omnino St, duorum praecedentium; ratione alt. tem numeri et crassitiei punctorum, inter illos medium te, net. Thoracis seriebus lateralibus et marginalibus St. praeo ecdentium.

Longitudo $2_{4}^{5}-4$ lin.

Caput, thorax et abdomen glaberrinsa, colore semper n?-. gerrimo. Elytra et pedes rufi vel testace.

Habitat in stercore sicciore.

St. nitidus Panzer Fn. G. H. 2\%. t. 8.

Groffr. Hist. St. n. 10. N. B.?

${ }_{8} S t$, elegans, nigro-fuscus; thorace nigricante, antice ru* fescente, seriebus dorsalibus quinque - punctis; elytris pedibusque testaceis.

Habitu St. praecedentium; punctorum numero St. elongs. ti, subtilitate St. ochracei.

Longitudo $3 \frac{\mathrm{T}}{2}-4 \mathrm{l}$.11.

Habitat Mus. Prof. Hellwig.

St. elegans Olivier Ent. St. n. 20. pl. V. f. 50.

- Iricolor Payk. Mon. St. \$1. 23.

- Payk. Fn. Suec. St. n. 15.

An Paederus tricolor Falr. eadem sit species, dubito, quia punctorum thoracis nulla facta est mentio.

6g St. ustulatus niger, nitidus; limbo coleoptrorum, ano, pedibus, antennis, palpisque rufis; thoracc laevissimo.

Hobitu St. praecedentium; statura autem minus gracili. 


\section{Stapbylinus. F. IV.}

\section{Longitudo 4 lin.}

Caput oblonguin, nitidissimum, laeve; punctis aliquot lateribus impressum, vix thoracis longitudine et latitudine; nigrum; antennis, capitis longitudine, palpisque rufis.

Thorax basin versus vix angustatus, niger, nitidissimus; punctis paucissimis, quatuor vel sex, impressus.

Coleoptra thorace paulo longiora, ejus vero latitudine, nitida, subpuncta, rufa, medio nigra.

Abdomon nitidum, obscure fuscum; ano rufo.

Pedes rufi ; tarsis anticis dilatatis.

Habitat Brunsuigae.

7o St. fulminans, nitidus, nigro-fuscescens; antennis, elytris, pedibusque rufis; thorace laevi.

Habitu et statura St. prascedentis, et forte mera ejus va. rietas. - A St. sequente, cui caeterun habitu similis est, statura minore et angustiore, thorace punctis paucissimis obsoletis impresso, pedibus totis rufis, capite angustiore, antennis gracilioribus, differt.

Longitudo $3 \frac{2}{3}-5$ lin.

Caput ovatum, nitidum, subpunctum, thorasis magnis tudine.

Thovax subrectangulus, laevis, puncris vagis, quatuor tel sex, impressus.

Coleoptra, thoracis magnitudine, puncta, puncto $-6 u b-$ striata.

Ablomen obscurum, ano pallido.

$\boldsymbol{P}_{\text {eles, }}$ tarsis anticis dilatatis.

Habitat - Mus. Prof. Hellwig. 
S. fulgides Olivier Ent. St. n. 19. pl. IV. f. 34.

Paederus fulgichus Panzer Fn, Germ. H. 43, t. 20.

7I $S_{t}$. fulgidus niger, nitidus; antennis fuscis; clytris tarsiso que rufis; thorace seriebus dorsalibus quinque - punctis.

Habitu omnino St. praecedentis; statura autern majore et latiore, thoracis punctura, femoribus cibiisque nigris, diจersus.

Longitredo 5 lin,

Habitat - Mus. Frof, Hellhuig.

St. fullgidus Park. Mon. St. 11. 22,

- Payk. Fn. Suec. St. 11. 14.

Pacderus fulgidus Fabr. E. S. Paed, n, 6 .

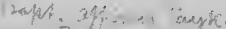

72 St. alternans, nitidus, rufus; capite, elytris, abdominist que apice nigris; capite quadrato.

Habifu St. praecedentium; statura autem graciliore, ca. pite quadrato.

Longitudo $2 \frac{x}{4}-4$ lin.

Corpus filiforme, gracile, nitidum.

Caput suborbiculatum vel quadratum angulis obtusis, nitidissimum, laeve, punctis perpaucis basi impressum; an. tennis capite longioribus,

Thorax nitidissimus, punctis perpaucis vagis impressus, capite angustior.

Coleoptra nitidissima, laevissima, nee puncta, nec puac. so- striata. 


\section{Staphy linus. F. IV:}

Abdomen rufum, apice nigrum; ano attamen rufo.

Pecdes, tarsis anticis dilatatis.

Color coleoptrorum variat.

Var. $x$ St. major; coleoptris totis nigris.

$\operatorname{Var}_{\mathrm{a}} 2 S t$. minor ; coleoptris nigris, basi albescentibus.

* $\quad \therefore$ Habitat sub cortice arborum denortuarum.

St. alternans - Mus. Prof. Knoch.

73 St. palmula niger, nitidus; abdominis basi rufa; antennis, pedibusque testaceis; capite quadrato.

Longitudo $=\frac{\pi}{3}$ lin.

Caput quadratum, nitidum, punctum, thorace vix latius, nigrum; ore antennisque testaceis; his, structura et longitudine ut in St. praecedente.

Thorax latitudine-palo longior-, subquadratus, nitidus, coleoptrorum maguitudine, punctis perpaucis vagis impressus.

Coleoptra subquadrata, nitida, laevia.

Abdomen, longitudine dimidii corporis, apicem versus sensim dilatatum, coleoptris multo latius, sitidum, punctum, rufum; segmentis penultimo et antepenultimo nigris.

Pedes rufo- testacei.

St. palmula - Mus. Prof. Kroch.

O34 St. cinerascens, niger, subopacus; elytris pedibusque rufescentibus; therace puncto-substriato. 


\section{Longitudo 2 lin.}

Caput quadratunt, angulis obtusis, thorace paulo latius, subnitidum, confertim punctum (antennae desunt.).

Thorax oblongus, subrectangulus, angulis obtusis; punctus, subpuncto-striatus, medio laevis nitidissimus ; coleope tris angustior et brevior.

Coleoptra rectangula, subtilissime puncta, opaca, subfus. eescente-sericantia.

Abdomen subfuscescente - sericans.

$P e d e s$ pallidi, rufo-fusci.

St. cinerascens - Mus. Prof. Knoch. 


\section{Genus II.}

\section{L a throbiu m.}

$P$ a $1 p i$ acuminati.

Thora $x$ oblongus, punctus.

Corpus elongatum.

Caput supra convexum, infra planum; punctum - Palpi acuminati; anteriores quadri - articulati; posteriores tri articulati - Antennae filiformes; articulis primo maximo, secundo brevi, tertio majore, clavatis; sequentibus suborbiculatis; ultimo ovato acuto - Oculi parvi.

Thorax elongatus, angulis obtusis, convexus, lateribus de. clinatus, punctus. Ora laterali deflexa, glaberrima, basi lata, apicem versus angustata.

Coleoptra rectangula, subdepressa, thorace paulo longiora, lateribus deflexa.

Abdomen marginatum, supra et infra convexum.

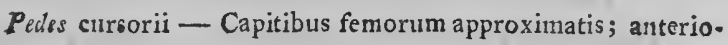
ribus femore duplo brevioribus et multo gracilioribus; posticis brevissimis, absconditis - Femoribus crassiussulis (brevioribus et validioribus quam in genere praece-

$\mathrm{D}_{2}$ 
dente) - Tibiis ciliatis - Tarsis; articulis brevibus, omnibus longitudine aequali; anticis plerumque dilatatis.

L. castaneum, fuscum, nitidum; infra pallidum; pedibus testaceis; thorace, seriebus dorsalibus nulti - punctis.

Habitu L. sequentium; seriebus autem punctorum thoracis, nitore splendidiore, pedibus grasilioribus, hoc genus cum familia ultima Staphylinorum nectitur

Longitudo $2 \frac{\pi}{3}$ lin.

Caput magnitudine thoracis; nitidum, punctum, rufofuscuur; infra testaceum.

Thorax paulo convexior et angulis rotundioribus, quam caeteris Lathrobiis; nitidus; lateribus multi - punctus; dorso laevissimus, seriebus duabus decem-punctis; rufo - fuscus, infra testaceus.

Coleoptra subrectangula, nitida, puncta, rufo-fusca.

Abdomen supra fuscum, infra basi rufum seu testaceum.

$P$ edes "graciles (ut in Staphylinis); testacei.

Staphylinus - Mus. Prof. Rnoch.

2L. mult ipunctum, nitidum, rufo-piceum, abdomine fusco. Lóngitucto 3 lin.

Coput suborbiculatum sive quadratum angulis obtusis, "nitidum, confertim punctum, rufescens; oculis nigris; thorace latius sed brevius.

Thörax subrectangultis; angulis obtusis; basin versus subangustatus; punctus; linea media longitudinali, obsoleta, laevissima; rufescens.

Coleoptra rectangula, thorace latiora, puncta, piceotestacea. 
Abdomen nigricans.

Polles rufo-testacei; tarsis anticis subdilatatis. Paederus multip. - Mus. Prof. Knoch.

3 L. badium, fuscum, infra pallidius; antennis palpisque xนfis; pedibus testaceis.

Longitudo 5 lin.

Coput ovatum; thorace latius; nitidum, subtiliter pun ctum; supra fuscum, infra testaceum seu rufum. Clypeotestaceo. Mandibulis arcuatis, gracilibus, acutis. Palpis, antemisque pallide rufis.

Thorax rectangulus, capitis longitudine, nitidus, rufofuscus, punctus; punctis irregularibus rugosis.

Coleoptra rectangula, thorace latiora, nitida, puncta, ad suturam subpuncto - striata; rufescentia.

Abilomen rufo-fuscum, versus apicem pilosum.

Pedes tenues, rufi; femoribus testaceis; tarsis anticis tenuibus.

Paederus badius - Mus. Prof. Knoch.

4. L. longulum, nigrum, nitidum; ore, antennis, pedibusque rufo-testaceis.

Hobitu L. praecedentis; statura autem multo minore et graciliore.

Longitudo $\mathbf{I} \frac{\mathrm{T}}{2}$ lin.

- Caput ovatum; basi latum, thorace latius, apicem versus angustatum; punctum, nitidum, nigrum; ore antennisque rufis vel fuscescentibus, his capite duplo longioribus.

Thorax rectangulus, angustus, nitidus, punctus, niger; linea media longitudinali glaberrima. 
Coleoptra rectangula, thorace paululum latiore, nitida, subtiliter puncta,

Pedes rufi vel testacei; tarsis anticis dilatatis. Paederus longulus - Mus, Prof. Knoch.

5 L. fracticorne nigrum, nitidum; pedibus testaceis; anten. narum articulo primo longissimo clavato.

Habitu L. elongati (n. 8.); statura anten graciliore, nito. re paululun splendidiore, antennarun articulo primo capitis fere longitudine.

Longitudo $2 \frac{\mathrm{T}}{3}$ lin.

Caput magnum, oblongum, thoracis latitudine, nitidum, punctum. Ore producto. Antennis capite thoraceque vix brevioribus; artıculis, primo longissimo clavato, secundo min.mo, cacteris subcrescentibus, ultimo obtusiusculo; ar. ticulus primus plerumque cum reliqua antennae parte angu. lum format, recto paululum majorem,

Thorax nitidus, niger, punctus, medio laevissimus; punctis, in strias interdum subdispositis, impressus.

Pedes testacei; tarsis anticis subtenuibus.

Habitat Brunsuigae.

Paederus fraiticornis Payk. Fu. Suec. P. n. 5.

Paed. filiformis Fabr. Ent. Syst. P. n. 8.

Staph. glaberrimus Payk. Mon. Car. App.p. 13\%. nd 1\%.-18.

6 L. lineare, nigricans; antennis ejytrisque fuscis; pedibus rufis.

Habitu et punctura L. elongati (n. 8.); statura autem graciliore, thorace multo angustiore. 
Longitudo $3 \frac{\mathrm{x}}{2}$ lin.

Paederus linearis - Mus. Prof. Hellivig.

7 L. termin at um, nigrum, nitidum; ore, antennarum basi, angulo inferiore exteriore elytrorum, pedibusque rufo - testaceis.

Habitu L. sequentis; statura autem multo graciliore, capite minore.

Longitudo $2 \frac{3}{4}-3 \frac{\pi}{2}$ lin.

Corpus nitidum, filiforme, gracile, confertim et subtiliter punctum.

Caput orbiculatum, thorace minus, nigrum; antennis fuscis, basi rufis; ore rufo, palpis anterioribus apice fuscis.

Thorax coleoptris paulo angustior et brevior, punctus, linea media nitida longitudinali.

Elytra, angulo inferiore exteriore, vel pustula hujus anguli, rufo vel testaceo.

Abdomen apicem versus attenuatum.

Pedes testacei; tarsis anticis latis.

Habitat in fimetis, sub lapidibus.

Paederus terminatus - Mus. Prof. Knoch.

Paed. filiformis Payk. Fn. Suec, P. n. 4. var. ß.

8. Llongetum, nigrum, nitidulum; coleoptrorum apice sanguineo - rufa, pediburs rufo - testaceis.

Habitu L. praecedentium; statura autem paulo latiore et najore.

Longitudo $3 \frac{\pi}{2}-4 \frac{\pi}{4}$ lin.

Corpus filiforme, subnitidun confertin punctum. 
Caput suborbieulatum, thoracis latitudine, subtilissime punctum. Auteninis moniliformibus, capite thoraceque breviorsbus.

Thorax subiectaingulus, látitudine paulo longior; angulis obtufis; capite paulo longior, punctus, linea media longitudinali laevissima nitida.

Côleoptra thorace paulo latiora et longiora; basi nigra, apice rufo-sanguinca.

Abilomen apicein versus subattenuatum.

Pides, tarisis anticis dilatatis.

Habitat in fimetis, sub lapidibus.

Paxderu's lonigatus Fabr. Ent. S. P. n. 3.

- Prylt. Fn. Suec. P. п. 3.

1 Panzer Fii. Germ. H. 9. t. 12.

Staphyl. elongatus Payk. Mour. St. n. I7. - Sikronti Austr. 11. 439.

9. pilosum, nigricans, nitiduin, autennis pedibusque fuscis.

Hibrtu L. praccedentis; statura autem minus gracili; thorace, vix latitudine longiore; subtilius puncto.

Longitude $3 \frac{T}{6}$ lin.

Conpüs nigrum vel nigro-fuseum, nudum vel pilosellum. Pacterus pilosus - Mus. Prof. Knoih.

O ro L. brunnipes, nigrum, subopacum; pedibus antennisque rufo-fuscis.

Habitu L. elongati (n. 8.); statura autem plerunque paulo latiore, punctura subtiliore: A L. praecedente statura plerumque paulo longiore, nitore fere nullo, differt.

Longitudo $3-4 \mathrm{lnn}$. 
Habitat in finetis, sub vegetabilibus putrescentibus.

Paederus brunnipes Fabr. E. S. P. n. 5.

Staphyl. punctatus Fourcr. E. Par. St. n. 14.

Geoffr. Hist. St. 11. 14.

Paederus filiformis Poyk. Fn. Suec. P. n. 4. v. u?

Nescio, an $\boldsymbol{P}$. fliformis $\boldsymbol{P}_{\text {ayk. meliore jure ad hanc vel }}$ ad pracedentem speciem referri possit, credo autem, cun ad unam alteramve speciem numerandum esse. Certe non est idem cum $P$. filiformi Fabr., cui primus antennarum articulus "magrius incurvus " est, Paykull enim dicit ipse de suo $P$. filiformi ,antennae, articulo baseos reliquis non "multo longiore" - An St.quadratus Payk. (Mon. St.) idem sit, dubito, quia, in hujus descriptione, punctorum capitis thoracis elytrommque nulla mentio facta est - Fabricius St. qualratum Payk. sub P. filiformi (Lathrob. fracticorne m. 5.) citavit. 


\section{Genus III.}

\section{$P$ a e d e r u s.}

Pa $1 \mathrm{p}$ i anteriores triarticulati.

$P$ a l p i posteriores acuminati.

A ntenna articulo ultimo orato.

Corpus clongatum.

Caput convexum, magnum. Antennis filiformibus; articulis, primo clavato, ultimo ovato acuto. Palpis anterioribus triarticulatis, clavatis, articulo ultimo caeteris crasa siore.

Thovax crassus, convexus.

Coleoptra rectangula, convexa, puncta, thorace longiora et latiora; lateribus deflexa.

Abdomen urarginatum, longum, obtusum.

Pedes cursorii. Capitibus fenorum approximatis; anticis femore brevioribus, hujus autem crassitie; mediis femore duplo brevioribus, hujus autem crassitie; posticis brevis. simis abscondits. Tibiis gracilibus subciliatis, Tarsis zracilibus. 


\section{Paederus.}

I. ochraceus nitidus, fuscus; capite nigro, thoraceque sub. quadratis.

Longitudo $\mathrm{x} \frac{\mathrm{T}}{2}$ lin.

Caput quadratun, angulis obtusis, thoracis magnitudine, nigerrimum, nitidissimum; palpis antennisque rufes. centıbus; his capite thoraceque longioribus.

Thorax quadratus, angulis obiusis, longitudine latitudimem vix superante, coleoptris paulo angustior, nitidus, rufescens; linea media longitudinali clevata, obsoleta.

Coleoptra subrectangula, thorace paulo longiora, nitidiuscula, subtilissime puncta, picco-testacea.

Abdomen nigricans, griseo - subsericeum, segnentorum narginibus rufescentibus.

Pedes testacei.

Aleochara ochracea - Mus. Prof. Knock.

2P. bicolor, nitidus, nigro-fuscus; elytris pallidioribus; capite nigro; thorace, pedibus, antennisque rufis.

- Habitu P. praecedentis; statura autem graciliore.

Longitudo I $\mathrm{T}$ lin.

Corpus filiforme, gracile, nitidum, punctum.

Caput suborbiculatum, seu quadratum angulis obtusis, thoracis magnitudine, nitidissimum, subtilissime punctum, nigrum; ore antennisque rufis; his capite loigioribus, moniliformibus, articulis, primo majore clavato, mediis campanulatis.

Thorax subquadratus, vix subrectangulus; coleoptrorum latitudine, rufus, nitidus, subtilissine punctus; linea media longitudinali lacvissima nitidissima. 
Coleoptra subrectangula, thorace longiora, depressiuscut: la, puncta, nitida, piceo-fusca, marginibus pallidiora.

Abclomen obscure fuscum, marginibus segmentorum pallidioribus.

Pedes rufo-testacei; femoribus crassioribus quain in caeteris Paederis.

Habitat sub lapidibus in locis altioribus, apricis, graminosis, tempore verno, - rarior.

P. bicolor Olivier Ent. P. n. 7. pl. I. f. 4 .

3P. castaneus subnitidus, fuscus; capite, abdominisque medio nigricantibus.

Habitu P. ochracei (n. I.); statura autem majore, thorace basin versus angustiore $\& \mathrm{c}$.

Longitudo 4 lin.

Caput quadratum, angulis obtusis; thorace paulo majus, confertissime subtilissimeque punctum, nitidulum, nigricans; ore antennisque rufescentibus; his capite duplo fere longioribus, articulis mediis campanulatis.

Thorax suborbiculatus, seu subquadratus angulis obtusis; basin versus pauio angustatus; coleoptris angustior; confertissine subtilissimeque punctus, nitidulus, rufo-fuscus.

Colecptra subrectangula, stibtilissime puncta, fuscescentia.

Abdomen subgriseo-sericeum, nigricans; infra pallidius, apice rufescente.

Pedes rufi.

Paederus casteneus - Mus. Prof. Knorh. 
$4 P$. Iittoralis, rufus; geniculis, capite, abdominisque apice nigris; elytris coeruleis; thorace globoso, suborbiculato.

Habitu, caeteris cospecicbus crassior, teretior.

Corpus nitidum, crassum; pilis crebrioribus rigidioribus, quan in cospeciebus, tectum.

Caput suborbiculatum, seu quadratum angulis obtusis; thorace majus, nitidum, laevissimum, nigrum. Antennis, capite thoraceque paulo longioribus; articulis, primo longiore, secundo brevi, terio paulo longiore quam secundus, breviore autem quam primus, sequentibus, longitudine decrescente, subcylindricis seu oblongo-campanulatis, ultimo ovato acuto, fuscis; articulis tribus primis totis, quarto autem basi tantum, rufis. Palyis rufis; anterioribus, articulo ultimo apice nigricante tuberculato, tuberculo brevi obtuso.

Thorex convexior quam in P. praecedentibus, globosus, sub-orbiculatus, quibusdam basin versus angustatus; coleoptris angustior, nitidus, glaber, punctis paucis vagis im. pressus. Ora laterali deflexa, basi latiore, apicem versus angustata.

Colesptra rectangula, thorace longiora, punctis confertis crassis cicatricosis impressa, nitidula, convexa. -

Abdomen teretiusculum, apicem versus subangustatum.

Pedes, tibiis ciliatis.

Variat forma thoracis.

Vor. I $P$. thorace, longitudine latitudinem paululum superante, cordato; capite magno orbiculato; longitudine 4 lin.

$V$ ar. $2 P$. thorace globoso orbiculato; capite magno: longitudine 4 lin. 
Habitat circa Blankenburg.

P. litioralis - Mus. Prof. Knoch.

Hic Paederus hucusque saepius cum P. sequente confu. sus et pro ejus varietate declaratus est. Characteribus au. tem constantibus, capite magno, thorace globoso, statura majore, distinctus est. Nec habitat cum P. sequente; in jegionibus humilioribus, circa Brunsuiganı nunquam capo tus.

5 P. riparius rufus; geniculis, capite, abdominisque apice, nigris; elytris cocruleis; thorace oblongo, lateribus paralIelis.

Habitu P. praecedenti simillinus; capite autem parvo, paulo minore quam thorax; thorace oblongo, pedibus gracilioribus; statura minore.

Longitudo 3 lin.

Habitat in gramine, ad radices arborum, primo vere, haud infrequens.

$P$. riparius Fabr. Ent. Syst. P. n. I.

- Payk. Fn. Suec. P. n. 2.

- Rossi Fn, Etr. 11. $62 \sigma$.

- Panzer Fn. Germ. H. 9. t. It.

- Olivier Ent. P. n. 2. pl. I. f. 2.

Stophyl. riparius Linn. Fn. St. n. 846.

- Payk. Mon. St. n. r9.

- DiGeer Mem. St. n. 14.

- Sihrank Austr. n. 441 et Boic. n. 892

- Fourcr. Ent, Par. St n. 2r.

Geoffr. Hist. St. n. 2 r.

Staph. gregarizs Siop. Carn. 11. 308. 
6 $P$. orbiculatus niger, palpis, antennis, margine colsop. trorum apicis, pedibusque pallide fuscis.

Longitudo $2 \frac{\pi}{3}$ lin.

Corpus, confertissime punctum.

Caput orbiculatum, thorace multo latitis, confertissime punctum, opacum. Clypeo prominente, transyerso, rotun. dato. Antennis capite longioribus; articulis mediis campa. nulatis.

Thorax subovatus, globosus; antice posticeque valde angustatus; capitis longitudine, opacus, confertissime punctus; linea media longitudinalí, subelevata, laevi, nitida; ora laterali deflexa, basi lata, apicen versus angustata.

Coleoptra subrectangula, convexiuscula, thorace longiora et latiora, puncta, nitida, nigra, margine apicis plerumque rufesccnte; pilis tenuibus, brevissimis, subflavo - sericantibua interdum tecta, interdum omnino nuda nitidissima.

Abdomen obtusum, nitidiusculum, nigrum, subflavosericans.

Pedes graciles, fusco-testacei; tibiis nudis, laevibus.

Habitat in quisquiliis, sub lapidibus, primo vere.

P. orbiculatus Payk. Fn. Suec, P. n. 6 .

- Panzer Fn. Germ. H. 43. t. 21.

- Olivier Ent. P. n. 6. pl. I. f. 7.

Staphyl. orbicul. Payk. Mon, St, n. 26.

Huc non est referendus $P$. orbiculatus Fubr. (Ent. Syst. $P_{\text {cad. n. }}$ 6.) qui cum $P_{\text {aed. }}$ fillformi (Lathrobium fracticont n. 5.) coriparatur.

7 P. argustatus niger; antennis, pedibusque fuscis; coleop. trio apice testaceis. 
Habitu P. práecedentis; statura autem graciliore, defectu lineae longitudinalis thoracis \&c. differt. .

Longitudo $: \frac{\pi}{2}-2$ lin.

Caput magnum, śubquadratum, angulis obtusis, thorace

- longius et latius, opacum, confertissime punctum. Ore producto. Antennis capite longioribus; articulis, primo longiore, secundo et tertio brevioribus, clavatis, sequentibus suborbiculatis, ultino ovato, mediis crassiore. .

Thorax globosus, suborbiculatus, opacus, confertissime punctus.

Coleoptra subrectangula, convexiuscula, thorace longio. ra et latiora, subnicida, confertim puncta, nigra; margine apicis, vel apice et sutura ultra medium, testaceis.

Caetera ut in P. praecedente."

Habitat etian cum illo, rarior autem.

$P$. angaustains Payk. Fn. Suec. P. n. 7. var. $\propto$.

Staph. engustatus Fabr. Ent. S. St. n. 4 h.

- Payk. Mon. St. 11. 27.

- Panzer Fn. Germ. H. I1. t. 


\section{Genus IV.}

\section{C a 11 i c e r us.}

Palpi anteriores triarticulati.

A n t e n n a e articulo ultimo longo cylindrico:

Cospus gracile, filiforme; depile.

Caput orbiculatum, thoracis circiter magnitudine, subriti= dum, subtilissime punctum. Antennis extrorsum paulo crassioribus; articulis, primo validiore; secundo et tertio brevioribis, clavatis; quarto ad nortum suborbicula. tis; decimo longiore, cylindrico vel elongato = campanulato; undecimo longissimo, longitudine fere tertiae partis totius antennae, cyliiidrico, apice rotindato. Mandibulis exsertis, validis; apice incurvis acutis, inargine interiore denticulatis. Palpis ariterioribus triarticulatis, articulo ultimo clavato, cateris crassiore; posterioribus acuminiatis.

Thorax suborbiculatus, coleoptroritm latitudines ora late. rali deflexa.

Coleoptra subquadinta, thorace longiora. 
Abdonnen crassum, obtusum, marginatun. $\boldsymbol{P}_{\text {edes omnino generis sequentis. }}$

C. abscurus, niger, nitidulus; antennis, ore, pedibusque rufo-testaceis; coleoptris fuscis, margine pallidis.

Longitudo I lin.

Caput; antennis, capite thoraceque multo longioribur, rufis, basi obscurioribus.

Thorax suborbiculatus vel subquadratus angulis obtusis, basin versus paulo angustior.

Elytra fusca; humeris et sutura, imprimis apicem vessus, pallidioribus.

Habitat in quisquiliis sub lapidibus, rarissimus; semel vantum captus Brunsuigaein horto aulico. 


\section{Genus V.}

\section{A 1 e o chara.}

P a lpi acuminati.

$T$ ibia e graciles, nudae.

Corpus elongatum, crassiusculum.

Cavut suborbiculatum. Antennis extrorsum plerumque crassioribus; articulis, primo longiore, secundo et tertio brevioribus, clavatis, sequentibus brevibus, ultino ovato. Ablomes marginatum, dorso planiusculo, ventre conveso. Pedes cursorii, graciles, nudi. Capitibus femorum anticis approximatis, femore crassioribus, ejus cutem longitudine; mediis subremotis, femore vix brevioribus, ejusque crassitie; posticis approximatis, brevibus, absconditis. Tibiis tarsisque gracilibus.

Fanilia I. Coleoptris quadratis, thorace latioribus; thorace convexo.

Familia II. Colcoptris quaniratis vel longioribus, thoracis circirer latimdine; thorace convexo, 
Familia III. Coleoptris transversis, thoracis latitudine; thorace convexo.

Familia IV. Coleoptris transversis, thorace latioribus; thorace convexo.

Familia V. Thorace deplanato.

\section{Fam. I.}

Caput globosum, thoracis magnitudine, vel paulo minus. Antennis, articulis mediis subtransversis.

Thorax orbiculatus vel globosus.

Coleoptra, thorace latiora, quadrata.

I Al. canaliculata, rufo-fusca; capite, abdominisque segmento antepenultimo, nigris; thorace canaliculato.

Hcbitu Al, sequentis; statura autem majore, thorace longiore. Ab Al. foveolata (11. 3.), thorace ovato oblongo, capitis latitudine, differt.

Longitudo $2-2 \frac{\pi}{3}$ lin.

Corpus subfiliforme, nitidulum.

Caput subtilissime punctum, thoracis latitudine. Antennis, capitis thoracisque longitudine; articulo ultimo oblongo, ovato, acutiusculo, valido; basi testaceis.

Thorax oblongo-ovatus, crassus, subtilissime punctus, capite longior; disco late fovcolato, fovea canaliculata; interdum basin versis paulo angustatus.

Coleoptra subquadrata, subtransversa; thoracis longitudine, puncta, opaca.

Abdomen longum, obtusum s sitidum, dorso pilis brevibus rigidiusculis subsparsis tectum, rufo-fuscum; segmen- 


\section{Aleochara. F.I.}

tis penultimo et antepenultimo, vel penultimo solo, obscu. rioribus vel nigricantibus.

Pedes testacei.

Habitat sub lapidibus, in quisquiliis et inter segetes, haud rara.

Staph. canaliculatus Fabr. Ent. S. St. n. 42.

- Payk. Mon. St. et Fn. Suec. St. 11, 23.

- Panzer Fu. Germ. H. 27. t. Is.

- Olivier Ent. St. n. 25. pl. III. f. 31.

Paederus impressus Rossi Fn. Etr. n. 627.

2 A1. linearis, nigro-fusca; antennarum basi pedibusque te. staceis; thorace subfoveolato.

Habitu Al. praecedentis; statura autem minore, thorace breviore.

Caput thorace angustius, confertissine et subtiliter pun. ctum, ocscure fuscum, opacum; palpis, antennarumque: basi testaceis yel rufis; fionte planiuscula.

Thorax suborbiculatus, longitudine latitudinem vix ex. cedente, opacus, confertim punctus, disco deplanato vel foveolato; fovea lata, haud canaliculata.

Coleoptra thorace paulo longiora, confertissime puncta, nitidula,

Abdonien nigrum, nitidulum; ano rufescente.

$P$ edes rufo-testacei.

Habitat sub arborum demortuarum cortice.

Al. linearis - Mus. Prof. Knoch.

3 Al. linb at a, nitida, fusca; antennarum basi, elytrorur humeris, abdominis basi, pedibusque rufis; thorace foveolato. 
Habitu AI. sequentis; thoracis autem foveola longitudinali latiore. Ab Al. canaliculata (n. r.) thorace brevi, sub. globoso \&c. satis differt.

Longiturio $2 \mathrm{~lm}$.

Cerpus crassum, subuitiadun.

$C a_{p}$ ut. orbiculatum, sloboum, thorace angustius, ree tractum, laeve, obscure fuscum; oculis nigris; antennis fuscis, $b$ si palpisque rufis.

Th:rax, latitudine longitudinem paulo excedente, sub. globosus, apice truncatus, latcribus et bası rotundatus, co. leoptrorum lititudine, laevis, fuscus, marginibus lateralibus pall dior,bus, dorso fovea longitudinali lata impressus,

Coleoptra subtransversa, convexiuscula, laevia, nitida, rufa - fusca; humeris elytiorum pallidioribus.

Ablomen rufum, ntiùm; medo, segmentis tribus vel quatuor, fuscum seu nigricans.

Habilat - Mus. Prof. Heiln ig.

Staph. limbatus Payk, Mon. St. 11, 54.

- Pryk. F!s. Sues. St. n. 4 I.

Dom. Paykull, in Fin. Suec. ciravit St. flavescentenz Fabr, interrogative quidem, sed, uti mihi videtur, minus apte; Fabricius enim hune St. ratione staturae, cum St. fulvipedts marginato \&c. comparavit.

Quamquam haee Al., proportione thoracis et coleoptro: rum, a reliquis kujus familiae Aleocharịs decedere videtur, habitu attanen toto eis affinis est,

4 Al, lucida, obscure rufa, nitida; capite, elytrorum angulo apicis extcriore, pectore, abdominisque apice vigricantibus: thorace, ad bașin, fovecolato. 
Habitu Al. sequentis; statura autem crassiore.

Longitudo $1 \frac{2}{3}-2 \frac{\pi}{4}$ lin.

Curpus crassum, teretiusculum, nitidum, subtilissimo punctum.

Caput globosum, obscurum, nigricans, nitidum; oculis nigris; antennarum basi palpisque rufis; illis capitis thoracisque longitudine, articuliz, tertio paulo longiore quam se. cundus, quarto suborbiculato, sequentibus transversis lati. tudine crescente, ultimo ovato.

Thorax capite major, orbiculatus, subglobosus; apice angustior, angulis deflexis; basi latus; foveola transversa, ante basis marginem, impressus; rufescens seu fuscus, basis margine pallidiore.

Ccleoptra subplaniuscula, subquadrata, latitudine longitudinem paululum excedente, thorace longiora et latiora'; rufa vel fuscescentia, angulis apicis exterioribus fuscis vel nigris.

Abdomen rufescens, segmentis penultimo et antepenultimo nigris.

$P$ edes testacei.

Al. lucida - Mus. Prof. Knock.

5 Al. prolixa, nitida, infra rufescens, supra nigricans; antennis fuscis; elytris, ano, pedibusque rufis.

Habitu Al. praecedentis; statura autem paulo graciliore.

Longitudo $1 \frac{3}{4}$ lin.

Caput nigrum; anteunis palpisque fuscis.

Thorax obscure rufescens.

Coleoptra quadrata, rufa, basi nigricante. Abclomen nigricans; ano rufo. 
Pedés rufo - testacei.

Al. prolixa - Mus. Prof, Knnoch.

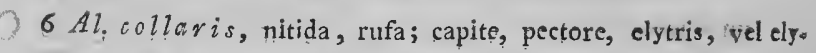
trorum angulo apicis exteriore, anoque nigris; thorace, ad bașisi, foycolato,

Hobsitu omuino Al, lucidae (11. 4.) statura autem minore,

Caput nigrum; antennis fuscis, apice rufis, articulo ultimo paulo validıre quan in Alẹocharis çonfinibus; palpis rufis:

Thorax, quibusdam speciminibus, longitudine paulo latior, subpubescens.

Colecptra subtransversa, convexiuscula, subpubescentia, nigricantia, vel rufa angulis apicis exterioribus obscuriorị 'büs.

Abdomen rufun; apice nigrum; ano rufescente.

Habitat in boletis, tempore aestive, haud frequens.

Staph. cellaris Payk. Fn. Suec, St. n. 43.

= Olivier Ent. St. n. 54. pl. II. f. I3.

? Al. $i \operatorname{mpressa}$, nitida; thorace, punctis duobus majoribus, sulcisque tribus longgitudinalibus abbreviatis, impresso, rụfescente:

Longituda $\mathrm{r}$ lin,

Corpus çrassiusculum, nitịdum:

Caput globosum, thorace paulo majụs, nitidissimum, laeyissimum, collo tenpissimo çun țhorace çohaerens, nigrum seu obscure fuscun; ; palpis antennisque rüfescentibus; his, basi pallidioribus, sapitis thoracisque longitudi: ne, articulis, secundo et tertio brevibus clavatis, quarto 
suborbiculato, sequentibus transyersị latitudine crescente, ultimo orbiculato acuto.

Thorax globosus, apice rotundatus angustior, basi truncatus latior, nitidissinus; rufescens, seu rufo-fuscus ma:gine basis pallidiore; sulcis tribus, mediis, longitudinalibus, abbreviatis, una ad apicem, duabus ad basin, punctisque duobus magnis ad basin, impressus.

Colecptra latitudine-paulo longiora; convexa, thorace longiora et multo latiora, glaberrikna, nitidissima, fusca, sulculis quatuor brevissimis lougitudinalibus ad basin impressa,

Abdomen obtusum, nitidum, rufunl, apice, segmentis tribus vel quatuor, nigrum,

$P_{\text {edes graciles, rufo - testacei. }}$

Habitat frequeıs in boletis et agaricis,

Staph, impressus Olivier Eut, St, 11, 28, pl. v. f. 4 r.

mintilia

SAl. vivularis, thoraçe, punctis duobus majoribus, sulcisque tribus abbreviatis longitudinalibus, impresso; nigerrima, nitidissima, pedibus antennisque rufescentibus,

Habitu toto, partiumque proporțione et sculptura, om= nịno Al. praecedentis; ștatura aụtẹn multo minore.

Longitudo $\frac{5}{6}$ lin:

Habitat in sylvis, in fimo bovino, rarior; sub cortice ạrboris demortuae semel tautummodo capta,

Al. rivulayis - Mus, Prof, Knoch.

9 Al, sulcata, thorace, foyea media longitudinali impresso; fusca, pedibus rufis. 


\section{Aleochara. F.I.}

Habitu Al. praecedentium; thorace autem cordato, uni. sulcato.

Longitudo $\mathrm{x}-1 \frac{\mathrm{T}}{3}$ lin.

Corpus glabrum, nitidum.

Caput globosum, thoracis magnitudine, fovea transver sali inter antennas impressum, nigro-fuscum; palpis antenaisque rufo-testaceis; his basi pallidioribus.

Thorax globosus, cordatus; apice rotundatus latus, bas? subtruncatus angustus; coleoptris angustior et brevior; sulea media longitudinali, profunda, lata, impressus; nigricans, vel fuscescens, margine basis pallidiore; rarius colo. re fugaci griseo sericans.

Coleoptra longitudine vix latiora, convexiuscula, nitidis. sima, glaberrima, fusca vel rufo-fusca, basi foveolis, dua bus, saepius obsoletis, impressa,

Ablomen fuscum vel nigricaus.

Habitat Brunsuigas

Slaph. sulcatus Olivier Ent. St. n. 2\% • pl. VI. f. 52.

- Payk. Mon. St. et Fn, Suec. St. n, 24.

co Al. obscura, nitida, nigro-fusca, subsericans; antennic, elytris, pedibusque rufescentibus; thorace subunifoveolato.

Habitu Al. praecedentis; capite autem minore, thoracis fovea subtiliore, nitore sericante, differt.

Longitudo I lin.

Caput globosum, orbiculatum, thoracis magnitudine; occipite paylulum depresso; nigricans, palpis antennisque rufescentibus; his capite thoraceque sublongioribus.

Thorax globosus, nitidissimus, cordatus; sulca media longitudinali, saepius obsoletiore, impressus. 


\section{Aleochara. F.I.}

Coleoptra glabra, quadrata, rufescentia, basi foveolis duabus impressa,

$P_{\text {edes testacei. }}$

Habitat, primo vere, locis apricis, sub lapidibus, inter quisquilias.

Paederus obscurus - Mus. Prof. Hellevig.

II Al. picea, nigra, nitidissima; pedibus, antennis, soleop. trorunn margine apicis pallide fuscis; thorace, puncto ante basis marginem, impresso.

Habitu Al. praecedentis; statura autem multo minore, thorace haud sulcato.

Longitudo $\frac{3}{4} \mathrm{lin}$.

Corpus subtilissime punctum, nitidum.

Caput globosum, thorace vix majus, laevissimum, nigrum; p.lpis antemisque fuscis; his capite thoraceque pauIo longioribus.

Thorax suborbiculatus, basin versus paululum angustior; puncto magno, interdum obsoletiore, ante basis mar. ginem, impressus.

$P$ edes fusco - tescacei.

Al. picea - Mus. Prof. Knock.

\section{Faterviva}

12 Al. nigra, nigra, nitidissima; antennis pedibusque fuscis; thorace unisulcato,

Habitu omnino Al. praecedentis; thorace autem paulo rotundiore, sulca media longitudinali impresso.

Longitudo $\frac{3}{4}$ lin.

Al. nigra - Mus. Prof. Knoch. 
13 Al. corticalis, nigra, nitida, laevis; colcoptrorum apice, pedibus, antennisque runis.

Longitudo $1 \frac{\mathrm{x}}{5}$ lin.

Corpus gracile, subfiliforme, nitidum, subtilissime punctum.

Caput orbiculatum, thorace vix minus, nigrum; palpis, antennisque rufis; his capitis thoracisque longitudine, extrorsum paulo erassioribus, articulo primo paululum validiore quam in affinibus Aleocharis; cacterum ut in Al. praecedentibus.

Thorax suborbiculatus, apice subangustior, coleoptris paulo brevior et angustior.

Coleoptra quadrata, convexiuscula, basi nigra, apice rufa.

Abdomen obtusum, sigrum; ano pallidiore.

$\boldsymbol{P}$ edes testaceo - fusci.

Habitat rarior sub cortice arborum demortuarum.

14 Al. an a 7 is, nigra, nitida; palpis, elytris, pedibus, anoque testaceis; thorace, puncto ante scutellum, impresso.

Habıtu gracili et filiformi Al, praecedentis; differt autem statura mị̂nore nẹc nou colore.

Longituto I lin.

Caput thorace paslo minus, nigrum; basi astennarum palpisque testaceis.

Thorax transyersus, rotundatus, coleoptrorum fere magnitudine,

Coleoptra subtransversa, piceo - vel fusco - testacea, basi nigricantia. 
Ablonen colcoptris plus quadruplo longius, nigrum; ano testaceo.

Habitat? Brunsuiga.

aledere

15 Al. Aethiops, nigerrima, nitida, griseo-subsericea; plantis antemisque fuscis.

Habitu Al. corticalis; corpore antem graciliore, nitidiore; capite minore; pedibus tentioribus \&c.

Longitudo $1 \frac{\mathrm{T}}{5}$ lin.

Corpus gracile, nitidissimun.

Caput orbiculatum, thorace vix minus, urigrum; palpis antennisque fuscis; his articulo ultimo ovato.

Thorax suborbiculatus, coleoptris paulo brevior et angustior, niger, subgriseo-sericetıs, foveola media, ad basin, impressus; subtilissime subpunctus.

Coleoptra quadrata, convexiuscula, subcilissime punctu, griseo - subsericantia,

Abdomen nigrum, nitidum, infra praesertim griseo - sericans.

$P$ edes tenues, longiores et graciliores quam in reliquis Aleoch.

Semel tantum capta in gramine prope Ildehausen, die $\mathrm{XX}$ Junii amno 1800.

\section{Fa m. II.}

Caput orbiculatum, thoracis latitudine, vel paulo angustitu.

Thorax coleoptrortim latitudine vel subangustior convexus.

Coleoptra quadrata, vel rectangula, thorace longione. 
16 Al. inquinula, picea; capite abdomineque nigris, nitidis; pedibus testaceis; antennis fuscis.

Longitudo vix $\frac{x}{2}$ lin.

Caput orbiculatum, nitidulum, thoracis latitudine, nigrum; antennis fuscis, capitis thoracisque longitudine; articulis, primo val diore, secundo et tertio brevioribus, cla. vatis; sequentibus latitudine crescentibus; ultimo ovato acuto.

Thorax opacus, piceus; foveola media, ante marginem basis, impressus; transversus, rotundatus.

Culcoptra opaca, picea, quadrata.

Abdomen obtusum, depressiusculum.

$P$ edes testacei vel fuscescentes.

Variat colore obscuriore vel pallidiore.

Habitat in fimo bovino; rarior sub arborum demortua. rum cortice.

I7 Al. pusilla, nigra, nitidula; elytris, antennis pedibusque testaceis.

Habitu Al. sequentis; capite autem majore, antennis crassioribus, coleoptris longioribus - Ab Al. praecedente, statura graciliore, satis distincta est.

Longitudo $\frac{2}{3}$ lin.

Corpus gracile, filiforme, nitidulum.

Caput thoracis nagnitudine, nigrum, nitidulum; palpis; antennisque fuscescentibus; his, capitis thoracisque longitudine.

Thorax subtransversus; quibusdam obsolete longitudina: liter bi-sulcatus, latcribus rotundatus. 


\section{Aleochara. F. II.}

Coleoptra rectangula, thorace duplo fere longiora, depressiuscula, fusca vel piceo-testacea.

Abdomen obtusum, teretiusculum, nitidum, nigerrimum•

$P$ edes testacei vel fuscescentes.

Al. pusilla - Mus, Prof. Knock.

wheriar

18 Al. elongatula, filiformis, tenuis, opaca, nigricans; an. tennis, elytris, pedıbusque pallıdioribus.

Habitu gracil Al. praecedentis; statura autem et anten nis longioribus, capite coleoptrisque minoribus.

Longitndo 1 - $1 \frac{\mathrm{T}}{3} \mathrm{lin}$.

Caput thorace paulo angustius, subnitidum, nigrum; palpis rufis; antemnis fuscis, capite thoraceque duplo fere longioribus, extrorsum subcrassioribus, articulo ultimo ovato acuto.

Thorax orbiculatus, depressiusculus, nigro-fuscus.

Coleoptra quadrata, thorace paulo longiora, nitidula, ssbtilissime puncta, pallida; vel obscure fusca, vel picea, vel piceo - testacea.

Abdomen elongatum, obtusum, fusco - nigrum, marginibus segmentorum pallidioribus.

Pedes testacei.

Habitat Brunsuigat, semel tantumnodo capta in gramine prati uliginosi.

19 Al.teres, gracilis, nitidissima, nigerrima; elytris picescen. tibus; pedibus testaceis.

Habitu gracili Al. pracedentium; ab Al. pusilla (n. 17\%) statura majore, coleoptris quadratis; ab Al. elongatuia (n. 18.), nitore splendidiore, sapite majore \&c. differt. 
Longitudo I lin.

Caput thoracis magnitudines antennis, capitis thoracisque longitudiue.

Thorax orbiculatus, coleoptris paulo angustior.

Coleoptra quadrata.

Abdonten gracillimun, colcoptris quadruplo longius, nitidissimum, nigerrimum.

Al. teres - Mus. Prof. Knoch.

$20 \mathrm{Al}$. longiuscula, gracilis, nigra, nitidissima ; pedibus fusa ris; elytris nigro - fuscescentibus.

Habitu Al. precedentis; statura autem majore, capite minore, abdomine breviore et latiore.

Longitudo $1 \frac{\mathrm{T}}{2}-\mathrm{I}_{3}^{2}$ lin.

Coput, thorace paulo angustius, nigrum; antennis nigricantibus vel fuscescentibus, capitis thoracisque longitudine, vel paulo longioribus.

Therax stiborbiculatus, convexiusculus, coleoptris angustior.

Coleoptra quadrata, piceo-nigricantia vel fuscescentia.

Abdomen obtusum; coleoptris triplo longius; nitidissi1มum.

Al. longiuscula - Mus. Prof. Knoch.

21 Al. bolet $i$ nigricans, nitidula; autennis; elytris, pedibusque plerumque pallidioribus.

Habitu, Al. praecedentibus crassior.

Inter omnes hujus generis species hace sane maxime va: riat, ratione tum magnitudinis, tum formae, proportionis ef coloris partium singularium. Longitudo antennarum, 


\section{Aleochara. F. II.}

forma thoracis, color elytrorum antennarum et pedum, inconstantissimi sunt.

I. Al. nigra nitidula; pedibus elytrisque testaceis; his, circa scutellum et angulo apicis exteriore, obscurioribus.

Var. I, thorace orbiculato; antennis capite thoraccque longioribus, gracilibus; longitudine $1 \frac{\mathrm{T}}{4}-2 \mathrm{lin}$.

$V$. $a$. antennis palpisque nigris.

$V$. b. palpis antennarumque basi testaceo - rufis.

Var. 2, thorace suborbiculato, longitudine vix latiore; antennis capitis thoracisque longituidine; longitudine $1 \frac{\mathrm{T}}{4}$ lin.

$V$ ar. 3 , thorace transverso; antennis, capitis thoracis. que longitudine; longitudine $1-1 \frac{i}{4}$ lin.

$V$. $a$. antennis palpisque fuscis.

$V . b$. palpis, antennarumque basi rufo-testaceis.

$V$ ar. 4, thorace subtransverso; antennis capite thoraceque brevioribus; longitudine $1 \frac{\pi}{4}-1 \frac{\pi}{2}$ lin. - rarior.

II. Al. nigra, niridula; elytris fuscescentibus; pedibus pallidis; thorace transverso.

$V$ ar. 1 , antennis, capite thoraceque longioribus, gracilibus; longitudine $\frac{3}{4}-1 \frac{t}{2} \mathrm{lin}$.

t. a. elytris fuscis; pedibus testaceis.

V. b. elytris pedibusque fuscis.

$V$. c. elytris fuscis, humero pallidiore.

$V$. d. elytris fuscis; circa scutellum et angulo apicis exteriore, nigricantibus.

$\operatorname{Var} .2$, anternis, capitis thoracisque longitudine; longituidine $\frac{2}{3}-1 \frac{T}{3}$ lin.

$\dot{V} . a, b$, e et $d$ ut in $\dot{V} a \dot{r}$. praecedente.

li: $\rho$, elytris nigricantibus, pedibus obscire fuscis. 
V ar. 3, antennis, capite thoraceque brevioribus; elytris fuscis; pedibus rufis; longitudine $\mathbf{I}$ lin. - rarissime occurrit.

Quamquam autem hae Aleocharae satis inter se discrepare videntur, nihilominus persuadeo mihi, omnes unius ejusdemque speciei varietates esse. Copiam satis magnam speciminum collegi, quibus transitus a varietate ad varietatem, a maximis ad minimas, a pallidis ad obscuras \&c. satis clare ostenditur. Figura thoracis orbiculati sensim in figuram thoracis suborbiculati et transversi dilatatur; antennae longissimae graciles sensim in antenuas brevissimas crassiores contrahuntur; elytra et pedes testacei plus plusque cum nigredine miscentur, et tandem prorsum nigricantes apparent - Notatu autem dignissinum est, quod magnitudo corporis formae etian thoracis et colori elytrorum pedumque respondeat, qui sensim cum illa unutautur: Individuis maximis sunt thorax orbiculatus, antennac longac, coleoptra pedes palpi et antennarum basis testacei; minoribus antennac breviores et palpi fuscescentes, colcoptra obscuriora, thorax suborbiculatus; minimis, thorax transversus, palpi antennae et pedes obscturiores, elytra nigricantia. Sunt autem, uti supra jam monui, specinnina, quibus onnes hae varietares arcte nectuntur.

Quae auten ommibus communia sunt paucis proferam.

Corpus subnitidum, subtilissime punctum; statura minus gracili quam in praecedentibus hujus familiae Aleocharis.

Caput orbiculatum, thorace paulo angustius, nigrum; antennis plerunuque pallidioribus.

Thorax coleoptris vix angustior, lateribus rotundatus, niger. 
Coleoptra quadrata, thorace paulo longiora.

Abuonen obtusum, ngrum.

Victitant gregatim in boletis et agaricis, frequentes per totum annun. Aliae vero habitant etiam alıbi, semper au= teth rariores et singulae, et forsan defectu tantum boletbrutn et agaricorum: - In succo putrido sub cortice quercus, var. I, I. - In fino ovino, var. II, 2, b; semel tantum capta. - In cadavere talpae, var. II, 2, a, specimina quaedam.

Staph. Boleti Linn. Fn. 11. 859 .

- Schrank Austr. n. 453.

- De Geer Mem. St. n. is.

- Scopoli Carn. n. 305.

- Staph. socialis Payk. Fn. Suec. St. n. §t.

- Olivier Ent. 8t. 11. 53. pl. III. f. 25.

Staph. Boleti Linn. et Schrank ad var. I; 1, b; 3, b. II ; 1, a; 2, a refercndi sunt. - St. Bolefi De Geer et Scopoli ad var. II; 1, a; 2, a. - St. socialis Psyk, et Olivier ad var. I; $1, b ; 3, b$.

Huc auten non referendus est St. Boteti Payk. (Mori. St. n. 44 et Fn. Suec. St. n. 62.), qui potius Tachinus esse videtur, cum cel. auctor cum, (Fin. Suec. n. 62.) inter Staph: lunulatum et melanocephalun ponat, qui ambo Tachini sunt. Dicit etiam „St. Boutti differt a St. sociali elytrorum conve"xitate، “

22. Al. at errima, nigra, nitidula; pedibus arteninisque fuscesccrtibus; his dimidii corporis longitudine.

Habilu, Ml. praecedentis varietati minori obscturae similis; statura autem erassiore, antemis multo longioribus.

$$
\text { F } 8
$$




\section{Longitudo $\frac{3}{4}$ lin.}

Al. aterrima Mus. Prof. Knoch.

2) Al. tenuis, nigra, nitidula; antennis fuscis; elytris rufis, humero nigro; pedibus pallidioribus; thorace quadrato.

Longitudo 1 lin.

Corpus filiforme, gracile, nitidulum.

Caput subquadratum, angulis obtusis; thoracis magnitudine, nigrum; antennis fuscis, basi palpisque pallidioribus; oculis parvis prosilicutibus.

Thorax quadratus; angulis obtusis, convexiusculus, coleoptris angustior et paulo brevior, laevis, niger.

Coleoptra subquadrata, nitidula, planiuscula, laevia, rufa, humeris nigris.

Abdomen obtusum, coleoptris quadruplo longius.

$P$ edes testacei scu rufi.

Al. tenatis - Mus. Prof. Hellwig.

\section{Thavifuitis}

24 Al. nigricollis, rufo-fusca; elytris pedibusque pallidioribus; capite thoraceque scabriculis, nigris.

Longitudo 2 lin.

Corpus gracile, filiformé.

Crppt orbiculatim, thorace angustius, opacum, scabrum seu confertissime punctun; punctis crassioribus; nigricans; palpis, antennisque rufescentibus; his dimidia totius corporis longitudine, extrorsum crassioribus.

Thorax suborbiculatus, convexus scaber, vel colfertissime punctus: punctis crassis; coleoptris paulo angustior et brevior, opacus niger. 
Coleoptra quadrata, convexa, confertissime puncta, nitidula.

Abdomen crassum, obtusum, coleoptris quadruplo longius, nitidissimum, fusco-rufum.

$\boldsymbol{P}$ edes testacei.

Habitat - Mus. Prof. Hellwig.

Staph. nigricollis Poyk. Fur. Suec. St. n. 42.

25 Al. nigritula, nitida, nigricans; elytris fuscescentibus; antennis pedibusque testaceis.

Habitu, Al. Boltti (n. 21.) gracilior; nitore etiam, capite majore, thorace angustiore $\& c$; ab illa differt.

Longitudo $\frac{4}{5}$ lin.

Ceput orbiculatun, thorace vix angustits, nigrum; palpis antennisque testaceis seu dilucide ochraceis; his, capitis thoracisque longitudine, extrorsum valde crassioribus, articulis quarto ad decimum transversis, latitudine crescentibus, ultimo, illis longiore, ovato, obtusiusculo.

Thorax orbiculatus, coleoptris paulo angustior et brevior, niger.

Coleoptra quadrata, nitida, subtilissime puncta, castaneo - fusca; marginibus suturaque subobscurioribus.

Abdonen obtusum, nitidulum, coleoptris plus duplo longius.

Pedes ochracei.

Habitat in fimo, praesertim ovillo et hominum.

26 Al. alternans, nitidula, rufo - testacea; capite, thoracis disco, angulis coleoptrorum apicis exterioribus, seguentisque perultimis, obscurioribus. 
Habitu gracili.

Longitinio I $-\mathrm{I} \frac{\mathrm{T}}{3}$ lin.

Caput orbiculatum, thorace angustius, subtilissime subpunctun, nigro-fușcun; antenniş ochraceis, capitiş tho. racisque longituline; palpis testaceis.

Thax suborbiculatus, apice vix paulo angustior, sub. tilissime punctus, fusco-testaceus; disco obscuro,

Scuttllum obscurum.

Coitoptra quadrata, thorace longiora et paulo latiora, confertisinine puncta, rufo-testacea; circa siutellum, sutusa, et angulis aprcis vel apice tota, fuscis vel nigris.

Abionven obtustum, coleoptris duplo longius, rufum; segmentis penultimo et antepenultimo nigris, vel fuscis.

Prútes tesfacei,

Habitat gregatim in boletis, per totum annum frequens, Rarius capia in fimo humano; rarissime ịn cadavere aỵis, Al. alternans - Mus, Prof̣. Knoch.

\section{Therat}

27. Al. pygmaea, nigriçans, nitida; elytris testaceis, basi ni* gricantibus; pedibus testaceis.

Habitu 31. duarum sequentium, Differt antem ab Al. ob. fuscesta nitore splendidiore, antcunis longioribus, thorace paulo lațore; $\mathrm{ab}$ Al. longicormi, antennis gracilioribus, tho: race paulo latiore, elytrịs minime nițidis, nec punctis.

Longitudo 1 lin:

Corpus breve, crassiusculum:

Coput thorace angustius, subretractum, nitiaum, nigrum; anten!nis capite thoraceque longioribus, gracilibus, fuscis, basi pallidarore; articulis, unediis çampanulatis, ultimo ovato obțisso, 


\section{Aleochara. F.II.}

Thorax transversus, rotundatus, coleoptris vix angustior, nitidus, rufo-nigricans.

Coleoptra quadrata, minus nitida, laevia, testacea; basi nigricante subsericea.

Abdomen nigricans, griseo-subsericeum; ano rufescente. Al. pugnala - Mus, Prof, Knoch.

3. 7 in, $2 \%$.

28 Al. obfuscata, nigricans, subopaca; thorafe elytrisque pallidioribus; antennis pedibusque rufescentibus.

Hcbitu Al. praecedentis; multis autem differt.

Longitudo $\frac{3}{4}-1$ lin.

Cofpus breve, crassum, subrilissime punctum, nitidulum.

Caput, thorace angustus, nigrum; antennis fusciă; palpis pallidioribus; illis capitis thoracisque longitudne, extrorsun crassioribus.

Therax rotundatus, subtransversus, apicem rersus paulo angustatus, angulis anticis defiexis; convexior quam in Al. affunibus, obscure fuscus, marginibus lateralibus plerumque pallidioribus; coleoptrorum latitudine.

Coleoptra quadrata, pallidiora, seu fusco-picea.

Abdomen nigricans, subobtusum, coleoptris vix triplo longius.

Pedes testacei,

Habitat in fino ovillo et humano, haud frę̧uens,

29 Al. Iongicornis, nigra, nitida; elytris piceis; pedibus pallide tzstaceis; antennis longis.

Habitu Al. pygrazare (11. 27.); corpore autem toko nitido, puncto, pilosello, satis distincta est - Ab At. praecedente ommino differt. 
Longitudo I lin.

Curpus breve, crassum, nitidum, punctum; punctis di: stinctior sus quam in Al. affinibus; pilosellum; pilis rigidis,

Caput thorace angustius, nigrum; antennis fuscis, capite thoraceque ảuplo fere longioribus.

Thorcx rotundatus, subtransversus, apicem versus vir paululum angustatus, coleoptris subangustior, nitidulus, nigro - piceus.

Coleoptra quadrata, picea, circa scutellum obscuriora; nitida.

Abdomen breve, obtusum, nigro - fuscum, setosum.

Habitat in aridis, in fimo ovillo; semel tantummodo capta die XIX Junii; anno 1800.

30 Al. cinnamomea, nitida, cinuamomea; fapite abdomines que obscurioribus;

Habitu Al. Boleti (11.21.) Var. I, 3; thorace autem trans: verso, latiore et convexiore, colore \&c. distinctą:

Longitudo $1 \frac{\mathrm{r}}{4}-2 \frac{\mathrm{r}}{4}$ lin.

Corpus nițidulum, subtilissime confertissimeque punctum:

Caput thorace angustius, retractum, nitidulum, nigriçans seu nigro - fuscum, oculis nigerrimis majoribus; palpis fufis; antennis, capitis thoracisque longitudine, vel fusces: centibus basi pallidiore, vel rufis.

Thorax convexus, transyersus, lateribus rotundatus, coleoptrịs vix anguststior, suḷca interdun media longitudị: nnali obsoleta impressus, rufo - vel nigro - fuscescens.

Colecptra subtransversa.

Abdomen obtusum, nitidun, nigro- fụscum. Pedes pallidi: 


\section{Aleochara, F. II,}

Variat colore thoracis, elytrorum \&c.

Var. I, major; elytris thoraceque rufo - fuscis; pedibus, antennarumque primo articulo ochraceis.

Var. 2, minor; antennis echraceis; coleoptris piceotestareis, angulis apicis nigricantibus ut in v. 1 ; pedibus testaceis.

$V a r .3$, minor; antennis ochraceis; coleoptris piceotestaceis; pedibus, antemarumque axtıculo primo testaceis.

Habitat ull suçco putrido sub aṛborum cortice.

31 Al.opaca, nigricans, opaca, subgriseo-sericea; elytris, pedibusque pallidis.

Hobitu quibusdam Al. familiae sequentis, e. g. Al. fuma. tae (n. 4.2.) similis; colcoptris auten quadratis.

Longitudo $2-2 \frac{\pi}{2}$ lin.

Corpus crassum, subtilissime punctum; supra infraque, imprimis yero pectore et yentre, tomento tenui griseo-sericante tectum,

Caput thorace minus, retractum, migro-fuscum; antennis basi pallidis, capitis thoracisque longitudine.

Thorax convexior quam in reliquis hujus familiae Aleocharis, apicem versus paululum angustatus.

Abdomen apicem versus subangustatum, ṇigricans; mạ:ginibus segmentorun pallidioribus,

Variat colore:

Var. $x$, major; coleoptris fusco-testaceis, angulis infe: rioribus suturaque circa scutellum obscurioribus; pedibus țestaceis.

Var. 2, minor; coleoptris obscure fuscis, apice rufes: çente; pedibus antennisque ochraceis. 
Var. 3 , minor; thorace, lateribus pallidioribus; caetera ut in var. 1 .

Habitat Brunsuigae - Unicum specinen var, I captum in flore Echii vulgaris,

32 Al. umbrata, opaca, nigra, subsericans; elytris pallidioribus; pedibus testaceis.

Habilu omuino Al. praecedentis; slatura autem multo minore semper distmeta.

Longitudo I lin.

Variat elytris pallide fuscescentibus, seu nigricantibus apice pallide fuscescente.

Habitat Brunsuigae

33 Al. humeralis, nitidula, obsçure fusca; pedibus, antenua. rum basi, elytrorumque huneris, qchraceis.

Longitudo 3 lin.

Caput thorace angustius, nigricaus; anteunis fuscis, articulo primo palpisque ochraceis,

Thorax subrotundatus, subtransversus, coleoptris paulo angustior, planiusculus, nigricans; foveis quatuor obsoletis, una scilicet longitudinali media, altera minima media ad basiu, tertia et quarta lateralibus, impressus.

Coleoptra quadrata, depressiuscula, nigricantia, macula elytrorum humerali ochracea.

Abionen coleoptris plus duplo longius, obtustm, fus. cunn, apice nigricante.

A1. humeralis - Muã Prof. Knoch. 


\section{F a m. III,}

Caput parvun, orbiculatum, retractum, thorace multo misus.

Thorax transversus, coleoptrorum longitudine et latitudine, convexus, apice plerumque angustior,

Coleoptra transversa,

34 Al. ruficornis, nitida, fusca; antemis, thoracis lateribus, çoleoptris, pedibusque rufo-testaceis,

Longitulo $2 \frac{2}{3}$ lin.

Coryus totum, imprimis capite thorace coleoptrisque, pilis brevibus fulvo - subsericeis tectum; subtilissime punctum; minus coactum et convexum quam in specicbus sequentibus.

Caput atrum; antennis, captis thoracisque longitudine, extrorsum crassioribus, palpisque ochraceis.

Thorax subrotundatus, convexiusculus.

Ablomen nigro-fuscum, segmentorum marginibus palli: dioribus, obtusum, coleoptris triplo longius.

Pedes testacei.

Habitat in agaricis, rarissima, semel modo capta. trmuer.as:

35 Al. strumosa rufo-fusca; thorace, marginibus elevatis.

Hobitu omnino Aleocharae hujus faniliae; statura autem corporis et figura thoracis a cospeciebus valde discedens.

Longitudo $3-4$ lin.

Corpus crassum ; coactum, latum, nitidulum,

Caput parvum, supra impressum, thorace multo angustins, subtilissime punctum, subopacum, fuscum; oculịs nigris; antennis, capite thoraceque longioribus, filiformini 
bus, moniliformibus; articulis, primo crassissimo, secundo brevissimo, sequentibus globosiș aequalibus, ultimo ovato acuto.

Thorax nitidus, punctus, fuscus; angulis apicis rotundatis, basis acutis; marginatus; margin bus apicis et basis sub. elevatis angustioribus, laterum adscendentibus latioribus; supra scutellum productus; disco convexiusculo, sulca media longitudinali obsoleta, impresso.

Coleoptra subgibbosa, thorace vix paulo longiora et latiora, nitidissima, impuncta, rufescentia, angulis acutis.

Ablonven crassum, latum, coleoptris triplo longius; seg. mento penultimo sinuato; marginibus lateralibus elevatis; nitidum, fuscum.

Pedes pallidi, validi; tibiis autem laevissimis, tarsis te: nuissimis.

Habitat Blankenburgŏ.

Al. strumosa - Mus. Prof. Hellwig.

Staph. strunosus Fabr. Enc. Syst. St. n. 28.

- enuarginatus Payk. Mon. St. 11. 56.

- Payk. lin. Succ. St. n. 44 ,

Species huc non referenda St. Strumosus $P$ ougk. (Fn. Suec. St. 11. 45.) , thorace antrorsum emarginato, longitudine vix "latiore" esse videtur - St, emarginatus. Olivier (Ent. St. n. 44 pl. II.-f. 12.) hae multo minor et idem est, quem $F a$ bricius (Ent. Sysc. St, 11. 46.) sub hoc nomine descripsit.

Bun whelere

36 Al. fuscipes, nigra, nitidula; disco elytrorum rufo - sanguineo; pedibus fuscis.

Habitu Al. sequentis; statura autem majore, thorace minus collvexo. 


\section{Aleochara. F. III.}

\section{Longitudo $2 \frac{\pi}{2}-3 \frac{\pi}{4}$ lin。}

Corpus coactum, crassum; confertissime subtiliterque punctum, tomento tenui brevi griseo-sericante tectum.

Coput atrum, palpis fuscis; antennis brevibus, validis, extrorsum multo crassioribus, capite longioribus; articulis, primo valido clavato, tertio et secundo brevioribus gracilioribus clavatis, quarto orbiculato, sequentibus transversis latitudine crescente, ultimo, medis longiore, obpyriformi.

Thorax transversus, convexus, apice angustior, angulis anticis deflexis, basis margine medio paululum producto.

Coleoptra vix longitudine thoracis.

Abdowen obtusum, crassum, coleoptris triplo longius.

Habitat in cadaveribus, boletis, et fimo humano, haud rara.

Staph. fuscipes Payk. Mon. St, n. 38 .

- Payk. Fn. Succ. St. n. 39.

- Rossi Fn. Etr. 11. 619?

Huc, uti credo, St. fusciptes Fubr. (Ent. Syst. St. n. 38.) non referendus est, cum sit „parvus, clytris pedibusque ,p piceis“ - Nec S\%: fusiipes Linn. cui sunt , thorax, ca„,put et maxillae ratione naguituainis insignes; magnitudo pediculice \&re. - St. juscipes Panzeri (Fn. Germ. H. 2\%. t. 12.) longe est diversa species, ad Twihinum quemdam referenda:

\section{At sicars lunein}

37 Al. bi puncteta, nigra, uitidula; pedibus ochraceis ; ely. tris macula apicis rufo-sanguinea; thorece gibboso.

Habitu A1. praecedentis et sequentis; differt anteu statura crassiore, thorace convexiore, colcoptris minus nitidis crassius punctis. 
Longitudo $\mathrm{I} \frac{\mathrm{T}}{2}-2 \frac{\mathrm{T}}{3} \mathrm{lin}$.

Corpus crasstun, confertim punctum, pilis brevissimis, supra rarioribis, infra crebrioribus, griseo - sericantibus, tectum; nitidurn.

Caput antennis ut in Al. praec.

Thorax, marginibus rotundatis, apicem versus angustior, lateribus deflexus, antice posticeque declinatus, nitidus, nigricans.

Coleoptra vix thoracis longitudine, brevissima; elytris quadratis, subritidis, punctis crassioribuis impressis; nigris, apice rufo-sanguinea; vel rufo - sanguineis, sutura marginibusque basis ct laterali nigris.

Abilonen vel obtusum vel apicem versus pattlo angusta. tแบ.

Pedes rufo-fusci vel rufo-testaces.

Habitat in fimo bovino, equino, ovillo, humano \&c. haud infrequens.

Staph. bipuntetatus Otiv. Ent. St. 11. 43. pl. V. f. 44.

038 Al. lanuginosa, nigra, nitida; summo colcoptrorum apicis margine pedibusque fusecsentibus; lanugine mollissima tenuissima tecta.

Habitu toto Al. praecedentium; difert autem ab Al. fuse eipede, statura minore; thorace converiore; ab Al. bipunctata thorace minus convexo, lateribus quidem deflexo, posfice vero haud declinato; statura minus coacta; $a b$ ommibus autem Aleocharis, lanugine, sen pilis tenuibus erectis, ntido oculo vix conspicuiș, quibus totuin corpus obsitunt est.

Lengitudo s $\frac{+}{2}-2$ lin. 


\section{Aleochara. F. III.}

Habitat in fimo equino et bovino, tempore vernali; haud frequenter occurrit.

39 Al. laevis, nigra, nitida, griseo-sericans; antennis pedibusque fuscis.

Habitu Al. vuficornis (n. 34.):

Longituclo $2 \frac{T}{2}$ lin.

Caput thorace duplo minus, nigrum, palpis antennisque fuscis; his capite thoraceque paulo longioribus, caeterum ut in Al. praeced.

Thorax coleoptris paulo angustior, puncto majore ante scutellum impressus.

Abdomen niģricans, segmentorum marginibus rufescertibus; tomento rufo-griseo - sericante, ventre imprimis, tectum.

Al. laevis - Mus. Prof. Knoih.

40 Al. Iugens, nigra, nitidula; elytris fuscescentibus; pedibus, palpis, anteunarumçue basi, fusco-ochraceis.

Habitu Al. praecedentis; statura autem paululun crassio. re, minore.

Longitudo $1 \frac{\mathrm{x}}{2}$ lir.

Corpus subsericeo-nitens.

Thorax coleoptrorim latitudiue.

Colropts thoracis longitudine, convexiuscula, uitida, laevissima, cmuino inipuncta, obscure fusca.

Ablonkn obtusum, coleoptris plus triplo longius, ssitidissimum, nigrum, scriceo-nitens.

Habitat - Mus. Prof. Hellucig. 
4I Al. moesta, nigra, nitida; antennis, pedibus, elytrisque fuscis vel obscure ochraceis.

Hubitu omnino $\mathrm{Al}$. sequentis; thorace autem angustiore et minus convexo; elytris crassius punctis.

Longitudo $1 \frac{\pi}{2}-2 \frac{r}{3}$ lin.

Habitat - Mus. Prof. Hellwig:

$42 \mathrm{Al}$. funiata; nigra, subnitida; abdomine nigro-fusco; antennis; elytris, pedibusque pallıdioribus.

Habilu Al. lanuginosae (11. 38.); thorace autem minus declinato, corpore monus nitido, elytris fuscis, lanae des fectu \&c. satis distincta est.

Lrigitudo $1 \frac{\dot{\mathrm{x}}}{2}-2$ lin:

Corpius crassum, nitidulim; subtilissime punctum; pilis brevibus griseo-subsericantibus, praccipue infra, tectun.

Variat colore elytrorum et antennarum:

$V$ ar. 1 ; major; clytris; antennarumque articulo primo pallide fuscis.

$V a r .2$, minor; elytris antennisque totis obscure fuscis.

Habitat in boletis, haud frequens. zin $7 x_{i}=s_{1}$

$43 A$. pulle; stbnitida, fusco = nigricans; elytris pallidioribus, pedibus testaceis.

Habitu Al. praecedentis; statura autem minore; abdo. mine graciliore; nitore caeciore; thorace paillo angustiore \&.c. differt.

Longitudo $\mathrm{r} \frac{\mathrm{t}}{3}$ lin:

Curants stibgriseo- sericans.

Captt thorace quadruplo minus; nigricans, opacimi: ainteninis capitis thoracisque longittione. 
Therax opacus, nigricans vel fuscescens, marginibus lateralibus interdum pallidioribus.

Coleoptra subtransversa, fusca, opaca, subtilissine punsta.

$P_{\ell}$ des ochracei,

Al. pulla - Mus. Prof. Knoch.

Stipee wales of

44 Al. nitida, nigerrina, nitidissima; elytris, macula apicali rufa; pedibus fuscescentibus.

Habitu Al. fuscipedis (n. ;6.) et similium; nitore autern splendidissimo, colore aterrimo, punctis crassioribus paucioribus distincta.

Longitudo $1-1_{4}^{3}$ lin.

Corpus crassum, punctum, nitidissimun, interdum pilis brev: bus tenuibus griseis sparsim tectum.

Elutra, nacula, anguli apicis interioris, majore ve! minore, orbiculari, circuitu distincto vel evanescente; rufa, rarius rufo-testacea, suturam attamen haud attingente.

$P$ edes obscure fusci seu ochracei.

Habitat in aridis, in fimo ovillo, haud frequens. Al. nitida - Mus. Prof. Knoch

45 Al. morion, nigra, opaca; pedibus antennisque nigro - fuscis.

Habitu crasso, gibboso, onnino Al bipunctatae (n. 37.); thorace ctiam lateribus deflexo, antice posticeque declinato; differt autem statura multo minore, coloße nigerrimo opaco - Colore toto nigro opaco ab omnibus Alcocharis distinctà est:

Innirititido I lins, 
Corpus crassum, opacum, pilis perpaucis sericantibus, interdum plané nullis, sparsim tectum, confertim punctum. Autennae obscure fuscae seu nigrae.

Habitat in fimo bovino, haud frequens; in fimo humano seinel tantummodo capta, die XXV. Maji, anno 1800.

46 Al. pumilio, nigra, opaca; elytris antennisque nigro-fuscis'; pedibus testaceis.

Habilu et punctura onınino Al. praccedentis; statura autem duplo minore; coleoptris, apice, ad suturam, profun: dius sinuatis.

Longitudo ${ }_{2}^{\frac{T}{2}}$ lin.

Habitat in aridis, in fimo ovillo, rarissima; semel tantummodo capta, die XXIX Junii, anno 1800.

\section{Fam. IV.}

Corpns nitidum, depressiusculum, breve.

Caput transversum; oçulis prominulis; antennis extrorsum valde crassioribus; articulis, primo validiore, secundo ef tertio brevioribus gracilioribus, clavatis, quarto suborbiculato, sequentibus transversis, latitudine crescente, u'timo ovato acuto.

Tharax transverstis; latiis; longitudine duplo fere latior; lateribus rotundatis; convexiusculus.

Coleoptra transversa, thorace latiora et duplo fere longiora, laevia.

Abdornen òbtusum.

\section{bos t wista}

(7) 47 . nana, nitida, testacea; thorace, angulis coleoptroruu apicis, segmentis penultimis, cbscurioribus; capite nigro. 


\section{Aleochara. F. IV.}

Longitudo $\frac{3}{4}-\mathrm{I}$ lin.

Caput thoracis fere latitudine; antennis, capite thoraceque longioribus; nigruns, antènis palpisque testaceis.

Thorcax punctis aliquot; duabus ante basin distinctioribus, impressus; nigricans sen fuscus; warginibus pallidioribus.

Speciminibus majoribus sunt thorax; ânguli apicis coleoptrorum, segmenta penultimum ef antepemkimtim, higri; tninoribus fusci.

Habitat gregatim in boletis et agaricissece .. : $\quad$. - Siaph. nanus Payk. Fn. Sicc. St. 11. 52.

Staph. melanurus Schrank in Füessly Ni Ml. II: P:324.

48 Al. polita, nigra, nitidas, antennis pedibusque testaceis.

Hobitu Al. praeceảenti simillima; statura autem minore; capite angustiore.

Longitudo $\frac{3}{4}$ lin.

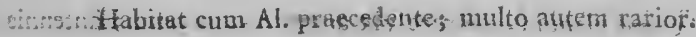

$$
\text { Fam. } V \text {. }
$$

Cerpus planiusculum, nitidum, laeve, subpunctuis. i?

Caput orbiculatum, thorace paulo angustius; anteninis extrorsum crassioribus; articulis, primo validiore longiore, secundo et tertio brevioribus gracilionibus, clavatis, quarto et quinto suborbiculatis, sequentibus transversis, latitudine crescente, ultimo ovato acutiusç̧ulo i

Thorax transversus, colcoptris brevior et paulo angustior, disco plano:

Coleoptra quadrata. 
49 Al. depressa, nitidula, pallide fusca; capite abdomineque abscurioribųs.

Longitudo $\mathrm{I} \frac{\mathrm{T}}{3}-2 \frac{\mathrm{r}}{\mathrm{T}} \mathrm{lin}$.

Caput suborbiculatum; nigrum; antennis, capitis thora. cisque longitudine, fuscis; ore, antennarumque articulo primo testaceis.

Thorax, lateribus rotundatis, rufescens, maculis interdum duabus magnis obscurioribus.

Elytra rufo-testacea; marginibus, imprimis circa scutellum, subobscurioribus.

Abuomen obtusum, coleoptris plus duplo longius, fuscuim; ano pallido.

Pedes testacei.

Al. depressa - Mus. Prof. Krioch.

so Al. de plan ate, nitida, fusca; pedibus testaceis.

Longitudo I lin.

Caput planum, thorace vix angustius, nigrum; antennis fuscis, capitis thoracisque longitudine.

Thorax basin versu's angustatus, coleoptris vix angustior, thigro-fusetus, medio longitudinaliter subcanaliculatus.

Coteoptra thorace duplo fere Iongiora, depressiuscula, obscure picea.

Abdonven obtusum, coleoptris duplo longius, nigro-fus. ctum.

Habitat in aridis, in funo ovillo; rarissina; semel tan. tuni capta. 


\section{Genus VI.}

\section{$\mathrm{O} \times \mathrm{y}$ t e 1 u s.}

$P$ a 1 p i acuminati.

Th o r a $x$ brevis, sculptus.

$T$ i b i a validae, spinosae.

Corpus elongatun, plurimis depressiusculum; nudun, de. pile.

Coput suborbiculato-angulosım, rugosum; oculis prosilientibus. Antennis extrorsum cras-ioribus; articulis, primo maximo, valido, secundo parvo, gracili, sequentibus latitudine crescentibus, ultimo ovato acuto. Palpis anterioribus quatriariculatis.

Thorax coleoptris paulo angustior, punctis sulcisve impres sus; ora tateralt infra deflexa.

Coleoptra subquadrata, thorace longiona.

Abaomen obtusum, marginatum.

Podes validi. Capitibus femorum approxinatis; anticis femore brevioribus, ejus anten crassitie; mediis femore duplo brevioribus, vixque ejus crassitie; posticis brevissimis, absconditis. Tibiis validis, subincurvatis, spi- 
nosis. Tarsis ; articulo ultimo, sive ungula, longo, clavato, articulis reliquis brevibus, subtransversis.

\section{miontersens}

I O. fuliginosus, niger, nitidus; pedibus testaceis; thorace lacritusculo,

Lirus?udo I lin:

Corpus gracile, filiforn:e,

Caput orbiculatum, thorace paulo minus; antennis yix capitis th sracisque longitudine.

Thorax transversus, convexiusculus, apice latior, basin versus angustarus, nitidus, coleoptrus vix angusior, laevis; scrob bus duobus, haud profundis, lateralibus, oculo bene armato conspicuis, impresso,

Coleoptra latitudine paulo longiora, subtilissime puncta, linea longitudinal elytrorum prope suturam inıpressa, sub: ṇitida, cinẹrascentia.

Pedes testacei; tibiis validis, vix autem spinosis.

Haec species, uti e descriptione apparet, inter Aleoclaa. rạs et Oxytelos mediun tenet; tibiis attamen validis, tho. race transycrso, basin yersus angustiore, subfoveolato, po. ţius ad hoc genus spectare videtur.

Al. fuliginosa - Mus. Prof. Knoch:

20 , pedicell us, niger, nitidulus; elytris, pedibus, abdomi: nisque bași pallidis; thorace rugoso,

Longitedo $\frac{x}{4}-\frac{\pi}{3} \operatorname{lin}$,

Compus crassiusculum, filiforme,

Caput thoracis latitudine, nigrum; antennis fuscis , ca: pite longionibus, 


\section{Oxytelus.}

Thorax transversus, coleoptris vix angustior, longitudine duplo latior; lineis tribus longitudinalibus, narginibusque omnibus elevatis.

Coleoptra atro - picea, subnitida.

Ablomen obtusum, colenptris vix duplo longius, nitidum, nigrum, basi fusco - testaceum,

$P$ edes fusco-testacei.

Habitat in fimis, haud rarus.

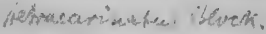

30 . depressus, niger, opacus; antennis fuscis; pedibus fusco-testaceis; thorace, linkis quatuor elevatis.

Longitudo $\frac{2}{3}-$ I lin,

Corpu depreșsum, filiforme, opacum.

Caput subtransversum; vel paulo majus quam thorax, quadratum, angulis obtusis; vel thorace paulo ninins, suborbiculatum; nigrum; antemnis fuscis.

Thorax transversus, planus, longitudinaliter quadrilineatus; lincis elevatis rectis; coltoperis vix angustior.

Colecptra plana.

Abdomen obtusum, coleoptris longius.

Pedes testacei, fenoribus fuscis.

Victitat gregatim in excrementis, Lectus vero etiam, satis copiose, in floribus Echii vulgaris, die XVI. Juhi anno 1800; nce now in gramine et in terra uliginosa.

Staph. a'pressus Olivier Ent. 5t. 17. $5^{1}$ pl. III. f, 26.

St. pireus Simrank Poica n. 885 .

\section{Thaphaterian}

40. caelatu\&, nigricans, nitidulus; antenuis, elytris, pedibusque pallidiorikus; thorace quadrifoweolato, foveis duabus mediis arcuatis. 
Longitudo $1 \frac{\pi}{6}-2$ lin.

Corpus vix depressiusculum, nitidulum, punctum.

Caput vel thorace majus, mandibulis validioribus; vel thorace minus, mandibulis gracilioribus; nigrum; ore, antennisque fuscis; his, capite thoraceque longioribus; articulis quarto ad septimum suborbiculatis crescentibus, octavo ad decimum trạsversis, ultimo suborbiculato acuto.

Tirorax convesiusculus, coleoptris paulo angustior, ba: sin versus angustatus, longicudinaliter quadri - foveolatus; foveis duabus mediis profundioribus arcuatis, concavitate extro:sum versa; lateralibus obsoletioribus; foveis omnibus punctis.

Coleoptra confertim puncta, thorace duplo fere longiora, Abdonen obtusum, coleoptris duplo longius,

Color variabilis est:

$V$ as. I $O$. niger seu obscure fuscus; pedibus, ore, an* tennarum basi, ochraceis,

$V$ ar. 20 . niger; antennis fuscis; ore rufo; elytris pi: ceo-teslaceis; pedibus ochraceis.

$V$ e r. 30 . niger; ore, autennarumque basi othraceis; coleoptris pedibusque testaceis,

$V a r .4$, minima; $O$. fuscus; abdomine nigros pedibus testaccis.

Habitat frequentissime in stercore bovino, per totum annum. Captus vero etiam in succo putrido, sub cortice quercns, die VIII Junii, et in terra uliginosa, die XVI Julii, inno 1800. - Varietatem 4 semel tantummodo, cum speciminibus qubusdam var. 2 , in terra uliginosa ce. pi; licet autem, statura graciliore et minore, nee non colore, a varictatibus praeccdentibus, discrepet, in essentia- 


\section{Oxytelus.}

libus tamen cum illis congruit, et ego non ausus sum, hanc pro specie peculiars habere, cum specimen tantum unicun hujus varierais possideam - Varictatem simillinam, statura autem adisuc srablore, longutudus suodo $\frac{4}{5}$ lin., vidi in collectione Prof. Km: h, Al. catluta - Mu. Pyof. Knoih.

Os 0. piceus, niger nitidus; thorace quinque-foveolato; fovea mediu recta; elytris ped busque testaccis.

Habitu Ox. praecedentis; statura autem latiore et minus convexa: thorace quinque - fovcolato \&

Longitudo $1 \frac{\pi}{2}-2$ lin.

Corpus nitidum, planiusculum, Iatiusculum, punctum,

Capizt rugosum, punctis quibusam iniressum; vel tho. race majus, mandibulis exsertis, longis, denticulatis; vel thorace minus, nandubulis minoribus; antennis capite longioribus, caetcrun ut is sp. praecedente.

Thurit subtransversus, lateribus rotundatis, medio latior; angulis chtucis; quinque foveolatus, foveis tribus disci profundioribus, lateralibus obsoletioribus; media recta; duabus, mearac adjacentibus, subcoliquis vel subarcuatis, concavitate extrorsun versa, lateralrbus latis obsoletis; inintertitiis forcarum, thoracisque marginibus subelevatis. Hae foreae, interctitis quatuor clcvatis linearibus, sejunguntur, unde thorax etiam "quadrilineatus" nominari potest.

Elyfra planitiscula, ante humerum depressa; linea longitudinali prope suturam, punctisque cicatriculosis confertis, impressa,

Abdomen obtusum, coleoptris plus duplo longius, 
Victitat in fimo bovino, equino, ovillo, suillo, per totum anum; rarius in stercore humano; primo vere etiam locis apricis, in quisquiliis, sub lapidibus.

Staph, piceus Fabr. Ent. Syst, St. n, 55 .

- Payk, Mont. St. n. 12. $\alpha$,

- Pcyk, Fn. Succ. St. n. 22. $\alpha$.

- Panzer Fn, Germ, H. 27. t. I4.

- Olivier Ent. St. 11. 23, pl. III. f. 30.

- Schrank Austr. n. 449.

- Rossi Fn. Etr. 11. 622?

- Müller Zool. Dan. Pr, n. 1094 p. 97.

- rugosus Schrank Boica 11, 886.

- picens Rossii huc pertinere videtur, quamquam ei sunt ,magnitudo pediculi, elytra lacvissima“ et quamquam, in ligno putrido habitat. “6

mearens 7 .

60 . carinat $u s$, niger, nitidulus; elytris fuscescentibus; pedibus pallidioribus; thorace quinquefoveolato.

Hcbitu 0 . pici: thorace autem angulis anticis acutioribus, elytris nuı:quam testaceis,

Longitudo $1-2 \frac{\mathrm{T}}{\mathrm{S}}$ lin.

Variat capite najore et minore, colore elytrorum antennarum et pedum \&c.

Var. I, O. thorace conyexiusculo nitido:

1. niger; ore, antennis, pedibusque rufis; elytris nigro. subrufescentibus; longitudine $2 \frac{T}{3}$ lin.

2. niger; ore, ancenuis, elytrisque fuscescentibus; pedibus rufis; longitudine $2 \frac{\mathrm{T}}{3}$ lin.

3. niger; antennis pedibusque fuscis; longitudine $1 \frac{x}{3}-2$ lin. 


$$
\text { Oxytelus, }
$$

4. niger; elytris obscure fuscis; pedibus rufo-testaceis, fenoribus fuscis; longitudine $1 \frac{\mathrm{T}}{3}$ lin.

$V$ a $x$. II. O. thorace plauiusculo opaco.

I. niger; elytris obscure fuscis, pedibus testaceis, femoribus obssurioribus; longitudine $1 \frac{1}{3}-1 \frac{3}{4}$ lin.

2. niger; elytris pedıbusque fusco - piceis; longitudine $1 \frac{\pi}{3}$ liin,

3. niger; elytris obscure fuscis; pedibus testaceis; lot1gitudine $1-1 \frac{\mathrm{T}}{4}$ lin.

Omules hae varietates sensim una in alteram transeunt sicque unam speciem sistunt.

Habitat cum O. prdecedente, frequentior attamen.

Slaph. carinatus Panzer Fn. Germ. H. 57. t. 24.

- sulatus Fourcroy Ent. Par. St. n. 16.

Geoffr. Hist. St. 11, 16. tratures F. a....

70, pulcher, niger, nitidus; antennis, ore, elytris, pedibusque rufis: thorace quinquefoveolato.

Habifu O. praeccdentis; statura autem graciliore; thorace longitudine vix paulo latiore,

Longitudo $2-2 \frac{T}{4}$ lin.

Antennae elytris paulo obscuriores.

Thorax vel subnigro = rufescens, vel obscure sangtineus,

Coleoptra dilute rufa, basi nigricantia.

Habitat cum O. piceo é carinato sub lapidibus in horta aulico, Brunsuigas, tempore verno; multo attamen rarior.

O C, nitiduIus, niger, nitidus; elytris picescentibus; pedibus pallidioribus; thorace quinquefoveolato. 
Habitu inter varietates minimas $O$. carinati et $O$. depres. sum medium tenet; ab illis auten, statura serrper multo minore, ab hos, nitore splendidiore et capite rugis profundioribus impresso, satis differt.

Longitudo $\frac{4}{5}$ lin.

Thorax, sulcis seu foveis tribus mediis parallelis.

Habitat in fimo, cum O. piceo et carinato, rarior autem. An varietas minuta $O$. carinati?

20. morsitans, nitidus; thorace, sulca media longitudinali, impresso,

Habitu O. praecedentis; statura autem breviore, crassiore, paulo convexiore; thorace unisulcato \&e.

Corpus crassiusculum, breve, subdepressiusculum, nitidum,

Caput ut in specie praecedente, nitidum, magnitudine etiam variabili.

Thor ax transversus, coleoptrorum latitudine; apice, trun câtus, latissimus; lateribus et basi rotundatus; convexiusculus, nitidus; subtiliter, nec confertissime, punctus; punctis minorum speciminum cicatriculosis, minimorum crassioribus; sulca media longitudinali exaratus.

Colcoptra subtransversa, thorace paulo longiora, planiuscula, nitida, puncta, pallidiora.

Abionen obtusum.

Color et magnitudo variant:

$V a r, I O$. totus niger; longitudine $\mathrm{I} \frac{\mathrm{T}}{4} \mathrm{lin}$.

$V a r .2 O$. niger; pedibus, elytrorumque disco testaceis; longitudine $x-1 \frac{2}{3}$ lin. 


\section{Oxytelus.}

$V a r 30$. niger; elytris pedibusque fusceseentibus; longitudaine $1-1 \frac{3}{5}$ lin.

Hibitat frequenter in stercore ovillo, bovino, humano; in terra etian uliginosa.

Staph. morsitons Payk. Fin. Suce. St. 1i, 21 .

- tsilcbus O azer Ent. St. n. 22. pr. V. f. 48.

- pallidiprnnis Panzer Fn. G. H. 27. t. I6.

Ad var. 2 solus $S t$. pallidipemis $P_{z .}$ referendus est; reliqui Staphylini, a me citati, ad var. 3 .

10 O. cornutus, nitidus; capite bispino; thorace unisulcato.

Habitu omnino O. praecedentis; capite antem, thoracis magnitudine, bispinoso; spinis, inter antennas sedentibus, porrectis, acutis.

Longitulo $\mathrm{r}_{\frac{\mathrm{T}}{2}}^{\mathrm{T}}$ lin.

Corpus nigrum; elytris tarsisque fuscescentibus.

Alecch. cornuta - Mus. Prof. Knoch.

\section{Bledius}

II O. tricornis, thorace quadrato, convero, scabro, unisulcato - maris cornuto; feminae mutico.

Longitudo $1 \frac{1}{2}-3$ lin.

Corpus subnitidum, punctum, longius et teretins quan in cospeciebus hujus generis.

Coput angulosum, thorace paulo angustius, punctum, opacum, nigrum; antennis et ore fuscis; ferminze muticum, maris bicornutum; comubus seu spinis validis, porrectis, ante oculos sedentibus; antemis capite thoraceque vix brevioribus, articulis, primo longissimo crasso, secundo breviore, tertio tenuissimo, clavatis, quarto ad septimum or- 
biculatis crescentibus, octavo ad decimum transversis, ultimo ovato acuto.

Thorax subquadratus, augulis basis obtusis, convexus, coleoptrorum latitudine vel paulo angustior, niger, opacus, punctus; punctis confertis crassis cicatricosis; sulca media longrtudinali impressus; fewinae muricus, maris umicornutus ; cornu, apicis thoracis medio insidente, porrecto, longitudine capitis.

Coleoptra subquadratà, convexiuscula, subnitida, confertissine puncta; vel tota rufo - fusca; vel sutura, imprimis circa scutclluu, uigra.

Abdomen terctiusculum, obtusum, nitidum, coleoptris plus duplo longius, nigrum, apice fuscescente.

$P$ edes testacei, interdun femoribus obscturioribus. ,

Habitat Brunsuigae; - mas auten rarior.

Staph. tricornis Payk. Fu, Surec. St. n. 38.

- Olivier Ent. St. n. 4r. pl. VI. f. 56.

- armatus Panzer Fu. G. H. 66. t I' (mas.). 


\section{Genus VII.}

\section{$\mathrm{O}$ m a 1 i $\mathrm{u} \mathrm{m}$}

$P$ a 1 p i filiformes.

$T$ h or a $x$ marginibus lateralibue elevatis.

A n te n a e extrorsum crassiores.

Corpus elongatum, depressitusculum, punctum.

Caput rugosun, angulosum, thorace minus. Oizli prosilientes. Palpi filiformes; anteriores quadriarticulati, posteriores triarticulati. Anlennae extrorsun crassiores; ax. ticulis, primo longiore validiore, secundo minore, tertio paulo longiore; quarn secundus, clavatis; sequentibus cressentibus ; ukinio acuto.

Thwox transversus, marginatus, coleoptris paulo angustior, antice posticeque truncatus; ora laterali deflexa, glaberriina, basi lata.

Coleoptra recrangula, thorace longiora; elytris, angulis apio cis interioribus acutis.

Abilomen obtusum, planiusculum, latiusculum, breve. 
Pedes; capitibus fomortm approxinatis, anticis, femore brevioribus, ejus auken crassitie, posterioribus brevissimis, absconditis; tibiis gracilibus ciliatis; tarsis tenuibus.

Familia I. Coleoptris, thorace paulo longioribus.

Fanitia II. Coleoptris thorace duplo et plus duplo longioribus.

\section{Fam. I.}

- O. planum, nitidum, deplanatum, nigricans; elytris, anrennis, pedibusque pallidis; thorace subfoveolato.

Longitudo $\mathrm{s} \frac{\mathrm{r}}{\mathrm{C}}$ lin.

Corpus nitdum, subrilissime punctim, deplariatum; pla nutis quam in reliquis cospecicbus.

Caput triangulare, thoracis fere latitudine, nigrum; ore antennisque rufis; his, capitis thoracisque longitudine, basi pallidiore.

Thorax colcoptris paulo angustior'; disco plano, foveis tribus sublaevibus, saepinis obsolctis, impresso; niger, vel obscure fuscus, marginibus pallidioribus, lateralibus rotundatis.

Coleoptra confertim puncta, picea, elytris trilineatis; lineis elevatis, longitudinalibus, laevibus nitidissimis, sacpius obsoletis.

Abdomen nigro-fuscum.

Pedes ochracei, tibiis subciliatis.

Habitat? - Quaedam specimina volatu cepi.

Staph. plantrs Payk. Fut. Suec. St. 11. 48. 
20. depressum, nitidulum, rufescens; capite, thorace, abdomineque obscurioribus; thorace laevi, convexiusculo.

Longitudo $1 \frac{\mathrm{t}}{3}-\mathbf{1} \frac{\mathrm{T}}{2} \operatorname{lin}$.

Corpus nitidulum, subtilissime punctum.

Caput subtransversum, thorace paulo angustius, nigrofuscum; ore antennisque rufis; his capitis thoracisque longitudine.

Thorax coleoptris paulo angustior, nigro - fuscus, convexus; marginibus lateralibus et basis rufis; illis subelevatis, basin versus latioribus.

Ablonsen fuscum; apice obscuriore.

Pectus nigro fuscum.

$P$ edes testacei.

Victitat? - Copiam speciminum domi ad fenestras legi, dicbus vernalıbus et autumnalibus anno 1800 .

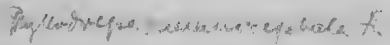

3 0.6 run neuth, nitidum, rufescens; capite, elytrorum et ab. nominis apice plerumque obscurioribus; antennarum articulo ultimo orbicnlato, acuto.

Habitu Om. praecedentis; statura autem majore, punctura crassiore.

Longitudo $\frac{3}{4}-1 \frac{\pi}{2}$ lin.

Corpus nitidum punctum.

Thorax rufus; disco, foveolis duabus, saepius obsoletis, impresso.

Coleoptre confertim puncta, interdum subpuncto - striata. Pedes testacei.

Variat magnitudine et colore:

$V$ ar. I O. rufun; capite, elytrorum abdominisque apice nigris - minus. 
I 4 Omalium. F.I.

Var. 20 . rufum; oculis, anoque nigris; elytris puncto-striatis. - majus.

$V$ ar. 3 O. totum rufum, colcoptris punctis, haud puncto-striatis. - minimum.

Hahitat Brunsuigae.

Slaph. brunneus Payk. Mon. St. n. 45.

- Payk. Fu. Suec. St. n. 47.

- Fobr. Ent. Syst. Supl. p. 180 ?

4 O. crenturas

lcoptris crestuscum, nitidulum; pedibus pallidioribus; coacuto.

Habitu omnino Om. praecedentis varrietatis majoris; statura autem latiore et majore; antennis, capite thoraceque paulo longioribus, articulo ulcimo ovato, gracilioribus; co. leoptris semper puncto - seu crenato-striatis; punctura crassiore.

Loingitulo $1 \frac{\pi}{2}-2 \frac{\pi}{4}$ lin.

Variat antennarum basi, thorace et elytris, concoloribus vel pallidióribus.

Habitat - Mus. Prof. Hellevig.

Staph. crenotus Pank. Fn. Stiec. St. n. 46.

Dom. Paykull, loco citato, allegavit etiam St. crenatuns Fobr. (Eut. Syst. St. n. 26.) sui Fabricius ipse, comparatione cuin St. strialulo et St. frulgido, staturam et magnitudinem St. politi tribuit.

50. Urachypterim fuscum, nitidulum; antennis, thorace, elytris, pedibusque pallidioribus; capite nigro. 


\section{Onalium. F. I.}

Habitu omnino Om. praecedentis; differt attem: thorace subquadrato, basn versus sensim subangustato; coleoptris brevibus, thorace vix longioribus, crenato-punctis, vix strintis.

Longitudo 2 lin.

Habitat - Mus. Prof. Helletig. enderia reves i...

6 O. rufum, rufum, ritidum; pedibus pallidioribus; oculis nigris; thorace quadrato; coleoptris puncto - striatis.

Habitu O. praecedents; colcoptris auten !ongioribus $\mathrm{Ab}$ O. brunneo et crenato, statura longiore, thorace quadrato, coleoptris paululum brevioribus crassius punctis, distinguitur.

Longitudo $=\frac{T}{3}$ lin.

Corpess crassius punctun quam in cospeciebus.

Thorax marginatus; margine autem tenui.

Celeoptra puncta, disco puncto-striato.

Habitat Brunsuigae.

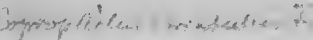

7 O. rugosuni, nigro-fuscum, nitidntum; antennis pedibusque pallidioribus; thorace foveolato; coleoptris crenatostriatis,

Longituds $2 \frac{T}{2}$ lins.

Corpus nitidiflum, punctum; punctis crassioribus, quam in Om. praecedentibus; depressum.

Caput; antennis, capitis thoracisque longitudine, extrorsin subcrassioribus.

Thurax subquadratus, basin versus subangustatus, planiusstulus, foveolatus; foveis tribus; una media longindi- 
nali abbreviata, duabus obliquis basi convergentibus abbreviatis; ita positis, ut quasi formam anchorae exhıbeant.

Coleoptra, thorace paulo longiora, crenato - et punctostriata.

Habitat in quisquiliis; semel modo captum, tempore verno, sub lapide, in horto aulico, Brunsuigac.

Staph. rugosus Olivier Ent. St. n. 42. pl. V. f. 43.

\section{Fam. II.}

80. vivulare, nigrum, nitidum; coleoptris pallidioribus; pedibus rufis; thoracc foveolato.

Longitudo $1 \frac{\mathrm{r}}{6}-1 \frac{2}{3}$ lin.

Corpus depressiusculum, latiusculum, nitidum, punctum. Caput thorace duplo minus, nigrum, rugosun; rugis duabus longitudinalibus abbreviatis inter antennas positis; palpis, antennisque fuscis; his capitis thoracisque longitudine, articulo primo rufo.

Thordex basin versus vix paulo angustatus; lateribus ro* tundatis, marginibus lateralibus basi latioribus; foveolatus, foveis tribus disci longitudinalibus, abbreviatis, nec basin nce apicem thoracis attingentibus, media, ad apicem, misiima, saepius obsoleta, duabus alteris majoribus, constantibus, basi latioribus, apiccun versus attenuatis; niger, marginibus lateralibus interdum pallidis.

Coleoptra confertissine puncta, interdum subpuncto-striata, fuscescentia, elytrorum humeris subpallidioribus.

Abdomen breve, obtusum, ano acuto, ventre interdun rufesecnte. 


\section{Omalium. F. II.}

Habitat frequens in floribus, in gramine, in agaricis et boletis, in fimo bovino et humano. Specimeu unicum, longitudine $1 \frac{\pi}{\delta}$ lin, thoracis marginibus lateralibus pallidioribus, cepi in cadavere talpae, die X. Maji, anno I\$or.

Staph. rivularis Payk. Mon. St. n. 4 G.

- Payk. Fn. Suec. St. 11. 50.

- Olivier Ent. St. n. 49. pl. III. f. 27.

- Panzer Fn. Germ. H. 27. t. 15?

Quem Doun. Panzer, loco citato, exhibuit St. rivularis, coleoptris nimis brevibus delneatus est, nec conveniens cum descriptione ejus Paykullıana, , clytra, capite thorace"que fere longiora" - An hujus speciei?

9. Viburni, nigrum, nitidum; ore pedibusque fuscescentibus; thorace vix subfoveolato; colcoptris nigricantibus seu fuscis,

Habitu, medium tenct inter sp, praecedentem et sequentem; statura, illa paululum latius, hac paululum angustius; punctura, paulo subtiliore quam illa, paulo çrassiore quan haec \&c,

Longitudo $1 \frac{\mathrm{T}}{4}-1 \frac{\mathrm{T}}{2} \mathrm{lin}$.

Caput Om. praecedentis; antennis totis nigris.

Thorax nitidus, punctu; ; foveis duabus obsoletis, aute scutellum, inpressus; caeterum Om. sequentis,

Abdomen et coleoptra Om. sequentis; his autem vel nigricautibus, vel fuscescentibus, vel picescentibus.

Pedes vel ochracei, vel piceo-testacei femoribus fuscis.

Anthophagus Viburni - Mus. Prof. Knoch. 
to 0 , fiovale, nigrum, nitidum; antennis, ore, pedibusque rufis; thorace laevi.

Habitu O. praecedentis; statura paululum latiore; punctura subtiluore, thorace haud foveolato.

Lningituto $1 \frac{\mathrm{x}}{4}-\mathbf{x} \frac{\mathrm{T}}{2} \operatorname{lin}$.

Caput laeve, vix subrugosum.

Thorax conpexiusculus, lateribus rotundatus, nitidissimus, subtilissine punctus; margine laterali clevato basin versus latiore; disco interdum puncus duobus najoribus impresso.

Coleoptsa obscure fisca; oblique, a margine laterali ad suturam, truncata.

Ablomen Ons, rivularis (n. 7.).

Habitat in floribus.

Staph. floralis Pinzer Fi1. G. H. Ir. t. 20.

- Payk. Mon. St. 11. 47.

- Payk. Fn. Succ. St. n. 49.

Fabricii (Ent. Syst. St. n. 52.) St floralis huc non referri potest, quia est , parvus, depressus, thorace plano, " et quia coleoptrorum longorum nulla mentio facta est.

II $O$. $R$ anunculi, nigrum, nitidum, ore, antennarum basi, pedibusque rufis; thorace subopaco, laevi.

Habitu Om. praecedentimm; statura autem paulo crassiore; thorace convexiore; coleoptris longioribus, abdomen fere totum t:ige:itibus.

Longitado I lin.

Corpus nitidum; confertissime, subtiliter punctum.

Coput subrogosum, nigrum; anternis fuscis, basi rufis; ore rufo; cacterum ut in sp. praecedente. 


\section{Omalium. F.il.}

Thorax convexus, subopacus, subilissime confertissimeque punctus; disco intcrdun punctis qqubusdam majoribus impresso; caeterum ut in sp. praec.

Coleopter thorace plus duplo longiora, subpuncto-striata, p ea, oblique truncata, quibusàam specmninibus praeterea appendiculdta, angulo scilicet interiore apicis elytrorum producto (uti in Silpha appendiculata.).

Avtomen, maximam partem a colcoptris tectum; ut in Cm. praec.

Anthoph. Ranunculi - Mus. Prof. Knoch.

Silpha minuta Fabr. Ent. Syst. S. 11. 26?

12 O. striatum, nigrum, nitidun; pedibus rufescentibus; elytris puncto - striatis.

Habitu O. praecedentium; statura autem minima. Longitudo vix 1 lin.

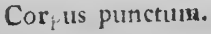

Antemat fuscac, basi interdum rufescentes - Palpi rufescentes.

Thorax longitudine du, 10 fere latior, plerumque foveis disci duabus obsaletis impressus.

Colecpira iutcr.'um subrufescentia.

Habitat in floribus. 


\section{Genus VIII.}

\section{Anthophag a s.}

\section{P a $1 \mathrm{p} \mathrm{i}$ filiformes.}

A ntennae filiformes.

Cospus depressiusculum, depile,

Caput suborbiculatum, rugosuın, thoracis magnitudine, Q. uli parvi prosilientes. Antennae filiformes; articulis, primo validiore clavato, sequentibus campanulatis, longitudine subdecrescentibus, ultimo ovato acuto.

Thorax subquadratus, convexiusculus, basin versus angustior, punctus, coleoptris angustıor et brevior; ora laterali deflexa, laevissima, basi latiore. Coleoptra rectangula, plana, puncta, Abdomen deplanatum, latum, obtusum; ano acuto, Pedes; capitibus femorum approximatis, anticis femore bre. vioribus, ejus autem crassitie, posterioribus brevissimis absconditis; tibiis laevibus tenuibus; tarsis gracilibus.

1. caraboides, testaceus, nitidus; thorace antennisque rufis; capite, abdominisque apice nigris. 


\section{Anthophagus.}

\section{Longitudo $\frac{2}{3}$ lin. \\ Corpus gracile.}

Caput nigrum; ore antennisque rufis; his capite thora* ceque longioribus.

Thorax convexus, immarginatus, cordatus, vix latitudine paulo longior; angulis anticis rotundatis, posticis acutis; subtilissime confertissimeque punctus, rufus disco fus. cescente.

Coleoptra confertim puncta; punctis crassioribus quam reliquae corporis partes.

Ablonkn basi testaceum, apice nigrum; quibusdam speciminibus, segmentis duobus, qubusdam, segmentis tribus vel quatuor ultimis nigris.

Habitat in floribus Cratacgi oxyacanthae, haud rarus,

Staph. caraboides Payk. Mon. St. n. 19.

- Pryk. Fin. Suec. St. 11. 25.

Carabus abbreviatus Fabr. Ent. S. C. n. 188.

2 A. testaceus, testaceus, nitidus; capite thoraceque rufis; abdominis apice obscuriore; oculis nigris.

Hebitu, partiumque forma ac proportione, A. praecedenti simillimus; statura autem majore; punctis thoracis capitisque distinctioribus, haud subtilioribus quam puncta co. leoptrorum,

Longitudo 2 lin.

Abdonen segmentis ultimo et penultimo nigris vel fusces. centibus,

Habirat in floribus Crataegi Oxyacanthae, $\operatorname{sum~A.~prae.~}$ cedente; rarior autem - Nondum mihi specimina occurre. runt, quae, ratione puncturac, magnitudinis et coloris, hune 
et praecedentem Anthophagum, modo facili, conjunxissent, et me persuasissent, ambo ad unam eandemque speciem numerandos esse.

Staph. araboides Limn. (Fn. Suec. 11. 854.) et Fabr. (Ent. Syst. St. 11, 53.) a quibusdam Entomologis huc referuntur; ille autem pediculi est masnitudine; hunc autem Fabricius vix tum procul a Carabo abbrtvato suo (Anthoph. caraboides.) remuisst, si ed adeo similis fuisset. Hac de causa ego tllos sitare nohi,

3. armiger, nitidus, rufus; elytris pedibusque testaceis; oculis abdomineque nigris.

Habitu A. praecedentiun; statura autem majore.

Longitudo: $\frac{3}{4}-2$ lin.

Cxyst mavis, thorace latius, bicornutum; cormubus bre. vibus, porrecris, apice subaduncis, ad basin antennarnm; mandibulis validis: femina thorace subangustius, inerme, mandibulis tenuioribus.

- Thurax confertim punctus; quibusdam specinsinibus sub. marginatus, qubusdan inmarginatus.

Coleoplra confertim puncta, subpuncto - striata, abdomen plus dimidio tegentia.

Anth. armiger - Mus. Prof. Helloig.

* A. obscurus niger, nitidulus; elytris pedibusque pallidioribus.

Habitu, A. praecedente paulo angustior; thorace con* vexiore.

Longitudo $1 \frac{3}{4}$ lin. 
Corpus minus nitidum et laeve quam in speciebus praecedentibus.

Caput nigrum; antennis fuscis.

Coleoptra confertissime puncta,

Variat colore elytrorum et pedum.

$V$ ar. I $A$. elytris pedibusque fuscis.

Var. $2 A$. elytris pedibusque testaceis.

$V$ ar. 3 A. elytris fuscis, pedibus testaceis.

$\mathrm{H}$. bitat in floribis.

Staph. obscurus Payk. Fn. Succ. St. n, 28,

Hunc Anthophagum olim sub nomine Stazh. tecti Payk. accepi; persudsum auten ne habeo, illum ab hos prorsum diversum esse. Anth obscuro sunt nec ,thorax in medio "s longitudine plus quam dimidio latior" nee, antennae ni"grae, basi pallidiores;“ id, quod Paykull St. tecto tribuit. Aenorrencius

5 A. plagiatus, niger, nitidulus; antennis pedibusque fuscis; elytrorum disco sanguinco.

Habitu omnino A. praecedentis; statura autem multo ma. jore.

Longitudo $2 \frac{\mathrm{T}}{\mathrm{T}}$ lin.

Elytra, striga discoidali longitudinali, subobliqua, nee basin nee apicem attingente, sanguinea.

Habitat - Mus. Prof. Hellwig.

Staph. plagiatus Payk. Fn. Suec. St. n. 26.

An W\%. plagiatus Fabr. (Ent. Syst. Suppl, p. 180.) cui, tho. $n$ rax planus" est? 


\section{Genus IX.}

\section{T a c h y p o r us.}

p a pi acuminati.

$T$ h or a $\mathrm{x}$ brevis glaber.

$\mathrm{T}$ i b i a e spinosae.

Corpus laevissinum, nitialum, elongatum, convexum, apisein versus attenuatum.

Caput, retractum, thorace angustius. Palpi anteriores quadriarticulati; posteriores triarticulati. Antennae extrorsum crassiores, capitis thoracisque longitudine, articulis, primo brevi valido, secundo tenuissimo, subclavatis, sequentibus crescentibus subcampanulatis, ultimo ovato longìore.

Thorax convexus, brevis, glaber; lateribus deflexis; latitldine coleoptrorum, vel paulo latior; ora laterali infra reflexa, abscondita,

Coleoptra, thorace longiora.

Abdomen apicem versus attenuatum, pilosellum.

$\boldsymbol{P}$ edes cursorii; capitibus femorum approximatis, anticis femore srassioribus nec longioribus, mediis femore duplo 
brevioribus ejus autem crassitie, posticis brevissimis ab. sconditis; tibiis subciliato - spinosis; tarss gracihbus, articulo primo longiore.

Familia I. thorace suborbiculato.

Familia II. thorace transverso.

\section{F a m. I.}

Corpus gracilius quam in familia sequente, antice posticeque attenuatum.

I. dissimilis, niger, nitidus; pedibus antennisque rufo-te. staceis.

Longitudo $1 \frac{\pi}{4}-1 \frac{3}{4}$ lin.

Corpus laevissimum, nitidissimun.

Caput subovatum, thorace paulo angustius, nigrum; antennis; capitis thoracisque longitudine, fuscis, articulo primo rufo vel testaceo; palpis rufis.

Thorax suborbiculatus, apicen versus vix subangustior, basi subrotundatus, fuscus, vel nigricans marginibus sun. mis pallesceritibus.

Coleoptra subquadrata, nitida, convexiuscula, confertissime subtiliter puncta, vel obsolete puncto -striata; nigrofusca, marginibus subpallidis.

Abdomen nigro - fuscum.

Habitat Brunsuigae.

Oxyporus rufipes Panzer Fn. G. H. 27. t. 20? 


\section{Fam. II.}

Corpus minus gracile quam in familia prima; abdomine at. teiluato.

Caput orbiculatum.

2 T. nitidulus, nitidissimus, laevissimus, gracilis; coleoptris planiusculis; colore variabili.

5nit Habitu graciliore quam Tachyp. sequentes; coleoptris auten planis praecipue differt.

7. Longitudo $1 \frac{\mathrm{T}}{5}$ lin.

Cajut, thorace inulto angustius.

Thorax transversus, lateribus rotundatus, antice posticeque truncatus, coleoptris paulo latior.

Coleoptra rectängula, plana, impuncta.

Peles rufi vel testacei; tibiis ciliato-spinosis.

V ar. I T. fuscus; capite atro; antennis, thoracis lateribus, elytris, pedibus, se rementorumque marginibus, testaceis.

$V$ ar. $2 T$. varietati I similis; vitta' autem elytrorum marginis exterioris nigra.

$V$ as: $3 T$. niger; thorace nigro - rufescente; antenuis, pedibus, coleoptrorum margine apicali, segmentorumque marginibus, rufo testaceis.

Habitat in fino; haud frequens.

Staph, nitidulus Fabr. Sp Ins. St, 11. 17.

- Olivier Ent. St. n. 48 . pl. III. f. 28.

Oxup minutus Fabr. Ent. Syst. O. n, 20. 
3. abdominalis, rufus, nitidus; antennis pediburgue palidioribus; abdomine fusco; oculis nigris.

Habitu $\mathrm{T}$. praecedentis; thorace aitem coleoptrorum la. titudine; coleoptris convexis.

Longitudo $\mathbf{I}_{4}^{\mathrm{T}}$ lin.

Habitat Brunsv. - Mus. Pr. Helleig.

Oxyp. abdumin. Fabr. Ent. S. O. n. 17 .

+T. lateralis, niger, nitidus; antennis, palpis, thorace, pedibus, elytrisque rutis; his, basi vittaque marginis exterioris, nigris.

Habitu T. praecedentis; statura autenn latiore; coleoptris thorace paulo angustioribus.

Longitado $1 \frac{1}{2}$ lin.

Habitat Brunsuigae.

Taibyp. lateralis - Mus. Pr. Knoch.

5T. marginatus niger, nitidus; antennis, pedibus, thoracisque lateribus testaceis; elytris rufis, vitta marginis exterioris nigra.

Habitu $\mathrm{T}$. praecedentis; statura pauluhum latiore.

Longitudo $1 \frac{\mathrm{T}}{3}-1 \frac{\mathrm{T}}{2}$ lin.

Thorax niger, marginibus lateralibus, praecipue basin versus, testaceis.

Habitat in quisquiliis et in floribus, haud infrequens.

Oxyp. marginatus Fabr. Ent. S. O. n. 6.

- Panzer Fn. Germ. H. 27. t. 17 .

St. dispar var. $\beta$. Payk. Mon. St. n. 54.

- Payk. Fn. Suec. St. n. 6g. v. B.

- thrysomelimus Rossi Fin. Etr. n1. 616. v. 2. 
St. Blattinus Schronk Austr. 11. 447.

- Schrank Boica n. 878 .

Dom. Paykull Oxyp. brunneun et Hypnorun Fabr. cum hac specie conjunxit. Dubito, an juste? His Tach.marginc tus elytrorum vitta marginali nigra distinctus est. Staoh. nitidulus Fabr. meliore jure ad Tach. nitidulum $(\mathrm{n}, 2$.$) refertur.$

6 T. ruficollis, nitidus, nigricans; coleoptrorum summo apice pallidiore; thorace pedibusque rufis.

Habitu omnino T. praecedentis; colore constantissimo differt.

Longitudo $1 \frac{x}{4}$ lin.

Caput nigrum; antennis palpisque fuscis.

Coleoptra subquadrata, thoracis latitudine, nigro-fusca; margine apicis plus minusve pallescente.

Habitat - Mus. Prof. Hellwig.

St. chrysometinus Rossi Fu, Etr. n. 616. Var. 1. a. $\beta$.

- dispar Payk. Mon. St, n. 54. d. et Fn. S. St. m, 69. d.

7 T. chrysomelinus, rufus, nitidus; capite, scutello, cole. optrorum basi et marginibus lateralibus, abdomine et pectore nigris.

: Habitu omnino T. praecedentium; colore autem semper differt.

Longitudo $\mathbf{I} \frac{t}{4}-1 \frac{\pi}{2}$ lin.

Caput nigrum; ore, antennarumque fuscarum basi, te. staceis.

Thorax, coleoptris latior, plerumque rufo - testaceus seu testaceus, rarissime nigro-fuscus. 
Coleoptra plerunaque dilute rufo - testacea, marginibus lateralibus eț circa scutellum nigra; rarius rufo-castanea, basi lateribusque nigris.

\section{Pevils testacei.}

- Vicritat frequens in floribus, in foliis, et in gramine; rarior in fimo bovino.

Staph. chrysom. Limn. Fn, Suec. n. 855.

- Rossi Fin. Etr. n. 6ı6. var. I. a. a.

- Sihrank Austr. n. 448.

- Sihrank Boica n. 879.

- Fourrer. Ent. Par. St. n. 18.

- Olivier Entrt. St. n. 47 . pl. III. f. 22.

Oxyporus chrysons. Vabr. Ent. S. O. 11, Is.

- Panzer Fn. Germ. H. 9. t. 14.

Staph. dispar Payk. Mon. St. 11. 54. var, $\boldsymbol{\alpha}$.

- Payk. Fu. Suec. St. n. 6g. var. $\alpha$.

Dom. Paykuil, loco e Fn. Suecica allegato, citavit etian Ox. pygniaceum Fabr. (Ent. Syst. O. 11. 13.), quem ad Tuchynun melanocephatum reculi (v. n. 15.). Tachup. chrysoms. nunquam in bolecis mihi occurrit - Dom. Fabricius, loco allegato, St.obtusun citavit, quem ipse in Mantissa Ins:ctorum descripsit. Apparet autem ex hac descriptione, ilium ad Tach ' p rum sequentem pertinere - Nec var. $y$ St. dis paris Pa? k. (Mon. St n. 54 et Fn. Suec. Sc. n. 69.) ad Tait. chrusomeim. recerenda est, uti Dom. Panzer (Fn. Ins. Germ. H. 9. 11. I . .) credı, sed ad T. sequentem.

$\mathrm{O}^{8 T}$ T a nalis, nitidus, rufo-testaceus; oculis, pectore, elytro. rum basi, scutello, abdominisq̨ue apice, niguris. 
Habitu T. praecedentibus simillimus; colore autem sem. per distinctus.

Longitudo $1 \frac{\pi}{4}-2 \frac{r}{4}$ lin.

Caput rarius nigricans.

Coleoptra seminigra, semirufo-testacea.

Victitat cum $T$. praecedente.

Oxyporus analis Fabr. Ent. S. O. n. 10.

- Panzer Fn. Germ. H. 22. t. 16.

Oxyp. obtusus S.hrank Boica n. 892.

Staph. obtusus Fabr. Syst. Ent. St. n. 10.

- Schrank Austr. n. 45 I.

- Rossi.Fn. Etr. 11.62r.

- chrysemelimus Rossi Fn. Etr. n. 6i6. Var. I.b.

- disuar Payk. Mon. St. n. 54. v. $\gamma$.

- Pmyk. Fn. Suec. St. n.69. v. $\gamma$.

Non credo, Dom. Paykull, loco citato, St. chrysomelinum Linn. (Fn Suec. n. 855.) jure allegasse. Vide sp. praecedentem.

Dom. Paykull hanc et tres praecedentes species; sub nomine speciali St. disparis (Mour. St. n. 54 et Fn. Suec. St. n. 69.) conjunxit. Licet autem ommibus eadem sit statura, eadem magnitudo, eademque partium forma et proportio, licet onnes iisdem locis habitent, color attanien constantissimus et satis distiuctus singularium specieruin me inhibuit, quo minus exemplum viri cel. secutus sim; inter magnam enim multitudinem speciminum ne unicum quidem interme. diu m reperi, quod unan alteramque speciem connexisset.

9 T.pubescens nitidulus, fuscus, subrufescens, subsericans; pedibus antennisque pallidioribus. 
Habitu, $\mathrm{T}$. praecedentibus convexior at gracilior; abdomine breviore et angustiore; colore obscuro subopaco.

Longitudo $1 \frac{2}{3}-2 \frac{1}{4}$ lin.

Tibiae subspinosae.

Vhariat corpore subnitido et opaco, plus miuus sericante; colore rufescente vel fusco.

Habitat passim in sücco putrido sub arborum demortuarum cortice.

Staph. pubescens Payk. Mon, Carab. ap. p. 138. r. $53-54$ var. $\beta$.

Staph cellaris Paylk. Fu, Suec. St, n. 67. v. $\beta$.

10 T. bellayis, nitidulus, sericeo-fuscus; ore, antennis, thoracis arigulis basis, macula magna clytrorum humerali, pe: dibusque; rufo-testaceis.

Habilu, T. pracecedente brevior et latior.

Longitudo $1 \frac{\mathrm{T}}{2}-2$ lin.

Coleoptra et abdomen plus minusve, interdum vix, sericant - Abdomen breve, valdc attenuatum et gracile, Ieoptris maxiniam partem tectum.

Habitat cum $T$. praecedente; rarior attamen.

Staph, cellaris Payk. Fn. Suec. St. u. 67. v. $\alpha$.

- probesiens Payk. Mon. Carab. append. p. 138. 11.53-54 var. «.

Si speciebus hac et praecedente, verum.. St. cellarenn et vertim St. pubescenten Poyk. descripsi, quod utique credo, non intelligo, cur vir cel. ambo in unam speciem conjunxerit, cum satis inter se discrepent - Oxyp. cellaris et bima- 
culatus Fabr. (Ent. Syst. Ox. n. 5 et 8.) valde invicem congruere videntur; unus illorum certo, forsan vel uterque, huc referri potest.

11 T. bipustulatus, nitidulus, nigricans; pedibus fuscis; macula elytrorum basis, prope suturam, rufescente.

Habitu onnino $T$. praccedentis; convexior attamen et panlo major.

Longitudo $1 \frac{\mathrm{T}}{2}-2$ lin.

Corpus subtrissime griseo-subsericans.

Caput, ore antennisque fuscis; his, in individuis mino. ribus, articulis duobus ultimis testaceis.

Elylra, macula basis subquadrata rufa, magnitudine tertiae partis elytri, nec marginem exteriorem nee suturam attingente, huic autem propiors, speciminbus minoribus unnus determinata.

Amis ct pedes rufescentes.

T. bipustulatus - Mus. Pr. Kroch.

$12 T$. binotat us, niger, nitidus; antennis, macula elytrorum humerali, pedibusque fuscis.

Habitu T. cellari (n. ro.) sinilis; statura autem breviore, crassiore, convexiore; thorace nitidissimo, apicem versus angustato.

Longitudo $\mathbf{I} \frac{\mathrm{T}}{4}$ lin.

Thorax laterıbus subpállidior.

Abclonen subfuscum.

Habitat - Mus, Pr. Rellivig. 
$13 T$. bipunctab nigro-fuscus, subsericeo-nitens; puncro elyerortm humeral pedibusque rufis; antennis rufis, medio obscuriontus.

Habitu T. praecedentis; statura autem graciliore et con. vexiore.

Longitudo $\frac{3}{4}$ lin.

Habitat - Mus. Pr. Helleig.

14 T. pedicularius fuscus, subsericeo-nitens; antennis pe. - dibusque testaceis.

Habitu T. pubescenti (11. g.) similliunus; statura autem multo minore.

Longitudo $\frac{3}{4}$ lin.

Thoracis margines, elytrorumque apex interdum pallidiores sunt.

Habitat - Mus. Pr. Helloig. 


\section{Genus X.}

\section{T a c h in u s.}

P a $1 \mathrm{p}$ i filiformes.

A n t e n n a e extrorsum crassiores.

$T$ h o $\mathrm{r}$ a $\mathrm{x}$ inmarginatus, basi truncatus.

Corpus laeve, nitidum, elongatum, convexum, apiceth versus attenuatum.

Caput thorace angustitis, retractum. Clypeites angustus, apicem versus angustatus, obtusus. Palpi filiformes, anteriores quadriarticulati, posteriores triarticulati. Antent noe capitis thoracisque longitudine; articulis, prino valido, sectindo teinissimo tertioque, clavatis, sequentibus sensim validioribus, ultimo ovato.

Thorax convexus, lateribus deflexus; ora laterali infra res flexa, abscondita, vix conspicua.

Coleoptra convexa, thorace longiora.

Abdomen pilosum, apicrm versus attenuatum.

Pedes ut in genere praecedentè ; tibiis spinoso - ciliatis; tartsis tenuibus; excepto $T$. análi, (1i. 18.). 


\section{Tachinus, F. I.}

Familia I. thorace transverso.

Fanilia II. thorace suborbiculato.

\section{F am. I.}

Corpus ninus gracile quam in familia II subtilissime confertissineque punctum; punctis oculo bene armato conspicuis.

Caput suborbiculatum, thorace triplo minus; ore producto. Thrax ransversus, lateribus leniter deflexis.

Coleoptra thoracis latitudine, angulis acutis.

I $T$. subterraneus niger, nitidissimus; elytris, macula humerali oblonga testacea.

Habitu T. sequentium; statura autem angustiore, capite majore \&c.

Lingitulo $2-2=\frac{r}{2}$ lin.

Caput thorace vix triplo minus, nigrun; antennis fuscis. Colenptra rectangula.

Pedes fusci.

Habitat Brunsuigae.

Oxyporzs subterr. Fabr. Ent. S. O. n. 4 .

Staph. subterr. Poyk. Mon. St. n. 52.

- Pauk. Fn. Suec. St. n. 66.

- Rossi Fn. Etr. n. 617.

- Linn. Fn. Suec. n. 849?

Limnei St. subterraneum interrogative allegavi, cum ejus corpus pediculo tantum duylo majus sit.

$02 T$. bipustulatus, niger, nitidus; antennis, pedibus, clytrorum macula humerali, rufescentibus. 
Habitu, T. praecedente multo convexior et latior - A T. sequente antennis brevioribus, crassioribns, totis rufis, macula elytrorum humerali magna quadrata satis determina. ta, distingui potest.

Longitulo 2 lin. vel paulo longior.

Caput thorace plus triplo longius.

C leoptra subquadrata.

Hibitat in fino; rarior.

Oxyporus bipust. Fabr. Ent. S. O. 11. 9.

- Panzer Fn. Germ. H. 16. t. 21.

De St. bipustulato Rossii (Fn. Etr. n. 620.) superius, in descriptione St. bipustulati Fabr. (n. 54.) jam locutus sum.

$3 T$. humeralis, niger, nitidus; articulo antennarum primo, thoracis margine laterali, pedibusque rufis; colore elytro. rum variabili.

Hablu omnino T. praecedentis; antennis autem longio. ribus gracilioribus, fuscis, articulo prino pallidiore - A T. sequente sat differt.

Longitudo $2 \frac{1}{2}-3$ lin.

Variat colore elytrorum.

$V$ ar. $1 T$. colcoptris nigris, basi summoque apicis margine rufis.

$V a r .2 T$. elytris rufis, disco obscuriore.

$\operatorname{Var.} 3 T$. ut V. 2 ; thoracis margine basis summo ru. fescente.

Habitat cum $T$. praecedente et sequentibus in fimo.

Oxyp. huneralis Schneid.

- marginellus Panzer Fin. G. H. 9. t. 13?

Stojh. warginalis Schrank Boica n. 881. 
Stoph. rufipes Payk. Mon. St. n. 53. v. r.

- Payk. Fn. Suec, St. n. 65. v. $\beta$. $\delta$.

Dom. Paykull (Fn. Suec. St. n. 6s v. E.) Staph. flavescentem Linn. et Oxyp. masginellun Fobr. cum hac specie conjunxit. Nolui autem ejus cxemplum sequi, cum Oxyp. marginellis Fabr., statura, magnitudine, partitunque forma \&ic ab loc Tachino valde recedat - St. flavescentem Linn hand novi; forsan varietas junior cujucpian Tachini est - Tallin. rusfipes nunquam lateribus thoracis testaceo - rufsscentibus occurrit; rarissime izargine tantum stmmo latcrali pallescente. Quapropter hatd cunctatus sum, varietates St. rufpetils Pciyk. allegatas hic citarc.

Oxyp. marginellun Panzeri sub hac specie allegavi, quia, nagnitudine et colore omuino ab Oxyp. margintllo Fabr. diversus, huc potius spectat.

4T. rufipes, niger, uitidus; antennis fuscis; pedibus palli. dioribus; colore elytrorum variabili.

Habitu, T. praecedenti similis; statura autem paulo graciliore; thorace angustiore, ninus convexo, later bus minus rotundatis, concoloribus; antennarum articulo primo obscuro.

Longitudo $2-2 \frac{2}{3}$ lin.

Thorax apicenı versus paulo angustatus, capite vix triplo major, niger; rarissime margine laterali summo subrufessente.

Coleoptra subrectangula.

Ablomen plerunque breve obtusum, rarius elongatum, apicem versus sensim attenuatum; segmento quinto reliquis longiore, infra vel sinuato seu (abdomine nempe angustio- 
re) inciso, vel simplici, margine integro; penicillis tribus vel quatuor, et forcipe cornea brevi, saepius abscondita, infrale segmento quinto provenientibus, a segmentis ultimo et penultimo tectis, penicillis attamen tribus ano longıri. bus - Ornamenta plane similia, eodenque modo differen. tia, in specicbus praecedentibus Tachinorum observavi. Revera differentam sexus indicare videntur, nec vero differentian speciei; id quod ex analogia concludo, cum 110 nuilis Staphylinorum speciebus smiles sint sinus et incisiones segmentorum penultimi et antepenultimi - Confer quae huc pertinentia in praefatione monui.

Ratione coloris, varierates sequentes mihi occurrerunt: Var. I $T$. Coleoptris nigris; summo apicis margine, elytrorumquc humeris rufis.

$V$ Cr. $2 T$. elytris nigris; macula humerali, margine apicis, suturaque, hac autem tenuissime, rufis.

$\operatorname{Var} 3 T$. dytris nigris; marginibus fuscis vel rufis.

$\operatorname{Var}, 4 T$. elytris rufis; disco obscuriore.

$V$ ar. $5 T$. elytris dihtide rufis.

Onnes hae varietates variant pedibus rufis vel fuscis.

Habitant in ommibtis excrementis; varietates $3 \mathrm{ct} 4$ fre. quentissimae, reliquae rariores.

Staph. rufipes Payk. Fn. Succ. St. n. 65. v. $\alpha$.

- Payk. Mon. St. 11. 53. v. $\alpha . \beta$.

- Rossi Fr. Etr. n. бr8.

- Oinvier Ent. St. n. 46. pl. IV. f. 35.

- spinipes Pontopp. Naturh. in Dän. p. 211. t. 16.

- marginatus Fourcr. Ent. Par. St. n. 19.

- Geoffr. Hist St. n1. 19.

- De Geer Mem. St. n. Ir. 


\section{Tachinus. F.I.}

Haud mirum videtur, hanc et praecedentes duas species, cum habitu invicem adeo similes sint, saepius etian confusas, et, quia hucusque nondum characteribus satis firmis et distinctivis sejunctae essent, cum aliis, longe discedentibus, conmutatas esse. Contigit mihi, numero speciminum majore, ut characteres eorum constantes distinctivos eruerim; et studui, has species, diagnosi descriptione et comparatione inter se, modo tacili et plano, disjungere - Oxyp. vufipes Ponzerz (Fn, G. H. 27. n. 20.) hitie non pertinet. Ego saltem nunquain Ox. mufipedenu aterrimum, antennis totis pedibusque rutis vidi; nee in agaricis putrescentubus degentem reperi - Don. I. Siurm olim Twin. nufipeden verum, et quidem var. 4 , sub nomine autem Staph. fuscipedis, mecum comnunicavit. Nec autem Strah. fuscipes Panzeri (Fn. G. H. 27. t. 12.) est, cui margo lateralis thoracis et antennae fuscescentes sunt; nee St. fuscipes Fabr. (Ent. S. St. n. 38.), qui janı ad Alcecharas relatus est Oxup. vutipes Fabr. (Ent. S. O. 11. 21.) tottis „, niger, pedibus rufis, " huc non numerantus est - \&c.

\section{rem $n_{4}$}

$5 T$. signatus, niger, nitidus; antenuarum articulo primo, elytrorumque puncto humerali, rufis; pedibus fuscis.

Habltu et lungitudine omnino T. praecedentis, imprimis varictatis 1; articulo autem primo anteunarum constanter rufo.

Tribus hujus speciei individuis, quae examintavi, sego mentum quintum abdominis infra margine simplici, nee sio nuato nee fisso, erat, et tres penicilli, quos hoc segmentum exserit, ano longiores erant. 
Variat elytrorum puncto humerali obsoleto, et margine sunimo apicis rufescente.

Habitat - Mus. Prof. Hellwig.

$6 T . \mu u l l u s$, niger, nitidus; antennarum articulo primo, pedibusque rufis.

Habitu omnino $T$. humeralis (n. 3.); statura autem paulo latiore; capite majore; thorace convexiore, latiore, margine laterali concolore; coleoptris quadratis \&c. - A T. p aecedente ct antepraecedente satis distiuctus est.

Longitudo $2 \frac{\mathrm{r}}{4}$ lin.

Antennae fuscae; articulo printo rufo.

Colroptra interdum summo apicis margine subrufescente. Abchoninis segmentum quintum varıat ita, ut 11 T. rufipede (n. 4.)

Trihyporus pullus - Mus. Pr. Knoch.

\section{danis $\%, F$}

7 $T$. castaneus, niger nitidus; elytris pedibusque fuscescentibus.

Habitu omnino T. rufipedis (n. 4.) statura auten breviore et paululum crassiore.

Longitudo $\mathrm{r}_{3}-2$ lin.

Variat colore pedum et elytrorum.

$V a r, I T$. elytris totis pedibusque fuscis.

$V a r .2 T$. elytris fiscis, humeris margineque laterali et apicis pallidioribus; pedibus fiscis?

$V$ ar. $3 T$. elytris pedibusque pallide castaneis.

Tachyporus castaneus - Mus. Pr. Knock. 
8 $T$. sordidus, niger, nitidus; antennis, thoracis marginibus, elytris, pedibus, anoque fuscis.

Habitu T. praccedentis; capite autem paulo minore, thorace paululum angustiore fusco - marginato.

Habitat - Mus. Pref. Hell i ig.

Staph. fuscipes Panzer. En. G. H. 27, t. 12?

9 $\boldsymbol{r}$. fimetarius, niger, nitidus; pedibus, thoracis margine laterali, elytrorun humcro et margine apicali, yufis.

Habitu et longitudine T. marginelli (n. I4.); duffert autem thoracis lateribus paulo rotundiorbus, antennis totis nigris, \&c. - A T. cxstaneo (n 7.) statura graciliore, thorace minus convexo lateribus rufo, dignoscitur.

Habitat in fimo.

to $T$. laticollis, niger, nitidus; elytris pallidioribus; pedibus rufis - thoracis margine laterali vel unicolore vel pa'ildo.

Habitu omnino T. humeralis (n. 3.); statura autem multo minore.

Longitulo $1 \frac{3}{4}$ lin.

Variat colore elytrorum:

$V a r . \quad T$. elytris nigricantibus, summo apicis margine Iufo.

$V a r, 2 T$. elytris nigricantibus, margine laterali et apjcis rufis.

$V$ ar. $3 T$. elytris fuscescentibus.

Habitat - Mus. Prof Hellwig.

II $T$. iorticin us, nitidus, brevis, convexus, crassus; colore variabili, 
Habitu breviore, crassiore, convexiore quam reliquae hujus generis species, Ta hyporo anali, chrysomelino et affi-

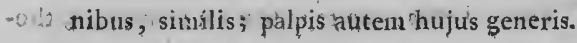

Longitucto $\mathrm{I} \frac{\mathrm{T}}{3} \mathrm{lin}$;

Color variat:

$V$ ar, $i \cdot T$. totus'testaceus.

Var. $2 T$. testaceus; capite, antennarum abdominisque äpice,; obscurioribus,

-Var. $3 T$. testaceus; capite obscuriore, antennarum 1. apice fusco; oculis nigris.

$\operatorname{Var.} \& T$. testaceus; antennarum apice, abdomiueque obscurioribus ; oculis 'nigris,

$\operatorname{Var} .5 T$. fuscescens; thoracis disco obscuriore; capite abdamineque nigris; antennarum basi pedibusque rufis.

Tachyporus corticinus - Mus. Prof. Knoih,

Oxyporus testaceus Fabr. Ent. S. O. n. I8?

Oxyp, brunneus Fabr. Ent, S. O. n, 19?

Conjicere tantum queo, Oxyporos citatos huc referendos esse. Diagnoses et descriptiones eorum in Fabr. Ent. Syst. nimium sunt breves, insectorum autem huc pertinentium et varietatum eorum multitudo nimis magna, quam quod aliquid certi de eorum synonymia dici possit,

$12 T$. immaturus fuscus, nitidus; capite nigro; anteunarum basi, thoracis elytrorumque limbis, segunentorum margini. bus, pedibusque, rufo-testaceis.

Statura, magnitudo, partiumque forma et proportio, omnino $T$, marginelli (n. $\mathrm{I}^{4}$.) ; forsan mera ejus varictas junior; colore satis distinctus est. 


\section{Tachinus. F. I.}

Habitat in fimo bovino; semel tantúmmodo captus.

An Oxyp. brunneus Fubr, Ent. S. O. n. 19?

OJ3 $T$. collavis, nigricans, nitidus; thorace pedibusque rufis.

Habitu T. sequentis; statura autem paulo gracilore.

Longitulo $1_{3}^{2}$ lin.

Caput, supra ingerrimum, infra rufescens; antennis, articulis trabus primis (reliqui deficumt) rufis.

Colicoptra thorace duplo ferme longiora, confertim et subtiliter puncta : punctis distinctis conspicuis; nigro - fuscescentia, margine apicis rufo.

Tachypor. collaris - Mus, Pr, Knoch.

$14 T$. marginellus, nigèr, nitidus; antennis basi pallidioribus; thoraris marginibus laterali et basis, pedıbusque testaceis.

Habitu T. laticullis $(1,90$.$) ; thorace autem paulo sninus$ convexo, lateribus minus rotundatis, rectis.

Longitudo $\mathbf{I}_{3}^{\frac{1}{3}}-\mathbf{I}_{5}^{3}$ lin.

Antemae fuscae, basi vallidae.

Variat eiytris totis picco - fuscis; vel nigris, humero et margine apicis, interdun etian margine laterali, testaceis.

Habitat in sylvis, in fimo bovino ct equino.

Oxyp, marginellus Fubr. Ent. S. O. n. 23.

Staph. rufipes Payk, Fin. Suec, St. 11. 65. v. 8.

Dubito, an Oxyp. marginellus Panzeri (Fn, Germ, H. 9. t. 13.) huc referri queat. Magnitudine et colore differt. Sub T. humerali (n. 3.) cjus jam mentionem fcsi $-\Lambda$ T. rufipede (St. rufip. Payk.) satis est distinctus, et nullo wodo ejus varietas. 
$15 T$. suturalis niger, nitidus; thoracis lateribus pedibusque testaceis; elytris testaceis, strigis duabus latis, una dusci, altera laterali, interdum medio confuentibus, nigris.

Habitu brevi, convexo, fere T. corticini (n. 10.).

Coleoptra subtransversa, vix quadrata.

Habitat in fimo; rarior.

Oxup. suturalis Panzer Fn. G. H. 18. t. 20.

Hic Tachinus apud nos semper sic invenitur, uti in diagnosi descriptus est - D. Panzer, loco allegato, eum descripsit , ater nitidus, thorace margine, coleoptris sutura, "apice, puncto baseos, anoque flavis," et figuram, huic descriptioni respondentem, accuratam, exhibuit.

\section{Fam. II.}

Corpus gracilius, quam in familia prima, nitidum, inpus. ctum.

Cosput, thorace angustius, fere autem ejus longitudiue, laevissimum, nitidissimun.

Thrax suborbiculatus; apice angustior, angulis deflexis.

Colecptra rectangula.

16 T. melanocephalus, capite subovato nigro; colore thoracis, elytrorum et abdominis variabili.

Habitu T. sequentis; statura autem minore et graciliore; thorace paulo angustiore \&c.

Longitucio $1-2$ lin.

Thorax coleoptris angustion:

Elytra lineis duabus longitudinalibus, una disci, altera prope suturain, crenulatis, interdum interruptis, obsoletis, impressa. 
Varietatum hujus speciei sumerus satis magnus est:

$V a r . I$. Thorace rufo; antenuis abdomineque fuscis:

1. elytris testaceis; longitudine $1 \frac{T}{3}-2$ lin.

Staph, melanocephalus Payk. Mon. Sc. 11. 42 -an Fn. Suec.

St. n. 63 ?

Ox?p. melanocephalus Fabr. Est. Syst. Ox. n. 16.

Staph. t, inaculatus Psyk. Fn. Suec, St. n. 69. v. $\gamma$.

2. elytris testaceis, angulo apicis exteriore nigro; longi . tudine $1 \frac{\mathrm{r}}{3}-2$ lin.

Oxup. pqgmatus Fabr. E. S. Ox, 11. 13.

- Panzer Fn. Germ. H. 27. t. 19.

Var. II. Abdomine et thoracis disco fuscis.

I. elytris testaceis, angulo apicis exteriore nigro; longitudine $i \frac{\pi}{2}-2 \frac{\pi}{4}$ lin.

Staph. trimaculatus Payk. Fin. Suec. St. n. 68. v. $\beta$.

2. elytris testaceis, angulo apicis exteriore et puncto ante scutellum nigris; longitudine $2-2 \frac{3}{4}$ lin.

Oxyp. trimaculatus Fabr. Ent. Syst. Ox. n. 7.

Staph. trinkaculatus Payk. Fn. Suec. St. n. 68. v. $\alpha$.

- bimaculatus Schraní Boica. n. 872.

- littoreus Payk. Mour. St. n. 55.

$V a r . I H$. $T$. fuscus, seu nigxicans; pedibus antennarumque basi testaceis;

1. clytris testaceis, angulo apicis exteriore nigro; longitudine $\mathrm{x}-1 \frac{2}{5}$ lin.

2. elytris rufis, angulo apicis exteriore nigro; longitudine $1 \frac{2}{3}$ lin.

3. elytris rufis, angulo apicis exteriore suturaque nigris ; longitudine $\mathrm{x} \frac{\mathrm{T}}{\mathrm{a}}$ lin. 
4. elytris nigris, macula magna humerali rufa; longitudine $\frac{\mathrm{T}}{2}$ lin.

$V$ ar. IV. rufo-fuscus; thorace rufo-testaceo; pedibus, coleoptrisque testacers; his, angulis aprcis nigris.

$V$ ar. $V$. rufus; thorace rufo-testaceo; pedibus coleoptrisque albicantibus, his, angulis apicis fuscıs.

Onnes liae vartetates victitant frequentissimae in boletis et agaricis; varictates $\frac{\pi}{\sigma}$ et $\frac{\pi}{\gamma}$ vero reliquis rariores.

Staph. lithoreus Payk, sub var etate II aliega:us, nou idem est ac St. littrorus Limn., ఇui nón solum oeconomia longe ab hoc discedit, sed, secundum ipsam descriptionem, insectum plane distinctum designare videtur - Dom. Paykull porro cecdit, Oxup. merdariun Fubr. et Sicuph. disparis 2ar. \& Payl. ad St. trimuculati var. $\gamma$ Payk. referendos esse; we autem persuasum habeo, aubo Tachypori gencris esseTandem dubito, Staph. melonocephalum Payk Fn. Suec. (St. 11. 68.) huc referri posse, cum, ,oculo armato, pube bre„vissima adspersus" apparcat, uti Paykull, loco citato, ip. se dicit. Tirh. Intlanoiphalo, quens bic descripsi, caput thorax et elytra nuda, omaino depilia, sunt.

\section{arefourcis}

0 17 T. striatus, fuscub; capite thoraceque obscurioribus; elytris rufis, apice nigris.

Habitu T. praecedenti simillimus; statura paulo majore. Longitudo $2 \frac{\pi}{5}-2 \frac{3}{4}$ lin.

Ceput orbiculatun, ore producto, thorace triplo minus, nigrun; autennis fusci:, basi rufis; orc ochracco.

Thotex nigricans, margine latcrali summo pallescente. 


\section{Táchinus. F.II.}

Elytra lufa ; apice, nigra; lineis duabus longindinalibus, subcrenato - punctatis, una disci, altera prope suturam, saepe obsoletis, inpressa.

Abdomen obscurum, segmentorum marginibus pallescentibus.

Variat colore elytrorum et pedum.

Var. I T. niger; elytrorum macula magna humcrali, margineque apicis summo, rufis; pedibus testaceis.

$V$ ar $2 T$. niger; pedibus, coleoptricque rufis; his, regione scutelli, maculaque magna angulorum apicis, nigris.

$V$ ar. 3 T. nigricans; ano, pedibus, elytrisque rufis; his, apice nigris.

$V a y+4$. obscure fuscus; ano rufo; coleoptris rufotestaceis, angulis apicis nigris; pedibus testaceis.

Habitat cun $T$. praecedente; minus autem frequens.

Slaph. strialus Oliv. Ent. St. n1. 37. pl. V. f. 47.

pusitato-strialus Payk. Fin. S. St. n. 6 .

O18 T. lunulnturs, rufus; capite, pectore, abdominisqute apice nigris; elytris nigro-cocruleis, basi summoque apicis marghine testaceis.

Hajilu T. praccedentium hujus farsiliae, elytris etiam crenato - striatis; capite autem ovato.

Iragitude $1 \frac{\hat{3}}{3}-2 \frac{x}{4}$ lin.

Cisput oblongo - ovatum, apicens versus sensim angustatuan; ore rufo testacco; antennis, articulis, tribus primis et ultimo rufo-festaceis, mediis fuscescentibus.

Coleoplye subquadrata.

Prdes testacci; capitibus femorum posticis nigris.

Ames niger, amsulo plerumque albicante. 
Oxyp. lumulatus Fabr. Ent. S. O. n. 3.

Staph. Iunulatus Linn. Fn. S. n. 845 .

- Payk. Mon. St. n. 41 et Fn. Suec. St. n. Gr.

Habitat in agaricis et boletis, cum $T$. praecedentibus.

19) T. atricapillus, nitidus, rufus; capite, pectore, scutello, abdominisque apice nigris; elytris nigro-coeruleis, macula humerali obliqua et margine apicali testaceis.

Habitu T. pracedenti sinillimus; statura autem majore, scutello et elytris circa scutellum nigris, semper differt Cactera omnia huic cum illo communia sunt.

Longitudo $3-3 \frac{\mathrm{T}}{4}$ lin.

Habitat cum $T$. praecedente, inulto autem frequentior. Stopli. atricap. Fobr. Sp. Ins. St. n. 19.

- Fabr. Ent. Syst. St. 11. 40.

- Payk. Mon. St. n. 35 .

- Payk. Fin. Suec. St, n. 60.

- Schrank Boica n. 877.

Oxyp. lunulatws Panzer Fn. G. H. 22. t. 15.

20 T. analis, niger; antennis, elytris, anoque rufis; pedibus testaceis.

Habitu T. praecedentium; statura autem paulo majore; capite orbiculato; tarsis anticis brevibus dilatatis.

Longitudo $3 \frac{\mathrm{x}}{5}$ lin.

Caput orbiculatum, nigrum; ore testaceo; antennis, capite thoraceque paulo longioribus, fuscis, articulis tribus primis ultimoque testaceis, hoc cylindrico, longiore quam in cospeciebus hujus generis, longitudine articuli primi, multo autem crassiore. 


\section{- Thorax coleoptrorum latitudine.}

Coleoptra thorace multo longiora; elytris, punctis qui. busdam disci majoribus obsoletis, vestigio quasi luneae crenato - punctae disci elytrorum specierum pracedentium, impressis.

Abdonen obtusum, nigricans; marginibus segmentorum fuscis; ano rufo.

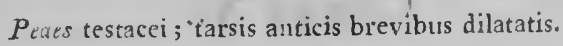

Hahitat Brunsuigae.

Staph. analzs Fabr. Ent. Syst. St. n. 35 .

- Pauk. Mon. St. et Fn. Suec. St, n. 34. $\alpha_{0}$

- Olivier Ent. St. n. 38. pl. III. f. 24.

Oxyporns bicolor Rossi' Fn. Etr. n. 625.

2I T. werdarius, niger; antenıis fuscis; thorace, pectore, elytris, anoque, rufis; pedibus testareis.

Habitu 'T. stricti (n. 16.); thorace autem latiore, apice minus angusto; coleoptris brevioribus, subpunctis.

Longitudo 3 lin.

Habirat Brunsuigae .

Staph. merdarius Oliv. Ent. St. 11. 39. pl. V. f. 45.

- analis Pcyk. Mon. St. et Faum. Suec. St. n. 34. Nar. $\beta$. 


\section{Genus XI. \\ O x y $\underset{y}{\mathrm{p}}$ or $\mathrm{r}$ u's.}

Pa lpi anteriores filifomes.

Palpi posteriores securidacei.

Corpus nitidissimum, elongatum, depile, convexiusculun. Coput maghixu, quadratum; anculis obtusis; laeve; quibusdam speciminibus thorace niajus, quibusdam thorace minus. Nondhoula poirectae, validac, Palpi; anteriores quadriarticulati, filiformes; posteriores securidacei, triarticulat, articulo ultimo maximo transverso triangulari. Antemnae, capicis longitudine, extrorsum crassiores com. pressae; articulis, primo elongato clavato, secundo minimo, tertio er quarto suborbiculatis, sequentibus trans. vercis, latitudine valde crescentibus, ultimo minore sub. orbiculato obtuso.

Thor ax convexus, antice truncatus, lateribus posticeque rotundatus, longitudine paulo latior, coleoptris angustior, laevissimus; ora laterali deflexa.

Coleoplra quadrata, thorace longiora; elytris laevibus, lineis duabus longitudinalibus interruptis crenato - punctis, una disci, altera prope suturam, impressis. 
Abdomen breviusculum, marginatum, obtustum; ano acittiusculo.

Pedes, capitibus femorum, anticis et posticis approximatis, mediis subremotis, anticis femore duplo brevioribus, ejis autem crassitie, medis femore plus duplo brevioribus, cjus autem crassitie, posticis minimis abcondits: tibiis ciliatis; tarsis gracilibus, articulo secundo reliquis paulu. hum longiore.

1 O. ufus, rufus; capite, pectore, scutello, coleoptrorum sutura ct apice, abdominis apice, femortunque capitibus nigris.

Longitudo $3-4$ lin.

Coput nigrum; antennis fuscis, basi rufis; palpis rufis.

Elytra nigra; macula magna humerali quadrata, rufo. testacea.

Habitat frequens in bolctis; rarior in agaricis.

Oxyp. rufus Fobr. Ent. Syst. O. n. 1.

- Pauk. Fu. Succ. O. n, r.

- Rossi Fn. Etr. n. 624.

- Otivier Fnt. O. 11. l. pl. I. f. r.

- Panzer Fn. Ins. G. H. 16. t. 19.

Staph. vufus Linn. Fn. Suec, n. 844.

- Siopoli Carn. 11. j07.

- Schrank Boica 11. \&91 et Austr. n. 438.

- De Geer Mcm. St. n. 10.

- Fourcroy Ent. Par. St. 11. 22.

- nigrofuluns Fourcr. Ent. Par. St. 11. 32.

Geoffy. Hist. St. n. 22. 
2 0 . muxillosus, testaceus; capite, thorace, coleoptrorunque angulis apicis obscurioribus.

Habitu, partiunque proportione forma et punctura $O$. praecedentis; thorace attamen minus transverso et rotunda. to, basin versus paululum angustiore.

Longitudo $2_{2}^{x}-3 \frac{4}{5}$ lin.

Colore variat:

$V$ ar. 10 . capite, thorace, angulisque apicis coleoptro. rum gris.

Oxyp. Maxillosus Fabr. Ent. Syst. O. n. z.

- Panzer Fn. Germ. H. 16. t. 20.

$V a r .20$. capite, thoraceque fuscis; angulis apicis coleoptrorum nigris.

$V a r .3 O$. capite, thoraceque rufescentibus; angulis apicis coleoptrorum fuscis.

I ar. $t$, capute, angulis coleopt prum apicis, thorace. que nigris, hoc punctis seu maculis dubus disci rufis.

$V a r .5$, minina, testacea ; capi:e tl:oraceque rufis; oculis nigris; angulis colcoptrorum apicis fuscis.

Habitat in sylvis, in agaricis; $O$. praecedente rarior. 


\section{Genus XII.}

\section{$S \quad t \quad e \quad n \quad u \quad s$.}

$P$ a $1 \mathrm{pi}$ anteriores triarticulati.

P 3 I p i posteriores filiformes.

Corpus elongatum, tcretiusculum, crassum, opacum, depile, cicatriculosum, seu punctum; punctis crassioribus.

Caput magnum, rugosum, thorace latius. Oculi maximi, prosilicntes. Palpi, anteriores longissimi, triarticulari, articulo ultimo clavato; posteriores triarticulati, breves, filiformes. Antennae medio tenues, apice crassae, capite longiores; articulis, primo valido, sccundo breviore, clavatis, tertio longissino tenuissimo, sequentibus longitu dine decrescente, filiformibus, octavo crassiore campanulato, nono et decimo crassissimis orbiculatis, ultimo suborbiculato seu subovato acuto.

Thorax ecretiusculus, medio latior, coleoptris angustior; ora laterali cicatricosa, vix, linea laterali subelevata, separata. 
Coleoptsa thoracis longitudine.

Abdomen subcylindricum, durum; ano acuto.

$\boldsymbol{P}_{e d e s}$ graciles, cursorii; capitibus femorum approximatis, ounibus brevissimis absconditis; tibiis laevibus, nudis; tarsis tenutbus.

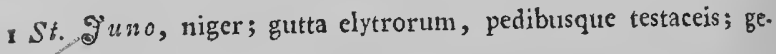
niculis nigris.

Longitudo $2 \frac{3}{4}$ lin.

Caput foveola media longitudinali impressum, i nigrum; antennis, capite duplo longroribus, obscure fuscis, articulo primo nitido; palpi testaces, anterioribus apice fuscis.

Thonax subfusiformis, canalicula meda longutudinali, subobioleta impressus,

Elytra, gutta disc1, apici attamen paulo propiore quam basi, rufo-testacea, nitente.

Prdes testacei, capitibus femorum, femorumque apicibus nigris.

Habitat Brunsuigae; rarior.

Staph. Funo Payk: Mon. St. n. 33. v. F.

Stenus

2 St. biguttat us niger: gutta elytiormin rufo testacea.

Habitu toto, partiunque forma et proportione St. prace cedentis; statura autem minore, punctis subtilioribus, palpis pedıbusque nigricantibus, obscure fuscescentibus.

Longitudo $2-2 \frac{\pi}{3} \operatorname{lin}$.

Habitat frequentissime in arenosis humidis, sub vegetabilibus putrescentibus in lacunis exsiccatis, interdum etiam 
sub lapidibus; semel in domo captus; nunquam autem cum St. praccedente.

Staph. biguttatus Lim. Fn. S. St. n. 85 i.

- Fabr. Ent. Syst. St. n. 36 .

- Rossi Fu. Etr.-11.623. var.2.

- Sihrank Austr, n. 446.

- Siliank boica n. 87 I.

- Panzer Fn. Germ. H. Ir. t. 17.

Pacderus bigutt, Oliv. Ent. P. 11. 4. pl. I. f. 3.

Stemris Juno Päyk. Fn. Suec. St. I. v. $\beta$. v.

Risenile \& ot.

3 St. oculatus, niger; palpis testaceis; antennis rufo-testa. ceis, articulo primo nigerrimo nitido; pedıbus testaceis, geniculis nigris.

Habitu toto, longitudine, punctura, partiunque forma et proportione St. praecedentis.

Captus in gramine, iucis uliginosis, haud frequens.

Slaph. oculatus Götre Beitr.

Sicnus Guno Payt. Fn. Suec. St. n. x. v. a.

O St. cicindeloides, niger; antemnis palpisque anterioribus testareis, apicibus fuscis; pedibus testaceo rufis; geniculis nigris.

Habitu, longifudine, punctura, partiunque forma et proportionc omnino St. Otinonis (n. i.); antennis autem palpisque testaceis, et defectu guttae elytrorum distinctus est. A. St. praecedente, statura majore, punctura crassiore, an. tennarum articulo primo testaceo \&c. satis differt,

Habitat Brunsuigae.

Staph. cicindeloides Sihaller Act. Hallens. Fom.I. re., 324. 
Staph. Buphthalmus Rossi Fn. Etr. St. n. 623. v. 3.

- clavicornis Scopoli Carn. n. 303?

Paeder. probosideus Olivier Ent. P. n. 5. pl. I. f. 5.

Dom. Scopoli, loco allegato, St. clavicorni suo tribuit, in. ter alios characteres, manifeste ad Stenum quendam referendos, "antennas semilincam longas, thoracem subtus rufo „villo pubescentem, abdomen villosum, elytris lucidius." Omnia haec ego in nullo Steno rcperi, et suspicor ideo, $S t$. clavicornem Scop. speciem distinctam esse.

5 St. olaviiornis niger, antennis testaceis, apice et articulo prino nigris.

Habitu St. oculato (n. 3.) similis; statura autem minore; pedrbus totis nigrus.

Longitudo $1 \frac{2}{3}-2 \frac{\pi}{3}$ lin.

Habitat Brunsuigae; captus, primo vere, in horto aulico, subb lapidibus in çuisquiliis; et, cun St. biguttato (n. 2.) sub vegetabilibus putrescentibus in lacuna exsiccata.

Staph. clavicornis Rossi Fn. Etr. n. 623. var. I.

6 St. Buphthalmus totus niger.

Habitu St. praecedentium; statura autem minore et breviore.

Longitudo $1 \frac{2}{3}$ lin.

Habitat in arenosis humidis; rarior; semel tantummodo captus, et quidem cum St. biguttato (11. 2.).

Staph. buphthalmus Sihrank Austr. 11. 445 et Boica n. 8770.

- clavicornis Panzer Fn. G. H. 27. t. 11. 
2 St. pallipes, niger; pedibus, palpis, antennisque testaceis; his autem articulis ultimis et primo nigris.

Habitu St. praecedentium; statura autem minore et paululum graciliore. Praeterea ab omnibus Stenis, pedibus totis testaceis, geniculis concoloribus, differt.

Longitudo $1 \frac{\mathrm{T}}{2}$ lin.

Habitat, cum St. oculato (11. 3.) in gramine, locis uliginosis, ubı duo hujus speciei specimina, copula juncta, prehendi.

Staph. clavicornis Fabr. Ent. S. St. n. 37.

8 St. fuscipes, niger; palpis, antennis, pedibusque fuscis.

Habitu quidem St. praecedentium; omnium autem minimus; thorace paulo breviore, pedibus rufo-fuscis, distincths.

Longitudo $1 \frac{\pi}{4}$ lin.

Habitat? - Brunsuigac.

St. circularis, nige:, nitidulus; thorace brevi, latitudine vix longiore.

Habitu, St. praecedentibus brevior.

Longitudo $\frac{4}{5}$ lin.

Anfennar et palpi fuscescentes; labrun testaceum.

St. circularis - Mus. Pr. Knoch.

Non potui sustinere, exemplum plurimorum Entonologorum sequi, omnes has Stenorum species in unam speciem redigentium. Characteribus gaudent constantissimis, proveniunt locis et temporibus diversis, et victitant nimis separatae, quam quod mihi persuadcre gossim, esse subspecies 
tantum speciei unius communis Sacpius magnam in: dividuorum hujus illiusve speciei multitudinem, uno eodem. que loco et tempore, reperi, rarissime autem cum aliis diversae spaciei mixtam; si hoc vero aliquando contigerit, semper attamen individua, eaque perpatica, speciei fuerunt, quan forsan omnium minime cum illa conjunxissem, (E. g. St. buphthalmi et St. biguttati; St. clavicornis et St. biguttati.) - Multo minus autem credo, varietatem magnitudinis et coloris partiun quarundam diffexentian sexualem respicere; experientia obstat. Dom. Paykull individua duo Steni, "gutta elytrorum testacea," copula juncta vidit; cgo ipse duo individua Steni pallipedis. 


\title{
Coleoptera Microptera
}

\author{
e $x$ o t i c s.
}

Ge nus I.

$S$ t. a phy 1 in us.

Fam. I.

I St. hivtus, nigcr; capite, thorace, abdominisque apice fulvis; colooptris cinereis, basi nigris.

Hubitu et partium forma as proportione St. maxillosi.

Longiludo 8- 10 lin.

Corpis, supra lanuginostun; infra nudun nigrum siti dum, cxcepta segmenti penultimi basi fulvo - lanuginosa.

Coput fulvum; oculis, ore antennisque nudis nigris.

Thorax fulvus, basi nuda nigra; linca media longitudinali nitida.

Siutellun nigro - sammetinum.

Coleoptra pilosa, basi nigra, apice cinerea subobsiure ncbulosa. 
Abdomen nigrum; segmentis tribus ultimis fulvis.

Habitat Bremae \&c.

St. hirtus Linn. Fn. Suec, n. 839 .

- Fabr. Ent. Syst. St. n. 2.

- Payk. Moll. St. et Fn. Suec. St. n, s.

- Penzer Fn. Ins. Germ. H. 4. t. 19.

- Bombylius De Geer Mem. St. n. 5.

2 St. villosus, niger, nitidus; thoracis angulis anticis, pectore, coleoptrorum vitta transversali, abdominisque medio, cinercis.

Habitu, partiunque forma ac proportione, St. maxilloso simillımus; angulis autem anticis thoracis, pectore, segmentisque modo cuobus mediis cinereo - villosis distinctus.

Longitudo $5 \frac{3}{4}$ lin.

Ablomen supra nigrum, segmentis duobus mediis lateribus cinereis.

Habitat in America septentr.

St. villosus - Mus. Pr. Knock.

\section{F a m. II.}

3 St. macrocephalus, nigricans, subuitidus; clypeo testaceo; coleoptris fuscis.

Habitu St. similis; statura autem majore, clypeo testaceo, capite thoraceque subaeneis \&c. satis differt.

\section{Longitudo 8 - 9 lin.}

Caput, thorace latius, nitidum, nigro - aeneum, linea media longitudinali obsoleta laevi nitida; clypco testacco; antennis, capite longioribus, extrorsum tenuioribus, arti- 
culis tribus ultimis rufescentibus; palpis fuscis, articulis apice pallıdiorıbus.

Thorct subnitidus, nigro-aeneis; linea media longitudinali obsolcta laevissima; coleoptris paulo angustıor et longior.

Colecptra transversa, opaca, rufo-fusca.

Abdomen subnitidum, fusco-nigrum.

Pedes nigro-fusci; tarsis pallidioribus.

Habitat in montibus Hercyniae.

St. mawoceph. - Mus. Pr. Hellwig.

4 St. tomentosus, niger, opacus; antennis extrorsum subcrassioribus.

Habitu St. olentis; capite auten orbiculato minore, antennis extrorsum paulo crassioribus, thorace coleoptrisque paulo longioribus, et statura graciliore.

Longitudo 6 lin.

Corpus opactun, subtilissime confertissimeque punctum, pilis brevissimis depressis vestitum.

Caput orbiculatuın, thorace paulo minus.

Thorax latitudine pauiulum longior.

Coleoptra subquadrata.

Hahitat in America septentr.

St. tomentosus - Mus. Pr. Knoch.

S St. cher, riger, nitidus; àntennis tarsisque fuscis.

Habilu St. Morionis; capite autem et thorace nitidioribus, parcius punctis; colcoptris latitudine paulo longioribus.

Longituido $7 \frac{\pi}{2}$ lin. 
Caput et thorax nitidiora quam reliquae corporis partes, linea media longitudinali laevi nitidissima.

Habitat in America septentr.

Si. ater - Mus. Pr. Knoch.

o St. violaceus, niger, nitidulus; coleoptris violaceis.

Habitn St. cyonei; capite antem et thorace nitidioribus, crassius, ucc confertissime, punctis; thorace paulitum convesiore.

Longitudo $G_{4}^{\mathrm{r}}$ lir.

Cisput punctum; linea media longitudinali laevi, nitida; nigruw, subviólaceo- niteîs.

Thorax niger, subiolaceo-et cyaneo-nitens; linea media longitudinali deficiente.

Habitat in America septentr.

St. violaceus - Mus. Pr. Knoch.

7 St. $\approx$ onatus, cupreus, subnitidus; femoribus, abdomineque nigris; segmentorum marginibus cinnabarnis.

Hobitu St. aeneocephali; stacura'auten longiore, punctura crassiore et colore diffèrt.

Longitudo $7 \frac{1}{2}$ lin.

Caput punctum, linca longitudinali deficiente, cupreo. aeneuru, infra nigrimu ntidum; clypeo testacto; oculs et mandıbulis nigris.

Thorax cupreo-aeneus, punctus, liriea media longitudinali obsolsta, lacvi, basin versus latiore.

Ablomen nigrum, apice rufum, marginibus segnento. rum connabarinis.

Pedes nigri, tibiis tarsisque rufis. 


\section{Staphylinus. F. It}

Habitat in America septentr.

Slaph. - Mus. Pr. Hellivig.

8 St. baltimorensis, fuscus, nitidus; capite thoraceque nigris nitidıssimis.

"Habitu transit ex hác Staphylinorum familia in sequentem. Capite sciliset nitido, parumpuncto, medio laevi, et thoracis punctis in series subdispositis, potius ad famliam sequentenn nunerandus est. Thorace autem quadrato, apice hand angustiore, cum reliquis huits familiae Staphylmis сонgrut.

Longitudo 5 - 6 lin.

Caput orbiculatum, thorace latils, punctum; punctis paucis subtilıbus; medio laevissinun nitidissirom, nigrum; antenris capite longionibus, extrorsun subcrassioribus fuscesecntibus.

Thosax quadratus, coleoptris angustior, convexior quam reliquis huius familiae Staphylinis, nitidissimus, medio lacvissinus, lateribus punctus'; punctis haud confertis, in serieš decem vel duodecun subdispositis.

Coleoptre quadrata, subtiliter cicatriculosa.

Pedes, tarsis anticis dilatatis.

Habitat in America scptentr.

St. brllinorensis - Mus. Pr. Knoch.

S St. pedator, niger, subnitidus; antennis pedibusque rufis.

Habiti, partiurique forina ac proportione St. weinectethli maximi; statura autcm paulo maiore, capite thoracegue crassius punctis et minus nitidis.

Jongitulo ? lin. 
Caput nigrum, linea media uitida laevi; palpis antennisque fuscescentibus, his articulo primo rufo.

Thorax linea media longitudinali nitidissima subelevata. ... Habıtat - Mus, Comı, de Hoffnunnsegg.

Io St. fuscatus, niger, opacus; capite thoraceque nitidis; hoc subtiliter nec confertim puncto.

Halitu partiumque forma ac proportione variętati latiori St. Ggeneocephali simillimus; capitę autem thoraceque paulo is crassius nec confertisimine punctis.

Longitudo 6 lin.

Caput et thorax linea media longitudinali obsoleta laevis. ais sinar nitidissima.

Antemnar et pedes fusci.

Coleopira ct abdomen opaça, nigricantia, subgrisescentisericantia.

Habitat - Mus. C. de Hofjorionunsggg.

It St. cinnantopterus, nigricais, subnitidus; coleoptris, sega mentorun marginibus, tarsis, tibiisque rufescentibus.

Habitu St. aeneocepholi; capite autenı et thorace crassius punctis, et minus nitidis,

Longitudo $5 \frac{r}{2}-6$ liu.

Caput et thorax aenei, subobscure rufescentes:

Addomen subgriseo - sericans.

Habitat Baltimore.

St. cinnamopt. - Mus. Pr. Knoch.

12 St. fossator niger, subopacus; elytris nigro-fuscis, macula apicis tulvo - testacea. 


\section{Staphylinus. F. II:}

Habitu St. fossori similis ; thorace autem breviore, Coleoptris paulo latioribus.

Longitudo $6 \frac{\mathrm{r}}{2} \mathrm{lin}$,

Caput et thosax quadrati; linea mcdia longitudinali hevi, basi nitidissima.

Coleoptra longitudine paulo hationa, nigro-fises, macula elytrorun apicis subquadrata.

Habitat in America septentr.

St. fossator - Mus, Pr. Kirocks.

13 $S t$, maculosius, pubescens, griseo-nebulosus, infra flavosericans; coleoptris fuscescentibus; tibiis et tarsis testaceis.

'Habitu St. pubescentis; statura autem maiore, colore et pube differt.

\section{Longitudo 9 - II lin,}

Corinus pube brevissima tenui tectum.

Coput quadratun, angulis obtusis, thoracis fere magnitudine; suprasubolivaceo-aeneutn, punctum; infra nigrum, 'nitrdum; linea media longitnduali deficiente; fronté corca oculos rufescente; ciypeo flavescente seu rufo-testaceo ; aitteunis, caputis longitudine, cxtrorsum subcrassioribus, fuscis, apice rufo-sericantibus, articulo primo apice rufo.

Thorax, colore et punctura capitis; linea media longitudinali, laevi, nitida, basin versus latiore.

Coleoptra obscure rufescentia, stibfusco - nebulosa.

Scutelhnm nigrum, medio sammctinum.

Abdonun supra pilis griséo - flarescentibus tmuibus tecrun, segmentis, medio, puttctis duobus obscuris; inira subflavescenti-sericants, marginibus segmentorum fiavis.

Prtus nigrum, pills brevibus teriuibus flavis secicans. 
Pedes testaceo-rufi ; capitibus femorum nigris; femorìhus anticis ot posticis nigris, margmbus et geniculis rufescentibus; fenoribus mediis nigris, margine inferıore et niculis rufis,

Habitat Baltinore.

St. maculosiss - Mus. Pr. Knoch.

14 St. cingulatus, nebulosus; pedibus antennisque fuscescentibus; pectore, abdominis apice, segmentorumque basi ventre, fulvo-sericantibus.

Habitu, partiumque forma, proportione, punctura, co. lore et signaturıs St. nebulosi; pectore autem, segmentis tribus ultimis supra totis, ounibus vero infra basi, fulvo. sericantibus, nee non statura maiore differt.

Longitudo 7 - 9 lin.

Habitat in Anerica septentr.

S\% cingulatus - Mus. Pr, Kinoch.

I5 St. chloropterus, viridi-aeneus; abdomine nigriçante, margiuibus segmentorum rufis; pedibus testaceis, fenoribus niģro - annulatis.

Hetitu ct partum forma ac proportione St. muvini.

Longituito a. lin.

Caput nitidulum, confertissime punctum; linca media longitudinali, laevi, nitida; subviridi-vel cupreo-aeneum; antennis palpisque rufescertibus.

Thorax nitidulus, colorc capitis, confertissime punctus; linea nucdia longitudinali, laevi, basin versus, latiore nitidissina.

Sufellun nigro-sammetinum. 
Coleeptrc nitidula, viridana, smaragdi colore, subobscure nebulosa, margine apicali ciliis brevibus flavescentibus fimbriata.

Abdomen nigrum, opacum; apice, segmentorumque margimbus rufis.

Pectus pilis tenuibus flava - grisescentibus sericans.

Pedes testacei; macnla sen annulo femorum, capitibus. que femortm nigris; his grisescenti - sericantibus.

St, chloropterus (Crentzer), Panzer Fn, Ins, Germ. H. 20 t. 36.

\section{Habitat in Austria.}

\section{Fam. III.}

16 St. cinctulus, niger, niridus; pedibus antennisque fuscescentibus; elytris aeneis; marginibus segmentorum primi ot secundi albidis.

Habitu quidem St. cenrecephato e familia secunda similis; thorace autem suborbiculato, scriebus dorcalibus tripunctis.

Longitulo 5 lin.

Caput orbiculatum, thorace paulo minus, laeve, nitidum, nigrum, basi punctum; antenuis, capite thoraceque brevioribus, fuscescentibus; oculis ovatis unagnis.

Thorax subquadratus; apice vix angustior, angulis minus deflexis quam in cospeciebus huins familiae; coleoptris paulo ininor; seriebus dorsalibus tripusctis, puncto ultimo remoto, ad basis marginen sito; seriebus lateralibus tripunctis; punctis marginalibus pluribus, duobus autem majoribus.

Coleoplra pilis brevibus tecta, subviridi - aenea. 
Habitat in Bengala.

St. cinctulus - Mus. Pr. Helluig.

I7 $S t$. cyanipennis, niger, nitidus; coleoptris vel cyaneis, vel coeruless, vel viridibus.

Habitu, partiunque forma ac proportione St, aenei; punctura auten subuliore et elytrorum colore differt.

Longitudo 5 lin.

Caput orbiculatum, vel thorace angustius, vel eius latitudine; punctis quibusdam subtilibus basi impressum.

Thorax seriebus dorsalibus quadripunctis, lateralibus ar: cuatis tripunctis, marginalibus bipunctis.

Coleoptra pilis brevibus tenuibus tecta.

$P$ edes, tarsis anticis gracilibus.

Habitat in America septentr.

St. cyanipennis Fabr. Ent, S. St, n, 29.

$18 \mathrm{St}$. metallicus, niger, nitidus; elytris aeneis; thorace sẹ: riebus dorsalibus quinquepunctis; capite orbiculato.

Habitu St, aenei; statura autem graciliore, splendore mi: nus nitido,

Longituda $3 \frac{3}{4}$ lin.

Caput orbiculatum, thorace minus; antennis capite thoraceque vix brevioribus.

Thorax seriebus dorsalibus quinquepunctis, lateralibus tripunctis, marginalibus bipunctis.

Colecpira quadrata, subpilosella, coeruleo - viridiqueaenea. Forsan nitor coeruleo-aeneus fortuitus, et viridiaenẹus solụs proprius est. 
Unicum, quod possideo, individuum huius speciei, verisimle cum aliis Staphylinis in fimo captum est prope Brunsuigam.

19 St. Virgo, niger, nitidus; thorace seriebus dorsalibus sexpunctis; capite suborbiculato.

Habitu St. variante gracilior.

Longitudo 3 lin.

Caput latitudine paulo longius, thorace angustius; antennis, capitis thoracisque longıtudine, gracilibus.

Thorax seriebus dorsalibus sexpunctis, lateralibus tripunctis, marginąlibus bipunctis, punctis șubtilibus.

Colreptrios quadrata depilia.

$P$ edes, tarsis anticis subdılatatis fuscis.

Habitat in Lusitania.

Staph. - Mus, Com. de Hoifmannsegg.

20 St, unbrinus, niger, nitidus; abdomine elytrisque subopacis; palpis pedibusque fuscis; thorace seriebus dorsalıbus quinquepunctis; capite orbiculato.

Habitu St. atrati.

Longinudo $3 \frac{\mathrm{T}}{2}$ lin.

Caput orbiculatum, thoracis fere magnitudine.

Coleoptro quadrața, subscricantia, depilia.

Abdomen subsẹricans,

Habitat in America septentr.

St. umbrinus - Mus. Pr. Knoch. 
21 St. umbratilis, niger, nitidus; coleoptris aenescentibus; N. palpis pedibusque pallide fuscis; thorace seriebus dorsalıbus quadripunctss; capite orbiculato.

Habitu, St. praecedente minor et gracilior; capite mino. re; coleo tris latutudine paulo longioribus

Longitudo 3 lin.

H.bitat in America septentr.

St. - Mus. Pr. Knoch.

22 St. ebeninus niger, nitidus; peribus piceo-fuscis; thorace seriebus dorsalibus quinquepunctis; capite orbiculato.

Habitu St. atrati; punctura autem thoracis et colore pedum distinctus.

Longitudo $3 \frac{\mathrm{T}}{2}$ lin.

Capret orbiculatum, nitidissimum, thorace paulo angustius; antennis, capite longioribus, palpisque obscure fus. cescentibus.

Thorax nitidissimus.

Coleoptra subquadrata, latitudine paulo longiora, pun: cta, nitida, pilis tenuibus grisescentibus vestita.

Abdomen nigrum, nitidum, pilis tenuibus grisescentibus sericans.

Habitat Brunsuigae.

23 St. thoracicus, niger, nitidus; basi antennarum, thorace, pedibus, elytrisque rufis.

Habitu St. marginati; statura autem paulo graciliore et minore, thorace paulo angustiore.

Longitudo 3 lin. 


\section{Staphylinus., F. III.}

Caput, subovatum, thorace minus, nitidissimum, nigrum; palpis, antennarumque articulo primo rufis; antennis, ca. putis thoracisque longitudine, articulo ultimo pallido.

Thorax nitidissinus, rufus; seriebus dorsalibus sexpun* ctis, lateralibus tjipunctis, marginalibus bipunctis.

Coleoptra quadrata, subuitida, subrilissime puncta, obo scure rufa, depilia.

Abdomen nigrum, subgrisco-sericans.

Habitat in Anerica septentr.

St. thorccicus - Mus, Pr. Knoch.

${ }_{24}$ St. rufipes, niger, nitidus; antennis, palpis, pedibusque rufis; thorace seriebus dorsalibus tripunctis.

Habitu, partimque forma ae proportione St. marginati. Longitudo $3 \frac{\mathrm{r}}{2}$ lin.

Caput suborbiculatum, thorace angustius, nitidurs; ocu. lis magnis oblongis.

Thorcx, coleoptris paulo angustior, nitinus; seriebus dorsalibus tripunctis, punctis subtilibus; seriebus lateralibus obsoletis; puncto marginali uno distincto.

Coleoptra quadrata, subopaca, devilia, grisescentia, subtilissime confertissimeque puncta.

Abdomeri subopacum, nigrum; ventre viridi-aeneo.

Prdes rufi: capitibus femorum medis et posticis nigris.

Habitat in Bohemia.

St. rufipes - Mus. C. d̉e Hoffinannsegg.

25 St. sericans, nitidus, fisco-nigricans, subsericeo - nitens pedibus pallidis thorace seriebus dorsalibus sexpunctis; ca. pite orbiculato. 
Habitu St. fusci'; thoracis autem seriebus dorsalibus sexpunctis.

Longitudo $2 \mathrm{lin}$.

Thorax colore fugacissimo obsoleto griseo sericans; seriebus dorsalıbus sexpunctis, lateralıbus tripunctis, puncto márginali uno.

Colevptra quadrata depilia,

Habitat in Anerica sepientr.

St. nitens - Mus. Pr, Knoch.

$26 S_{t}$. brunneus, nitidus, fusco-nigricans; pedibus rutis; thorace seriebus dorsalibus sexpunctis; capite orbiculato.

Statura gracilione et longiore, capite thoraceque proportionaliter mineribus, a St. pracecdente differ:.

Longitudo $2 \frac{\mathrm{r}}{2} \mathrm{lin}$.

:i3. Caput orbiculatum, thorace paulo nimus, nigricans; palpis, antenuarumque basi rufescentibus.

Thorax vel rufo-vel nigro-fuscus.

Abdomen subgriseo-sericaus.

Habitat in America septentr.

St. brunneus - Mus, Fr. Knoch.

27 St. praecox, testaceus, nitidus; sapite et thoracis disco fuscis.

Longitudo 3 lin.

Caput subcrbiculatum, thorace angustius, fuscum; ore, antennarumque basi pallitie rufis; his capite thoraceque brevioribus,

Thorax, coleoptrorum latitudine, fuscus, testaceo-marginatus; seriebus dorsalibus tripunctss. 
Coleoptra testacea, latitudine paulo longiora, subopaca, puncta, depilia.

Abdomen coloribus variis aeneis nitens.

$P \boldsymbol{P}$ des testacei; tarsis anticis dilatatıs.

Habitat in Lusitania.

St. - Mus. Comitis de Hoffinannsegg.

28 St. laticollis, niger, nitidus, anterinis, palpis, elytris, pedibusque rufescentibus; thorace serıbus dorsalıbus tripunctis; capite orbiculato.

Habitu quidem St. nitidi; thorace autem medio haud latiore, angulis apicis haud declivis, antennis multo gracilio* ribus, satis differt.

Longitulo $4 \frac{T}{3}$ lint.

Caput suborbiculatum, thorace minus, nitidissimun; palpis rufis; anterinis, capite vix paulo longiorıbus, gracilibus, fere filiformubus; fuscis; articulo primo interdum rufo.

Thorat suborbiculatus, nitidissimus, lateribus declina. tus; seriebus dorsalibus tripunctis, lateralibus bipunctis, punctis subtilibus; puncto autem marginalı uajore.

Coleoptre quadrata, subtiliter et confertim puncta, pilis brevibus tenuibus tecta, castanca vel nigro - rufa.

Abdomen nitidum, pilis griseis tenuissimis sericans.

$P$ edes rufo-fuscescentes, apice interdum pallidiores; tar. sis anticis dilatatis.

Habitat Baltimore.

St. laticollis - Mus. Pr. Knoch. 
29 St. vestralis, nitidus, nigricans; basi antennarum, podi. bus, segmientorumque marginibus ventre, rufis; thorace seriebus dorsálibus quiriquepunctis.

Habitu St. subitiformis.

Longitudo 3 lin.

Caput orbicilatuin, thorace angustius, nigrurn; ore rn.

fo; antenis, capite longioribus, fuscis, articulo prino rufo.

Thorax; seriebus dorsalibus quinquepunctis, punctis tribus medis approxinatis; seriebus lateralibus tri - vel quadrı. punctis, areuatis; marginalibus bipunctis.

Coleoptra quadrata depilia.

Pédes rufo-testaceí.

Habitat in Lusitania.

St. - Mus. Com. de Hoffmannsegg.

so St. obscurus, niger, nitidus; thorace seriebus dorsalibus quinquepunctis; capite suborbiculato.

Habitu St. opaci; statura auten paulo graciliore, capite paululum maiore, capitibus femorum anticis (quae St. opaco semper piceo-testacea sunt) nigris \&c. differt.

Longitudo fere $3 \mathrm{lin}$.

Caput thorace patilo angustius.

Coleoptra latitudine paulo longiora, pilis sparsis tecta.

Pedes obscure fuscescentes,

Habitat Brunsuigaé.

3I St. conteminatus, niger, nitidus; coleoptris subsanguineo-nitentibus; thorace seriebus dorsalibus quinquepun. ctis; capite suborbiculato. 
Hebitu, medium tenet inter St. bipustulatun et St, san guinólentu'tit.

Lonigituito $3 \frac{\mathrm{T}}{2} \mathrm{lin}$.

Coput suborbiculatum, thorace paulo minus, aritennis capite paululun longioribus, crassioribus et brevioribus quam in speciebus affinibus.

Thacrax St. bipustulati, paulo longior et angustior quan in St. scuguinolento; seriebus dorsalıbus quinquepunctis, pun1. ctis tribus mediis approximatis.

$P$ edes fuscescentes; capitıbus feinorum concoloribus, vis paulo pallidioribus.

Habitat Bnnsuigae.

${ }_{32}$ St. finetcrius, niger, nitiỏus; elytris acneis; pedibus pallidis; thorace seriebus dorsalıbus quadripunctis; capite subovato.

Hebitu St. ochropodis; thorace antem 'scricbus dorsalibus quadripunctis', statura maiore.

Longitudo $2 \frac{r}{2}-\hat{\gamma} \frac{T}{4}$ lin.

Caput subovatum, thorace plerunque paulo minus, ra. lius thoracis magnitudine; antennis vix capitio thoracisque longitudine.

Thotat St. ochropolis, seriebus autem dorsalibus quadris punctis.

Culenter subviridi - aerea, subpilosa.

Abiomen nigtum, interdum pilis grisescentibus vestitum.

Pedes vel testacei, vel fuscesceites; capitibus femorum anticis compressis, nitidissimis, pallidis,

Habitat Brusuigac, in fimo bovino et equino. 
33 St. sordidus, niger, nitidus; elytris aencis; thorace seriebus dorsalibus quadripunctis; capite suborbiculato.

Habitu et magnitudine Staph. ochropodis; thorace autem seriebus dorsalibus quadripunctis, capite paulo minore quam thorax, pedibus nigris.

Longitudo $2 \frac{\mathrm{r}}{2}$ lin:

Thorax St. ochropodis.

Habitat in fimo; cum St. praecedente.

34 St. Anthrax, nitidus; nigricans; pedibus rufis; thorace subqquadrato, seriebus dorsalibus quinquepunctis.

Habitu, parciumque forma proportione ac punctura Staph. ochropodis.

Longitudio 3 lins.

Capnt suborbiculatum, thoracis magnitudine.

Thorax antice haud angustior; subquadratus, latitudine paulo longior, nigro - fuscus.

Coleoptró quadrata, obscure fuscescentia, depilia.

Habitat in America septentr.

St. anithrax - Mus. Pr. Knoch.

\section{Fam. iv.}

sts St. emmesus, niger, nitidus; thorace, elytris, pedibus, änoque rufis.

Habitu, partiunque forma ac proportione St. ochracei; differt autem punctura thoracis et colore.

Ĺongitudo $2 \frac{3}{4}$ lin.

Caput nigerrimum; antemis, capitis longitudine, fuscis, basi rufescentibus; palpis rufis.

Thorax rufus; sexicbus punctorun St. elongati. 
Colcoptra testaceo - rufa, puncto - striata.

Habitat in America septentr.

St. ennuesus - Mus. Pr. Knoch.

36 St. longiceps, nigricans, nitidus; antennis pedibusque pallide fuscis; thorace lateribus nuthipuncto.

Habitu, partiumque forma ac proportione omnino St. ochracei; punctura autem thoracis differt.

Longitudo $2 \frac{3}{4}$ lin.

Thorax subtiliter, nec confertissime, punctus, linea media longitudinali lata laevissima; punctis interduın in series octo obsoletas subdispositis.

Coleoptra piccscentia.

1. Habitat in Lusitania.

St. longieeps - Mus. C. de Hoffmannsegg.

37 St. punctulatus, niger, nitidissimus; antennis pedibusque fuscescentibus; thorace lateribus multipuncto.

Habitu, partiunique forma proportione ac punctura Siaph. ochrecei; statura autem maiore - An, cum St. praecedente et St. oihraceo, ciusdem specici?

Longitudo $3-4$ lin.

Cospus nitidum, nigricans vel subfuscens, subacneonitens.

Coput subtiliter punctum, medio laeve, nigrum; anten. sis palpisque rufescentibus seu fuscis.

Thorax ut in St. praccedente.

Coleopista puncta, hand puncto- striata.

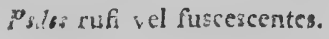


Habitat in Lusitania.

St. qunctulat. Mus. C. de Holfmannsege.

38 St. glabratus, niger, nitidus; elytris rufo-testaccis; thorace seriebus dorsalibus sexpunctis.

Habitu, partiumque forma ac proportione St. glabsi; statura autem multo maiore.

Longitudo 5.- 6 lin.

Caput, laeve, nitidum, basi punetum, nigrum; antennis et palpis fuscis.

Therax, sericbus dorsalibus sexpunctis, lateralibus quadripunctis, marginalibus tripunctis, ultimis duabus apice conjunctis uti in St. glabro, ochraceo \&c.

Coleoptra puncta; punctis crassis nec confertissimis; obsolete subpuncto - striata.

Pedes, femoribus obscure fuscis, tibiis tarsisque pallide fusçis seu rufescentibus.

Hahitat in Lusitania.

St. - Mus. Com. de Hojinannsegg. 


\section{Genus II.}

\section{L a throbium.}

I L. bicolor, nigrum, nitidum; thorace, elytris, anoque fusco-castancis; pedibus testaceis.

Habitu, partiunque forma ac proportione omnino $\mathrm{L}$. badii.

Longituto $4 \frac{\mathrm{T}}{\mathrm{S}}$ lin.

Caput confertin punctum, nigrum; palpis antennisque fuscis; his, capitis thoracisque longitudine, articulo primo rufo.

Thorax confertim punctus, linea media longitudinali laevi nitida.

Abdomen nigrum, segmentis duobus ultimis fusco - castaneis.

Pedes sestacei ; capitibus femorun rufis; tarsis tenuibus. Habitat in America septentr.

Paederus bicolor - Mus. Pr. Knoch.

2 L. pallipes, nigricans, nitidum; pedibus testaceis; ore an. tennarumque articulo primo rufis.

Longitulo $4-4 \frac{\mathrm{T}}{2}$ lin. 
- Corpues nigrum seu obscure fuscum.

Coput ovatum, thorace paulo latius et brevius, vel mage nitudine thoracis, nigrum, punctum; antennis, capite thosaceque paulo brevioribus, gracilibus, extrorsum vix paulo crassioribus, fuscis, articulis, primo rufo longissimo ut in 1. fraticorni, sequentibus elongato - campanulatis longitudine decrescente, ultimo orbiculato acuminato; ore rufo, mandibulis nigris falcatis.

Thorax coleoptris angustior, at vix paulo brevior, nitidissimus, punctus; linea unedia longitudinali laevissima gla. berrima.

Coleoptre nitidula, puncta, punctis cicatricosis.

Abdomen subpilosellum.

Pciles graciles, testacei; capitibus femorum rufis.

Habitat in America septentr.

Paederus pallipes - Mus. Pr. Knoch.

3. Lo fitum, nitidum, pallide fuscum; antennis pedibusque rufescentibus; capite nigricante; thorace elytrisque puncto. striatis.

Flabitu, nagnitudine, partiumqtie forma proportione ac ptunctura onnino L. sequentis. An hujus varietas junior?

Caput nigricans; antemis fuscis, articulo primo rufo; palpis rufis.

Thorax obscure fuscus.

Coleoptra fusco +rufesccatia.

Abdomen infra rufeseens, supra fuscum, tenuissime griseo-sericans.

Pides antici pallide rufi, medii fusci. 
Habitat in America septener.

Pacderus politus - Mus. Br. Knosh.

4 L. longiusculum, nigrum, nitidum; ore, antennis, clyoris, pedibusque rufescentibus; thorace elytrisque punctostriatis.

Hobitu, partiunque forma ac proportione L. elangati; punctura autem difîert.

Longitudo 3 lin.

Coput nitidum, subtiliter vage punctum, medio lacvissimum, nigrum; ore antemisque rufescentibus; his gracilibus, capitis thoracisque longitudine vel paulo longioribus.

Thorax nitidus, laevis; scriebus dorsalibus novempunctis, lateralibus et marginalibuis octopunctis; punctis subtilibus.

Colegptra subnitidula, puncto = striata; striis interdum -bsoletis; fusco-castanea.

Ablomes nigrum; segmentis tribus ukimis interdum obscure rufis; pilis brevibus tentubus grisescentibus tectum.

Pedes pallide rufi; tarsis anticis brevibus dilatatis.

Hauitat in America septentr.

Poederns longiusculus - Mus. Pr."Knoch - Coleoptris distincte puncto-striatis; abdomine nigro, segmentis ultinis margine subpallidis.

Habitat etiam in Lusitania. 
Mus. Coin. de Hoffmannsegg - Coleoptris obsolete pun. cto-striatis, ano rufescente.

5 L. gracile, uigrum, nitidum; ore, antennis, pedibus, co. leoptrorum et abdominis apice rufis.

Habitu, partiumque proportione forma ac punctura $\mathrm{L}$. elongati; statura autem multo minore, nitore splendidiore \&c. distinctum.

Longitudo 3 lin.

Coleoptra basi nigra, apice rufa; sutura attamen tota nigra.

Habitat in Lusitania.

Staph. gracilis - Mus. Com. de Hoffuannegg.

6 L. depressum, nigrum, nitidum, deplanatum; antenuis pedibusque fuscescentibus; coleoptris puncto - striatis, rufis, basi nigris.

Habitu ab omnibus cospeciebus satis discedit.

Longitudo $3 \frac{x}{2}$ lin.

Coput quadratum, angulis obtusis, apicem versus vix paulo angustius, depressum, magnitudine thoracis, nitidum, subtiliter, nec confertissime, punctum, nigrum; ore rufotestaceo; anteunis filiformibus, capite thoraceque vix longioribus, fuscis, articulis, primo valido, secundo brevi, tertio paulo longiore guam secundus, clavatis, sequentibus longitudine decrescentibus, ultimo ovato acuto. 
Thorax latitudine paulo longior, depressus, basin versus subanyutatus, nitidus, subtiliter, nec confertissime, punctis, angulis anticis acutis.

Coleoptra plana, subrectangula, thorace paulo longiora, subnitida, puncta vel puncto-striata.

Abiom n planum, nigrum; ano fuscescente.

Pedes rufi; femoribus posticis et capitibus fenorum nigricantibus.

Habitat in Lusitania.

Mus. Cons. de Hofunannsegg. 


\section{Genus III.}

$P$ a e d e r u s.

P. oovticinus, subnitidus, fusco-nigricans; ore, antennis, coleoptris, thorace, pedibusque pallidioribus.

Habitu P. castanei; statura autem breviore et minus gra. cili, capite et thorace latioribus \&ic, satis differt.

Longitudo $2 \frac{3}{4}$ lin.

Corpus supra obscurum, infra pallidum; capite, thorace, elytrisque nitidulis; subtilissime et confertissime pune etis, punctis oculo bene armato conspicuis.

Caput quadratum, magnitudine thoracis.

Thorax quadratus, basin versus vix ac ne vix quidem angustatus, coleoptris paulo minor, rufo-fuscus; linea we dia longitudinali laevi nitida.

Coleoptra quadrata, pallide picea.

Abdomen nitidulum, griseo-sericans; supra obscure fus. cum, marginibus segmentorum pallidis; infra rufescens,

Pedes ruf.

Habitat in America septentr.

Paed, corticinus - Mus. Pr. Kroch. 
a $P$, rufico $2 l i s$, nitidus, thiger veh subcyanescens; coleoptris cyaneis; thorace rufo.

Stahura, magnitudine, partiumque forma proportione ac punctura P. Tittorclis.

Caput; palporun anteriorum articulo medio rufo; apice interdum fuscescente.

Thorax subtiliter vage punctus,

Habitat sub lapidibus, in Germania, Lusitania.

P. Tuficollis Fabr. Ent. Syst. P. n. z,

- Panaer Fr. Germ. Y. 27. t. 22.

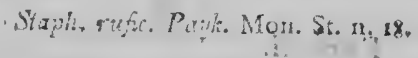




\section{6}

\section{Genus V:}

A le o chara.

F a m. II.

1. Aichroa, nigra, nitida; pedibus elytrisque testaceis.

Habitu omnino Al. Boleti; statura autem paulo graciliore. Longitulo I $\frac{\mathrm{T}}{5}$ lin.

Caput thorace uninus, rigrum; anternis fuscis, capite thoraceque longioribus, articulo primo rufo.

Thoorax transversus, lateribus rotundatus, nitidus, foveola ante scutellum impressus.

Coleoptra quadrata.

Habitat in America septentr.

Al. dichroa - Mus. Pr. Knoch.

\section{F a m. III.}

2 A. lata, Migra, nitida; coleoptris brevissimis.

Habitu omnino Al. fuscipedis maioris; tota autem nigra, coleoptris brevioribus, elytris quadratis.

Longitudo $2 \frac{\pi}{3}-3$ lir.

Habitat in America septentr.

Al. lata - Mus. Pr. Knoch. 


\section{Aleochara. F. III. $\quad 187$}

3. bimaculata, nigra, nitida; elytris apice rufo-testaceis; thorace obsolete bisulcato.

Habitu Al. fuscipedis; statura autem paulo angustiore, antennis gracilioribus, thoracis sculptura \&c. ab illa discedit.

Longitudo $2 \frac{\pi}{4}-2 \frac{3}{4}$ lin.

Caput nigrum; antennis, capite longioribus, palpisque fuscescentibus.

Thorax nitidus; foveis ante scutellum duabus obsoletis longitudinalibus, dimidii thoracis longitudine, punctis, im. pressus.

Coleoptra nigra, seu obscure fusca; macula anguli interioris elytrorum apicis testacea seu rufo castanea.

Abdomen nigrum, subgriseo-sericans.

$P$ edes obscure fusci.

Habitat in America septentr.

Al. bimaculata Mus. Pr. Knoch. 


\section{Genus VIII.}

\section{A n thoph a gus.}

1. Aichrous; subnitidus, niger; ore, antennis, thorace, scutelio, elytris, pectore, pedibusque rufis.

Longitudo $3 \frac{3}{2}$ lin.

Caput thoracis magnitudine; antennis capite thoraceque longioribus.

Thorex A, testacei, punctus, lateribus et ante basin intpresstis.

Coleoptra rectangula, thorace duplo longiora et latiora, cicatriculoso - puncta.

Habitat Dresdac.

Staph, dichrous - Mus. C. de Frofinarnsegg.

2. A. alpinus, niger, nitidus; apice antemnarun thoraceque fuscis; basi antennarum, elytris, 'yedibusque testaceis.

Habitu omnino A. armigeri; statura autem multo minore, capite nigro simplici.

Habitat in betula et salice, in summis alpibus Lapponiac.

Staph, alpimus Fabr, Ęnt. S. St. n, 33 . 


\section{Anthophagus.}

Staph. Payk. Fn. Suec. St. n. 27 .

Olivier Ent. St. n. 45. pl. VI. f. 55.

1. flagialus, niger, nitidus; pedibus antennisque fuscis; elytris disco sanguineis.

Habitu, partiumque forma ac proportione A. obscuri; magnitudine autem et elytrorum disco sanguineo distinctus est.

Longitudo $2 \frac{\mathrm{T}}{\mathrm{S}}$ lin.

Habitat - Mus. Pr. Hellwig.

Stcph. plegiatus Payk. Fn. Suec. St. n. 20.

An St. plagiatus Fabr. (Suppl. St. pag. 180.)? cui thorar est planus. 


\section{Genus IX.}

\section{Tachyporus.}

I. crassus, nitidus, brevis, subgrisen - sericans, nigrofuscus; antennis pedibusque pallidioribus.

Statura, T. prbescente multo latior et crassior. Longitulo $1 \frac{3}{4}$ lin.

Therax convexus nitidus.

Coleoptra nitidula, subquadrata, longitudine vis paulo latiora.

Habitat in America septentr.

T. crassus - Mus. Pr. Knoti. 


\section{Genus X.}

\section{T a c h. i n u}

Fam. I.

T. batychrous, niger, nitidus; antennis, pedibus, clytrorumque humeris rufis.

Habitu T. bipustulati et humeralis; thorace autem et coleoptris angustioribus.

Longitudo $2 \frac{x}{2}$ lin.

Caput nigrum; antennis rufo-fuscescentibus, articulis tribus primis rufis.

Therex niger, marginibus lateralibus subpallidioribus.

Cutentra latitudine paulo longiora, nigra; sutura et elytrortin macula humerali subquadrata obscure castaneis.

$P$ edes pallide rufi; capitibus femorum nigricantitus.

Habitat in America septentr.

Tachuporus betychr. - Mus. Pr. Knoch.

$2 T$. fimbriatus, niger, nitidus; coleoptris castancis, margine apicali nigro.

Hebitu T. mffipelis, statura auten multo maiore, thorace proportionaliter paulo latiore. 


\section{Lungitide $3 \frac{3}{4}$ lins.}

(Caput nigrum; antennis fuscis, capite thoraceque brevioribus, articulo primo rufescente; labro palpisque pallide rufis.

Coleoptra subquadrata, obsolcte striata, castanea, margire apicali ct uargine dimidio laterali nigris.

$P$ odes fuscescentes.

Habitat in America septentr.

Tachypor. finbr. - Mus. Pr. Krocin.

3. Temnonius, niger, nitidulus; ore, antennis, pedibusque sufis.

Habitu, partiumque forma ac proportione T. pello simiis; statura auten paulo maiore, nitore minus splendido.

Longitudo $2 \frac{x}{3}$ lin.

Caput nigrum, palpis anteñisquc fuscescentibus; tis basi pallidioribus.

Habitat in America scptententr.

Tachypor. memn. - Mus. Pr. Knoch.

$4 T$. narginalis, niger, nitidus; thoracis lateribus, coleoptrorum sutura ct margine apicali, pediburque testaceis.

Habitu, partiumque forna ac proportione omnino $T$. suturalis.

Longitudo I lin.

Coput cum antennis et palpis, nee non thorax ommino T. suivralis.

Colcoptra; stitura margineque apicali testaceis, hoc autem obsoletiorc.

Pedes testacci; capitibus fernorum nirris. 
Habitat in America septentr.

Techypor. marg. - Mus. Pr. Rnoch.

$$
\text { Fam. 11. }
$$

5T. niger, niger, nitinus; antennasum articulo primo, et segnenti perultini margine, rufescentibus.

Stwhy quidem magna ct colore nigro ab omnibus huiug familiae cospeciebus discedit; forma autem et proportione partinn, imprimis thoracis et ultimi antemarum articuli, utique cun illis congruit.

\section{Longitudo 5 lin.}

Cryput ovatum, thorace plus duplo minus, laeve nitidum, nigruni, clypeo testaceo; palpis antennisque fuscis, his, articulis primo et ultimo rufis.

Colectra subquadrata, latitudine vix panlo longiora, laevia ; elytris, serie disci obsolete tripuncta.

Ablomen pilis brevibus tenuissimis vestitum, nigrum; seğmento penultimo rufo, basi nigricante.

Habitat in America septentr.

Tachyp. niger - Mus. Pr, Knoch.

$6 T$. cinctus, nitidus, tufus; capite, pectore, anoque nigris; coleoptris chalybeis, basi et sutura rufis.

Habilu, partiunque forma proportione et punctura omnino T. atricapilli; statura auten minus gracili et sutura rufa differt. 
194 Tachinus. F. II.

Longitudo $2 \frac{\mathrm{T}}{2}$ lin.

Antennae nigricantes, articulis tribus primis et ultimo rufis.

Habitat in America septentr.

Tacilypor. cinctus - Mus. Pr. Krocir. 


\section{Genus XI.}

\section{O $x$ y p o r u s.}

1O. latevalis, nitidus, rufus; lateribus thoracis et capitis, angulisque colcoptrorum apicis uigris.

Habitu O. rufi; coleoptris auten multo majoribus, et thorace medio latiore.

Longitudo $3 \frac{T}{2}$ lin.

Corpus infra, cum palpis et pedibus, testaceum.

Caput, thoracis magnitudine, pallide vel obscure rufum; disco, oculis et angulis basis nigris.

Thorax pallide seu obscure rufus; lateribus zotundatis nigris ; colcoptris duplo angustior et breviox.

Coleopts $\alpha$ quuadrata, apicen versus paulo latiora, testacea; sutura interdum, angulis vero apicis semper, nigris; elytris, disco punctis et bistriatis, striis vero apicem haud attingentibus (ut in Oxyp. rufo).

Ablimen rufum, plerumque punctis duobus segmenti singuli nigris notatum.

Habitat in America septentr.

O. Iateralis - Mus. Pr. Knoch.

20 . vittatus, niger, nitidus; palpis, pedibus, coleoptrisque testaceis, his margine laterali atque sutura nigris. 
Habitu, partimque proportione, forma et sculptura onnino Oxyp. maxillosi - KB O. sequente, statura minore, capite thorace elytrisque nitidioribus, thorace breviore, pedibus totis testace:s differt,

Longritudo 3 iin.

Coput; antennis, capite paulo brevioribus, pallide fus cescentibus, articulo primo testaceo.

Thorax transversus, lateribus rotundatis, medio latissi. mus.

Coleoptra testacea ; sutura et vitta marginali, apicem versus dilatata, nigris.

Habitat in America septentr.

Ox. viltalus - Mus. Pr. Knoch.

3 o. femoralis, niger, nitidulus; palpis posticis, tibiis, tarsis, coleoptrisque testaceis; his sutura margineque laterali niguis.

Habitu O. praecedentis.

Longitudo $\hat{3}_{4}^{3}$ lin.

Thorax, longitudine latitudinis, basin versus subangustatus.

Coleoptra omuino ut in Oxyp. praeccacnte.

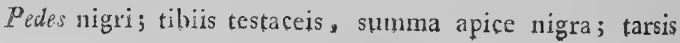
testaceis.

Habitat in America septentr.

O, vittati var, - Mus. Pr. Knoch.

40. cinctus, niger, nitidus; antennis, palpis pedibusque testaceis; abdoninis ventre margineque rufis; coleoptris testaceis, sutura atque lateritus nigris. 


$$
\text { Oxyporus. }
$$

Habitu omnino O. vitlati (1, 2.), a quo colore solummo. do differt - An cius varietas?

Longitudo 3 lin.

Coleoptra testacea; sutura ct vitta Laterali, apicem versus dilatata, latiore quan in Ox. littato, nigris.

Habitat in America septentr.

O. cintus - Mus. Pr. Knoih.

5 O. ca elatus, nitidus, cicatricosus, niger; coleoptris rufis, angulis apicis nigris.

\section{Longitudo 2 lin.}

Ceput, thoracis magnitudine, punctis crebris crassis nodulisque scabrum; oculis globosis prosilientibus.

Thorax convexus, quadratus, lateribus paululum rotundatis, coleoptrorum longitudine; punctis crebris crassis impressis nodisque cicatricosis scabrum; nodis septem maioribus insignibus, quorum quatuor, figuram quadrati exhi. bentes, in discum, quintus ante scutellum, sextus et septi* unus ad latera dispositi suut.

Coleoptsa transversa, thorace latiora, punctis impressis nodulisque cicatricosis irregularibus scabra.

Abdomen nigrum, marginibus subrufescentibus; serie nodulorum marginali, nodulis singuli segmenti duobus.

Pedes rufi; femoribus apice nigris.

Habitat in America septentr.

O. catalus - Mus. Pr. Knoch. 


\section{Genus XII:}

$S \quad t \quad e \quad n \quad u s$.

I St. cordatus, niger; pedibus rufis, genubus nigris; thorace cordato,

Habitu Stenorum plurimorum, thorace autem cordato, çlecperis proportionaliter latioribus, abdonine apicem versus attenuato, satis distinctus,

Longitudo 3 lin,

Corpres nitidulum, punctum, punctis autem subtilioribus quam in St. cicindeloide.

Thorce, longitudine latitudinis, cordatus, sulcis duobus longitudinalibus obsoletis impressus, coleoptris brevior et diuplo angustior.

Coleoptra quadrata lata.

Abroner apicen versus attenuatum.

Pecáes; femoribus basi rufis, apice niģris; tibiis rufis, basi niğris.

Habitat in Lusitania.

Mus. Com. de Huffromnsegg. 


\section{Genus XIII.}

\section{A s trapa e us.}

P a $1 \mathrm{p}$ i securidacei.

Tobitu, partiumque forma atque proportione staphylinorum familiac tertiac.

Caput; palpis, articulis ultimis securiformibus, reliquis clavatis.

1A. Ulmi, niger, nitiaus; antennarum basi, ore, elytris et segmenti penultimi margine rufis.

Habitu Staph. nitidi maioris.

Longitudo $4 \frac{\mathrm{r}}{2}-5^{\mathrm{r}}$ lin.

Coput suborbiculatum, thorace minus, laevissinum, nitidissimum, nigrum; antennis, capite paulo longioribus, fuscis, articulo primo rufo; clypeo testaceo; labro rufo; palpis rufo-testaceis.

Thorax, coleoptrorum magnitudine, suborbiculatus, apice angustior, lateribus deflexus, lacvissinus, nitidissimus, pun* cto interdum uno alterove impressus. 
Coleoptra guadrata, nitidissima, laevia; elytris, serie disci longitudinali recta quadripuncta.

Alulomen nitidulum.

Pedes nigri; tibiis tarsisque anticis fuscescentibus, his dilatatis.

Habitat sub cortice Ulmi, primo vere - Rossi.

Staph. Ulmi Rossi Fin. Etr. n. $61 \mathrm{t} \mathrm{tab}, \mathrm{V}$ fig. 6.

- Otivier Ent. St. 11. 17 pl. IV f. 37. 


\section{Genus XIV.}

Pinophilus.

I'alp i filiformes.

A nitennae filiformes.

Tho: ax quadratus, postice truncatus.

Habitu Lathrobiis affinis, prascipue L. pallipedi et L. badio, palpis autem filiformbus et thorace quadrato differt $-A$ Staphylinis thorace basi truncato distinctus.

Cespts filiforme Lathrobii.

Caput orbiculatum, thoracis fere latitudine, punctum. La. bro et ciypeo brevibus latis. Mandibulis falcatis acuris. Paipis filiformilus, anterioribus quadriarticulatis, posterioribus triarticulatis. Autennis filiformibus; articulis, ultimo suborbiculato acuminato, reliquis clavatis, primo lonxissimo valido, tertio et quarto longioribus quan secundus, sequentibus longitudine decrescentibus.

Thor $x x$ quadratus, basi truncatus, capite paulo longior, coleoptris paulo brevior, couvexiuscu'tus, punctus, linea me. dia longitudinali subobsuleta laevi nitids. Canalicula marginali puicta. Ord laterali deflexa glaberrima, basi latiore. 
Coleoptra rectangula, puncta, thoracis latitudine.

$\boldsymbol{P}_{\text {edes }}$ cursorii, subpiloselli; antici validi fossorii, capitibus femorun femore paulo brevioribus, ejus autem crassitie, femoribus tibiisque brevibus validis, tarsis brevissimis dilatatis; posteriores graciliores, capitibus femorum brevissimis, articulis tarsorum, primo longiore, tertio brevissimo, quinto, seu ungula, haud apici articuli quarti, sed basi ejus, seu apici articuli tertii, adhaerente; tibiis posticis apice oblique sinuatis.

I P. latipes, fusco-nigricans; palpis, antennis, pedibusque testacers.

Longitudo 6 lin.

Antennae, rapite thoraceque paulo breviores; articulis testaccis apice fuscescente, excepto primo toto testaceo.

$\boldsymbol{P}$ edes testacei; capitibus femorum nigricantibus.

Habitat in America septentr.

Paederas latipes $\rightarrow$ Mus. Pr. Knoch. 


\section{I n d e $x$.}

Nomina, literis cursivis impressa, significant genera nova vel species novas. Species, quibus litera e postpositu est, exoticae sunt.

\begin{tabular}{|c|c|c|c|}
\hline$A_{\text {ethiops }}$ & & Iucida & \\
\hline alterans & - 6 & lugens & - \\
\hline analis & -14 & noeste & $=$ \\
\hline aterrima & -29 & morion & $=$ \\
\hline $\begin{array}{l}\text { bimaculatze } \\
\text { bipunctatad }\end{array}$ & $=3$ & nana & 二 \\
\hline $\begin{array}{l}\text { bipunctatad } \\
\text { boleti }\end{array}$ & $=37$ & $\begin{array}{l}\text { nigra } \\
\text { migricollis }\end{array}$ & $\equiv$ \\
\hline canaliculata & $-\mathrm{I}$ & nigritula & - \\
\hline cinna nomea & - 3a & natida & - \\
\hline collaris & & obfuscatz & $\bar{E}$ \\
\hline $\begin{array}{l}\text { cortiealis } \\
\text { deplanata }\end{array}$ & $=13$ & $\begin{array}{l}\text { obscura } \\
\text { opaca }\end{array}$ & $\overline{-}$ \\
\hline $\begin{array}{l}\text { deplanata } \\
\text { depressa }\end{array}$ & $\begin{array}{l}50 \\
40\end{array}$ & picer & - \\
\hline $\begin{array}{l}\text { depressa } \\
\text { dichroae }\end{array}$ & -1 & polita & - \\
\hline $\begin{array}{l}\text { elongatula } \\
\text { long }\end{array}$ & -18 & prolixa & - \\
\hline fumats & -42 & pulla & - \\
\hline fuscipes & -36 & pumilio & 一 \\
\hline humexal is & -33 & pusilla & 一 \\
\hline impressa & $=7$ & pygmaz & 二 \\
\hline anqu inula & - 16 & xirularis & $=$ \\
\hline 1atvis & $=39$ & fuficorais & 二 \\
\hline Januginos a & $=38$ & strumosa & $=$ \\
\hline $\begin{array}{l}\text { lata e } \\
\text { limbata }\end{array}$ & $=2$ & $\begin{array}{l}\text { sulcata } \\
\text { tenuis }\end{array}$ & \\
\hline $\begin{array}{l}\text { limbata } \\
\text { linearis }\end{array}$ & 二 $\begin{array}{l}3 \\
2\end{array}$ & $\begin{array}{l}\text { tenuis } \\
\text { teres }\end{array}$ & - \\
\hline longicornis & -29 & umbrata & - \\
\hline longiuscula & -20 & & \\
\hline
\end{tabular}

Aleochara G. V. pag. 67 et IS6.

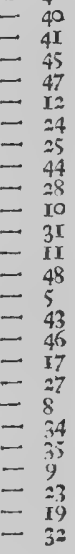

Anthophagus G. VIII.

pag. 120 et 188.
Alpimus e
armige $r$
caraboides
dichrouse
n. 2
$-\quad 3$
$-\quad 1$
$-\quad 1$
obscurus
plagiatus
testaceus
n.
$-\quad 5$
$\rightarrow \quad 2$ 


\section{Astrapaeis G. XIII. \\ pag. 199.}

VImi e

Obscurts

Badium bicolote brunnipes

castareu in depxessume elongatum fracticorne gracilee

Brachypteram brumeum cretratim depressum fiorale plasum

Cuelatuse cincture femoralise jateralise

Caelatus с анiлatus COIJutus depressus fuliginosus morsitans

Angustatus

bicolor

castaneus

corticinus litroratis
11. I

Callicerus G. IV. pag. III.

n. I

Lathrobium G. II. pag. 51 et 179.

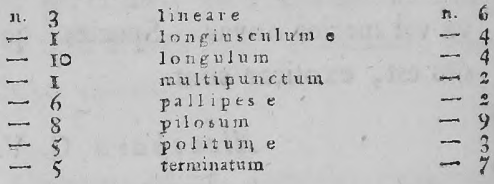

Omalium G. VII.

pag. III.

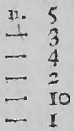

Fa unculi

rivulare

$x \sim \mathrm{fum}$

sogosutn

strizt $\mathrm{nm}$

Viburui

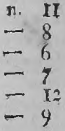

Oxyporus G. XI. pag. 150 et 195 .

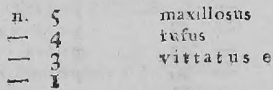

11.
$-\quad 1$
$-\quad 2$

\section{Oxytelus G. VI. \\ pag. 101.}

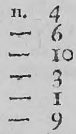

nitadulus pedicelius jiceus

palches

tricornis

21.
$-\quad 2$
$-\quad 5$
$-\quad 71$

Paederus G. III. pag. 58 et 184 .

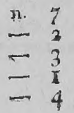

ochraceus

orbiculatns

riparius

ruficollis $e$

5
$-\quad 6$
$-\quad 3$
$-\quad 2$ 


\section{Pinophilus G. XIV. \\ pag. 201.}

Inatipese

Aeneocophaius

aereus

albipes.

alternans

Anthrax p. 176

atese

a texrimus

atratus

attenuatus

baltimoreas is e

bimaculatus

binotatus

hipustulatus

boops

brevicornis

br $\mathrm{x}$ u $\boldsymbol{x}_{11} \in \mathrm{us}$ e

rarbonarius

castanopterus

cephalotes

chioptertus e

cinctuluse

cineras cens

cingulatus e

cinllatioptertuse

concinnus

rontaminatus p. $\mathbf{I 7 4}$

corruscus

erassicollic

cyantus

cranipenifis $e$

debilis

decor us 5

discoideus

Ebenith HS P. I\%O

elogans

elougatus

entinesus e

esythropterus

finetapins p. 175

fossitorte

feossor

Ix a gilis

ivigidus

faligitoos us

fulmitians

f.lvipes

fuscatus e

fuscus

g)

blabratuse

hirtus $t$

impresstus a. I

\section{Staphylinus G. I.}

\section{pag. I et 159.}

\begin{tabular}{|c|c|c|}
\hline n. & 8 & laninatus \\
\hline - & 18 & Iatera! is \\
\hline$\infty$ & 40 & Iaticollis e \\
\hline- & 72 & $1 \in p+d u s$ \\
\hline$\longrightarrow$ & 34 & linearis \\
\hline - & 5 & Jongicepse \\
\hline & 62 & Iucidus \\
\hline- & 23 & mactocephaluse \\
\hline$\rightarrow$ & 38 & miculosuse \\
\hline & 8 & margitatus \\
\hline - & 55 & Maxillorus \\
\hline$\rightarrow$ & 39 & metillicus p. 168 \\
\hline 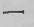 & 54 & micans \\
\hline & 26 & motio \\
\hline$m$ & 28 & murems \\
\hline- & 26 & nebulosus \\
\hline$\rightarrow$ & 31 & nigritulas \\
\hline- & IO & niteus \\
\hline 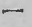 & 27 & nitidulus \\
\hline - & 15 & nitidns \\
\hline$\longrightarrow$ & 16 & obscurus P. I74 \\
\hline$\cdots$ & 74 & ochraceus \\
\hline - & 14 & ochropus \\
\hline- & II & olests \\
\hline- & 25 & opacus \\
\hline$\rightarrow$ & 31 & palmula \\
\hline$\longrightarrow$ & 47 & parvicormis \\
\hline- & $q$ & patiolas \\
\hline - & 5 & pedatore \\
\hline$\longrightarrow$ & 17 & politus \\
\hline 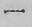 & 52 & praceox \\
\hline$一$ & 20 & jubescens \\
\hline - & 56 & punctulatuse \\
\hline 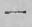 & 22 & punctus \\
\hline$一$ & 68 & rigilicornis \\
\hline 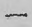 & 66 & rufipennis \\
\hline 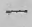 & 35 & Iufipese \\
\hline 一 & II & sauguinolentus \\
\hline- & 32 & sericanse \\
\hline - & $\mathrm{I}^{2}$ & sinitis \\
\hline 一 & 9 & sordidus p. I76 \\
\hline- & 44 & splendidulus \\
\hline- & 71 & splenctens \\
\hline 一 & 49 & stercorarius \\
\hline$\longrightarrow$ & 70 & subuliformis \\
\hline$\ldots$ & 33 & tenvis $>$ \\
\hline- & 10 & texminatus \\
\hline 一 & $4 I$ & thotacicas e \\
\hline$\longrightarrow$ & 67 & tomentosus b \\
\hline$\longrightarrow$ & 38 & tris:olor \\
\hline$\longrightarrow$ & $x$ & tristis \\
\hline & $5 I$ & Hulisatilis e \\
\hline
\end{tabular}

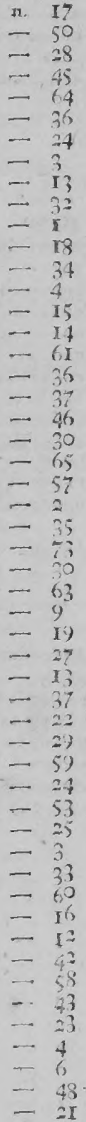




$$
\begin{aligned}
& \text { umbrinuse } \\
& \text { ustulatus } \\
& \text { varians } \\
& \text { ventralise }
\end{aligned}
$$

Bignttatus

buphthalmus

creind loides

circularis

clavicormas

Analis

atricapillus

batychrous $e$

bipustulatus

castaneus

cinctuse

collaris

corticinus

finbriatuse

fimetarias

humeralis

imaturus

laticollis

Iunulatus
n. 20
- 69
- 21
- 2)

\section{Stenus G. XII,}

pag. 15; et 198.

म. 2
$=6$
$=4$
$=5$

cordatuse

I1. I

$-8$

- I

$-3$

\section{Tachinus G. X.}

\section{pag. 134 et 191.}

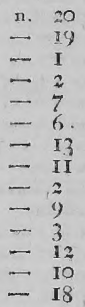

marginalis $\mathrm{A}$ matginellus

melanocephalus

memantuse

me $r$ kt a $r$ ins

x. 4

- 14

- I6

$\rightarrow 3$

- $2 \mathrm{I}$

$\rightarrow 5$

niger e

puilis

$x$ ufipes

siginatas

sordidus

striatus

subter waiteas

suturalis

-6
$-\quad 4$

- 5

$-8$

$-17$

$\rightarrow$ I

- IS

\title{
Tachyporus G. IX.
}

\section{pag. 124 et 190.}

\author{
Abrominalis \\ amalis \\ binetatus \\ bip unctatus \\ bipustulatus \\ cellevis \\ chrysomelinus \\ crassuse
}

dissimilis

lateralis

marginatus

nitiduitus

pedicularius

pubescens

ruficollis $\begin{array}{ll}\text { ก. } & 4 \\ = & 5 \\ = & 2 \\ = & 14 \\ = & 9 \\ - & 6\end{array}$ 


\section{Errata emendanda.}

Pag. Vil lin. I tege Coleoptera.

- - nol. 1 - Ulysses.

- Iin. 5 - invenimus.

- VIII - - plures.

- - -6- secrionis.

- IX - 9- respondent.

- XII - 2- "antennis.

- - - - tenuioribus."

- XIII - 9- Tachinus.

- XVII - 8- carum.

- XXIV 53 lin. a lege Alcocha-

-- XXVII not. I lin, a lege Co-

- XII - $4-6 \frac{\text { leopterorum. }}{\text { pro sq. }}$

.... XIIV lin. I post circumdatus adde est.

... - -10 lege angulum.

- I not. 1 lin. 9 post multis ponendum est).

- LIII lin. 13 lege sexrum.

- IXIII - wlima lege et pro

- 11 n. 12 lin. 3 lege a St.

- 12 lin. 6 lege flavicante.

- 13 n. 14 lin. 2 lege angulis.

- $14-15-4$ vix quidem.

- 15 fam. IIl lin. 8 lege magnitudi-

in- 36 n. 53 delenda est Var, 6 St. coleoptris nigris; sutura sanguinea.
Pag. $4 \mathrm{i}$ Var. 1 lin. 2 lese rufis-

- 54 lin. 20 lege Drunsuigae.

- $64-17$ - angustatus.

- 66 - ult. - Brunsuigae.

- $74-17$ - Brunsuigae.

- - n. 10 lin. 7 lege paululunit.

- $79-18-17-$ Brunsui.

- 90 lin. 12 lege Brunsuigae.

- $92-15$ - Blankenbuir-

- 116 n. 8 lin. 9 lege thorax.

- $117-9-9$ pro? lege,

- 120 Characterious genericis addendus est Thorax cordatus.

- Ij 1 n. 10 lin. 7 lege a co.

- 138 lin 3 lege infra e.

- - 7 - Revera.

- 142 n. 12 lis. 5 lege 14 pro

13.

- $143-14-4-10-9$.

- 144 lin. 4 lege II pro 10.

- $146-8-1 V$ et V pro

- $147-2$ - punctis. 6 et 7.

- 155 - ult. post Hallens. adde Tom. I pag. 324 .

- 157 - ult. lege eas esse.

- 177 n. 37 lin. 7 lege fusces-

cens.

- $92-3-6$ - antennis. 